\title{
Henry LÉMERY
}

homme politique français, premier Martiniquais à devenir membre

d'un gouvernement en France

(1936)

\section{La Révolution française à la Martinique}

\author{
VERSION \\ SANS LES PLANCHES DANS LE TEXTE
}

\author{
Un document produit en version numérique par Jean-Marie Tremblay, bénévole, \\ professeur de sociologie au Cégep de Chicoutimi \\ Courriel: jean-marie_tremblay@uqac.ca \\ Site web pédagogique : http://www.uqac.ca/jmt-sociologue/ \\ Dans le cadre de: "Les classiques des sciences sociales" \\ Une bibliothèque numérique fondée et dirigée par Jean-Marie Tremblay, \\ professeur de sociologie au Cégep de Chicoutimi \\ Site web: http://classiques.uqac.ca/ \\ Une collection développée en collaboration avec la Bibliothèque \\ Paul-Émile-Boulet de l'Université du Québec à Chicoutimi \\ Site web: http://bibliotheque.uqac.ca/
}




\section{Politique d'utilisation de la bibliothèque des Classiques}

Toute reproduction et rediffusion de nos fichiers est interdite, même avec la mention de leur provenance, sans l'autorisation formelle, écrite, du fondateur des Classiques des sciences sociales, Jean-Marie Tremblay, sociologue.

Les fichiers des Classiques des sciences sociales ne peuvent sans autorisation formelle:

- être hébergés (en fichier ou page web, en totalité ou en partie) sur un serveur autre que celui des Classiques.

- servir de base de travail à un autre fichier modifié ensuite par tout autre moyen (couleur, police, mise en page, extraits, support, etc...),

Les fichiers (.html, .doc, .pdf., .rtf, .jpg, .gif) disponibles sur le site Les Classiques des sciences sociales sont la propriété des Classiques des sciences sociales, un organisme à but non lucratif composé exclusivement de bénévoles.

Ils sont disponibles pour une utilisation intellectuelle et personnelle et, en aucun cas, commerciale. Toute utilisation à des fins commerciales des fichiers sur ce site est strictement interdite et toute rediffusion est également strictement interdite.

L'accès à notre travail est libre et gratuit à tous les utilisateurs. C'est notre mission.

Jean-Marie Tremblay, sociologue

Fondateur et Président-directeur général, LES CLASSIQUES DES SCIENCES SOCIALES. 
Cette édition électronique a été réalisée par Jean-Marie Tremblay, bénévole, professeur de sociologie au Cégep de Chicoutimi à partir de :

Henry LÉMERY

La Révolution française à la Martinique.

Paris : Larose Éditeur, 1936, 338 pp.

\section{VERSION SANS LES PLANCHES DANS LE TEXTE}

Polices de caractères utilisée :

Pour le texte: Times New Roman, 12 points.

Pour les citations : Times New Roman, 12 points.

Pour les notes de bas de page : Times New Roman, 12 points.

Édition électronique réalisée avec le traitement de textes Microsoft Word 2004 pour Macintosh.

Mise en page sur papier format : LETTRE (US letter), 8.5’’ x 11'’)

Édition numérique réalisée le 22 décembre 2008 à Chicoutimi, Ville de Saguenay, province de Québec, Canada. 


\section{Henry LÉMERY}

homme politique français, premier Martiniquais à devenir membre d'un gouvernement en France

\section{La Révolution française à la Martinique}

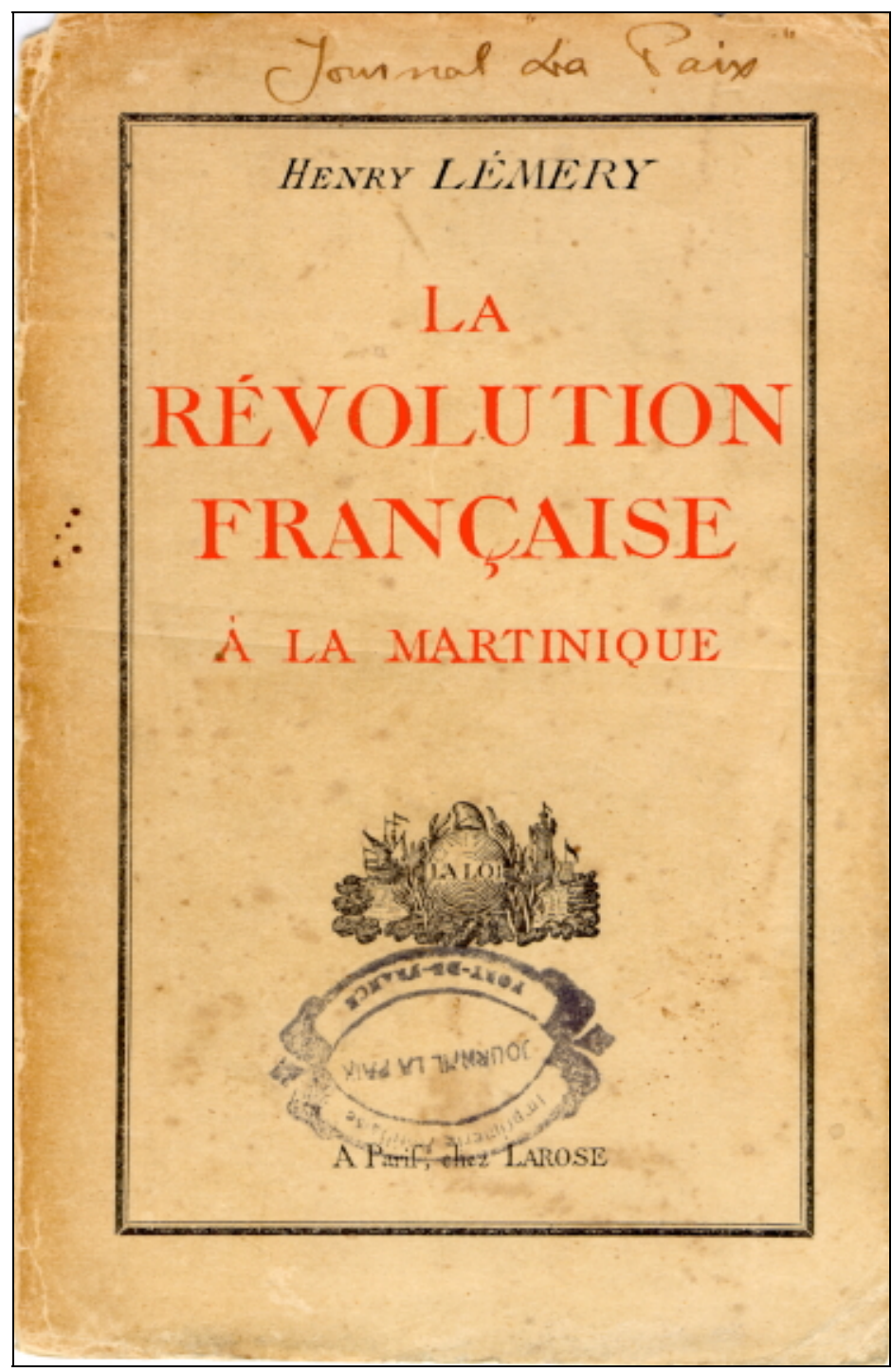

Paris : Larose Éditeur, 1936, 338 pp. 


\section{Table des matières}

Liste des Ministres de 1789 à 1794

Table des planches

Introduction

$\underline{\text { Liste des ministres de } 1789 \text { à } 1794}$

Biographie des principaux personnages

Chapitre Ier. La cocarde tricolore

Chapitre II. Les partis s'affrontent

Chapitre III. $\quad$ La France parle

Chapitre IV. La guerre civile

Chapitre V. La Métropole arbitre

Chapitre VI. $\quad$ Remous de France

Chapitre VII. La rébellion

Chapitre VIII. Le vent tourne

Chapitre IX. La dictature républicaine

Chapitre X. L'intervention anglaise échoue

Chapitre XI. La révolution progresse

Chapitre XII. La révolution succombe

Chapitre XIII. Fin et conclusion

Références générales

Documents annexes:

Procès-verbal dressé par l'équipage de la frégate L'Embuscade

Adresse des Citoyens de couleur de la Martinique à l'Assemblée Coloniale

$\underline{\text { Lettre de Sir Edward Mathew à M. de Damas }}$ 


\section{Table des planches}

Planche I. Carte réduite de l'île de la Martinique.

Planche II. Le Marquis du Houx Viomenil, Maréchal et Duc de France.

Planche III. J.C. Dugommier.

Planche IV. $\quad$ Louis-François Du Buc.

Planche V. Lettre du Roi à nos bons amis sujets, les Colons des îles du Vent.

Planche VI. Proclamation des Commissaires réunis au Fort-Bourbon concernant les gens de couleur libres qui ont pris les armes contre les citoyens, du 22 septembre 1790.

Planche VII. L'Abbé Grégoire.

Planche VIII. Terre des esclaves, terre de la liberté: arrivé là on ne recule pas.

Planche IX. Proclamation. Jean-Pierre-Antoine de Behague, LieutenantGénéral des armées du Roi, Gouverneur-Général des Îles du Vent, Commandant en chef des Forces de Terre et de Mer.

Planche X. Le Capitaine de Vaisseau Lacrosse.

Planche XI. Le dernier moyen de conciliation, entre la Mère-patrie, et les colonies révoltées.

Planche XII. Rochambeau.

Planche XIII. Au nom de la République française. Proclamation. Nous Donatien-Marie-Joseph Vimeur ROCHAMBEAU, Lieutenant-Général des armées de la République, Gouverneur Général de la Martinique et Commandant-Général des Isles du Vent. À tous les hommes libres de la Colonie.

Planche XIV. Extrait des registres des délibérations de l'Assemblée représentative de la Martinique. Séance du 26 octobre 1793, l'an 2 de la République.

Planche XV. Lord Gardner.

Planche XVI.

Planche XVII. Extrait des registres des délibérations de l'Assemblée représentative de la Martinique. Séance du 26 et 28 octobre 1793, l'an 1er de la République.

Planche XVIII. Le Général Grey.

Planche XIX. View of the storming and taking the Fort and Town of Fort Royal in the island of Martinico by General Sir Charles Grey, March 1794.

Planche XX. La Convention Nationale déclare abolie l'esclavage des nègres dans toutes les colonies; en conséquence, elle décrète que tous les hommes, sans distinction de couleur, domiciliés dans les Colonies, sont citoyens français et jouiront de tous les droits assurés par la Constitution.

Planche XXI. Fraternité. 


\section{Liste des Ministres de 1789 à 1794}

MM.

DE LA LUZERNE, du 24 décembre 1787 au 24 octobre 1790.

DE FLEURIEU, du 24 octobre 1790 au 6 mai 1791.

DE THÉVENARD, du 6 mai 1791 au 15 mars 1792.

DE LA COSTE, du 15 mars 1792 au 10 juillet 1792.

Du BOUCHAGE, du 10 juillet 1792 au 12 août 1792. MONGE, du 12 août 1792 au 10 avril 1793.

DALBARADE, du 10 avril 1793 au ler avril 1794.

La loi du ler avril 1794 supprima les ministères et les remplaça par des « Commissions Exécutives ». 
La Révolution française à la Martinique

\section{Biographies des principaux personnages}

$\underline{\text { Retour à la table des matières }}$

BÉHAGUE (Jean-Pierre-Antoine, de), né en 1727, lieutenant-colonel en 1761, gouverneur de la Guyane en 1763, brigadier en 1768, lieutenant général en 1791. Nommé à cette époque gouverneur général des Iles du Vent, il quitta la colonie en janvier 1793. Il fut envoyé, par la suite, en Bretagne par le comte d'Artois, mais ne put s'entendre avec Cadoudal. Il mourut en Angleterre.

COQUILLE DUGOMMIER (Jean-François), né en 1736, à Basse-Terre, à la Guadeloupe. Partisan de la Révolution, il passa à la Martinique en 1790 et y devint commandant de la garde nationale. Il se rendit en France en 1792 comme député des Patriotes de la colonie et participa, l'année suivante, au siège de Toulon. Devenu commandant de l'armée des Pyrénées-Orientales, il reprit aux Espagnols Saint-Elme, Collioure, etc... Il fut tué le 17 novembre 1794 à Sierra Negra. La Convention fit inscrire son nom au Panthéon.

CURT (Louis de), né en 1722 (?), aide de camp du comte d'Estaing en 1778, après avoir été capitaine dans les troupes coloniales de la Guadeloupe. Passé en France, il fut nommé le 8 août 1784 commissaire du Roi pour la vérification et la suppression du papier monnaie aux îles Mascareignes. Admis comme député de la Guadeloupe à la Constituante, le 22 septembre 1789, il proposa, le 27 novembre, la création d'un Comité des Colonies, mais ne réussit pas à faire adopter sa mo- 
tion. Il émigra en Angleterre après la mort du Roi et demeura à Londres où il négocia avec le gouvernement. Il mourut à une date inconnue.

DU BUC (Louis-François), né le 22 mai 1759, cinquième enfant de JeanBaptiste Du Buc, député de la Martinique auprès du Bureau du Commerce, puis premier commis de Choiseul. Il fut d'abord officier au régiment de Bouillon, se fixa ensuite à la Martinique où il bénéficia rapidement de l'influence que sa famille avait acquise depuis un siècle. Nommé, en 1789, président de l'Assemblée Coloniale, il conserva cette situation, sous les conditions indiquées au chapitre III, jusqu'au moment où il se rendit en Angleterre sous prétexte de rejoindre le Roi. Il négocia le traité de Whitehall et joua un rôle dans l'attaque de la Martinique par les Anglais en 1793, après qu'elle se fût ralliée à la Révolution. Il y rentra en 1794 à la suite des armées britanniques, fut élevé au poste d'administrateur général et président du Conseil Souverain. La colonie, redevenue française, l'envoya comme député à Paris.

Son père, qui vivait encore en 1794, fut enfermé, malgré ses 77 ans, au « repaire des suspects » de la ville de Blois et ne fut relâché qu'après le 9 thermidor.

HUGUES (Victor), né à Marseille en 1770, d'un négociant. Il se fit rapidement une situation grâce à la Révolution. Accusateur publie à Brest et à Rochefort, il fut ensuite nommé commissaire à la Guadeloupe ; il avait alors 24 ans. Il réussit à reprendre Pointe-à-Pitre, Basse-Terre sur des forces plus considérables que les siennes, et parvint à se maintenir dans l'île. Il reprit ensuite Sainte-Lucie, temporairement au moins, les Saintes, la Désirade, Marie-Galante, mais échoua à la Martinique. La Convention décréta, le 11 septembre 1794, «qu'il avait bien mérité de la Patrie ». Par ses abus, il finit par indisposer la population guadeloupéenne et se fit rappeler en France. Revenu dans la Métropole, en mars 1799, il desservit son successeur, le général Desfourneaux, et réussit à obtenir sa disgrâce, mais il ne put retourner à la Guadeloupe. Le Directoire le nomma, le ${ }^{\text {er }}$ septembre, agent particulier à la Guyane qu'il administra jusqu'en 1808, époque où les armées portugaises le contraignirent à capituler. Accusé de faiblesse, il se rendit en France et fut absous à l'unanimité. Il regagna la Guyane, s'y établit et ne la quitta que lorsqu'il eut perdu la vue. Il mourut près de Bordeaux, en 1826.

LACROSSE (Jean-Baptiste-Raymond, baron de), né à Meilhan (Lot-etGaronne), le 5 septembre 1765. Il sortit à 18 ans de l'Ecole Militaire des gardes de 
la Marine. Il accomplit sa première campagne dans les Indes à Gondelour ; acquis à la Révolution, il se rendit, en décembre 1792, aux Iles du Vent et soumit la Martinique et la Guadeloupe révoltées. Rappelé en 1793, il fut incarcéré sur l'ordre du Comité de Salut publie et libéré en 1795 seulement. Réintégré dans les cadres de la Marine l'année suivante, il participa à l'expédition d'Irlande. Elevé au grade de contre-amiral, il devint ambassadeur en Espagne.

Capitaine général de la Guadeloupe en 1802, il y fut victime d'une sédition et tomba aux mains des rebelles ; après avoir obtenu la liberté et s'être réfugié à. la Martinique, il réussit à rétablir la situation. Rentré en France, il devint préfet maritime du Havre, puis commandant en chef de la flottille destinée à l'invasion de l'Angleterre. Il occupa ensuite le poste de préfet de Rochefort et fut fait, à tous ces titres, baron de l'Empire. Destitué en 1815, il se retira à Meilhan où il mourut en 1829, le 9 septembre.

ROCHAMBEAU (Donatien-Marie-Joseph de Vimeur, vicomte, puis comte de), fils du maréchal, né en 1750. Il servit dès l'âge de 12 ans dans le régiment d'Auvergne, fut nommé colonel en 1779 et se rendit en Amérique en 1780 avec son père. Maréchal de camp en 1791, lieutenant général en 1792, il fut nommé gouverneur général des Iles du Vent en remplacement de Béhague. N'ayant pu débarquer à Fort-Royal, il se rendit à Saint-Domingue et participa à la lutte contre les noirs. Revenu à la Martinique en février 1793, il tint tête aux Anglais en avril et juin, y établit le régime révolutionnaire, mais dut capituler l'année suivante devant une flotte de 77 bâtiments et 16.000 hommes de troupes. Demeuré en Amérique à la disposition de la Convention, il fut nommé par le Directoire, en 1796, gouverneur de Saint-Domingue. En opposition avec les commissaires civils qui l'entouraient, il fut destitué par eux et renvoyé en France où il fut quelque temps incarcéré. En 1800, il fit partie de l'armée d'Italie comme commandant d'une division et, en 1802, de l'expédition de Saint-Domingue conduite par Leclerc. Devenu commandant en chef à la mort de ce dernier, il heurta les mulâtres et créa un soulèvement général ; assiégé par les Anglais, il dut se rendre à eux en 1803 et fut emmené en Angleterre. Libéré en 1811, par suite d'un échange, il rentra au service en 1813 et fut, la même année, tué à Leipzig. 
VIOMÉNIL (Charles-Joseph-Hyacinthe du Houx, comte, puis marquis de), né à Ruppe, en Lorraine, en 1734. Aide de camp de Chevert pendant la guerre de Sept Ans, il participa à la campagne de Corse sous le maréchal de Vaux et combattit en Amérique sous les ordres de Rochambeau. Gouverneur de la Martinique en 1789, il retourna en France en 1790, émigra, rejoignit l'armée de Condé, puis se rendit en Russie où il obtint de Paul I ${ }^{\mathrm{er}}$ le grade le lieutenant-général. Il passa ensuite au Portugal, dont le roi Jean IV lui confia le commandement de ses troupes comme maréchal. Obligé de se réfugier en Angleterre en 1808, il rentra en France en 1814 avec Louis XVIII, qui le nomma maréchal de France en 1816. Il mourut en 1827. (Voir son éloge funèbre prononcé par le duc de Damas-Crux, Archives Parlementaires, 2e série, tome 500, pp. 175 et suiv.). 


\section{La Révolution française à la Martinique}

\section{Introduction}

\section{Retour à la table des matières}

Les révolutions changent de caractère à mesure que leurs effets se développent non seulement dans le temps, mais dans l'espace. Chaque milieu réagit à sa façon à l'incendie qui se propage, révélant parfois le pouvoir explosif d'idées et de situations profondément différentes de celles qui ont occasionné la première déflagration.

La grande Révolution de 1789 en est le plus frappant exemple. Nul autre mouvement d'humanité n'a eu une telle puissance d'expansion. Tout contribuait à en faire un événement entre tous exceptionnel : la méditation séculaire d'un peuple de penseurs, une soudaine floraison de l'intellectualité et du sentiment, l'ardente poussée de sève d'une race d'élite en pleine maturité. Nous en connaissons assez les effets au pays de l'Esprit des Lois et du Contrat social. Mais le ferment de rénovation porté au-delà de nos frontières par les armées de la République, diffusé par nos écrivains et nos philosophes à travers l'univers, devait produire des résultats auxquels nul n'avait tout d'abord songé : en Europe l'affirmation du principe des nationalités et les nouveaux impérialismes qui en procèdent ; dans le monde, la croissante et chaque jour plus troublante complication du problème des races. Et sans doute les effets de la grande commotion, après bientôt un siècle et demi, n'ont-ils pas encore fini de se développer.

L'histoire de la Révolution française à la Martinique n'est qu'un bien petit épisode au milieu des convulsions titaniques où se forma la France moderne. Elle présente cependant l'intérêt de faire apparaître, comme en une expérience de labo- 
ratoire, la déformation que subissent les idées et les passions transportées hors de leurs conditions d'origine. En croyant suivre le courant qu'elles leur impriment, les hommes obéissent sans presque s'en rendre compte aux impulsions de leurs sentiments et de leurs intérêts propres, et suivent la gravitation spécifique de leur milieu social.

Il ne semblait pas, à vrai dire, que les principes nouveaux qui suscitaient l'enthousiasme de la France entière, pussent être accueillis autrement qu'avec une frémissante sympathie par les descendants de ces pionniers qui, en quittant le sol natal, étaient allés chercher dans des terres vierges une existence plus indépendante et plus large. Ce que la Révolution leur apportait, c'était en somme la réalisation définitive, la consécration légale de cette liberté qui les avait poussés à s'expatrier, et en laquelle ils voyaient leur bien le plus précieux, celui qu'ils avaient le plus âprement défendu et dont ils avaient obstinément désiré la reconnaissance officielle.

En fait, ils y étaient déjà largement parvenus, et la Martinique, comme les autres îles françaises de la mer des Antilles, apparaissait, sous l'ancienne monarchie, comme un asile béni où chacun pouvait travailler et posséder, à l'abri de l'arbitraire et des vexations du pouvoir central.

La sécurité assurée par des milices locales de formation démocratique, conjointement avec des régiments entretenus aux seuls frais de la métropole, des impôts légers de l'emploi desquels l'administration avait à rendre compte dans un document public soumis à l'affichage, une justice rapide et gratuite, égale pour tous, les propriétés agricoles protégées par l'interdiction de la saisie immobilière, n'était-ce pas de quoi suffire au programme de plus d'un réformateur de l'ancien monde?

Et quels privilèges eût-on abolis là où il n'y avait point de charges ni d'offices, où les lettres de noblesse étaient tombées dans un tel discrédit qu'en 1710 le Ministre avait dû renoncer à en distribuer sur l'avis qu'elles ne trouveraient pas d'acquéreurs ${ }^{1}$, où le droit d'aînesse n'avait jamais existé encore que l'intégrité du domaine familial fût préservée par l'attribution à un seul héritier auquel incombait la charge de dédommager ses co-partageants ?

1 MAY (L.-Ph.) : Histoire économique de la Martinique. 
En vérité, la Martinique semblait réaliser une sorte «d'Utopie » par la sécurité de son régime et le libéralisme de ses institutions.

Mais il faudrait tout ignorer des ordinaires faiblesses de la nature humaine pour imaginer qu'une petite société, vieille de plus d'un siècle et demi, eût pu échapper aux mille raisons de discorde et de division que font naître les inégalités des situations et la divergence des intérêts.

Au seul point de vue économique, la Martinique était, à la veille de la Révolution, dans une situation hélas éminemment propice à l'éclosion de la guerre civile.

Deux groupes très différents de colons s'y disputaient la prépondérance : les planteurs d'une part, créateurs et propriétaires des exploitations agricoles réparties dans toute la campagne ; les négociants d'autre part, concentrés dans la ville maritime et commerçante de Saint-Pierre.

Un seul détail suffit à indiquer quelle pouvait être la tension de leurs rapports : les premiers devaient aux seconds 20 millions de livres ${ }^{2}$; et les créanciers ne pouvaient pas plus poursuivre leurs débiteurs que ceux-ci n'avaient le moyen d'arrêter la marée montante de leur dette.

C'était là un effet direct, et le plus fâcheux, du Pacte colonial que la France, comme d'ailleurs toutes les autres nations coloniales, avait aux XVIIe et XVIlIe siècles, appliqué à son domaine d'outre-mer.

Il était fondé sur ce principe que chaque métropole doit être seule à bénéficier de l'exploitation de ses colonies. La Martinique, possession française, ne devait donc vivre que par la France et pour la France ; il lui fallait réserver la totalité de ses produits à la Mère-Patrie comme en attendre exclusivement les objets et les denrées qui lui faisaient défaut. Enfin la marine nationale pouvait seule être employée au transport des marchandises ; c'est ce que l'on appelait aussi le régime de l'Exclusif.

On avait concédé aux colons des terres en quasi gratuité ; le Roi leur avait donné la paix et la justice ; il les avait libérés du joug fiscal et des obligations privées ; il exigeait d'eux, en retour, qu'ils contribuassent à l'enrichissement du royaume.

2 Environ 450 millions de francs actuels. 
Les planteurs de la Martinique avaient répondu à ces vues au delà de toute espérance en abandonnant peu à peu les cultures vivrières pour celle de la canne à sucre qui leur rapportait davantage. La savane indispensable aux bestiaux n'avait guère tardé à être envahie, elle aussi, par les plantations et les ateliers ; tant et si bien que, dès le commencement du XVIIIe siècle, la Martinique était assez semblable à une grande usine à sucre dont le personnel, sans cesse augmenté, devait se procurer au dehors tout ce qui était nécessaire à sa vie ${ }^{3}$.

Pour ces clients de choix, il valait la peine de se déplacer. Bordeaux, Nantes, Dieppe, Le Havre, Marseille et la plupart des autres villes maritimes du royaume avaient envoyé dans l'île leurs agents qui s'étaient postés, ainsi qu'il fallait, au débarcadère des marchandises, autour du mouillage des navires marchands. C'était Saint-Pierre que sa situation géographique, sa belle et vaste rade, ses défenses naturelles désignaient tout particulièrement pour ce rôle.

Bientôt des négociants travaillant pour leur propre compte s'y établirent à leur tour. Ils devaient réussir, étant nécessaires dans un pays d'échange où l'un des échangistes n'était à même de s'acquitter qu'au moment de la récolte.

On oublie trop, lorsqu'on maudit l'intermédiaire, qu'il est toujours en même temps un banquier, et que ceux qui font appel à son concours pour faciliter leurs opérations, sont beaucoup moins attirés par ses bons offices que par le crédit qu'ils trouvent auprès de lui.

L'activité de ces auxiliaires parut d'abord providentielle ; grâce à eux les capitaines marchands purent vendre leur cargaison sans plus attendre et trouver les barriques de sucre prêtes à emporter ; les planteurs n'eurent plus à se préoccuper des arrivées et des départs des navires ; ils purent désormais acheter au fur et à mesure de leurs besoins ; les magasins de Saint-Pierre étaient toujours garnis. Le rythme des affaires s'en trouva accéléré, le commerce assaini, la vie régularisée dans les concessions les plus lointaines.

Mais les capitaines de navires et les commissionnaires, exerçant de par les lois prohibitives un monopole de fait, achetaient et vendaient aux prix les plus avantageux pour le commerce de France et pour eux-mêmes, et si les sucriers, gens fort magnifiques, imprévoyants et superbes, dépensaient sans compter, les négociants

3 Cf MAY (L.-Ph.) : Histoire économique de la Martinique. 
penchés sur leurs registres comptaient, eux, sans oublier un sol. Il en résultait que la balance des comptes était ordinairement défavorable aux planteurs, lesquels, même en livrant tous les fruits de leur industrie, voyaient d'année en année s'accroître leur solde débiteur.

Ils en éprouvaient une amertume d'autant plus grande que de continuelles infractions faites au régime de l'Exclusif, sous la pression de la nécessité, leur permettaient de mesurer à quel point la sujétion économique où ils étaient tenus favorisait leurs créanciers.

Pour que le pacte colonial fût rigoureusement observé, il aurait fallu que la métropole pût assurer régulièrement la subsistance de ses colonies ; mais en dépit de leurs efforts et de leurs prétentions les négociants n'y parvenaient pas de façon bien suivie. Tantôt la récolte avait été déficiente, tantôt la marine avait manqué ; souvent aussi la guerre paralysait la navigation : si bien qu'à peine d'acculer les habitants à mourir de faim sur leurs monceaux de sucre, il fallait autoriser pour un certain temps l'échange des marchandises avec l'étranger dans tous les points de l'île.

Périodes de prospérité pour les planteurs: Anglais, Espagnols, Américains leur vendaient 50\% moins cher la morue, le bois et, en général, tous les matériaux et les vivres dont ils avaient besoin ; ils leur payaient les tafias et les mélasses le double des prix pratiqués à Saint-Pierre. Des doutes s'insinuaient alors dans l'esprit des ruraux sur la légitimité de leurs dettes ; ils sentaient se fortifier à la fois leur rancune contre les citadins et leur naturelle propension à la contrebande.

Celle-ci eut lieu de tout temps, et sur la plus grande échelle. Et cependant le Pacte colonial craquait de toutes parts malgré les ordonnances de Versailles fulminant contre le commerce étranger, lesquelles alternaient d'ailleurs avec les permissions accordées chaque fois que les circonstances l'exigeaient.

Mais si les planteurs faisaient volontiers usage du crédit, que les négociants intéressés au premier chef à la multiplication et à l'activité des ateliers ne pouvaient leur refuser, ils préféraient de beaucoup charger le plus possible de leurs denrées dans une anse isolée. Ils avaient ainsi le double avantage de frauder les droits de sortie et de soustraire leur marchandise aux saisies-arrêts par lesquelles les commissionnaires n'eussent pas manqué de sauvegarder leurs créances. On imagine que ces procédés n'amélioraient pas les relations entre les deux partis. 
Les commerçants enrageaient de la mauvaise foi de leurs débiteurs immunisés, comme il a été dit, contre la saisie immobilière par une loi conçue jadis en faveur des plantations et des manufactures. Les « habitants » reprochaient à leurs créanciers de s'être enrichis, hors de toute proportion raisonnable « uniquement du fait de la violence législative » ${ }^{4}$. Ils comparaient leur pays «à un enfant rachitique dont la tête est extrêmement grosse aux dépens d'un corps exténué » ${ }^{5}$.

Et, conscients d'être la source véritable de la prospérité du pays et des fortunes édifiées aux dépens de leur travail, ils revendiquaient la prépondérance politique et les moyens de l'exercer.

L'union de tous les blancs de la Martinique se faisait pourtant spontanément chaque fois qu'il s'agissait de défendre les franchises octroyées, d'en obtenir de nouvelles ou de réclamer le contrôle, par leurs représentants, de l'Administration à laquelle ils étaient soumis.

Mais si le pouvoir central respectait leurs privilèges, il entendait, en revanche, que le soin des affaires publiques restât intégralement aux mains du Gouverneur et de l'Intendant, nommés par le roi. On traitait les colons en éternels mineurs à l'égard desquels on était d'ailleurs disposé à témoigner « toute la bienveillance d'un bon père de famille » ${ }^{6}$ pourvu qu'ils se montrassent soumis.

Or la soumission n'est point, comme l'on pense, la vertu cardinale de gens assez hardis et entreprenants pour rompre avec toutes leurs traditions et affronter les dangers d'une grande aventure et d'un climat nouveau. Au cours des trente années qui suivirent celle où Pierre d'Esnanbuc aborda le premier à la Martinique, les colons de cette île ne se révoltèrent pas moins de trois fois. Un demi-siècle plus tard, en 1717, ils " pacquetaient » ${ }^{7}$ fort proprement le gouverneur et l'intendant et les jetaient avec leurs papiers et leurs effets dans un bateau prêt à faire voile pour la France, non sans accompagner ces étranges ambassadeurs de protestations d'amour pour leur prince.

4 LESCAILLER (baron Daniel) : Note sur les causes et la nature de l'opposition entre Saint-Pierre et « La Campagne ».

5 Lettre d'un planteur. Archives Dxxv 115.

6 Lettre de Colbert, citée par May (L.-Ph.).

7 SAINT-SIMON : Mémoires, T. 14, page 85. 
Saint-Simon se divertit fort de cette plaisante exécution, et toute la cour dut y prendre amusement comme lui ; mais le Régent fut mieux assuré que jamais que la prudence commandait d'ignorer officiellement l'opinion de ces « testes folles ». $\mathrm{Au}$ vrai, il savait fort bien quelles tendances particularistes s'affirmaient dans les colonies d'Amérique, et que le roi y faisait figure de souverain étranger.

Aussi la seule proposition d'un député auprès du bureau du commerce à Paris (comme en possédaient toutes les villes commerçantes de France) ou d'une compagnie chargée simplement d'élaborer des mémoires et des projets, lui paraissait attentatoire à sa Majesté. Il ne fallait lui parler ni de syndic ni même de municipalités, car, après un siècle d'existence, la Martinique ne possédait que des paroisses dépourvues d'organisation communale.

Faute de mieux, le Conseil Supérieur qui n'avait à connaître que des règlements de police et d'industrie, s'attribuait la mission qui eût été assignée à un corps politique régulièrement constitué, singeait tour à tour les parlements de France et d'Angleterre, et ne cessait de faire pièce à l'administrateur et à l'intendant, à l'intendant surtout qu'il considérait comme son adversaire né.

Ce fut seulement en 1759 que Berryer, ministre de la Marine, désireux de relever la Martinique éprouvée par la guerre avec l'Angleterre, décida la création d'une Chambre mi-partie de commerce et d'agriculture, nommée par le Conseil Supérieur, et l'institution d'un député, à Versailles.

La première de ces tentatives ne fut pas aussi heureuse que l'espérait le ministre. Le Conseil prouva que ses aptitudes à l'art de la politique passaient son goût pour l'équité, en accommodant le décret de manière que la Chambre ne fût composée que de planteurs ou d'anciens commerçants ralliés, soit par leurs attaches familiales, soit par des propriétés récemment acquises, aux intérêts des planteurs.

La nouvelle Compagnie s'érigea aussitôt en protectrice des « sucriers », en critique impitoyable de l'administration royale, attaqua à boulets rouges le malheureux intendant et, pour finir, livra sans combat la Martinique aux Anglais ${ }^{8}$.

Lorsqu'après le traité de Paris la colonie revint à la France, le roi préféra se passer des lumières du Conseil Supérieur et désigna lui-même les sept colons

8 « Après des mois de famine et d'abandon, il est vrai ». Histoire économique de la Martinique (L.-Ph. MAY). 
créoles appelés à former la nouvelle Chambre. Celle-ci, d'ailleurs, de même que la première, ne représentait que les grands propriétaires fonciers. Du moins dissipat-on toute équivoque en la disant « d'agriculture » seulement.

Pour ce qui est du député, la Colonie aussi bien que la Métropole n'eurent qu'à se louer de leur choix. Sur trois candidats proposes par le Conseil Supérieur, Choiseul avait agréé Jean-Baptiste Du Buc, membre d'une des plus puissante familles de planteurs et type achevé du grand blanc. Nommé en 1759, il fut confirmé dans ses fonctions en 1763. Le succès personnel qu'il rencontra à la cour de Versailles, les honneurs et les profits qu'il y sut gagner, ne lui firent pas oublier les intérêts des Iles du Vent. Devenu premier commis au bureau des Colonies, il obtint du Conseil du roi l'ouverture à Sainte-Lucie et à Saint-Domingue de deux ports d'entrepôt où serait autorisé le trafic avec les navires étrangers. "Quand Du Buc cessa ses fonctions de premier commis en 1770, la cause des colons perdait, auprès du pouvoir, son meilleur avocat $» 9$.

Mais déjà le cours souverain des réalités emportait les conceptions anciennes. Le libéralisme gagnait tous les esprits. A la veille de la catastrophe où elle devait périr, la monarchie donnait à ses colonies d'Amérique une preuve effective de sa bonne volonté : le 17 juin 1787, une ordonnance royale établissait à la place des Chambres d'agriculture, une "Assemblée Coloniale » comprenant un "Conseil Intermédiaire » chargé de garder le contact avec les agents des ministres dans l'intervalle des sessions. Le gouvernement avait fait l'expérience à la Guadeloupe de ce genre de conseils composés sur le modèle des Assemblées de SaintDomingue, et avait décidé de les acclimater définitivement dans les deux îles jumelles.

On se proposait d'associer les habitants à l'administration et, dans ce dessein, on les invitait à élire un député par paroisse. Au vrai, aucune compétence n'était encore reconnue à ce corps de représentants. Le gouverneur et l'intendant, présidents de droit, en demeuraient les maîtres; mais les élections, les discussions et la réunion des délégués de la Colonie entière devaient développer les échanges d'idées et permettre à l'opinion publique de s'exprimer.

Elle n'en prit que mieux conscience des raisons qui la divisaient et qui n'étaient pas toutes d'ordre économique.

9 A. DUCHÈNE : La politique coloniale de la France. 
La question des dettes ne se fût-elle pas avérée aussi irritante, que la campagne et la ville eussent encore été animées l'une contre l'autre par leurs prétentions et leurs vues politiques inconciliables.

Les planteurs, en dépit de ce nom évocateur de simplicité patriarcale - mais c'était « les sucriers » qu'il eût fallu dire - les planteurs avaient fini par composer une puissante oligarchie dans les mains de laquelle les milices démocratiques du début s'étaient changées en instrument de domination. A la fois chefs d'industrie et capitaines de compagnies, ils alliaient le pouvoir que leur conférait la richesse au prestige qu'ils recevaient de leur grade d'officier ou de leur dignité, de conseiller. Maîtres absolus d'une population noire dépourvue d'existence civile, forts de leur droit de premiers occupants, enracinés au soi de leur pays, ils méprisaient non pas seulement les hommes de couleur, mais autant et peut-être même plus l'élément flottant des commerçants tard venus dans l'île, et pour le temps d'y faire fortune. Ils n'aspiraient pas seulement au libre-échange, mais encore à une quasiautonomie leur assurant la direction effective de la colonie sous le protectorat de la France.

Quant aux négociants, outre qu'ils tenaient pour sacro-saint le régime prohibitif qui les enrichissait, ils souhaitaient âprement d'abaisser la superbe de ces arrogants débiteurs qui les traitaient de grands seigneurs à manants. Habitants fortuits d'une ville qui n'était pas, comme on l'eût pu penser, la tête de la Martinique, mais bien le principal comptoir de la Métropole pour toutes les Iles du Vent (et qui devait garder quelque chose de ce caractère jusqu'à sa destruction par l'éruption du Mont-Pelé en 1902), ils étaient porté§ à se flatter, fût-ce envers et contre le Gouverneur, de personnifier la Mère-Patrie.

L'opposition de ces mentalités si dissemblables de la campagne et de la ville devait naturellement trouver dans le premier relâchement de l'autorité centrale et dans l'avènement d'un nouvel ordre de choses, l'occasion de s'accentuer et de dégénérer en conflit déclaré. Forcément, les idées et les passions de la métropole devaient trouver un terrain tout préparé dans l'élément urbain, encore tout attaché à ses origines et en relations plus directes avec les milieux de France. L'élément rural, au contraire, tout à ses préoccupations particularistes, devait normalement se désintéresser d'un mouvement qui lui était étranger par ses raisons et par son but, et ne voir dans l'occultation du pouvoir royal qu'un moyen d'affirmer ses tendances et d'atteindre plus sûrement ses objectifs. 
Telle fut la première cause de la déviation des événements. La Mère-Patrie, il est vrai, ne cessera (du moins jusqu'en 1793), de prêcher aux deux partis rivaux la paix et la concorde. Elle aura la sagesse de comprendre que la nouvelle constitution qu'elle enfante dans les larmes et le sang, peut ne pas convenir là où les conditions d'existence sont toutes différentes de celles qu'elle offre elle-même. Elle recommandera aux colons de ne se livrer à aucune innovation en matière de régime, mais de tâcher à s'accorder pour élaborer des projets qu'elle s'engage à examiner avec la plus entière bienveillance.

Les honorables commerçants de Saint-Pierre auraient sans doute entendu ces conseils pleins de sens s'ils ne s'étaient laissé entraîner par deux éléments fort inégaux quant à la qualité mais non quant à la véhémence : la jeunesse et la canaille.

Précoces, ardents, électeurs à 16 ans ${ }^{10}$, enclins comme tous ceux de leur âge à faire table rase du passé, nos jeunes créoles de la ville et des bourgs pouvaientils résister à la contagion révolutionnaire et ne pas prendre feu pour une cause qu'ils croyaient juste ? Ils seront les premiers champions de la « régénération » et les plus désintéressés. On les verra fronder le gouverneur, défier les officiers, échanger entre eux des lettres enflammées qu'ils qualifieront mutuellement de « sublimes cantiques » 11 .

Allaient-ils se soucier d'être submergés et souvent compromis par l'espèce la moins recommandable: flibustiers, aventuriers, matelots déserteurs, bagnards évadés, tourbe qui se dépose à toutes les époques dans tous les ports - lesquels, n'ayant rien à perdre, ont tout à gagner et ne demandent pas mieux que de bouleverser le pays qui leur a donné asile, pour s'établir sur ses ruines ? ${ }^{12}$.

Aux milices des planteurs comme aux troupes du gouvernement, les négociants étaient à même d'opposer des partisans qu'ils n'avaient que la peine de contenir - à quoi ils ne réussirent d'ailleurs pas longtemps.

10 A la seconde assemblée coloniale, l'âge minimum des électeurs fut fixé à 25 ans.

11 Correspondance échangée entre les jeunes citoyens des bourgs et des villes. Arch. Col. Dxxv 117, Dossier 915.

12 Lettre de M. de Laumoy au ministre. Arch. Nat. Col. C8A 89. 
Mais en cet an de grâce 1789, ni l'un ni l'autre des adversaires dressant son ambition et sa haine au-dessus de la masse des hommes de couleur, n'envisageait que cette multitude attentive dont ils allaient, au cours des années suivantes, se disputer la fidélité, posait, par sa seule présence, le problème le plus grave.

Ce n'est pas impunément que quelques milliers de blancs appellent au travail un nombre huit ou neuf fois supérieur de noirs, ceux-ci fussent-ils importés comme du bétail et réduits en servitude.

Et c'est ici qu'apparaît le caractère proprement spécifique que devait prendre la tourmente révolutionnaire, transportée de la vieille société métropolitaine où elle avait pris naissance, dans le milieu profondément différent de la vie coloniale.

Car la mise en valeur du pays, la création de ces florissantes exploitations dont planteurs et négociants se disputaient les profits, n'avaient été possibles que par le moyen d'une main d'oeuvre importée et utilisée par les deux Procédés barbares de la traite et de l'esclavage.

Ces institutions d'Etat, verrues énormes d'une société qui s'estimait civilisée, étaient si profondément entrées dans les mœurs, elles étaient si intimement liées à l'existence même de la colonie, que les bénéficiaires du régime n'en avaient pour ainsi dire pas conscience. Le noir ne comptait pas. Viendrait-il à l'esprit d'un de nos fermiers que ses animaux domestiques pussent avoir des droits, et qu'il fallût confronter ces droits avec les siens? Ainsi, ni les planteurs ni les négociants n'imaginaient qu'une question eût jamais à être posée au sujet de ce troupeau jugé négligeable et dont l'importance allait être primordiale.

Ils ne songeaient pas que cette conception égoïste et féroce - même en supposant qu'elle fût susceptible de demeurer viable en se maintenant jalousement cohérente avec elle-même - avait déjà subi de redoutables atteintes.

Car si l'on avait la prétention de conserver indéfiniment les noirs, amenés d'Afrique par force, dans l'état de «propriétés pensantes » (comme le dira dans un langage élégant l'un des commissaires de la Révolution), il eût fallu n'en affranchir jamais aucun, et encore moins s'unir à leurs femmes...

Mais les lois de la nature se jouent de celles des hommes.

Aussi aveuglément méprisés qu'ils fussent alors, les hommes de couleur libres étaient là. Nombreux, orgueilleux d'être du sang des grands blancs, supérieurs par 
les connaissances qu'ils avaient su acquérir aux petits blancs qui régentaient Saint-Pierre, enrichis d'autant plus rapidement qu'ils travaillaient eux-mêmes à leurs terres, miliciens pour la plupart et formés au combat, ils constituaient désormais une classe importante avec laquelle il fallait bien compter.

Quoique la division se fût aussi glissée dans son sein - les esclaves et les hommes libres se détestant mutuellement - la « Couleur » était déjà l'élément prépondérant dans les destinées des Antilles françaises. Elle ne l'apprendra elle même qu'en l'apprenant au monde. Il faut constater l'évidence : à Saint-Domingue, Toussaint Louverture et ses congénères extermineront les Européens sans recours ; - Victor Hugues ne reconquerra la Guadeloupe que grâce à l'aide des noirs ; à la Martinique, la victoire favorisera ou trahira chaque parti selon qu'il sera soutenu ou abandonné par les mulâtres.

Sans doute, sous le Consulat, «la Couleur » devra-t-elle reprendre le joug ; sans doute faudra-t-il deux autres révolutions pour qu'elle accède définitivement à cette liberté à peine entrevue, à cette égalité si précairement goûtée ; mais ce couronnement ne pouvait que s'accomplir.

Et c'est bien là ce qu'il y a de plus impressionnant dans ce grand drame dont les acteurs eux-mêmes n'avaient pas conscience : à leur insu, il se transposait plus haut que leurs rôles, leurs intérêts, leurs idées et même leur idéal ; si haute que fût la pensée française, elle était dépassée par les forces qu'elle avait, par occasion, mises en branle.

Planche I. Carte réduite de l'ïle de la Martinique.

Voir Les Classiques des sciences sociales. 


\section{La Révolution française à la Martinique}

\section{Chapitre I}

\section{La Cocarde tricolore}

$\underline{\text { Retour à la table des matières }}$

Ce soir de septembre 1789, les acteurs qui s'évertuaient sur la scène du théâtre de Saint-Pierre, sentaient avec dépit qu'ils ne parvenaient pas à captiver l'attention du publie. Les spectateurs étaient manifestement distraits. Beaucoup chuchotaient entre eux, se désignant furtivement de l'oeil ou de l'éventail un jeune homme qui venait d'entrer dans la salle, portant à son chapeau, non sans quelque ostentation, une cocarde bleue, blanche, rouge.

C'était la première fois qu'on voyait à la Martinique cet emblème, et il intriguait fort tout le monde. Des loges au parterre, on se répétait que le particulier, objet de la curiosité générale, était débarqué du jour même et qu'il arrivait de France où il venait de faire un séjour assez long.

Or, depuis plus de deux mois, on était sans nouvelles directes de la métropole.

Certes, les « papiers » anglais avaient répandu quelques bruits des événements inouïs qui s'y passaient ; certes, Saint-Pierre ne manquait pas plus qu'aucune ville au monde de ces informateurs bénévoles chez qui le désir de paraître renseignés l'emporte sur le souci de l'exactitude. Mais on suspectait le gouvernement de Londres de chercher à créer aux Antilles des troubles dont il eût pu tirer parti. Ces rumeurs ne venaient-elles pas, comme on le verra plus loin, de susciter une agitation difficilement réprimée chez les Noirs? Aussi les esprits raisonnables fai- 
saient-ils observer qu'on ne pouvait encore tenir pour avérés d'autres faits que la réunion des Etats Généraux et le serment du Jeu de Paume.

L'impatience était fort grande d'interroger le voyageur et d'apprendre quelle discipline, quel mot d'ordre, quel idéal nouveau peut-être motivaient le port de l'insigne tricolore.

Les préoccupations politiques, que l'on était venu tenter d'oublier un instant au théâtre, reprenaient leur acuité. La réalité reléguait à l'arrière-plan les fades attraits de la fiction.

Dès l'entr'acte, on se précipita. Entouré, pressé de questions, le nouvel arrivant jeta pêle-mêle à l'avidité de son auditoire le récit étonnant des faits sans précédent qui s'étaient succédés en France à un rythme de fantasmagorie. Il dit tumultueusement le 14 juillet et le 4 août, la capitulation du pouvoir séculaire de la monarchie absolue, l'avènement de la souveraineté populaire, la formation de la Constituante chargée d'élaborer la charte de la Nation désormais maîtresse de ses destinées. Et il déclara fièrement que sa cocarde était l'ETENDARD DE LA LIBERTÉ 13 .

Un tel langage semblait tenir de la féerie. La fièvre qui transportait les esprits en France, la foi communicative qui s'allumait comme une traînée de poudre et renversait les idoles du passé dans la fulgurante véhémence des conversions, l'enthousiasme de la vérité enfin découverte et proclamée, arrivaient comme un souffle de fournaise sur la population encore paisible mais sensible et frémissante, de la cité martiniquaise.

Le lendemain, la foule commentait avec ferveur la prise de la Bastille, l'abolition des droits féodaux, les promesses de la prodigieuse régénération qui s'accomplissait dans l'unanime élan des esprits et des cœurs. L'ardente jeunesse SaintPierraise prenait feu. Il n'était plus, chez elle, personne qui ne voulût aussitôt porter cocarde.

Un bâtiment de Bordeaux arriva à point pour approvisionner les citoyens de cet emblème dont ses passagers et ses hommes d'équipage étaient déjà pourvus.

13 Lettre de Vioménil au ministre pour l'informer des événements qui se sont passés depuis le mois de septembre, en date du 17 oct. 1789. Arch. Nat. Col. C8A 89. 
Le courrier qu'il apportait confirmait entièrement les assertions de l'amateur de spectacles.

Les trois couleurs fleurirent maints chapeaux. L'irrésistible pouvoir des Idées, la croyance instinctive au miracle opéraient leurs effets prestigieux.

M. de Laumoy, commandant en second, homme honnête et pondéré qu'une telle effervescence troublait, s'émut et s'empressa de prévenir son chef, qui résidait à Fort-Royal (aujourd'hui Fort-de-France).

Charles-Joseph-Hyacinte du Houx, comte de Vioménil, Gouverneur et Général intérimaires de la Martinique en l'absence du titulaire, M. de Damas, était un homme impétueux. Intelligent et fin, brave jusqu'à la témérité, sensible comme on l'était au XVIIIe siècle, inondant volontiers son gilet de larmes, mais sachant aussi l'ouvrir pour dénuder sa poitrine devant les fusils braqués contre lui ${ }^{14}$, il n'arrivait pas toujours, comme on le verra plus tard, à plier sa fougue naturelle aux exigences de la diplomatie ou à l'exacte observation des formalités.

En recevant les nouvelles que lui mandait M. de Laumoy, il bondit hors de son fauteuil et se mit à arpenter son cabinet à pas furieux. Les raisons de son irritation affluaient à son esprit : ces jeunes gens perdaient-ils le sens ou avaient-ils la mémoire si courte qu'ils eussent déjà oublié la grande frayeur que venaient de leur causer les esclaves révoltés ? Il n'y avait cependant pas plus de deux semaines que les noirs ayant eu connaissance de la lettre adressée par le marquis de Condorcet au nom de la Société des Amis des Noirs à tous les baillages de France, s'étaient persuadés que le Gouverneur avait ordre du Roi de leur donner la liberté et n'était retenu de le faire que par les sollicitations de leurs propriétaires ${ }^{15}$. Ils avaient aussitôt déclaré, dans une lettre insolente, qu'ils se libéreraient eux-mêmes « à la faveur des coups ». " Il en sortira avant peu, ajoutaient-ils, des torrents de sang qui couleront aussi puissants que nos ruisseaux qui coulent le long des rues » 16 .

14 ) M. de Vioménil a ouvert sa poitrine en défiant un qui le visait et que ce trait d'audace a désarmé ». Lettre de M. de Laumoy, février 1790. Arch. Col. Mart. 269.

15 Lettre de Foullon d'Ecottier, 24 oct. 1789. Arch. Nat. C8A 89.

16 Lettre adressée à $\mathrm{M}$. de Molerat, major commandant de la ville de SaintPierre et signée : « Nous nègres ». 28 août 1789. Arch. Nat. Col. C8A 89. 
Voilà, pensait M. de Vioménil, le brillant résultat de cette Société des Amis des Noirs, constituée à Paris par des philosophes sans doute éminents et bien intentionnés, mais profondément ignorants des choses coloniales. N'avaient-ils pas réclamé la mise à l'ordre du jour des Etats de l'abolition de l'esclavage ? Ah 1 ils ne s'embarrassaient pas dans les difficultés qu'entraînerait l'exécution de leur rêve, ces généreux illusionnistes ! Ignoraient-ils que la traite - comprise, naturellement, dans le régime de l'Exclusif - provoquait un mouvement d'affaires de 59 millions de livres par an ${ }^{17}$, auquel la métropole ne pouvait renoncer brusquement sans courir à un désastre économique et financier ? Car, sans compter le trouble jeté dans le travail des exploitations, un fournisseur honnête doit, en tout état de cause, rembourser ses clients s'il lui prend fantaisie de les déposséder de leurs achats ; comment l'Etat, entrepreneur de l'approvisionnement des planteurs en maind'oeuvre, pourrait-il éluder cette obligation?

C'était grand dommage, en vérité, que quelques-uns de ces apôtres ne fussent pas venus faire un tour à la Martinique la semaine passée ! Ils auraient eu le plaisir de voir la horde des noirs armés des instruments dont ils coupent les cannes, se répandre dans la campagne, les planteurs et leurs familles tremblants dans leurs habitations barricadées, la terreur régnant sur la ville et sur les bourgs ! Peut-être eussent-ils tiré de ces tristes tableaux quelques réflexions salutaires...

Et M. de Vioménil, poursuivant le cours de ses réflexions, songeait que, fort heureusement, les mulâtres des milices coloniales s'étaient trouvés à point pour réprimer ce dangereux mouvement. Par une rencontre dont l'ironie ne lui échappait pas, c'étaient les hommes de couleur qui avaient sauvé les blancs de la Martinique exposés par les blancs de France à périr de la main des esclaves ! Encore avait-il fallu que le général agît promptement et énergiquement. Par ses soins, une chasse générale avait été organisée, les mutins ramenés au travail, les nègres marrons rendus à leurs maîtres, les meneurs arrêtés et deux d'entre eux, jugés les plus coupables, exécutés sur la place publique. Les procès en cours donnaient à supposer que le foyer de la conjuration était à Saint-Pierre même. Et voilà le moment que choisissaient les jeunes étourdis de cette ville pour étaler aux yeux des noirs encore tout frémissants de leur grande illusion perdue, un emblème qu'ils disaient

17 Avec les Rouges aux Isles du Vent. Souvenirs du chevalier de Valous, 17901793. Calmann Lévy, 1930. 
être celui de la liberté ? La liberté, mot magique, qui pouvait bien avoir pour le peuple de France un sens sublime, générateur de grandes choses, mais qui, pour d'humbles cerveaux de primitifs assujettis à la servitude, ne pouvait signifier que : l'affranchissement.

« Au surplus, remarquait le Gouverneur en son soliloque, qu'y a-t-il d'authentique dans ces contes que l'on fait et dont je ne trouve aucune relation dans la correspondance qui m'arrive du royaume ? Et, supposé que cette cocarde ait été effectivement adoptée par le peuple français à l'occasion d'une révolution en faveur de la liberté civile, qu'aurions-nous à en faire ici ? S'il ne me paraissait aussi dangereux, je pourrais trouver plaisant l'engouement de ces fous pour le symbole d'un bien qu'ils ne veulent du tout accorder aux seuls individus qui n'en jouissent pas dans nos îles. Mais tout me prouve qu'ils attachent à cette marque distinctive des idées d'indépendance, de rapprochement et de confusion des Etats bien éloignées de sa véritable signification » 18.

Ayant ainsi exprimé ses idées pour soi-même, $M$. de Vioménil répond sur le champ à M. de Laumoy que, pour leur propre sécurité, il faut empêcher les habitants de porter la cocarde.

M. de Laumoy, homme de grand sens, parfaitement loyal et désintéressé, entre entièrement dans les vues du Gouverneur et s'emploie a y convertir les jeunes gens. Il y réussissait assez bien, quand l'un des plus entêtés ayant lassé sa patience, il le place enfin dans l'alternative de quitter sa cocarde ou d'aller en prison. L'opiniâtre préfère ce dernier parti et, tout aussitôt, ses camarades reprennent l'insigne séditieux et exigent en tumulte l'élargissement du prisonnier.

M. de Vioménil, averti, arrive à Saint-Pierre, rassemble les chefs de commerce et les notables de la ville devant lesquels il convoque les jeunes indociles. Là, il explique ses raisons, argumente et supplie tour à tour trois heures durant, finit enfin par persuader, et regagne Fort-Royal tout heureux de son succès.

Il n'a pas longtemps à s'en féliciter. Pour emporter l'assentiment des SaintPierrais, il a dû s'engager à autoriser l'emblème tricolore et à l'adopter lui-même aux premières nouvelles certaines. Or, un bateau venant de Sainte-Lucie en apporte dès le lendemain. Le gouverneur s'exécute.

18 Rapport de Vioménil au ministre. 17 oct. 1789, déjà cité. 
« Puisqu'il est constant, écrit-il aux commerçants dans un dernier effort pour prévenir les interprétations tendancieuses, puisqu'il est constant que les chefs et les citoyens des différentes provinces de France ont pris et portent la cocarde qui est le signe de la réunion el de la concorde de tous les ordres de l'État... ».

Lorsqu'il paraît au théâtre de Saint-Pierre avec les trois couleurs, M. le comte de Vioménil peut mesurer à l'ampleur des acclamations qu'il soulève, la gravité des difficultés qui l'attendent.

Il n'est plus pour lui que de sauver la face en donnant un caractère officiel à l'enthousiasme populaire.

De retour à Fort-Royal, s'il refuse de faire chanter un Te Deum, alléguant qu'il n'a pas d'ordres du Roi, il régale du moins les habitants d'une parade militaire suivie d'un banquet sur l'esplanade du fort.

Pour traiter les «Patriotes » - c'est le nom splendide que se donnent maintenant, à l'imitation de ce qui se fait en France, les partisans de l'ordre nouveau - la garnison a reçu, par son ordre, force boissons et victuailles et « tout ce qu'il faut pour assurer sa joie et l'unir à l'allégresse publique » ${ }^{19}$.

Les plus importants parmi les hommes de couleur ont demandé à être admis à ces réjouissances. Le Gouverneur a d'autant moins cru devoir s'opposer à leur désir qu'il y a vu l'occasion de récompenser le zèle qu'ils viennent de montrer pour le bien de la colonie et que l'assemblée coloniale, d'ailleurs, a déjà reconnu en leur offrant la cocarde. Tout se passe le mieux du monde.

Le lendemain, M. de Vioménil, cédant à des instances répétées, permet enfin le Te Deum. Ne lui assurait-on pas qu'on en avait fait de semblables à Bordeaux et dans les villes considérables du Royaume, et pouvait-il, en outre, paraître désapprouver M. de Laumoy qui venait d'en autoriser un à Saint-Pierre ?

La journée s'annonçait sous les plus heureux auspices. Tout faisait présumer la joie et la bonne entente.

L'orage éclata le soir même.

19 Rapport de Vioménil au ministre. 
Les patriotes devaient rendre à la garnison la politesse qu'ils en avaient reçue. Or, si leur situation d'invités les avait obligés, la veille, à supporter la présence des hommes de couleur, il n'en allait plus de même dès qu'ils faisaient, à leur tour, figure d'amphitryons. Pour écarter plus facilement les indésirables convives, ils décidèrent que le second festin aurait lieu à l'intérieur du fort.

Le soir venu, M. de Vioménil, qui traitait lui-même au Gouvernement 60 notables de la ville, et «se livrait à tout ce que la franchise et la cordialité pouvaient lui inspirer (le plus propre à affermir la paix » ${ }^{20}$, fut demandé par un mulâtre qui accourait se plaindre à lui de ce qu'on l'eût repoussé à l'entrée de la citadelle. C'était un architecte fort lettré, nommé Sablon Dumas.

Je l'ai dit : M. le Gouverneur était un impulsif. L'empire qu'il avait dû prendre sur lui au cours des dernières journées, la générosité des vins où il avait puisé sa gaîté de commande, la bienveillance - « aussi constante qu'impolitique » ${ }^{21}$, disait l'Intendant Foullon - où son coeur l'inclinait envers une race humiliée, tout concourut à lui faire perdre l'exact contrôle de soi-même.

Il entraîne Dumas vers le fort, pénètre avec lui et les autres mulâtres qu'ils trouvent mortifiés à la porte, fait irruption à leur tête dans la salle du repas.

L'apparition de M. le Général ainsi escorté, la fureur qui se manifeste sur son visage, laissent tout le monde interdit. Il exige - inutilement d'ailleurs - le nom de celui qui a donné la consigne, prend fait et cause pour les hommes de couleur, exhorte les citoyens à les mieux traiter. Des murmures lui répondent ; une bagarre s'ébauche, un homme de couleur est frappé et renversé. Ce spectacle achève de mettre M. de Vioménil hors de lui. Il éclate en reproches, exprime sans détours son sentiment personnel sur la valeur comparée des mulâtres cultivés et celle de certains blancs qu'il vaut mieux ne pas regarder aux épaules, en appelle au major Castella et au commandant Laubenque qu'il prend au jabot de sa chemise, trinque avec Dumas et va jusqu'à lui donner l'accolade. Pour le coup, le hourvari est à son comble : les femmes glapissent et se trouvent mal, les hommes vocifèrent. Voulant dominer ce tumulte, M. le Général fait battre un ban et, comme il est d'usage en pareil cas, met l'épée à la main. A cette vue, tout le monde s'enfuit dans une bousculade affreuse et « va répandre le bruit et la crainte par la ville ».

20 Rapport de Vioménil au ministre.

21 Foullon au ministre. Ministère des Colonies, Martinique, 268. 
Ce fut un beau scandale dont on mena fort grand vacarme. M. de Vioménil écrit que « pendant près de deux jours, il fut hautement menacé de voir porter des mains téméraires sur le représentant de Sa Majesté ». Mais enfin, pour cette fois, on s'en tint aux menaces et aux cris. Le bilan de l'émeute apparaît tout à fait rassurant lorsqu'on lit le certificat de M. Clavery, substitut ou Procureur du roi en la sénéchaussée de Fort Royal, attestant : «que les troubles n'ont occasionné aucun accident à homme, femme ou enfant dans toute la ville, pas même de fausses couches aux femmes » 22.

L'incident semblait donc ramené à ses justes proportions quand Saint-Pierre s'en mêla. La canaille de ce port se sentant particulièrement visée par les paroles du gouverneur, saisit la balle au bond pour créer des désordres dont elle espérait profiter.

Les hommes d'ordre - et ceux qui, malgré l'outrance de leurs opinions, ont encore l'ambition de mériter dans une certaine mesure ce nom - oublient trop le rôle que ne manquent point de s'attribuer les éléments troubles dès que l'autorité paraît faiblir ou perdre la face. C'est une grande responsabilité pour les détenteurs du pouvoir comme pour ceux qui aspirent à prendre leur place. Ce qui fait dévier, ce qui ensanglante les mouvements populaires, ce sont toujours les excès des gens sans aveu à qui les divisions des états-majors sont une simple occasion de mauvais coups.

La responsabilité des agitateurs - encore qu'ils se défendent toujours « d'avoir voulu cela » - y est directement engagée. Aux effets s'apprécient les causes. Et c'est pourquoi la faiblesse ou l'énervement de ceux qui détiennent les moyens de maintenir la paix publique, est toujours la plus grave des fautes. «Empêche les commencements ». «Principiis obsta », dit l'adage latin.

A Saint-Pierre, la nouvelle de l'émeute, assez anodine, qui avait à la ville voisine terminé une soirée de liesse, suffit à déchaîner la pègre.

Une folle effervescence, bientôt tournée en rage homicide contre M. de Vioménil, s'empare de la population, Les plus modérés veulent partir sur le champ à Fort-Royal pour embarquer le gouverneur. M. de Laumoy rassemble en hâte les

22 Arch. Nat. Col. C 8 A 89. 
notables et tombe d'accord avec eux sur ce qu'il importe, avant tout, de gagner du temps. Ils lui proposent alors de constituer un comité chargé de vérifier les faits.

« Je n'ai eu garde de m'y opposer, dit M. de Laumoy, tant par l'espoir que cela me donnait de voir bientôt des gens raisonnables à la tête de ce peuple, que pour conserver au moins la considération en perdant une partie de l'autorité, car ils l'auraient fait malgré moi ». - « Je n'ai pas été long à m'en repentir », ajoute-t-il 23.

Les membres du comité avaient été cependant choisis parmi les plus honorables bourgeois de Saint-Pierre, dont MM. Ruste et de Corio qui en étaient les président et vice-président. M. de Vioménil lui-même voyait d'un fort bon œil cette députation, « comptant sur elle pour remettre les choses au point et contenir la multitude ». Pourtant, quand ces messieurs eurent entendu de la bouche des délégués de Fort-Royal que tout était apaisé et se réduisait à un différend de peu de conséquence, ils passèrent outre à ces assertions et s'en furent par la ville recueillir les ragots.

\section{Planche II. Le Marquis du Houx Viomenil, Maréchal et Duc de France. Voir Les Classiques des sciences sociales.}

Les commissions d'enquête n'ont jamais rien apaisé. Celle-ci, selon la règle générale, se sentait tributaire des passions qui l'avaient fait naître. Elle n'estimait pas fort prudent de revenir bredouille devant des forcenés impatients d'alimenter l'indignation publique ; ensuite, elle voyait dans cette affaire l'occasion d'établir, sous prétexte de juger le Gouverneur, une assemblée d'un mode nouveau où le nombre des élus étant au prorata de celui des électeurs, Saint-Pierre fournirait à lui seul le tiers des représentants de la colonie.

Les notables ainsi réunis ne manquèrent pas d'en solliciter la formation de MM. de Laumoy et Foullon d'Ecotier, intendant, stipulant que « M. de Vioménil n'y devait coopérer en rien » - toutes les convenances s'y opposent, écrivent-ils. Il est accusé par la voix publique de faits et de propos graves qui intéressent la Na-

23 Rapport de M. de Laumoy au ministre, Arch. Nat. Col C8A 89. 
tion et plus particulièrement la Colonie. « Sans une justification, il ne peut vivre parmi nous avec honneur ».

Et ils se mettent en devoir de rédiger l'acte d'accusation : « Il a fait battre un ban et publié lui-même, l'épée à la main, à la tête de ses troupes, qu'il fallait regarder les mulâtres comme citoyens, comme confrères et faire société avec eux ; il a donné l'accolade à l'un d'eux... Le ban publié en faveur des mulâtres, l'acte violent de les proclamer égaux aux blancs confirment qu'il n'a que trop réellement les opinions manifestées dans ses propos... Il y a tout à craindre d'un homme qui avilit ceux qu'il commande et ameute ceux qui doivent être maintenus dans une classe inférieure » 24.

On le voit, ces disciples des grands révolutionnaires de 89 ne professaient l'Egalité et la Fraternité qu'à leur bénéfice. C'est là une erreur dont on ne saurait s’étonner, car elle est si naturelle qu'on en rencontre encore des exemples de nos jours 25 . « Je réclame pour moi les droits que je refuse à mes adversaires », sera la devise éternelle de tous les partis.

Mais M. de Vioménil n'est nullement en humeur de lâcher la barre. Il répond aux arguments de MM. Ruste et de Corio « que les dispositions de l'ordonnance du 17 juin 1787, portant création de l'Assemblée Coloniale sont décisives » et que, « puisque c'est aux administrateurs généraux que la convocation appartient, il s'ensuit qu'il est de l'obligation de leurs places de la faire dans des occasions importantes comme celle-ci ». Cependant, comme il discerne fort bien les mobiles de l'intransigeance du Comité, il autorise les paroisses de Saint-Pierre à envoyer 12 députés supplémentaires et celles de Fort-Royal 6.

L'Assemblée se réunit le 9 octobre. Le 15, elle décide « qu'elle s'abstiendra par respect » de prononcer sur le cas du Gouverneur. Les députés de Saint-Pierre ont d'ailleurs paru se désintéresser complètement de cette question. La seule qui

24 Rapport du Comité de Saint-Pierre. Arch. Nat. Col. C8A 89.

25 Berclery, dans un rapport rédigé en 1795 pour les besoins de la cause (la Convention entendait appliquer l'égalité tout de bon), Berclery imagine une extravagante histoire tendant à prouver que les patriotes de 1789 nourrissaient les sentiments les plus fraternels pour les mulâtres abusés par le machiavélisme de Vioménil. Le réquisitoire du Comité de Saint-Pierre montre assez le crédit qu'il faut accorder à ces sottises. 
les soucie est la formation d'une Assemblée générale où le nombre des représentants de chaque paroisse serait fonction de celui de ses citoyens. Ils réussissent à en faire adopter l'idée par leurs collègues et par M. de Vioménil. Pour l'intendant Foullon, il y était déjà tout acquis, ne fût-ce que pour professer une opinion opposée à celle qu'il supposait au Gouverneur.

La nouvelle assemblée est convoquée pour le 16 novembre. Le nombre des députés est fixé à 1 pour 50 votants ou pour tout reliquat égal ou supérieur à 25 . Sont votants «tous hommes créoles et européens portant armes, depuis l'âge de seize ans, ou tous hommes de l'âge susdit pouvant justifier du payement des impositions ».

Lorsqu'à la date convenue elle se réunit à Fort-Royal, les planteurs constatent, avec quelque effarement, le résultat du nouveau mode d'élection : Saint-Pierre a 37 sièges sur 121. Ils s'émeuvent d'une proportion aussi élevée qui va donner à la représentation urbaine une importance redoutable pour leurs intérêts et, pour obvier à ce danger, ils élèvent la majorité nécessaire à la validité des délibérations aux deux tiers des votants.

Pour les négociants, la grande satisfaction qu'ils retirent de ce premier succès les dispose à la concorde. Ils sentent fondre leur rancune contre M. de Vioménil. Ce qui les y invite d'ailleurs encore plus, c'est que les esclaves, ayant entendu au prône la lecture du décret de la Constituante dans lequel le Mot LIBERTÉ revient fort souvent, ont eu l'impertinence de penser qu'il pouvait concerner ceux qui souffrent de la servitude, et ont esquissé une nouvelle révolte. L'économe d'une habitation a été tué 26.

Devant le danger, toute la colonie éprouve le besoin de se resserrer autour du Gouverneur, comme le poulailler autour du coq, et c'est à l'unanimité que l'Assemblée décide de réconcilier M. de Vioménil et Saint-Pierre.

Au grand complet, elle se transporte avec lui dans cette ville. Ils sont reçus par le Comité qui les conduit à la salle du théâtre. Le Gouverneur après y avoir prononcé un de ces discours "pleins de sensibilité » dont il a le secret, donne à $\mathrm{M}$. Ruste le baiser de paix. Le peuple, d'abord hésitant, s'enflamme tout à coup d'un grand amour pour l'objet récent de sa haine. M. de Laumoy nous le décrit « dans

26 Lettre de Foullon, 29 nov. 1789. Arch. Nat. Col, C 8A 89. 
l'ivresse du sentiment, rendant l'hommage le plus pur à M. le Général, chaque citoyen à l'envi s'empressant de l'approcher pour jouir de ses embrassements et présentant une scène attendrissante qu'il est impossible de bien peindre ».

M. de Vioménil a tout pardonné, tout oublié. Il exulte ! C'est le plus beau jour de sa vie. Il se persuade - avec raison - que les membres du Comité ont été tentés par l'occasion et poussés par la peur mais n'en demeurent pas moins d'honnêtes gens avec lesquels il n'est que de s'entendre 27.

Et l'on s'entendit en effet... pendant dix jours.

L'Assemblée Générale de la colonie n'avait pour objet que la rédaction des cahiers de doléances et la nomination des députés chargés de les remettre à l'Assemblée Nationale. Elle se crut législative. Les représentants de Saint-Pierre et des paroisses qui suivaient la politique de cette ville, proposèrent la création de Municipalités. Dans l'euphorie de la réconciliation, tout le monde adhéra à ce projet dont il était question depuis nombre d'années et M. de Vioménil l'approuva. A la vérité, personne ne savait au juste de quoi il s'agissait: les uns pensaient que « le mot Municipalité exprimait un établissement favorable au peuple qui, en le contenant, devait servir sa tendance à la liberté et qui, étant de son choix, secondait l'exercice des droits de l'homme » ${ }^{28}$. Les autres se laissèrent entraîner à donner leur sanction.

Mais déjà les planteurs aiguisaient leurs arguments contre l'entrepôt unique et les privilèges de fait des gens de Saint-Pierre. Les députés du commerce jugèrent prudent de s'en tenir à l'avantage qu'ils venaient de remporter. Ils imaginèrent un moyen simple et pratique de paralyser leurs adversaires : c'était de se retirer de l'assemblée afin que le quorum n'y fut plus atteint.

Saint-Pierre et ses alliés rappelèrent donc officiellement leurs délégués.

27 Lettre de Vioménil : « La conduite tenue à mon égard par le Comité a été forcée par la nature des circonstances et par le danger réel qui, depuis le commencement des troubles, n'a pas cessé d'exister pour les personnes des individus (sic) qui composent le Comité sur la tête desquelles le poignard et le feu ont été continuellement levés ». Arch. Nat. Col. C 8 A 89.

28 Extraits des faits que la ville de Saint-Pierre prie M. le baron de Clugny et les membres de l'Assemblée Coloniale de la Guadeloupe et du Comité de Basse-Terre de prendre en considération. 21 mai 1790. Min. des Col. Mart., 275. 
Ainsi, dès le premier contact des idées et des récits venus de France, tout ce que la population de la colonie retenait de l'impulsion reçue de la Mère-Patrie, c'était qu'une ère d'innovations s'ouvrait, et aussitôt les divergences d'intérêts et d'aspirations qui couvaient dans son sein s'étaient affirmées, chacun croyant le moment venu de matérialiser ses espérances.

De tout ce qui agitait l'opinion nationale par delà les mers, de la nécessité d'ajuster une constitution nouvelle aux besoins d'un peuple las d'une trop longue tutelle et pressé de se sentir majeur, de l'adaptation du vieil édifice des institutions monarchiques à des conditions exigeant une refonte totale des mœurs et des lois, la Martinique n'avait cure. La rivalité des négociants et des planteurs, l'abolition ou le maintien du régime de l'Exclusif, voilà les questions qui passionnaient les esprits. Tout le reste n'était qu'apparence ou prétexte.

L'incident des cocardes avait mis en lumière quelque chose de plus préoccupant, mais dont personne, dans la population dirigeante, ne semblait apercevoir la gravité : l'extrême fragilité d'un état social où une faible minorité, les blancs, avait tous les droits, et où les travailleurs, les noirs, et les soutiens de l'ordre, les mulâtres, n'en avaient aucun.

Assurément, en ces premiers jours de troubles, le véritable révolutionnaire avait été celui qui s'en doutait le moins - M. de Vioménil, gentilhomme et chef militaire, embrassant publiquement un mulâtre et rendant hommage au précieux et indispensable loyalisme d'auxiliaires injustement méprisés.

Il ne pensait pas d'ailleurs que la même force de logique qui lui dictait ce geste, jouerait en faveur des frères plus humbles de ceux pour qui, en toute droiture et avec le sentiment exact des réalités, il réclamait un commencement de considération et d'honneurs.

La question, tout de même, était posée. La courte vue des hommes empêchait d'apercevoir que c'était de beaucoup la principale, et peut-être même la seule importante.

Les esprits avancés qui se faisaient gloire de soutenir la cause de la Révolution en niant les conséquences les plus évidentes et les plus inéluctables de ses principes, allaient d'ailleurs travailler, sans le vouloir et sans le savoir, à en accélérer les développements. Les actes humains se dispersent en tous sens et s'annu- 
lent ; la pesanteur sociale, à qui leurs agitations permettent de se manifester, totalise dans son sens inflexible les résultats.

\section{CHAPITRE PREMIER : RÉFÉRENCES.}

Lettre de M. de Vioménil au ministre. 17 octobre 1789. Arch. Nat. Col. 8A 89.

Lettre de M. de Laumoy au ministre. 8 octobre 1789. Arch. Nat. Col. 8A 89.

Lettre de M. Foullon au ministre. 25 octobre 1789. Arch. Nat. Col. 8A 89.

Lettre adressée à M. de Molerat, major-commandant de la ville de Saint-Pierre et signée. « Nous, Nègres ». Arch. Nat. Col. 8A 89.

Lettre de M. Ruste, président du Comité de Saint-Pierre, à MM. Foullon et de Laumoy. 5 octobre 1789. Arch. Nat. CoI6 8A 89.

Ordonnance du 22 octobre 1789. Arch, Nat. Col. 8A 89.

Extraits des faits que la ville de Saint-Pierre prie Messieurs le baron de Clugny et les membres de l'assemblée générale de la Guadeloupe et du comité de Basse-Terre de prendre en considération. 21 mai 1790. Ministère Col. Martinique, 275.

Lettre de M. Foullon au ministre. Ministère des Colonies Martinique, 268.

Certificat de M. Clavery. Certificats de MM. de Laubenque et Castella. Arch. Nat. Col. 8A 89.

Lettre de M. de Laumoy au ministre. Nov. 1789. Ministère Colonies Martinique, 268.

Lettre de M. de Vioménil au ministre. Nov. 1789. Arch. Nat. Col. 8A 89. 


\section{La Révolution française à la Martinique}

\section{Chapitre II}

\section{Les Partis s’affrontent}

$\underline{\text { Retour à la table des matières }}$

L'Assemblée Coloniale accueillit avec indifférence la carence concertée des députés du commerce. Les planteurs, qui en formaient de ce fait la totalité, décidèrent tout bonnement que les résolutions votées seraient valables quel que fut le nombre des présents. Et ils se mirent en devoir de profiter du départ de l'opposition pour prendre les dispositions qui leur tenaient le plus à coeur.

Ainsi les partis adverses se trouvaient avoir pris, presque sans y songer, leur position de combat : l'incompétence de l'Assemblée sera dorénavant le grand cheval de bataille des " patriotes ». " Elle est inconstitutionnelle, répèteront-ils inlassablement, elle ne représente pas toute la colonie, elle n'a aucun des droits qu'elle s'attribue ». - «L'Assemblée est légalement constituée, répartiront les planteurs, elle a été convoquée d'après un règlement sanctionné et enregistré à la sénéchaussée, elle représente la grande majorité des paroisses de l'ile et est toute prête à accueillir dans son sein les députés du négoce ».

L'opposition déclarée de la ville et de la campagne trouvait d'ailleurs dans la haute administration de la colonie d'autres occasions de se manifester.

M. de Vioménil et M. Foullon d'Ecotier étaient fort portés à observer la tradition qui voulait que le Gouverneur et l'Intendant se détestassent cordialement. L'opposition de leurs caractères aggravait la mésentente ordinaire entre titulaires 
de leurs charges. M. Foullon était aussi froid, calculateur et habile à dissimuler que M. de Vioménil l'était peu. Si celui-ci s'excusait sur sa sensibilité, celui-là se recommandait de la Vertu, dont il eût dégoûté quiconque par l'usage qu'il en faisait. Le chevalier Du Buc, grand propriétaire, qui devait prendre bientôt une place prépondérante dans la direction des événements, l'accusait d'avoir amené la zizanie partout où il avait passé et assurait que le seul désir de fuir cet insupportable intendant avait déterminé $\mathrm{M}$. de Damas à demander son congé.

Le grand sucrier couvert de dettes avait trop de raisons personnelles de juger sans indulgence le défenseur naturel de l'Exclusif pour que nous puissions nous fier entièrement à son témoignage. Mais il apparaît que M. Foullon, fils du contrôleur général des Finances de la métropole, usait volontiers de la menace du crédit de son père dans ses démêlés avec les Gouverneurs. Un tel avantage est de ceux qu'il est tentant de rappeler parfois à ses adversaires. L'argument n'ê̂t-il aucun rapport avec la question traitée, n'en possède pas moins quelque valeur pratique.

Le sort voulut cependant qu'il se retournât brutalement contre l'intendant. Aux premières nouvelles des événements de la révolution en France qui parvinrent à la Martinique, M. Foullon d'Ecottier apprit la fin tragique du contrôleur général, tiré par la foule de la prison où La Fayette, pour le sauver, l'avait fait mettre après le 14 juillet, et pendu à la lanterne avec son gendre Bertier.

Accablé de chagrin et d'horreur, il se retira dans sa maison de campagne. Les " patriotes » de Saint-Pierre, montrant plus de zèle que de tact, vinrent l'y trouver et lui offrirent cette même cocarde dont le succès à Paris avait eu pour effet spontané la promenade, au bout d'une pique, de la tête de Monsieur son père.

« Je l'acceptai avec reconnaissance, écrit Foullon, et les sentiments du patriotisme étouffèrent quelques instants en moi ceux qu'une pareille démarche devait nécessairement me rappeler » 29 .

Cet héroïsme à la Brutus se concilie trop bien avec le souci que l'intendant prenait de sa sécurité et de ses intérêts pour imposer à la postérité une admiration sans réserve. Outre que M. Foullon, défenseur par fonction de l'Exclusif, ne pouvait s'appuyer que sur le parti des négociants, il éprouvait désormais, de la tou- 
chante marque de sympathie de ses administrés, une considération assez imprévue pour la volonté populaire.

Toutefois, il se tint d'abord dans une prudente expectative. Sa douleur et son mauvais état de santé lui étaient d'excellents prétextes pour se soustraire à la vie publique. Il ne se fit pas faute d'en jouer : le 9 octobre, il est dans l'impossibilité d'aller soutenir M. de Vioménil à la réunion de Fort-Royal, car sa maladie le retient à Saint-Pierre. En revanche, voici qu'elle le force à s'aliter à Fort-Royal le jour de la réconciliation du gouverneur avec la place de commerce. Bien mieux : ses incommodités sont parfois si violentes qu'elles l'empêchent de contresigner les ordonnances que lui envoie le gouverneur.

L'Assemblée Coloniale, cependant, commençait ses travaux. Son premier geste fut, tout naturellement, de proroger jusqu'au ler avril 1790 l'ouverture provisoire des ports de Saint-Pierre, Fort-Royal, la Trinité et le Marigot aux navires étrangers chargés de vivres et de matériaux de construction. M. Foullon dut se résigner à sanctionner cette mesure.

Mais, pour s'en excuser auprès de ses amis les négociants, il prétexta que son consentement lui avait été extorqué par la menace. Précisons que ladite menace consistait en une fort décente argumentation des planteurs tendant à prouver que sans le maintien de cette dérogation, d'ailleurs maintes fois accordée antérieurement, au régime de l'Exclusif, ils seraient hors d'état d'acquitter leurs impôts 30.

Après ce premier succès, les députés de la campagne, maîtres absolus, comme il a été dit, de l'Assemblée Coloniale grâce à la retraite de leurs adversaires, s'employèrent congrûment à justifier l'adage que « les absents ont toujours tort ».

La création des municipalités, décidée dans les conditions imprécises que j'ai dites, avait été le principal succès de ceux-ci.

Le 2 décembre, l'Assemblée, inquiète de la manière dont les «partisans de la régénération » pourraient concevoir leur rôle d'échevins, complète l'arrêté instituant les municipalités par les articles 31 et 32. Le premier plaçait sous l'inspec-

30 «Il est bien différent de menacer de ne pas payer l'impôt ou de dire : diviser l'entrepôt qui va diminuer le prix de nos comestibles et les frais de leur transport afin que nous puissions payer l'impôt. Les mains de M. Foullon sont méphitiques ; elles corrompent ce qu'elles touchent » (Lettre de L.-F. Du Buc. Min. Col. Martinique, 268). 
tion directe des administrateurs les juges municipaux, le second les rendait responsables des désordres qu'ils auraient pu prévenir en appelant le pouvoir exécutif.

Le 8 décembre, l'Assemblée pose le principe d'une nouvelle assemblée qui doit se réunir le 25 février. L'âge des électeurs est élevé à 25 ans et le nombre des députés réduit à 81, dont 9 pour Saint-Pierre et 7 pour Fort-Royal.

Enfin, le 10, l'Assemblée, ayant terminé tous ses travaux - à l'exception des seuls qui étaient son objet officiel et qui consistaient, on s'en souvient, en la nomination de délégués à la Constituante et la rédaction des cahiers - pense à se séparer en laissant derrière elle son comité permanent, présidé par son animateur, Louis-François Du Buc.

Au dernier moment, M. de Vioménil en obtient encore licence d'établir la loi martiale. C'est qu'il n'ignorait pas que les jeunes Saint-Pierrais activaient la formation de leurs milices citoyennes. Ces milices, qu'on avait envisagé de créer pour remplacer l'ancien corps de milices dont il était Général, lui inspiraient une répugnance compréhensible. Il faisait observer que ces nouveaux corps n'auraient ni la discipline ni le sentiment de la hiérarchie des anciens, et qu'ils donneraient aux municipalités une force dangereuse. Il faisait valoir, en outre, que les « patriotes » étant fort mêlés de canaille ; « les Anglais pourraient en profiter pour manoeuvrer cet élément trouble et jeter le désordre ».

Un violent incident allait résulter de cette initiative.

Pressé par les événements, exaspéré, de buter sans cesse sur la force d'inertie de M. Foullon, M. de Vioménil se détermine à rendre l'ordonnance seul et charge M. de Laumoy de la remettre à la sénéchaussée après l'avoir fait imprimer.

Cette décision a aussitôt le plus heureux effet sur la santé chancelante de l'Intendant. Du coup, il recouvre toute sa vitalité ; il se précipite chez l'imprimeur et lui arrache l'ordonnance des mains sous le prétexte d'une erreur de date que son honneur, prétend-il, lui défend de laisser passer. Il eût été assurément plus simple de signaler cette erreur au Général qui l'eût aussitôt rectifiée ; le scandale n'avait d'autre nécessité que celle de donner à M. Foullon l'attitude de défenseur des opprimés. 
La conséquence désirée ne tarde pas : le peuple de Saint-Pierre, déjà inquiet d'avoir vu récemment renforcer la garnison s'affole. "Appréciant le tort que devait lui faire ce règlement, par l'éclat de l'acte d'autorité majeure de $\mathrm{M}$. l'Intendant », il se porte au greffe où ses meneurs exigent le registre, et renversent le contenu d'un encrier sur le texte abominé.

M. de Vioménil, en grand courroux, rappelle l'Assemblée et dénonce l'incident à son Conseil.

Celui-ci fait preuve d'une indulgente philosophie. Certes, il ne manque pas à flétrir " cet oubli caractérisé, de toutes les règles et loix de la Société », mais il ajoute « qu'on peut l'attribuer à une interprétation outrée des droits de l'homme et à l'explosion de cette effervescence que l'Assemblée Nationale a considérée comme l'un des abus indispensables pour la régénération de la France ».

On le voit, les planteurs ne rappelaient que d'assez loin les «tigres féroces » auxquels les " patriotes » n'hésitaient pas à les assimiler. Ils faisaient ainsi preuve d'un sens politique averti. Ils n'avaient, pensaient-ils justement, aucune raison de prendre les premiers une dangereuse offensive, puisqu'à la faveur du relâchement et de l'incertitude du pouvoir central ils obtenaient insensiblement la réalisation de leurs voeux les plus chers et somme toute raisonnables : une part active à la législation intérieure de leur pays et l'autorisation d'échanger certaines denrées avec l'étranger sans passer nécessairement par l'entrepôt de Saint-Pierre.

Aussi conseillent-ils en bons apôtres « d'attendre en paix sous le régime ancien les lois nouvelles en préparation $»{ }^{31}$.

Comme bien l'on pense, les gens de la ville ne partageaient nullement cet avis. Impatients de posséder une organisation capable de tenir tête à celle de leurs adversaires, ils procédèrent à la constitution de leur municipalité sans même daigner nommer les députés à la seconde Assemblée Coloniale.

Mais quand révélation leur fût faite des articles 31 et 32 (qui, je l'ai dit, plaçaient les communes sous la dépendance des agents du roi), leur zèle se glaça tout net.

Saint-Pierre retentit de clameurs indignées.

31 Arrêt du 26 décembre 1789. Durand Molard, tome IV. 
Ses éventuels officiers municipaux entreprirent une longue controverse épistolaire avec M. de Vioménil. Elle ne donna rien,

Alors, les «patriotes » exaspérés prirent, pour la seconde fois, l'initiative de la rupture. Ils décidèrent, de leur seule autorité, la création d'une Chambre de Représentants du Commerce composée de 61 membres.

C'était la scission. La ville et les bourgs s'érigeaient en puissance indépendante en face de la campagne, maîtresse de la seule Assemblée représentative qui avait jusque là existé. Et l'on se plaisait à penser que si celle-ci avait joui de la faveur et de l'appui du Gouverneur, l'autre tout naturellement bénéficierait de la sympathie de l'Intendant.

Qu'allait faire, devant cette déclaration de guerre, l'Assemblée Coloniale ?

Fidèle à la méthode de temporisation que lui conseillait l'homme dont la perspicacité guidait sa politique, le chevalier Du Buc, elle accepta l'innovation, et songea aussitôt à en tirer tout le parti possible.

Ses membres se rendirent dans leurs paroisses respectives sous le prétexte d'y obtenir les pouvoirs nécessaires. Ils y répandirent un habile manifeste où il était dit :

« Les habitants agricoles d'une part, et commerçants de l'autre, devaient rester paisibles spectateurs des convulsions qui agitent la France pour profiter ensemble des fruits bienfaisants que la métropole aurait seule arrosés de ses larmes. Comment se peut-il que cet esprit de vertige ait traversé les mers ? Est-ce l'habitant des campagnes, est-ce celui des villes qui a transporté cette plante exotique ? SaintPierre a fait scission avec M. de Vioménil que nous aimons ; il a tenu des propos indécents contre l'Assemblée et tous ses membres... Nos coeurs repoussent tous moyens violents, mais puisque Saint-Pierre se sépare de nous, séparons-nous de lui. »

Sous le style élégant et modéré de ce document, il est assez facile de discerner la pensée profonde de son inspirateur. Nous la verrons se développer au cours des événements ultérieurs. Comme tous les conservateurs, le chevalier Du Buc et les planteurs qui le suivaient, pensaient que les perturbations sociales n'ont qu'un temps, et que les choses reviennent toujours d'elles-mêmes à l'équilibre. 
Ils se persuadaient, en conséquence, qu'il n'y avait qu'un mauvais moment à passer, en limitant la bagarre et en sauvegardant l'essentiel de leurs intérêts, jusqu'à ce que le rétablissement de l'ordre ancien ramenât le calme : le pouvoir relevé leur tiendrait compte de leur fidélité, de leur modération et ne leur enlèverait pas les quelques conquêtes, anodines pour lui, précieuses pour eux, qu'ils auraient faites entre-temps.

Sagesse certaine, que l'événement immédiat devait justifier. Sagesse à courte vue cependant, car jamais, après de telles perturbations, l'état de choses antérieur ne se reconstitue intégralement. Les forces mises en mouvement, pas plus que les torrents et les fleuves, ne reviennent en arrière, et les transformations qu'elles portent en elles s'accomplissent toujours tôt ou tard.

Mais celles-ci dépassaient la portée des intelligences qui s'efforçaient de voir clair.

Planche III. J.C. Dugommier.

Voir Les Classiques des sciences sociales.

En dépit des protestations d'amour que le manifeste des planteurs contenait à son adresse, M. de Vioménil, représentant l'autorité régulière, ne pouvait rester impassible devant le dédoublement imprévu de la Colonie confiée à ses soins. Il fit de son mieux pour l'empêcher, suppliant les uns, raisonnant les autres. En vain ! La sensibilité au service de l'éloquence se révéla impuissante à entamer des opinions fortement assises sur l'intérêt personnel.

En apparence, cependant, la paix semblait revenue.

La Révolution s'installait à Saint-Pierre comme, dans une « concession », l'Occident s'installe en Chine.

L'intérieur du pays continuait de lui échapper ; on y procédait paisiblement aux élections pour l'assemblée du 25 février.

L'Intendant se préoccupait des soins à donner à l'arbre à pain et à l'hévi que le ministre venait d'envoyer à la Martinique avec quelques autres espèces qui réussissaient moins bien. Il réclamait par le prochain courrier des canneliers et des 
girofliers, des poivriers aussi, tout ce qui pouvait contribuer à l'essor d'une colonie retournée au calme.

Les planteurs écoulaient en toute tranquillité leurs rhums et leurs sirops dans les ports du Sud et de l'Est (les sucres étant toujours théoriquement réservés au commerce français qui se faisait par Saint-Pierre).

Les patriotes attendaient le sort glorieux que la Nation ne manquerait pas de leur faire bientôt et s'appelaient « citoyens ». En somme, tout avait l'air d'aller fort bien.

Un spectateur qui portait la cocarde avait innocemment déchaîné la première série de troubles ; un spectateur qui ne la portait pas provoqua la seconde.

Les gens de Saint-Pierre qui avaient été. les promoteurs de la scission, s'indignaient qu'elle eût pour conséquence de tarir la source de leurs richesses. Ils voyaient avec colère les denrées fuir par les autres ports et accusaient les planteurs de vouloir faire faillite à leurs engagements envers leurs créanciers. « Avant de se séparer, il faut payer ses dettes » observaient-ils. A quoi les sucriers répondaient que telle était bien leur intention et que les mesures les plus exactes seraient prises pour désintéresser les commerçants. Ces bonnes paroles ne pouvaient guère en imposer à des gens qui avaient - tout au moins en matière de finances - le sens des réalités. Sous des apparences de calme fermentait une exaspération que le plus mince prétexte devait suffire à faire exploser. Ce prétexte fut fourni par M. du Boulay, capitaine à la garnison de Saint-Pierre.

Le dimanche 21 février 1790, cet officier occupait paisiblement une seconde loge au théâtre lorsque de jeunes bourgeois vinrent lui faire l'observation qu'il ne portait pas la cocarde et lui en présentèrent une. M. du Boulay estimant qu'il n'avait pas de leçon de civisme à recevoir de ces blancs-becs, leur conseilla sans douceur de réserver leur vigilance à leurs affaires personnelles.

Il n'en fallait pas tant pour dresser ces jeunes coqs sur leurs ergots. Ils insistent d'une manière agressive ; la discussion s'envenime et se propage. M. de Laumoy interpose sa sagesse, calme M. du Boulay et l'engage à accepter la cocarde afin de clore au plus tôt ce regrettable incident. « Fort bien, Monsieur, répond le capitai- 
ne, je le ferai donc par respect et obéissance envers vous qui êtes mon chef ». Des huées, mêlées aux applaudissements ironiques, éclatent de toutes parts.

Les officiers qui sont dans la salle épousent la querelle de leur camarade. M. de Malherbe, entre autres, et M. de Rancé, se distinguent par la vivacité de leurs propos. « Puisqu'il en est ainsi, déclare ce dernier, la première fois que j'aperçois un bourgeois sans cocarde, je lui coupe les oreilles ». Il corse sa menace par des expressions d'une verdeur toute militaire dont il demande, excuse aux dames, que cette marque de courtoisie envers leur sexe n'empêche pas de quitter la salle avec des caquets et des pépiements effarouchés.

La représentation s'achève cependant tant bien que mal ; mais, à la sortie, des groupes se forment d'où s'élèvent, dans la douce nuit antillaise, des commentaires acerbes : «Ces rodomonts, remarque un officier, nous viennent toujours provoquer et assaillir lorsqu'ils ont l'avantage du nombre. Nous ne sommes que 14 ; nous attendons qu'il plaise à 14 des plus intrépides de venir se mesurer avec nous ».

Le cartel est relevé. Le lendemain, 14 jeunes héros en armes se rendent au fort, escortés d'un grand concours de peuple plus curieux que menaçant. Les officiers sortent ; on s'aborde avec politesse, on parlemente. L'ardeur combative de la veille s'étant fort tempérée, l'affaire allait sans doute se terminer honnêtement par quelques bouteilles de rhum vidées à la santé du Roi, de la Nation et de la Colonie, quand les soldats, dans la meilleure intention du monde, gâtèrent tout. Il est constant que les bonnes intentions ont des conséquences désastreuses lorsqu'elles naissent dans des esprits mal éclairés.

Les hommes de troupe, voyant leurs officiers palabrer au milieu de cette foule, les crurent menacés et s'élancèrent l'arme au poing à leur secours. La panique s'empara des bourgeois ; chacun courut à son mousqueton. Le sang n'aurait pas tardé à couler si MM. de Laumoy et Foullon n'avaient réussi à reprendre en mains soldats et officiers et à les convaincre d'abandonner la place pour gagner le FortRoyal.

Pendant que s'opère cette prudente retraite, $M$. de Lanmoy, insoucieux du danger auquel il s'expose, tient tête à une bande de frénétiques qui lui réclament MM. du Boulay et de Malherbe. Mais il est abusé par un quidam se disant leur ami : « Donnez-moi un objet auquel ils reconnaissent que je viens de votre part, 
lui murmure celui-ci à l'oreille, et je saurai les persuader de partir ». Le commandant lui donne le morceau de canne brisée qui lui restait dans la main et le traître va ordonner aux deux officiers de se livrer.

M. de Laumoy, atterré de les voir arriver dans le moment qu'il les croyait soustraits à la fureur du populaire, consentit qu'ils se rendissent à la municipalité, sous la condition qu'on se contenterait de leurs excuses.

Une telle preuve de mesure dans l'animosité était, à la vérité, fort improbable. On le fit bien voir aux deux capitaines qui s'étaient acheminés en toute confiance vers la maison commune. Ils n'y eurent pas plutôt pénétré qu'ils y furent injuriés et malmenés.

Dans la rue, une foule irritée demandait leurs épées et leurs épaulettes ; ils n'en avaient point. Elle exigea leurs habits qu'on lui lança par la fenêtre. Elle les mit en pièces et sut se satisfaire de cette exécution symbolique, sur l'assurance que les objets de sa vindicte avaient été jetés dans un cachot à nègres et seraient embarqués le lendemain sur la corvette Les Deux Cousines.

Ils le furent, en effet, et Saint-Pierre se hâta de remplacer les troupes qui l'avaient abandonné par des milices citoyennes.

M. de Vioménil, informé de ces événements, les trouva détestables. L'outrecuidance des patriotes qui se substituaient aux corps judiciaires, au pouvoir exécutif et à la force armée, lui parut, à bon droit, inadmissible. Il lança La Gracieuse à la poursuite des Deux Cousines, récupéra ses officiers qu'il fit régulièrement incarcérer et les envoya lui-même en France sur la frégate L'Active, pour qu'ils fussent jugés par la Constituante ${ }^{32}$.

Entre temps, le Gouverneur adressait à M. de Thommasseau, maire de SaintPierre, des lettres dont la courtoisie aggravait plutôt qu'elle ne l'atténuait le caractère menaçant. Il y exigeait des excuses pour la lacération des uniformes, y peignait sous les couleurs les plus sombres le ressentiment de la garnison et priait «Qu'on veuille bien l'avertir si le peuple de la ville se chargeait désormais de défendre à lui seul la partie de la colonie qui était à sa portée ».

32 La Constituante estima d'ailleurs que les deux officiers avaient été suffisamment punis et les réintégra dans leurs fonctions. 
Tout ceci ne semblait guère favorable à la formation de la seconde Assemblée Coloniale.

Elle se réunit pourtant le 26 février, mais fort incomplète. Non seulement les représentants de Saint-Pierre faisaient défaut, mais plusieurs paroisses, dont une partie des habitants avaient été gagnés aux idées des « patriotes », s'attardaient en des querelles intestines sans parvenir à élire leurs députés.

Se voyant en nombre insuffisant, les membres de cette Assemblée s'abstinrent sagement de légiférer et se bornèrent à remplir le programme négligé par leurs prédécesseurs. Ils nommèrent donc des députés à la Constituante avec mission de présenter et de défendre un projet selon lequel la Colonie recevrait de la métropole les lois générales, discuterait avec elle les lois de commerce et établirait sans elle, sous la seule sanction du Roi, ses lois particulières. En revanche, il était recommandé aux députés de la Martinique de renoncer à délibérer sur les questions concernant exclusivement la Mère-Patrie.

C'était faire entendre à celle-ci : « Nous ne nous mêlons pas de vos affaires intérieures, ayez la bonté de ne pas vous occuper des nôtres ».

La Constituante pouvait d'autant moins se ranger à ce parti que les patriotes lui députaient à leur tour MM. Ruste et de Corio afin de plaider leur cause. Dans le même temps qu'on récusait sa compétence, on sollicitait son arbitrage.

Mais le verdict de la France était encore loin et Saint-Pierre s'inquiétait de ne pas avoir fait sa paix avec M. de Vioménil. Le bruit courait qu'une expédition punitive se préparait contre la ville. Les nouveaux miliciens, malgré leur vaillance, ne se sentaient pas en force.

Ils firent part de leurs craintes à leurs amis des îles voisines. Ils en comptaient beaucoup à la Guadeloupe où l'annonce de la Révolution française avait pareillement animé les uns contre les autres planteurs et négociants, encore que le gouverneur, M. de Clugny, eût réussi tant bien que mal à les maintenir en paix.

Les jeunes patriotes de Basse-Terre n'en furent que plus enthousiasmés de voir un champ s'ouvrir à leur activité. A peine la situation de Saint-Pierre leur fut-elle connue qu'ils voulurent « voler au secours de leurs frères ».

Ils trouvèrent un chef tout désigné en la personne de Coquille Dugommier. Cet ancien lieutenant-colonel, qui avait donné sa démission à la suite d'un passe- 
droit, se montrait chaud partisan de la Révolution, qu'il devait, plus tard, servir brillamment. Il prit le commandement de l'armée des volontaires. De son côté, M. de Clugny, « considérant que le seul moyen de contenir cette jeunesse bouillante était de se mettre à sa tête ", s'embarqua le 5 mars avec les députés de l'Assemblée Coloniale de la Guadeloupe sur la frégate La Sensible.

"Toutes les îles antillaises, écrira-t-il, s'étaient déjà réunies pour défendre la ville de Saint-Pierre si elle eût été attaquée. Deux mille hommes avaient traversé les mers dans cette résolution ; chaque jour, on voyait arriver de nouveaux détachements ».

Devant cette invasion inattendue, M. de Vioménil et l'Assemblée sentirent la nécessité d'un accommodement.

Déjà le régiment de la Martinique blâmait l'effervescence de la garnison et déclarait qu'il n'avait jamais eu l'intention de s'armer contre Saint-Pierre. «Cette seule idée affligeait tout le corps ».

M. de Clugny et M. de Gimat, gouverneur de Sainte-Lucie, obtinrent la conciliation. Il fut convenu que la place de commerce conserverait son régime particulier en attendant les décisions de l'Assemblée Nationale, tandis que le reste de la colonie demeurerait sous les lois anciennes.

Les volontaires regagnèrent leurs foyers et le peuple de Saint-Pierre se mit en devoir d'organiser ses municipalités sans plus se soucier des articles 31 et 32.

Mais l'efficacité de l'union entre gens du même parti venait de s'affirmer d'une manière qui avait frappé tous les esprits. Les habitants de la ville pensèrent à une réunion fédérative des patriotes des Iles du Vent et encouragèrent leurs adeptes des autres paroisses de la Martinique à former des municipalités et des milices citoyennes sur le modèle des leurs.

Dans le même temps, le chevalier Du Buc soufflait à M. de Vioménil le projet d'une confédération de planteurs et convenait avec lui que, puisque les municipalités étaient votées, il fallait en établir qui fussent conformes à la loi.

Leurs agents se heurtèrent aux prosélytes de Saint-Pierre ; dans de nombreux bourgs, des municipalités illégales s'opposèrent aux municipalités légales; ce ne fut plus seulement la lutte de la campagne contre la ville, mais la discorde civile généralisée. 
M. de Vioménil entendit la réprimer énergiquement. Il avait pour lui l'Assemblée et la majeure partie des habitants ; il avait surtout les mulâtres, miliciens fidèles, rempart du parti planteur, contre lequel se brisait la fureur méprisante des métropolitains et petits blancs.

Les mulâtres n'avaient pas oublié l'humiliation du 28 septembre. Ils rendaient haine pour haine, mépris pour mépris aux patriotes qu'ils traitaient, à l'imitation des grands blancs, de manants ou de brigands. Ceux du Gros Morne, rassemblés autour de M. Gaudin de Soter et de sa famille, ceux de Fort-Royal, d'autres encore, prenaient conscience de leur cohésion et de la puissance qu'ils constituaient.

Ils accoururent au commandement de M. le Général, lequel avait été invité par l'Assemblée à déployer toute sa force pour casser partout, autre part qu'à SaintPierre, les municipalités et les milices contraires à la loi.

La fin du mois de mars 1790 vit les patriotes dans les plus vives alarmes, échangeant d'un bourg à l'autre des lettres affolées et des volontaires qu'ils se reprenaient le lendemain.

Le parti adverse paraissait l'emporter ; la branche de laurier qui servait de signe de ralliement aux confédérés liés par serment au Roi, à la loi et au pouvoir exécutif, se substituait à la cocarde. Le 26, une foule en délire portait en triomphe son Gouverneur en clamant à tue-tête : «Vive Vioménil que nous avons rétabli dans ses droits! Vive la noblesse ! Vive la couleur 1 Merde pour les patriotes $! . . . »$

Ce beau jour fut le dernier du gouvernement de M. de Vioménil. Le soir même, à l'ébahissement général, ancrait dans la rade une corvette ayant à son bord le gouverneur titulaire, vicomte Claude Charles de Damas de Marsillac, fort éprouvé par une traversée particulièrement dure et dont seule l'idée du repos bien gagné qu'il goûterait enfin sous les ombrages de la Résidence avait soutenu le courage parmi la violence des éléments. 


\section{CHAPITRE II. RÉFÉRENCES :}

Procès-verbaux des séances de l'assemblée coloniale de la Martinique. 1789 et 1790. Arch. Nat. Col. 8A 30.

Lettre de M. Foullon au ministre. 25 oct. 1789. Arch. Nat. Col. 8A 89.

Lettre de Du Buc. Min. Col. Martinique, 268.

Dossier des plaintes faites au ministre par M. de Vioménil sur M. de Foullon et par M. Foullon sur M. de Vioménil. Ministère Colonies Martinique, 267.

Extraits des faits que la ville de Saint-Pierre... (déjà cité) Min. Col. Martinique, 275.

Lettre de M. Foullon au ministre. 25 janv. 1790. Min. Col. Martinique, 268.

Relations de M. de Vioménil, de M. de Laumoy, du comité de Saint-Pierre et de différents colons sur l'incident des officiers. Arch. Nat. Dxxv 115 et Min. Col. Martinique, 268.

Lettres de $M$. de Vioménil à $M$, Thomaseau et de $M$. Thomaseau à $M$. de Vioménil. Arch. Nat. Dxxv 115.

Lettre de M. de Clugny au ministre. 13 mars 1790. Min. Col. Martinique, 269. 


\title{
La Révolution française à la Martinique
}

\author{
Chapitre III
}

\section{La France parle}

$\underline{\text { Retour à la table des matières }}$

Pauvre M. de Damas !... Du moins ne s'aperçut-il pas au débarqué qu'il venait d'être jeté d'une tempête dans une autre. Il reprit possession de son poste et passa ses troupes en revue selon le protocole d'usage. Par la seule vertu des formalités tout s'était apaisé comme par enchantement.

Les jours suivants, M. de Vioménil et l'Assemblée Coloniale communiquèrent au Gouverneur les décrets et les projets que leur avaient inspirés les circonstances. Brave homme, plus avide de répit que de chicanes, M. de Damas approuva tout, sanctionna tout. Au reste, il ne trouvait dans les actes qui lui étaient soumis rien qui ne fût conforme à ses vues et à ses traditions. Le plan de confédération le séduisit ; l'établissement des municipalités dans les formes arrêtées par l'Assemblée lui parut tout à fait souhaitable ; il s'adressa aux commandants de milices pour faire connaître ses décisions aux paroisses.

Les milices démocratiques n'étaient pas dissoutes et les mulâtres continuaient de servir au grand déplaisir des patriotes. Le rétablissement de l'ordre était activement poussé et l'aristocratie, c'est-à-dire le parti planteurs, ne se fit pas faute, dans maint bourg, d'employer des procédés qui relevaient davantage de l'intimidation que de la persuasion. Saint-Pierre lança un nouvel appel de détresse aux îles voisines. « Dans les colonies, écrivaient ses officiers municipaux aux Guadelou- 
péens, un pacte où l'on consent que les mulâtres s'arment contre les blancs, est un pacte infernal. »

L'infortuné $M$. de Damas n'était guère préparé à ces orages. Les mulâtres n'avaient-ils pas été de tout temps constitués en milices par ordonnance royale ? Ces milices n'avaient-elles pas donné tout récemment une preuve précieuse de leur loyalisme et de leur utilité ? Et, par ailleurs, l'Assemblée Coloniale régulièrement constituée n'avait-elle pas voté les municipalités ?

Désolé, mal remis des fatigues du voyage, harcelé tantôt par le comité de Saint-Pierre, tantôt par l'Assemblée, entrepris d'un côté par M. Foullon et de l'autre par le chevalier Du Buc, le pauvre Gouverneur se trouva en grand péril de perdre sa raison.

S'il ne devint pas complètement feu, comme le bruit s'en accrédita, il subit à tout le moins une crise de dépression mentale assez grave. Le docteur Roux, appelé d'urgence à son chevet, dans la nuit du 4 au 5 avril, constatait « qu'il avait des disparates étonnantes ». Le lendemain les médecins consultants notaient encore «Prostration, manque de mémoire. »

M. Foullon ne craignit pas de colporter, au mépris de toute vraisemblance, que M. de Damas était prisonnier des aristocrates qui « l'avaient porté malade ». Il est plus légitime de penser que les planteurs exagérèrent à dessein le malaise très réel du Gouverneur dans l'espoir de retenir M. de Vioménil dont le chevalier Du Buc appréciait le caractère.

Mais M. de Vioménil n'avait aucune envie de reprendre une administration que, de l'aveu même de l'Assemblée Coloniale, « tout s'était succédé et réuni pour rendre pénible et orageuse ». Il s'excusa avec une sensibilité avivée par sa joie de regagner la France, et fila vent en poupe par le premier bateau. M. de BellevueBlanchetière, député à Paris par l'Assemblée Coloniale, y avait également pris passage. Sans doute les deux voyageurs purent-ils charmer les loisirs de la traversée en dissertant sur le passé et l'avenir des Antilles, et en comparant poétiquement leur nef exercée par les vents et les ondes à cette Martinique qu'ils laissaient derrière eux.

De celle-ci, le chevalier Du Buc est désormais le vrai pilote. Il pourra bien laisser les apparences du commandement aux personnages officiels; il pourra, avec autant de courtoisie que de politique, s'effacer devant ses collègues de l'As- 
semblée et du Conseil intermédiaire ; c'est lui qui, de près ou de loin, dirigera la manœuvre pendant toute la durée de la Révolution et s'efforcera - fût-ce au prix de moyens désespérés et incompatibles avec nos conceptions actuelles - de sauver la Martinique des désastres où elle risquait de s'abîmer.

\section{Planche IV. Louis-François Du Buc. \\ Voir Les Classiques des sciences sociales.}

Il est assez malaisé de tirer Louis François Du Buc de la coulisse d'où il actionnait ses marionnettes chamarrées. On n'a guère écrit de lui, sinon pour l'exécuter sans recours en quelques lignes. Cependant il apparaît, à travers les comptes rendus de l'Assemblée Coloniale, comme un homme remarquablement intelligent, d'une culture générale étendue, d'une éducation parfaite et d'une inébranlable fermeté. Et si l'on compare, en toute objectivité, le sort fait par ses initiatives à la Martinique à celui de la Guadeloupe déchirée et de Saint-Domingue anéanti, on sera porté à reconnaître qu'en dernière analyse, son action fut salutaire. Il avait de qui tenir. Sa famille était l'une des plus anciennes et des plus puissantes de la Colonie et plusieurs des tenants du nom s'étaient distingués par leur hardiesse et leur talent : Pierre Du Buc tout d'abord, qui, s'étant enfui à 18 ans de sa Normandie natale, avait vaillamment combattu les Caraïbes et s'était taillé à la pointe de son épée un domaine qui comprenait toute la presqu'île de la Caravelle ; puis Jean Du Buc l'Etang, le chef de ceux qui renvoyèrent si lestement au Régent de France ses administrateurs « pacquetés »; enfin Jean-Baptiste Du Buc, homme de génie, au dire de l'abbé Raynal, qui n'avait eu qu'à paraître à Versailles pour séduire le roi, Choiseul et la Cour, et qui, dans son vieil âge, jeté aux cachots de la Terreur, y soutenait par sa bonne humeur le courage de ses compagnons d'infortune et disait en s'éveillant chaque matin pour toute prière : « Mon Dieu, voyez le gaillard » 33.

Louis-François, le seul fils qui restât à cet intrépide vieillard à l'époque de la Révolution, était né à la Martinique en 1759. Après avoir fait ses études à l'école d'artillerie de Strasbourg il fut nommé à 16 ans sous-lieutenant au régiment de Bouillon, participa aux campagnes de Mahon, de Gibraltar et de Cadix, et démis-

33 E. Rufz : Etudes historiques. Citation du Testament politique du comte X. 
sionna en 1783. En 1789, la première Assemblée Coloniale l'élut pour président. Depuis, s'il céda périodiquement le titre à l'un ou à l'autre de ses collègues pour se contenter de celui de vice-président, il n'en demeura pas moins l'âme du Conseil et l'inspirateur de toutes les mesures prises.

Ses détracteurs diront qu'élevé en jeune satrape, prodigue, orgueilleux, somptueux en toutes choses comme avaient accoutumé de l'être les sucriers, il était dans une situation financière désespérée. A dire le vrai, toutes les habitations qu'il tenait de son père étaient grevées d'hypothèques, et les « espérances » qu'il avait encore ne pouvaient suffire à l'extinction de dettes immenses dont une bonne part (1.580.627 livres argent de France) avait été contractée envers le gouvernement royal par J.-B. Du Buc pour la création d'une raffinerie que des gérants incapables ou peu scrupuleux avaient conduite à la ruine.

Mais le fait qu'il se trouvât plus endetté qu'aucun autre n'aurait vraisemblablement pas suffi à désigner le chevalier à l'estime de ses compatriotes. S'ils lui restèrent toujours attachés, s'ils ne cessèrent de le considérer comme leur chef et leur sauveur, c'est qu'il les dominait par la supériorité de son esprit et la solidité de ses opinions.

La postérité peut lui reprocher de n'avoir pas témoigné à la France l'aveugle fidélité que lui doit un Français ; elle peut l'accuser d'avoir caressé le même rêve que ses ascendants : faire de la Martinique une république oligarchique sous la protection de la métropole ; elle ne peut, sans mauvaise foi, contester que LouisFrançois Du Buc fut un homme de valeur qui eût eu le droit de dire, aussi justement que le fit son noble adversaire Rochambeau : « J'ai été ferme devant moi. »

M. de Damas, momentanément hors d'état, M. de Vioménil parti, l'intérim revenait de droit à $\mathrm{M}$. de Clugny, Gouverneur de la Guadeloupe, à son défaut à $\mathrm{M}$. de Gimat, Gouverneur de Sainte-Lucie. Ni l'un ni l'autre ne le revendiquèrent : ils se trouvaient apparemment assez occupés dans leurs colonies respectives. Le nouvel appel des Saint-Pierrais les détermina néanmoins à se rendre à la Martinique où ils arrivèrent bientôt, précédés et suivis de troupes de volontaires. Ce n'était que dans l'honnête dessein de réconcilier pour la seconde fois les deux partis adverses.

Celui de Saint-Pierre disposait tout justement d'un nouveau grief : l'Assemblée avait écarté du commandement général $M$. de Molérat, major de la ville, et déféré 
l'intérim à M. Damoiseau, maréchal de camp du génie et Directeur de fortifications.

Les médiateurs eurent fort à faire.

Les patriotes, se sentant soutenus, posaient fièrement leurs «conditions de paix » qui n'étaient rien de moins que celles-ci : les habitants des bourgs qui avaient adhéré aux idées de Saint-Pierre seraient maîtres d'organiser leurs municipalités à leur gré et de suspendre, quant à eux, les droits de l'Assemblée Coloniale jusqu'au jugement définitif de la nation ; les mulâtres seraient désarmés et les personnes qui les avaient mis en mouvement, poursuivies par les tribunaux judiciaires.

Il n'y avait naturellement aucune chance pour que l'Assemblée acceptât de telles clauses. Les conciliateurs étaient les premiers à en convenir et commençaient à s'exaspérer eux-mêmes contre leurs commettants.

M. de Clugny, pressé de regagner sa colonie où les esclaves s'agitaient, dépêcha le règlement de la contestation. Il décida qu'en attendant le rétablissement de M. de Damas l'autorité demeurât à l'Assemblée Coloniale (plus exactement au chevalier Du Buc) par le truchement de M. Damoiseau. Il accepta également de maintenir l'ouverture des quatre rades chères aux planteurs jusqu'à la décision de la Constituante, à la condition que cessât le boycottage dont se plaignait le port de Saint-Pierre. Enfin les deux partis durent faire la preuve de leurs résolutions pacifiques, l'un en désarmant les nègres et les mulâtres, l'autre en remerciant les volontaires.

Pour le surplus, la tâche de M. de Clugny se trouvait grandement simplifiée car à ce moment même arriva dans la colonie un décret de l'Assemblée nationale rendu le 8 mars, par lequel le Pouvoir souverain faisait connaître ses volontés. Une instruction interprétative du roi était en même temps annoncée, qui devait préciser les conditions d'application de ce texte.

La France parlait. Il n'y avait qu'à s'incliner.

Toutefois, avant de se séparer, les patriotes voulurent donner corps à leur idée de confédération. Ils se rassemblèrent dans la salle du théâtre, firent serment « de respecter les décrets de la Constituante, de haïr les émigrés, de se réunir au pre- 
mier signal sous les ordres des chefs municipaux lorsque la colonie qui aurait besoin de secours en aurait formé la demande par son corps représentatif ».

Malheureusement, cette démonstration de fraternité faillit tourner à la discorde. Les Saint-Pierrais ayant bruyamment exprimé leur dessein de s'opposer au départ de $\mathrm{M}$. de Clugny qu'ils prétendaient, en dépit de ses refus, mettre à la place de M. Damoiseau, la bouillante jeunesse de la Guadeloupe, qui entendait ramener son Gouverneur, le prit fort mal. Une querelle assez vive s'ensuivit, que les plus sages parvinrent à apaiser, et le chef des conciliateurs put enfin gagner le port et s'embarquer avec ses auxiliaires encore tout échauffés.

Leur intervention n'était pourtant pas demeurée vaine. Planteurs et patriotes renoncèrent momentanément aux violences. Les uns et les autres attendaient l'instruction pour l'application du décret du 8 mars. M. de Damas, ayant recouvré par fortune et ses esprits et des administrés gouvernables, la reçut le 21 mai.

Planche V. Lettre du Roi à nos bons amis sujets, les Colons des îles du Vent.

Voir Les Classiques des sciences sociales.

L'Assemblée Constituante avait longtemps écarté la question coloniale de son ordre du jour, celui-ci étant chargé de problèmes dont elle possédait mieux les données et dont, par ailleurs, la solution lui semblait plus pressante. Avec beaucoup de sens, elle s'était refusée à rien innover dans un domaine qui lui était mal connu, et même à ouvrir aucun débat sur le régime des colonies avant que tous les députés des possessions françaises d'outre-mer ne fussent arrivés.

Cependant le club qui groupait autour de l'ex-ministre de la Marine, M. de Massiac, tous les grands planteurs résidant à Paris, ne ménageait pas plus ses avis à l'Assemblée nationale que le commerce ses réclamations. Elle était en outre quotidiennement importunée par «les Amis des noirs » dont beaucoup de bons esprits tenaient les conceptions pour fort hasardeuses, et auxquels Mirabeau dé- 
clarait brutalement qu'ils devaient avoir cure de travailler « au bonheur des Français, non à celui des Nègres 34 ».

En dépit de ces assauts, l'Assemblée s'obstinait à temporiser. Mais enfin il fallut bien s'apercevoir que l'importation des sucres se tarissait, réduisant l'activité des ports, provoquant du chômage et diminuant les recettes de l'Etat.

Devant des phénomènes si fâcheux et qui pesaient lourdement sur la situation déjà troublée de la métropole, la Constituante, se rangeant à l'avis d'Alexandre de Lameth, avait décidé la création du Comité colonial réclamé quelques mois auparavant par Louis de Curt.

Ce Comité avait été aussitôt formé. Ses douze membres, bien qu'appartenant à des catégories sociales fort diverses, étaient tout acquis aux idées des planteurs. Ils possédaient à fond leur sujet ; leur travail fut promptement terminé. Le 8 mars, Barnave développa à la tribune les considérants du rapport dont il était l'auteur.

Il proposa « de rassurer les colonies sur leurs plus chers intérêts », de recevoir d'elles-mêmes les instructions de gouvernement qui convenaient à leur prospérité et qu'il était temps d'établir enfin ; de les inviter à présenter leurs vues concurremment avec le commerce français sur leurs rapports réciproques ». L'Assemblée approuva son projet et invita le Comité à préparer l'instruction en forme de règlement d'administration publique qui devait compléter le décret rendu. Celle-ci fut adoptée le 28 mars.

Ces textes étaient inspirés par la sagesse même. L'Assemblée déclare tout d'abord que « considérant les colonies comme une partie de l'Empire Français et désirant les faire jouir de l'heureuse régénération qui s'y est opérée, elle n'a cependant jamais entendu les comprendre dans la Constitution qu'elle a décrétée pour le Royaume, et les assujettir à des lois qui pourraient être incompatibles avec leurs convenances locales et particulières ». Pour ces raisons « les lois destinées à régir intérieurement les colonies, indépendamment des relations qui existent entre elles et la métropole, peuvent et doivent sans difficulté se préparer dans leur sein ». On accorde même qu'elles soient provisoirement exécutées avec la sanction du Gouverneur. On réserve toutefois à la législature française et au Roi le droit de les

34 Avec les Rouges aux isles du Vent. Souvenirs du chevalier de Valous (marquis de Valous). 
approuver définitivement. Enfin, l'on souligne que « seules les lois à porter sur les relations entre les colonies et la métropole doivent recevoir de la Constituante existence et autorité ».

Saluons au passage la haute manifestation du bon sens et de l'esprit politique français qui ressort de ce document.

On dit trop souvent que notre peuple, épris d'abstractions, généralisateur à l'excès et féru de centralisation à outrance, n'a pas l'esprit colonial, et que c'est pour cette raison même qu'il a perdu son premier empire extérieur. On veut même douter que la leçon lui ait profité et que son nouvel empire soit assuré d'un meilleur sort.

C'est une grande injustice.

L'ancien régime avait su traiter nos possessions d'outre-mer avec un libéralisme remarquable pour l'époque et un sens très juste des réalités coloniales. Le système de l'Exclusif, qu'on objecte, n'était nullement une conception spécifiquement française. Les circonstances que le monde traverse actuellement permettent de se demander même s'il ne reposait pas au fond sur un principe juste ; et en tout cas, la métropole s'efforçait, en toute occasion, de l'assouplir.

La Constituante nous donne la preuve qu'au milieu de ses formidables embarras et de sa tâche gigantesque, elle avait une vision parfaitement claire des nécessités et des besoins de la France extérieure. Il est faux que la doctrine de l'assimilation ait dominé toute notre évolution coloniale. Le noble sentiment de l'unité française, à pousser aussi loin que le permet le progrès des moeurs et de la civilisation, s'est toujours concilié avec l'intelligente préoccupation d'une autonomie administrative mesurée aux circonstances. Il n'y a rien dans le décret de la Constituante que ne pourrait contresigner aujourd'hui même tel de nos plus grands bâtisseurs d'empires.

Les dispositions qu'on vient de lire, pour généreuses qu'elles fussent, ne réalisaient certes pas encore les rêves des réformateurs locaux. Les planteurs s'en contentaient pourtant, les patriotes aussi. Comme il arrive à l'ordinaire, chacun ne voyait dans le décret que les articles qui lui donnaient raison. 
L'intendant Foullon, ainsi qu'il était dans son rôle de le faire, s'arma du paragraphe qui précisait « qu'aucune innovation n'était portée aux règles en vigueur concernant le commerce » pour ordonner aussitôt la fermeture de tous les ports autres que Saint-Pierre. L'Assemblée Coloniale n'y fit pas d'objections. Elle eut même le bon sens de reconnaître qu'elle était trop réduite pour prétendre à représenter la Martinique et, conformément à l'article 4 de l'instruction, décida, le ler juin, d'interrompre ses séances jusqu'à ce que les Assemblées paroissiales lui eussent renouvelé leur confiance ou qu'elles eussent manifesté le désir de choisir d'autres représentants.

Cet article 4, relatif à l'électorat, allait être l'occasion de troubles imprévus. Il contenait une disposition intentionnellement imprécise et dont la portée pouvait être considérable. Indirectement, il posait la question des droits civiques pour les hommes de couleur.

Le Comité Colonial de Paris avait fini par le glisser dans l'instruction à la suite d'une discussion violente au cours de laquelle l'abbé Grégoire, porte-parole des "Amis des noirs », avait réclamé l'éligibilité des hommes de couleur.

Le Comité s'était tiré de la difficulté par cette formule ambiguë, destinée à donner aux avocats de la race opprimée une satisfaction platonique . "Toutes les personnes âgées de 25 ans, propriétaires d'immeubles ou, à défaut d'une telle propriété, domiciliées dans la paroisse depuis deux ans et payant une contribution, se réuniront pour former l'Assemblée paroissiale. »

Les membres du club Massiac se doutaient bien que, de quelque parti qu'ils fussent, les habitants chargés d'appliquer cet article n'en relèveraient pas l'imprécision. Pour mieux dire, il n'y avait pas, à leurs yeux, d'imprécision. En 1790, aux colonies, l'expression : «toutes les personnes » ne pouvait signifier que : «tous les hommes blancs », et les mulâtres (pas plus que les femmes) n'auraient l'outrecuidance ou le ridicule de suggérer une autre interprétation !

L'impartial et judicieux M. de Laumoy n'écrivait-il pas, quelques mois plus tôt, au Ministre : «Il n'est pas un blanc qui ne prétende participer aux bienfaits qu'elle (la nouvelle Constitution) nous promet. Mais il n'en est pas un qui ne frémisse à l'idée qu'un nègre ou même un homme de couleur libre peut dire : " Je suis homme aussi, "donc j'ai aussi des droits et ces droits sont "égaux pour tous. » Cette déclaration sera certainement ce qu'il y aura de plus dangereux à 
promulguer dans ce pays-ci » 35 . Et certes, les planteurs, en dépit de leur bienveillance naturelle à l'égard d'une classe dont ils appréciaient l'attachement à leur cause, étaient fort éloignés d'accorder à la couleur une existence civile. Mais les patriotes - on l'a vu déjà - l'étaient encore davantage, et ils allaient prouver brutalement leur exécration pour ces descendants d'esclaves dont quelques-uns avaient le front de les surpasser en connaissances et en biens.

Leur colère contre M. de Vioménil n'avait-elle pas été déchaînée par son geste publie d'affection et de considération pour des collaborateurs simplement teintés dont il honorait les mérites et le dévouement ?

Fait entre tous digne de remarque, qui en dit long sur les haines de race et qui eût désespéré, les philosophes de la fin du XVIIIe siècle : à la Martinique, le premier sang que firent couler les adeptes de la Révolution française fut, non pas celui des aristocrates qu'ils prétendaient égaler, mais celui des mulâtres qu'ils suspectaient de vouloir s'égaler à eux !

Le 3 juin 1790, à Saint-Pierre, la procession de la Fête-Dieu déroulait ses pompes sous un ciel radieusement bleu. Mais ni les magnificences du cortège, ni celles de la nature, ni même la pensée que ce Dieu pour qui l'on prodiguait les ors, les soies, l'encens, les pétales odorants, avait dit: «Aimez-vous les uns les autres », ne parvenaient à apaiser l'orgueil et la haine au cœur des hommes. A couvert des chants liturgiques des murmures s'échangeaient : « Les miliciens mulâtres de la garnison n'avaient-ils pas osé émettre l'intolérable prétention d'accompagner la procession sous les armes ?... Que c'eût été autrefois l'usage pour les troupes blanches, on le comprenait ; mais cette engeance se prenait-elle maintenant pour l'égale des soldats de France dont elle avait pris la place ?... Quel scandale ! ... N'était-ce pas assez d'avoir à supporter la présence de ces fils d'esclaves dans les forts ?... Leur audace, vraiment, ne connaissait plus de bornes !... Heureusement les avait-on remis vertement à leur place !... Car enfin quelle pouvait être leur intention, sinon de tenter un coup contre les blancs ?... Le bruit en avait fortement couru, et vraiment c'était l'évidence même que quelque chose se tramait... »

35 Lettre du 18 janv. 1790. Min. Col. Martinique, 268. 
Tandis que ces propos s'échangeaient dans la foule saint-pierraise, ceux que l'on vilipendait ainsi, groupés devant les logements de leurs officiers, ricanaient à la rumeur lointaine de la fête, amers et justement malveillants. Vers le soir, l'un d'eux avisa un jeune tambour noir qui revenait de la cérémonie : "Imbécile, lui criait-il en le secouant, pourquoi as-tu été à la procession des manants ? »

Un bourgeois passait qui prit la défense du négrillon. Faut-il plus qu'une étincelle pour mettre le feu aux étoupes ? Les épées sont dégainées, les fusils partent ; une clameur s'élève, s'enfle et se multiplie : «Aux armes ! Les mulâtres se révoltent contre les blancs!»

Incessant, affolant, le tocsin résonne, succédant aux carillons de fête. Des matelots en bordée, se souvenant d'une querelle ancienne, se lancent «comme des dogues » à travers la ville. Aidés de la populace, ils massacrent sauvagement les gens de couleur et jusqu'aux officiers blancs qui commandaient ceux-ci. La municipalité leur en soustrait fort heureusement beaucoup qu'elle jette en prison sous la promesse de les faire exécuter dans le plus court délai ; mais elle est à tous moments débordée par la rage meurtrière qui possède la foule.

Un officier de milice blessé, M. Dufau, appréhendé chez lui et porté à l'hôtel de ville, est arraché de son hamac, lardé de coup de baïonnettes, assommé, par les crosses de fusils, pendu. Et partout l'on renverse, on éventre, on égorge.

Quand les gardes municipaux réussissent enfin à rétablir l'ordre, 17 victimes ont été sacrifiées à la démence populaire. Dans maints endroits où la procession a passé, les roses effeuillées sont maintenant empourprées de sang.

Ainsi, pour la seconde fois depuis que le grand souffle de la Révolution avait passé sur la colonie, il s'avérait que la Martinique allait être beaucoup moins secouée par les impulsions reçues de la Mère Patrie que par ses propres passions.

De même qu'une maladie soudaine, en s'abattant sur un organisme, décèle ses vices internes et leur donne une gravité accrue, de même le choc de la crise Misait aussitôt apparaître les causes latentes de faiblesse et de déséquilibre qui préexistaient au sein de la société coloniale.

On peut, à volonté, s'étonner de cette sorte de vertige qui pousse les hommes à provoquer par leurs appréhensions inconscientes l'explosion de périls qui ne se 
sont pas encore précisés d'eux-mêmes, - ou méditer sur la surprenante inconséquence qui les amène, dans le même temps où ils revendiquent pour eux-mêmes le bénéfice d'un principe, à le repousser, quand leurs intérêts ou leurs instincts les y portent, pour ceux à qui logiquement il s'applique le plus.

Les mulâtres formaient, à la Martinique, un élément d'ordre, calme et discipliné, parfaitement honorable et disposé à attendre en paix l'élargissement progressif des minces satisfactions déjà obtenues et qui provisoirement lui suffisaient. Il eût été normal que cette attitude raisonnable et digne incitât les blancs, - responsables de sa formation -, à voir dans le mélange des sangs surtout l'apport de la race qui s'estimait supérieure. C'était d'ailleurs, - au rebours de ce qui se passe chez les Anglo-Saxons -, l'inclination spontanée du génie français, et l'état de choses qui s'était institué sous l'ancien régime en est une preuve évidente. Un trouble survient : c'est l'aveugle préjugé de couleur qui prend le pas sur la raison; et les gens de Saint-Pierre, en combattant un fantôme, en font une inquiétante réalité.

Et chez qui cette étrange aberration prend-elle aussitôt les allures d'une fièvre démente ? Ce n'est pas chez les représentants les plus autorisés de la race dirigeante, chez les fonctionnaires dont toutes les attaches sont en France, chez les propriétaires qui vivent en étroit et permanent contact avec l'humble troupe des sans droits, et à qui le sentiment de la conservation sociale a fait accepter un modus vivendi tolérable pour les opprimés. C'est chez une population flottante, intermédiaire, mêlée de déracinés, et qui n'est ni restée entièrement européenne, ni devenue proprement coloniale, les « petits blancs ».

Là, dès le premier jour, la fièvre monte et les idées s'embrouillent : la roture fait adopter d'enthousiasme la revendication d'égalité contre l'aristocratie ; l'orgueil du sang la lui fait répudier avec une véhémence accrue contre les victimes du pire asservissement.

La politique est véritablement le plus difficile de tous les arts, qui exige chez les conducteurs d'humanité une vision également claire de la physique des sociétés et de l'illogisme de leurs composants. 


\section{CHAPITRE III. RÉFÉRENCES :}

Extraits des faits que la ville de Saint-Pierre... (déjà cité) Min. Col. Martinique, 275.

Lettres de Foullon au ministre. Avril 1970. Min. Col. Martinique, 268.

E. RUFZ : Etudes historiques.

Dossier Du Buc. Ministère des Colonies.

Confédération des volontaires des Isles du Vent. 23 avril 1790. Arch. Nat. Dxxv 117.

Avec les Rouges aux Isles du Vent. Souvenirs du chevalier de Valous.

Décret du 8-28 mars 1790. Archives Ministère des Colonies Martinique, 267.

Lettre de M. de Laumoy au ministre. Min. Col. Martinique, 268.

Mémoire de la ville de Saint-Pierre. 26 juin 1790. Arch. Nat. Dxxv 117.

Pièces du procès de l'affaire du 3 juin. Arch. Nat. Dxxv 117.

Moniteur. Tome V, pages 301, 321, 345, 397.

Polémique entre les députés des planteurs et ceux de Saint-Pierre, à Paris, sur l'affaire du 3 juin. 


\section{La Révolution française à la Martinique}

\section{Chapitre IV}

\section{La Guerre civile}

Retour à la table des matières

À l'aube du jour qui suivit ces scènes affreuses, tout ce qui avait échappé au carnage et à la geôle arriva en trombe d'épouvante à Fort-Royal.

Si M. de Damas était bon homme, il avait une trop haute conception des devoirs de sa charge pour ne pas montrer de la fermeté quand les événements l'exigeaient.

Autant que l'Assemblée Coloniale convoquée d'urgence par son comité permanent, autant que l'opinion publique, la propre conscience du Gouverneur le requérait de procéder à l'épuration de Saint-Pierre.

Peut-être M. de Damas crut-il tout d'abord, ainsi que le chevalier Du Buc et l'Assemblée à sa suite le présumaient avec beaucoup de sérieux, que les honnêtes bourgeois de la ville attendaient impatiemment du secours, «n'osant élever la voix ni hasarder aucune démarche dans la cruelle appréhension où ils étaient de perdre leurs fortunes et leurs vies ». Ils s'efforcèrent, en tout cas, de conserver jusqu'au bout cette opinion, quoique les notables de Saint-Pierre fissent tout ce qu'il fallait pour leur démontrer que ce n'était qu'une illusion.

Sans doute, ceux-ci se montraient-ils fort marris de l'aventure ; mais c'était à la manière de chefs déterminés à excuser et à couvrir les excès de leurs partisans. 
Chacun plaidait comme il pouvait cette mauvaise cause. Malheureusement pour le succès de la défense les avocats se servaient d'arguments contradictoires. Tandis que le Conseil municipal rejetait toute la responsabilité de l'échauffourée sur « les matelots du Lutin, « les étrangers, les gens sans aveu, seuls suspects de ces atrocités », M. de Thomaseau, le maire, faisait état d'un prétendu complot ourdi par les gens de couleur et assurait que ces marins qu'on accusait, avaient concouru avec les citoyens à sauver la colonie ».

« Aveuglés, écrivait-il, par une ambition révoltante, les mulâtres, au lieu d'attendre les décrets, n'auront rien de sacré pour parvenir à l'égalité à laquelle ils aspirent... leur insolence qui s'accroissait chaque jour était le pronostic des maux qu'ils nous préparaient et le terme est venu où la colonie doit étendre sur eux la main puissante qui les fasse rentrer dans la classe dont ils ne devaient pas sortir. »

Quant à M. Foullon d'Ecottier, il colportait, avec un humour sinistre, que l'infortuné Dufau avait avoué, au moment d'être pendu, qu'il avait bien mérité son sort ${ }^{36}$.

Cependant la municipalité de Saint-Pierre enlevait au sénéchal l'instruction du procès des mulâtres emprisonnés pour la porter devant une cour prévôtale formée par ses soins. Il fallait agir. M. de Damas, décidément tout à fait remis de ses indispositions, le fit avec décision, rapidité et mesure.

Le 9 juin, ayant averti M. de Thomaseau qu'il estimait avec l'Assemblée coloniale et le reste du pays que le complot des gens de couleur libres (dont on n'avait même pas un commencement de preuve et que tout démentait au contraire) ne pouvait, eût-il même existé, excuser en rien les scènes d'horreur du 3 juin, ni la procédure illégale qui les continuait, $M$. le Général prit la tête des troupes réguliè-

36 Extrait de la déposition d'un témoin oculaire : «On en a tiré (d'un hamac) le sieur Dufau. On l'a entraîné contre un arbre où il a été mutilé et massacré à coups de baïonnettes. D'abord, il paraît quelques coups avec le bras, mais un inconnu ayant passé derrière lui lui a porté un coup de crosse de fusil sur la tête et lui a fendu le crâne. C'est alors qu'il est tombé et ensuite on l'a pendu » Arch. Nationales, Dxxv 117. 
res et des miliciens de toute la colonie et marcha contre Saint-Pierre. Dès la veille, il avait chargé $\mathrm{M}$. de Pontevès-Gien, commandant de la station navale, de vider la place de commerce de tous les matelots qui y traînaient, ce que cet officier fit le plus simplement du monde en ordonnant aux bâtiments étrangers de mettre à la voile et aux capitaines français de retenir leurs hommes à bord.

Investi par terre et par mer Saint-Pierre ne pouvait songer à se défendre. Son maire se résigna à la reddition pure et simple qui lui était imposée. M. de Damas consigna prudemment les mulâtres sur les hauteurs en dehors de la ville "pour éviter les effets de leurs justes ressentiments ». Il laissa sortir les femmes, les enfants, les habitants honorablement connus, ceux qui pouvaient justifier d'une profession avouable ou se recommander de quelque notable. Le surplus (deux cents personnes environ) alla remplacer, dans les prisons, les 70 mulâtres libérés. Beaucoup n'y restèrent qu'un jour ou deux. M. Foullon, qu'indignait fort cette opération, convenait toutefois «qu'on avait relâché promptement ceux auxquels on n'avait aucun reproche à faire ». Eût-il donc voulu qu'on élargit également les autres?

L'ordre était rétabli sans qu'il en eût coûté une goutte de sang. " Les bons citoyens de Saint-Pierre » pouvaient remercier M. de Damas « de son zèle et de sa prudence ». Ils le firent en effet, la rage dans le cœur - leurs municipalités avaient été cassées ainsi que celles des paroisses leurs alliées, et la présence d'un bataillon dans la ville décourageait tout retour offensif des factieux.

La colonie, purgée de ses émeutiers, put, au gré, de la métropole, procéder à la formation et à la consultation de ses assemblées paroissiales. Les patriotes n'osaient plus guère élever la voix, les excès du 3 juin leur avaient aliéné l'opinion ; les collèges électoraux furent unanimement favorables à l'Assemblée Coloniale.

Celle-ci se réunit à Fort-Royal le 7 juillet. Cette fois, les paroisses dissidentes, même celle de Saint-Pierre, avaient envoyé leurs délégués. L'Assemblée triomphait. Complétée, reconnue par le pays tout entier, elle ne se sentait plus retenue par la moindre inquiétude. Ses adversaires de l'intérieur étaient désarmés, surveillés, dominés, et ses agents de Paris semblaient posséder la confiance de la Consti- 
tuante. L'espérance caressée depuis un siècle se réalisait : la Martinique des planteurs devenait maîtresse de ses destinées.

Dès l'ouverture de la nouvelle Chambre, le droit de la colonie à légiférer sur tout ce qui concernait son régime intérieur fut solennellement proclamé.

Mais il faudrait être bien blasé ou d'une sagesse confinant à l'invraisemblance pour s'arrêter quand tout incite à élargir la victoire.

Les colons n'étaient ni blasés ni sages. Ils outrepassèrent donc quelque peu les prérogatives que leur avait libéralement octroyées la métropole. Ils adoptèrent les dispositions suivantes :

«L'Assemblée pourra faire aux décrets de l'Assemblée Nationale, sanctionnés par le Roi, qui lui seront adressés, les modifications qu'elle jugera convenables et ils auront, sous cette forme, leur pleine et entière exécution avec la sanction provisoire du Gouvernement, sauf la décision définitive de la législature française et du Roi.

«A l'égard des lois qui concernent les relations entre la colonie et la métropole, l'Assemblée aura le droit de les proposer et elles ne pourront avoir une exécution, même provisoire, avant d'avoir été consacrées par la volonté nationale et la sanction du roi si ce n'est dans les exceptions momentanées relatives à des nécessités urgentes.

«Les lois relatives au commerce qui auront été proposées et discutées dans le sein de l'Assemblée Nationale seront soumises à l'examen de l'Assemblée Coloniale et ne pourront être définitivement décrétées que d'après le résultat de ses opérations, combinées avec les raisons alléguées pour l'intérêt de la métropole. »

On le voit, les planteurs s'installaient fermement sur leurs positions et même élargissaient le terrain conquis. Le «Pacte colonial» devenait réellement un contrat bilatéral.

Notons encore que le nouveau statut des Assemblées Coloniales portait ce paragraphe assez insignifiant en apparence mais où se révèle l'art du chevalier Du Buc : «La durée de la fonction de président sera d'une semaine ; le vice-président passera de droit la semaine suivante, et le président sortant pourra être élu viceprésident. » 
Ainsi, permutant indéfiniment de la présidence à la vice-présidence et réciproquement, L.-F. Du Buc pouvait régner sur l'Assemblée sans exciter l'envie ni faire figure d'autocrate ancré sur ses prérogatives. A la manière de Périclès, il ne désirait pas compromettre, en la stérilisant par un titre défini ou une fonction permanente, l'autorité de fait que lui valait sa supériorité d'intelligence et de parole.

Le 12 juillet, l'Assemblée remplaça son Comité intermédiaire par un Directoire composé de 21 membres dont 4 pour Saint-Pierre, 2 pour Fort-Royal et 15 pour la campagne. Les directeurs devaient se partager le service de manière que 7 fussent toujours en fonction. Ils étaient chargés de la perception des impôts, de l'ordonnancement et de l'exécution des dépenses, de la gestion des fonds. M. Foullon d'Ecottier, entièrement dépouillé des obligations de sa charge, n'avait plus aucune raison de s'attarder dans la colonie ; on lui conseilla vivement de ne pas manquer le prochain bateau ; on l'aida même à faire ses paquets.

Les îles offrent cette grande commodité qu'on s'y peut débarrasser des indésirables en les déposant à bord d'un navire en partance. Les Martiniquais avaient accoutumé d'user de ce moyen. Ils le firent encore à l'égard de ceux des prisonniers de Saint-Pierre qui n'avaient aucune attache dans la colonie. Soixante furent embarqués sur le Prudent de Marseille, pour s'aller faire, sinon pendre, du moins juger ailleurs.

Enfin, l'Assemblée, « ne voulant pas établir, parmi les paroisses, de distinctions propres à ranimer des souvenirs qu'il fallait effacer », imagina de supprimer les municipalités légales comme elle avait supprimé les illégales et d'en créer de nouvelles qui borneraient leur zèle « à la police, notamment la propreté et la salubrité. », sous son contrôle et celui du Directoire.

Le chevalier Du Buc, on le voit, s'entendait, comme les grands chefs, à exploiter un avantage et à construire après avoir démoli.

La paix était revenue. Ce bon M. de Damas n'osait pas croire à son bonheur. Miséricordieux, il écrivait au ministre : «Quelque horreur que doive inspirer le massacre du 3 juin, l'aveuglement, le délire, les préventions qui l'ont produit réclament toujours une sorte d'indulgence pour les excès commis dans les troubles publics. " 
Il lui confiait aussi : «Une grande tranquillité règne dans toutes les parties de la colonie, mais on n'en jouit encore qu'en tremblant » ${ }^{37}$.

Puisqu'il tremblait, M. de Damas aurait bien dû faire surveiller plus étroitement les prisonniers restants - une quinzaine - qui attendaient dans le FortBourbon le moment de passer en jugement. Mais le Gouverneur était débonnaire et l'Assemblée assurée de son pouvoir. On toléra que les inculpés fussent visités par leurs familles. Elles les pourvurent de vivres et d'argent dont ils firent largement profiter les soldats de la garnison qu'ils éclairèrent du même coup sur les « vues liberticides de l'Assemblée Coloniale ».

Il est réconfortant de le constater : les mauvaises causes ne triomphent que servies par de bons sentiments : les soldats crurent qu'ils avaient été entraînés par leur général à soutenir des rebelles contre les seuls Français orthodoxes. Ils communiquèrent à leurs camarades l'indignation que cette idée soulevait en leurs coeurs fidèles à la patrie, si bien que le ler septembre 1790, lorsqu'on transféra les prisonniers à Fort-Royal, les troupes se révoltèrent. On vit le pavillon blanc qui flottait au bastion du Fort-Bourbon s'abaisser, disparaître ; bientôt après remonta un pavillon tricolore, fait de trois mouchoirs et le canon salua selon le rite ce « signal de la liberté ».

M. de Damas accourut pour parlementer. Il ne réussit qu'à se blesser malencontreusement à la jambe en redescendant du fort où il s'en était fallu de peu qu'on ne le gardât comme otage. Les circonstances n'en exigeaient pas moins une action prompte : Fort-Royal avait arboré à son tour les trois couleurs et ses hommes désertaient en masse. Mais le chevalier Du Buc veillait. Il ne se laissa pas démonter par la redoutable complication d'une sédition militaire et la malencontreuse indisponibilité du chef de la colonie. Avec l'esprit de décision qui le caractérise, il convoque, au nom de M. de Damas, toutes les milices blanches et de couleur, réunit un conseil de guerre à l'hôtel du gouvernement, fait porter vivres, munitions, pièces de campagne à l'habitation Levassor qu'il choisit comme lieu des séances de l'Assemblée Coloniale, envoie à la Trinité la seule compagnie restée fidèle, celle des grenadiers. Il parvient ainsi à retrancher tout son monde sur le Gros Morne, derrière une ligne de défense qui va du Lamentin à la Trinité.

37 Lettre du 12 août 1790. 
Pour assurer le ravitaillement de la colonie on ouvrit tous les ports à tous les navires pour toutes les denrées.

M. de Damas, opéré dans des conditions fort peu satisfaisantes, n'était plus en mesure de lutter, sinon contre la maladie. Le commandant de Rouil fut appelé à le remplacer provisoirement et les navires de la station navale reçurent l'ordre de croiser devant la baie de Fort-Royal. Les révoltés s'organisaient aussi. Leur colonel, M. de Chabrol, auquel les commissaires de Saint-Pierre assuraient la subsistance et le prêt de ses hommes, se laissa nommer commandant général de la milice citoyenne.

Persuadé que les colons, sans vivres et sans asile, à la veille d'une récolte, abandonneraient bientôt l'Assemblée pour rentrer chez eux, il saisissait, pensait-il, l'occasion de jouer un rôle et de devenir l'agent tout désigné de la conciliation, ce dont il escomptait prestige et avantages.

Des renforts ne tardèrent pas à lui arriver des îles voisines, et tout le premier, Coquille Dugommier, conduisant plusieurs compagnies du régiment de la Guadeloupe, au départ desquelles $\mathrm{M}$. de Clugny, retenu prisonnier en sa propre maison, n'avait pu s'opposer.

Tant de troupes n'effrayaient guère Du Buc. S'il n'espérait pas reprendre les forts, il savait bien que les planteurs, occupant la campagne, étaient protégés, plus encore que par leurs milices, par ce palladium : le sucre. Comment attaquer les colons sans saccager les récoltes, ce à quoi les négociants ni les capitaines marchands n'eussent consenti pour rien au monde ? Leurs alliés leur causaient même à ce sujet bien du souci. « Ces têtes exaltées, comme elles le sont, voudront marcher, gémissait l'un d'eux. Point de subordination, un seul esprit de récrimination. Je vois la campagne ravagée. Adieu la rentrée ! Vous devez penser l'inquiétude que j' ai. »

Aucun des deux partis n'ayant intérêt à employer ses forces à d'autre usage que l'intimidation, on se battit à coups d'arguments. Une correspondance quotidienne s'échangea entre M. de Damas et M. de Chabrol. La précision, l'assurance, la hautaine courtoisie dont témoignent les lettres du Gouverneur peuvent donner à penser que Du Buc épargnait toute fatigue inutile au blessé grelottant de fièvre. Quoi qu'il en soit, l'honneur ou la responsabilité en revient à M. de Damas, qui n'était pas homme à signer ce qu'il n'eût pas approuvé. 
M. de Chabrol et les commissaires de Saint-Pierre voulurent porter le débat sur le terrain politique, affectant de ne tenir aucun compte de la situation acquise par le corps de représentants de la colonie depuis le décret du 8 mars. Il fallait, selon eux, renvoyer les noirs aux ateliers, les agriculteurs à leurs habitations, dissoudre Assemblée et Directoire et les remplacer par une nouvelle Chambre dont l'objet serait de régler les intérêts respectifs des planteurs et des négociants. De surcroît, ces messieurs ne craignaient pas de marquer leur étonnement douloureux de ce que le général eût abandonné des forts occupés par ses propres troupes.

M. de Damas ne consentit d'aucune façon à envisager la question sous cet aspect. Il déclara extravagant qu'à propos d'une insurrection de soldats on vînt lui parler des intérêts des planteurs et des commerçants ; davantage qu'on prétendît remettre en cause la validité d'une assemblée régulièrement constituée d'après les plus récents décrets de France. Il rectifiait d'autre part : « Je n'ai point abandonné les forts. J'ai abandonné des troupes qui ne m'obéissaient plus pour me mettre à la tête des citoyens fidèles. Je suis le chef de la Colonie, la Colonie est aujourd'hui près de moi, je suis au milieu d'elle et c'est la seule place que je doive occuper. »

Devant ce ferme langage et cette logique inexpugnable, M. de Chabrol s'énervait, avouait la collusion des patriotes et des troupes, devenait menaçant : "Que cet événement ait été amené ou non par le parti de l'opposition, il n'en est pas moins vrai que les forteresses sont entre les mains de celui-ci... », observait-il, pour conclure que les temps étaient venus de traiter d'égal à égal et de désigner des conciliateurs.

M. de Damas se borna à le rappeler près de lui ainsi que M. Damoiseau et les autres officiers restés à Fort-Royal, « leur présence ne pouvant qu'être nuisible en autorisant en apparence la conduite du soldat, qui n'éprouve pas aussi fortement le sentiment de sa faute qu'il le ferait si tous les officiers s'étaient retirés ", observation forte et juste à laquelle les mutins ne trouvèrent rien à répondre, mais à laquelle ils se gardèrent de déférer.

Les choses cependant s'envenimaient peu à peu. La lutte épistolaire s'exacerbait. Les violences commençaient. Les hommes des deux partis, chaque fois que se présentait une occasion propice, se livraient à des massacres individuels.

Il devint bientôt inévitable de recourir aux armes. 
Déjà, le 21 septembre, deux détachements ennemis s'étaient trouvés face à face, de chaque côté de la rivière Sainte-Marie. Incertains, ils n'avaient pas osé s'attaquer et s'étaient éloignés avec dignité, après une heure et demie de «perspectives ». Il était clair qu'on ne pourrait indéfiniment s'observer ainsi sans finir par en venir aux mains.

Le 25, les patriotes se résolurent à prendre l'offensive. Deux colonnes, commandées l'une par M. de Chabrol, l'autre par Coquille Dugommier, marchèrent sur le camp des planteurs.

Ce fut alors que la toute puissance du sucre se montra, et de façon tout à fait imprévue, car les champs de cannes dont les colons avaient couvert le pays et que respectait l'avidité des gens du négoce, se trouvèrent recéler force batteries qui décimèrent les patriotes à bout portant, et les mirent en déroute.

\section{Planche VI. Proclamation des Commissaires réunis au Fort-Bourbon concernant les gens de couleur libres qui ont pris les armes contre les citoyens, du 22 septembre 1790. Voir Les Classiques des sciences sociales.}

Leur défaite inspira aux tenants de Saint-Pierre une thèse nouvelle. Il ne fut plus question de commerçants ni de planteurs, mais de blancs « en butte aux violences de nègres et de mulâtres soulevés par quelques traîtres ». Et pour prouver leur bonne entente avec les habitants, ils arguaient de ce souci d'épargner les propriétés qui leur avait été fatal.

Une fois de plus, la question se déplaçait, et la querelle se transposait du plan politique sur le plan ethnique.

Inlassablement, M. de Damas remet les choses au point : « Personne n'ignore que les mulâtres sont depuis longtemps armés et réunis en corps de milices par ordre du roi, qu'en paix comme en guerre ils font le service. Quant aux esclaves, ils ne sont révoltés que de la conduite des ennemis de leurs maîtres. » Inlassablement, il adresse aux troupes sommation sur sommation: "Que les soldats se soumettent, leur général leur promet l'amnistie. Passé le délai accordé, il les livrera à la justice du pays. » 
D'une proclamation à l'autre, l'excellent homme reculait le dit délai sans plus de succès.

L'affichage même des décrets de l'Assemblée Nationale sur le rétablissement de la discipline dans l'armée demeura à peu près sans effet. Les hommes des régiments de la Martinique et de la Guadeloupe restaient persuadés qu'ils prêtaient le secours de leurs armes à des Français dans le danger et suivaient ainsi la voie du devoir ; au surplus, les amitiés et les largesses que leur dispensaient les citoyens de Saint-Pierre les aidaient à penser que cette voie était la bonne. Quant aux décrets de la Constituante, ils les tenaient, suivant le dire des Patriotes, pour apocryphes et fabriqués au Gros Morne. Moins crédules, cependant, les officiers commencèrent à envisager, avec quelque inquiétude. les suites probables de leur insoumission et prétendirent donner leur démission. Sur le conseil de Dugommier, on les emprisonna.

La bataille du 25 septembre n'avait servi qu'à démontrer l'impossibilité de résoudre le conflit par la force. Les circonstances permirent un moment aux patriotes d'espérer réduire leurs adversaires par la famine.

Pendant tout le mois de septembre les bâtiments du roi avaient croisé hors de portée des canons des forts ; la mauvaise saison venue ils ne purent rester au large et, n'ayant plus de rade sûre, prirent le parti de faire voile pour la France sans attendre la station qui devait les relever.

Saint-Pierre arma aussitôt 13 petits corsaires pour investir les côtes et empêcher l'entrée des subsistances. M. de Damas, sur la réquisition que lui en fit le Directoire, écrivit alors au Gouverneur général des Antilles anglaises une lettre officielle dont il envoya copie au Ministre de la Marine. Il y priait son collègue britannique de ne pas prendre les insultes faites à son pavillon par des brigands et des révoltés pour des infractions à la paix, ajoutant que, pour sa part, il désavouait formellement ces pirates et «les livrait à la vindicte de quiconque a force en mains pour faire la police des mers ».

Les patriotes s'en autorisèrent pour accuser l'Assemblée d'ouvrir des négociations avec l'étranger. Un commerçant, bien renseigné, confiait à son correspondant : «On a trouvé beaucoup de lettres, entre autres du Général de la Dominique, portant à peu près ces mots : « Je suis réellement affligé des troubles qui règnent dans votre colonie. Je ne puis vous envoyer les secours que vous me demandez; 
mon cœur y répugne et ma délicatesse en souffre. Aussi, ne comptez nullement sur moi. Même je vous conseille de ne pas tarder de vous mettre du côté de la Nation. Vous ne pourrez tenir longtemps et vous serez toujours condamnables. »

Ce texte est en effet conforme, quant au sens, à celui d'une lettre que M. de Damas reçut de sir Edward Mathew ${ }^{38}$. Mais l'adaptateur omettait d'ajouter qu'elle était accompagnée d'un billet ainsi conçu : « J'ai l'honneur d'envoyer ci-inclus, à votre Excellence, une copie de ma réponse au Comité de Saint-Pierre en l'île de la Martinique », détail qui, on en conviendra, change singulièrement la conclusion à tirer du document.

Sur ces entrefaites, M. Du Barrail, lieutenant-colonel du régiment de la Guadeloupe, conçut le projet de rétablir, par le seul effet de son éloquence, la paix et la concorde dans l'île de la Martinique. Il y vint donc le 5 octobre à la tête d'une députation de conciliateurs.

Sa charitable initiative n'obtint pas le succès qu'il en espérait ; en revanche, il apprit à ses dépens que l'office de médiateur expose à bien des déconvenues. A la lettre toute pleine de paroles dulcifiantes qu'il adressa à $\mathrm{M}$. de Damas, celui-ci répondit qu'il ne savait ce que signifiait cette députation, mais qu'il savait fort bien que M. Du Barrail était sous ses ordres et qu'il lui enjoignait de ramener sur le champ les soldats de la Guadeloupe à M. de Clugny. MM. de Molerat et Félix recevaient également l'ordre de reconduire à Sainte-Lucie les hommes appartenant à la garnison de cette île.

Les conciliateurs obtinrent néanmoins, le 16 octobre, d'être entendus par l'Assemblée Coloniale. Louis-François Du Buc présidait ; il les reçut avec sa politesse infranchissable, et les morigéna, comme des étourdis, dans un impeccable discours en trois points.

Et d'abord il leur demanda de bien vouloir arrêter leur esprit sur le sens de cette expression : Ennemi de la Constituante, leur faisant remarquer combien il était plaisant que ceux-là justement qui obéissaient à la Constituante fussent déclarés ses ennemis. Il observa ensuite que les conciliateurs devaient, en débarquant dans lî̀le, s'adresser au seul corps constitué et non aux rebelles. Il rappela enfin que les

38 Voir aux annexes. 
commissaires de Saint-Pierre n'avaient aucun mandat valable, cette ville ayant ses représentants comme toutes les paroisses au sein de l'Assemblée Coloniale.

Après cela on peut imaginer le peu d'enthousiasme que durent quelques jours plus tard ressentir les infortunés médiateurs, à l'idée de présenter à l'Assemblée les conditions de Saint-Pierre. Elles étaient, à la vérité, insoutenables et montraient assez dans quel délire on entretenait les soldats ${ }^{39}$. L'Assemblée, en ayant pris connaissance, ne daigna même pas les examiner et déclara s'en tenir à la dernière proclamation du Gouverneur.

La députation de la Guadeloupe, revenue à Fort-Royal, y fut traitée d'une façon assez peu amicale qui la dégoûta définitivement du rôle qu'elle avait bénévolement assumé. Aussi, le 29 octobre, témoigna-t-elle à M. de Damas son désir de s'éclipser sans tambours ni trompettes, en se rembarquant à la Trinité.

Le Ier novembre, les bâtiments de la nouvelle station navale parurent. Les officiers qui les commandaient étaient presque tous des royalistes fervents et des hommes résolus. Leur chef, $M$. de Rivière, ayant été rendre ses devoirs à $M$. de Damas, déclara à Saint-Pierre et à Fort-Royal qu'il protégerait leur commerce comme celui des autres ports, mais qu'il ne tolérerait, sous aucun prétexte, que les patriotes approchassent ses matelots ${ }^{40}$.

De ce jour, le ravitaillement des planteurs se fit normalement et $\mathbf{M}$. de Damas put espérer que les dépêches et subsides du Gouvernement central lui parviendraient à peu près régulièrement ; en effet, La Ferme et L'Embuscade, préposées à la police des côtes, arrêtaient les bateaux porteurs du courrier et les dirigeaient sur Case-Navire.

Encore en échappait-il parfois à leur vigilance et les Saint-Pierrais, sourds aux réclamations du Gouverneur, confisquaient alors sans scrupule gourdes et piastres - sans compter la correspondance.

39 Le régiment de Saint-Pierre prétendait, entre autres conditions, demander à l’Assemblée Nationale de s'appeler dorénavant « Régiment National de la Martinique », d'indemniser largement les " patriotes », de châtier les officiers qui sont restés fidèles au gouverneur, etc... Arch. Nat. Dxxv 116, pièce 63.

40 « Ils (les patriotes) ont corrompu les troupes avec de l'argent, des promesses et des sophismes ; - qu'ils n'approchent pas mes matelots 1 ». Lettre de M. de Rivière, 25 déc. 1790, Ministère Colonies. Martinique, 268. 
La Martinique restait donc divisée en deux camps d'égale force : au centre de l'île, retranchés avec le général, avec l'Assemblée Coloniale, les planteurs et leurs auxiliaires de couleur ; à Saint-Pierre et dans les fortifications, des citoyens des villes, les régiments révoltés, un certain nombre d'habitants des paroisses voisines, et une quantité de patriotes venus de toutes les îles du Vent.

Le conflit ne pouvait désormais être réglé que par l'arbitre suprême : la France, dont chacun des partis rivaux réclamait à grands cris l'intervention. « Nous tenons toujours les forts, venez vite ! », suppliaient les patriotes. Et M. de Damas répétait désespérément au ministre : « Je bloque étroitement les forts afin de garantir la campagne. Nous attendons votre secours avec impatience, ne tardez plus!»

\section{CHAPITRE IV. RÉFÉRENCES :}

Lettre d'un capitaine marchand à ses armateurs. 11 sept. 1790. Arch. Nat. Dxxv 118.

Proclamations de M. de Damas. Septembre-octobre 1790. Arch. Nat. Dxxv 116.

Lettre de M. de Damas au ministre. 5 oct. 1890. Arch. Nat. Dxxv 116.

Réquisition du Directoire à M. de Damas, Arch. Nat. Dxxv 116.

Lettres échangées entre M. du Barrail et M. de Damas. Arch. Nat. Dxxv 116.

Procès-verbal de la séance de l'assemblée coloniale. 16 oct. 1790. Arch. Ministère Colonies Martinique, 268.

Lettre de M. de Rivière. 25 dée. 1790. Ministère Colonies Martinique, 268. 


\section{La Révolution française à la Martinique}

\section{Chapitre V}

\section{La Métropole arbitre}

$\underline{\text { Retour à la table des matières }}$

La métropole ne pouvait se désintéresser indéfiniment de la situation inadmissible créée à la Martinique par les hostilités déclarées entre les partis. Il fallait soutenir ou désavouer le représentant légal de l'autorité centrale, donner tort ou raison à ces révoltés qui protestaient de leur dévouement ardent au nouveau régime.

Mais j'ai montré combien, en se superposant aux idées directrices venues de France, les passions locales avaient embrouillé le problème au milieu de dires opposés et souvent en contradiction avec eux-mêmes.

M. Cloeret de Fleurieu, Ministre de la Marine, qui s'efforçait d'en éclaircir au moins les données, avait fort à faire. Et certes, quand il avait lu les lettres de $\mathrm{M}$. de Damas, entendu les députés de l'Assemblée Coloniale et les délégués extraordinaires dépêchés à Paris par Saint-Pierre, écouté les suggestions des Amis des Noirs, consulté les membres du club de Massiac, il devait penser en soupirant que la vérité n'est pas simple.

Il semblait que les idées des « patriotes » dussent rejoindre celles des philosophes qui, dans la capitale, représentaient l'opinion d'avant-garde. Or le principal grief qu'ils articulaient contre les colons, c'était d'encourager chez les hommes de 
couleur « l'ambition inacceptable d'être assimilés aux blancs ». Et cette imputation pouvait difficilement paraître fondée à qui connaissait les conceptions des grands planteurs résidant à Paris.

Ce fut cependant le thème le plus complaisamment développé par les envoyés de Saint-Pierre, et lorsqu'ils furent admis à la barre de l'Assemblée Nationale, le 31 novembre 1790, leur orateur, M. James Eyma, ne parla pas d'autre chose ;

\section{Planche VII. L'Abbé Grégoire.}

Voir Les Classiques des sciences sociales.

« Expliquez-vous clairement, messieurs, dit-il, ce qui forme la base du régime colonial. Nous désirons que chacune des castes qui peuplent les îles jouisse de tous les avantages qui peuvent être compatibles avec sa condition. Nous idolâtrons la Révolution, nous avons combattu pour elle en Amérique, mais nous devons vous dire avec franchise que les colonies sont perdues, que leur population disparaîtra de la surface du globe si vous ne conservez pas la ligne de démarcation qui doit séparer l'affranchi de l'homme libre et l'esclave de l'affranchi.

« Les philosophes, dont les écrits ont pénétré dans les colonies, ont été la cause de beaucoup de troubles. Ils travaillent directement contre ceux qu'ils paraissent protéger. Ils ont obligé les blancs à se montrer plus inquiets et plus sévères, et si leurs malheureuses doctrines finissaient par se propager, dans le bouleversement qu'elles opéreraient, ceux qu'on invite à l'insurrection en seraient les premières victimes. »

On s'attendait à une diatribe contre le Gouverneur et l'Assemblée Coloniale ; on en entendait une contre les Amis des Noirs !... Ces révolutionnaires coloniaux étaient gens bien déconcertants !

Il faut ajouter à cela que, pour les esprits jugeant les événements d'un point de vue central, le problème était d'autant plus compliqué qu'il prenait des aspects fort différents dans les diverses colonies de la mer des Antilles, dont les conditions étaient pourtant semblables. 
Ce n'est guère qu'à la Martinique que les planteurs, guidés par le grand sens politique du chevalier Du Buc, avaient adopté, vis-à-vis des hommes de couleur, l'attitude favorable que l'on sait : très éloignés de leur accorder d'emblée l'égalité politique, ils admettaient la nécessité d'une évolution des idées et des mœurs, mais la voulaient prudente et progressive ; ils s'étaient donc judicieusement concilié cette grande force d'avenir par un libéralisme relatif, et c'était à l'appui des mulâtres qu'ils avaient dû leurs succès et les avantages substantiels qu'ils avaient su acquérir.

Mais ailleurs il n'en allait pas de même. A Saint-Domingue surtout, - notre plus grande possession, - l'esprit étroit et intransigeant des colons avait, dès le début, singulièrement gâté les choses. Ils étaient entrés en conflit non seulement avec les «patriotes », mais avec le Gouverneur. Et lorsque fut promulgué le décret du 8 mars 1790, les troubles éclatèrent.

On se rappelle qu'un article, volontairement ambigu, de ce texte stipulait : «Toutes les personnes âgées de 25 ans... se réuniront pour former l'Assemblée paroissiale. »

A Saint-Domingue, les mulâtres, dont les planteurs ne s'étaient pas attiré les sympathies, revendiquèrent le droit qui leur était ainsi implicitement concédé. Ils se réunirent sous la direction d'un nommé Ogé, dont la situation devint rapidement désespérée. Ogé poursuivi, traqué, dût se réfugier chez les Espagnols de la colonie voisine ; ceux-ci le livrèrent et il périt sur la roue. Ces violences et cette cruauté devaient laisser des germes de dissensions plus graves, dont on connaît le développement redoutable et l'aboutissement désastreux.

Les pouvoirs métropolitains, en statuant sur le sort de la Martinique, ne pouvaient manquer d'être influencés par les inquiétudes que leur causait l'agitation de la grande île voisine.

Une chose, en tout cas, dominait le débat. La France ne recevait plus en suffisance de ses possessions antillaises leurs précieuses productions : sucres, cafés, rhums. Cette disette était pénible pour sa population, préjudiciable à son commerce, nuisible au Trésor. Il fallait à tout prix intervenir.

Comme la confusion des faits et des idées ne permettait guère une solution immédiate, on résolut d'enquêter, tout en donnant des pouvoirs de décision aux hommes chargés d'élucider les choses. 
Dès le 8 décembre 1790, un nouveau décret était rendu, qui modifiait celui du 8 mars précédent; la nomination était décidée de quatre commissaires, chargés d'en assurer l'application, d'informer sur les troubles passés et de rétablir la paix publique. En outre, le roi était prié de remplacer le Gouverneur et d'envoyer à la Martinique quatre vaisseaux de ligne et 6.000 hommes.

"Il est peu de missions aussi grandes, aussi honorables, aussi importantes... » enseignaient aux commissaires les Instructions qui leur furent remises au moment de leur départ. «Elle intéresse non seulement de vastes possessions lointaines qu'il s'agit de consoler du malheur de l'éloignement en les préparant à toute la prospérité dont elles sont susceptibles, mais elle ne tient pas moins intimement à l'intérêt et à la richesse de la France entière. Que ces deux considérations soient sans cesse présentes à leur esprit. »

A quels hommes l'Assemblée Nationale confiait-elle un mandat si considérable ? Quels pouvoirs leur étaient délégués ? Quelles recommandations leur furent faites?

Le choix du ministre se porta sur quatre personnages dont deux au moins avaient joué un rôle de premier plan au Bureau des Colonies, aussi bien que dans les colonies elles-mêmes. Le plus marquant de tous était Lemercier de la Rivière, aussi célèbre par l'intelligente audace et le désintéressement qu'il avait montrés dans ses fonctions d'intendant à la Martinique, de 1758 à 1762 et de 1763 à 1764, que par son retentissant ouvrage : "L'ordre naturel et essentiel des sociétés politiques », véritable code de la doctrine physiocratique, que certains contemporains, et non des moindres, portaient au-dessus de L'Esprit des lois. Le bruit de son mérite était à ce point répandu que la Grande Catherine l'avait appelé près d'elle dans le dessein d'obtenir de lui une constitution pour ses États ${ }^{41}$.

Le second des commissaires, par son importance, n'était autre que l'ancien premier commis La Coste, qui avait géré les affaires de l'Amérique et de la côte d'Afrique de 1776 à 1781, pendant que défilaient au ministère MM. de Boynes, Turgot, de Sartines et le maréchal de Castries. Il était devenu ensuite député du commerce de Saint-Domingue ; à tous ces titres, il était particulièrement désigné pour enquêter sur l'état de la principale des petites Antilles. Malheureusement, s'il faut en croire Mme Roland, c'était « un vrai commis de bureau de l'ancien régime,

41 MAY (L.-Ph.) : Le Mercier de la Rivière, intendant des Isles du Vent. 
dont il avait l'encolure insignifiante et gauche, l'air froid et le ton dogmatique. Il ne manquait point de ces moyens que donne la triture des affaires, mais son extérieur concentré cachait une violence de caractère dont les emportements dans la contradiction allaient jusqu'au ridicule ; il n'avait d'ailleurs ni l'étendue de vues, ni l'activité nécessaires à un administrateur ». La manière dont $\mathrm{M}$. de La Coste se comporta à la Guadeloupe montre assez que le portrait était ressemblant.

Un Commissaire général qui avait été ordonnateur à Cayenne, M. Lescailler, complétait, avec l'Administrateur colonial Magnytôt, le quatuor des délégués.

Malheureusement, au dernier moment, M. de Fleurieu vit ses judicieux arrangements bouleversés ; Lescailler, on ne sait pour quelles raisons, apparemment péremptoires, était empêché de s'embarquer ; et, défection plus regrettable, Lemercier de la Rivière, que ses 73 ans n'avaient point retenu d'accepter une pareille mission, était mis par une malencontreuse maladie hors d'état d'en affronter les fatigues. Le ministre nomma, pour les remplacer, deux autres administrateurs coloniaux, M. Linger et M. de Mondenoix, lequel connaissait bien la Martinique pour y avoir passé trois années en qualité d'intendant, de 1777 à 1780.

Le commandement des 6.000 hommes et le Gouvernement général furent remis au comte Jean-Pierre-Antoine de Béhague, ancien Gouverneur de la Guyane, honnête homme sans plus, scrupuleux, important, chez qui, ainsi que chez tous les êtres moyens qui ont reçu une forte éducation sociale, les vertus du personnage officiel suppléaient celles de la personne humaine.

La Constituante, en envoyant en Amérique des hommes compétents en matière d'administration des colonies, était en droit d'espérer des résultats satisfaisants. Elle leur rappelait d'ailleurs que : « leur ministère était un ministère de paix plutôt qu'un ministère de rigueur. » Il fallait que l'apparat de la force en prévînt l'usage. Il suffirait, sans doute, de parler à des Français au nom de la Nation, de la Loi et du Roi pour ramener le calme et, à cette fin, il valait mieux mettre un terme aux divisions que d'en rechercher trop indiscrètement les causes. «En un mot, résumait-on, il est nécessaire que tout fléchisse devant la loi du 8 décembre dernier, que tout rentre dans le devoir et dans la subordination... mais il est essentiellement à désirer que ce retour salutaire ne soit marqué par aucune trace de sang. »

Les commissaires s'informeraient sur tous les troubles, reprendraient la régie des finances au Directoire, donneraient l'impulsion à l'administration intérieure 
par voie réquisitoriale, pourvoiraient à l'approvisionnement des îles et à leur police.

Ignorant qu'une dépêche envoyée par le ministre, un mois auparavant et portant l'ordre de suspendre l'Assemblée Coloniale, était restée en souffrance à la municipalité de Saint-Pierre parmi d'autres paquets interceptés, l'Assemblée Nationale tenait la mesure exécutée et conseillait de rassembler quelques membres des deux partis opposés pour tâcher de les concilier.

L'atteinte que la Nation portait à l'amour-propre des planteurs en suspendant leur Chambre et en supprimant le Directoire, était largement compensée par la sollicitude qu'elle témoignait pour leurs intérêts : un nouveau port d'entrepôt était créé à la Trinité et les bâtiments étrangers obtenaient d'être admis à Fort-Royal pendant l'hivernage. Bien mieux, l'instruction ajoutait - « Cet article est impératif mais il n'est pas restrictif. » Les commissaires pouvaient donc aller au delà en cas de nécessité. Le Pacte colonial recevait le coup de grâce 1

D'une manière générale, la France s'en remet aux délégués qu'elle a choisis et leur laisse la plus large initiative. Elle va jusqu'à leur recommander de s'écarter de ce qu'elle leur prescrit «si, en s'écartant, ils remplissent exactement le voeu de pacification, d'ordre public et de bonheur pour les habitants des îles du Vent ».

Mais aucun de ces messieurs ne possédait un goût très vif des responsabilités, et quoi qu'on leur eût dit, tous se sentaient liés étroitement par les formules ministérielles.

Quant à M. de Béhague, il n'avait d'action qu'autant qu'il était requis par les commissaires et, dans ce cas, il devenait leur associé ; mais il intervenait de droit dans les délibérations à l'occasion des quatre cas suivants : usage offensif ou non emploi des troupes, renvoi en France d'un régiment, renvoi d'un fonctionnaire et désarmement des esclaves.

Le 12 mars 1791, l'escadre française parut devant l'île.

Du pont de leur vaisseau les délégués de la Constituante regardaient se révéler progressivement les côtes de la Martinique, lorsque le canon gronda dans l'air bleu. M. de Béhague haussa un sourcil indigné. Est-ce ainsi que des soldats accueillaient leur général ?... Tandis qu'il réfléchissait sur la conduite à tenir en une 
si choquante conjoncture, un pli qu'on lui apporta de la part de M. de Damas vint le tirer d'embarras.

Le Gouverneur lui adressait ses compliments de bienvenue et l'engageait à aborder à Case-Navire ${ }^{42}$. M. de Béhague suivit le conseil et, sitôt débarqué, se rendit à l'Assemblée Coloniale avec les quatre commissaires. Il y trouva matière à rasséréner son âme : M. de Damas, trop heureux d'être relevé de ses orageuses fonctions, le recevait comme un sauveur, l'Assemblée l'assurait de sa soumission aux décrets de l'Assemblée Nationale.

Le lendemain, 13 mars, le général dictait une proclamation impérieuse à l'adresse des révoltés quand il éprouva la surprise de celui qui, se préparant à enfoncer une porte, la voit s'ouvrir. Les "patriotes", tout contents et tout fiers " d'être parvenus à force de constance à empêcher les nègres el les mulâtres d'entrer dans les forts, et d'avoir la gloire de les remettre à M. de Béhague, dépositaire de la loi et des décrets de l'Assemblée Nationale », lui envoyaient une députation préparée à accepter avec une feinte modestie les éloges dont il ne pouvait manquer de l'accabler.

La réception qu'elle trouva ne fut pas précisément celle qu'elle avait escomptée. M. de Béhague n'avait pas digéré les coups de canon. En vain lui expliqua-ton que c'était un malentendu - Fort-Royal voyant les dix-huit vaisseaux filant sur une ligne avait tiré à blanc pour avertir Saint-Pierre. Le général, peu convaincu, n'en fit pas moins afficher sa proclamation; et l'on pût lire le jour même sur les murs des deux citadelles :

«Soldats du régiment de la Martinique, êtes-vous Français ? Est-ce bien vous qui, à la vue des forces formidables que la Nation vous envoie pour tout pacifier, pour tout faire rentrer dans l'ordre, osez bombarder vos frères du haut de ces murs que l'Empire des François n'a élevés que contre ses véritables ennemis ? Qu'attendez-vous pour m'en apporter les clefs ? Est-ce la Loi qui m'envoie pour les reprendre ? Je vous la notifie. »

Les intéressés, éberlués, protestèrent qu'ils étaient effectivement Français et l'étaient même " avec transport ", qu'ils se remettaient à la discrétion des représentants de la Nation. Mais rien ne pouvait détourner M. de Béhague de l'idée

42 Ce centre a été débaptisé et forme aujourd'hui la commune de Schœlcher. 
qu'il venait de mater, par ses seuls talents de chef, des rebelles endurcis. La mauvaise grâce que l'on témoigna à évacuer les forts lorsqu'on sut qu'ils allaient être occupés, sur son ordre, par les grenadiers restés fidèles, le confirma dans son erreur. Il crut avoir vaincu ceux qu'il avait seulement dépités ; il écrivit au ministre : «C'est ainsi que le Gibraltar de l'Amérique est rentré au pouvoir de la Nation sans qu'il en ait coûté une goutte de sang. »

Au pouvoir de la Nation... On eût bien surpris le général en lui révélant que, malgré ses querelles intestines, la Martinique n'avait pas cessé, d'y être et que l'assimilation de Fort-Royal à Gibraltar était une image littéraire quelque peu osée.

Il s'agissait maintenant de ramener le calme, ce qui était beaucoup moins facile.

Les quatre commissaires s'y employèrent sans génie mais non sans conscience. Ils essayèrent honnêtement de démêler la vérité parmi les avis et les plaintes contradictoires dont on les harcelait.

Chacun des deux partis jouait la victime épouvantée : les planteurs affirmaient que les troupes allaient encore se révolter, les « patriotes » que « les mulâtres allaient fondre sur la ville ».

La première mesure qui s'imposait était évidemment d'éliminer les forces des deux adversaires. Outre la sécurité, on y gagnerait de réduire l'un et l'autre parti à ses seuls éléments authentiques et d'y voir ainsi plus clair.

Les commissaires ordonnèrent donc aux habitants des îles voisines, dont la plupart étaient, à leur jugement, « des gens inconnus et peu recommandables », de rentrer immédiatement chez eux.

D'accord avec M. de Béhague, ils firent embarquer les régiments révoltés, lesquels, loin de « voler », comme ils s'en étaient flattés, « dans les bras de leurs frères », et d'être fêtés par eux comme des héros, avaient été soigneusement tenus à l'écart des troupes fraîches.

Enfin, les nègres, qui formaient une bonne partie des milices constituées par les planteurs, furent désarmés et invites à rentrer chez leurs maîtres. 
Tout cela n'alla pas, comme l'on pense, sans provoquer quelques incidents.

A Saint-Pierre, les "patriotes » avaient vivement ressenti le blâme implicite infligé à leurs amis soldats. Ils assistèrent à leur embarquement, "consternés comme s'ils eussent perdu un appui dont l'éloignement devait les livrer aux plus grands maux ».

Les commerçants aisés, il est vrai, malgré les figures de circonstance qu'ils s'efforçaient de prendre, ne parvenaient pas à dissimuler entièrement le soulagement qu'ils éprouvaient à se voir délivrer de « ces nombreux et exigeants commensaux $» 43$.

Plus d'un Saint-Pierrais fit passer sa mauvaise humeur, feinte ou réelle, sur ses esclaves récupérés. Ces pauvres gens n'appréciaient guère la fin des hostilités qui était pour eux la fin des vacances. Bien qu'ils fussent environ 80.000 pour 10.000 blancs, l'habitude de la soumission les poussa, une fois de plus, à déposer leurs armes et à regagner le logis de leurs maîtres. Les commissaires de France ne leur garantissaient-ils pas, par voie d'affiches, « qu'ils pouvaient avoir confiance, qu'ils seraient reçus avec humanité et bonté ? " C'était beaucoup s'avancer ; les blancs de Saint-Pierre n'oubliaient pas si vite que leurs propres esclaves avaient combattu pour les planteurs et plusieurs se montrèrent cruels, sans souci des proclamations comminatoires que multipliaient les commissaires indignés.

Quant aux hommes de couleur libres, les «patriotes » se contentèrent de les insulter et de leur défendre de porter la cocarde ; puis, sur l'injonction que leur fit M. de Béhague d'avoir à se tenir tranquilles, ils quittèrent eux-mêmes leur cher symbole plutôt que de le partager avec des êtres d'une race qu'ils jugeaient inférieure.

Saint-Pierre gardait sa manière bien personnelle de comprendre l'Egalité, la Liberté et la Fraternité !

Ses citoyens étaient d'ailleurs, pour un cas plus sérieux, en difficulté avec les envoyés de France.

Dès leur arrivée, ceux-ci avaient, en bonne justice distributive, cassé le Conseil de Ville de Saint-Pierre, comme ils avaient suspendu l'Assemblée Coloniale. Ils avaient ensuite demandé aux deux partis de désigner chacun douze

43 Lettre des commissaires, Arch. Nat. Dxxv 116. 
membres particulièrement qualifiés pour exposer les dissensions de la colonie. Toutefois, ils eurent soin de signifier aux « patriotes » que ce comité conciliateur ne pouvait être recruté ni parmi le conseil de Saint-Pierre, ni parmi les commissaires des quatorze paroisses réunies, et devrait être exclusivement composé de personnes prises dans les quatre classes suivantes : négociants - propriétaires de maison ou de magasins - particuliers exerçant une profession publique ou domiciliés depuis deux ans au moins - habitants honorablement connus des quatorze paroisses.

On put constater ainsi que les meneurs du parti « patriote » étaient, sinon tous des aventuriers, du moins des Martiniquais d'occasion. Les Saint-Pierrais en apportèrent la preuve en se récriant sur « cette distribution anticonstitutionnelle qui tendait à écarter les gens qui les avaient représentés dans les troubles ». Après avoir bien chicané et s'être copieusement lamentés, ils durent cependant élire leur Comité tel que les commissaires l'exigeaient. Ils s'en consolèrent en chargeant le plus notable de leurs chefs bénévoles, Coquille Dugommier, d'aller défendre leurs intérêts en France ${ }^{44}$.

L'île semblait en voie de se calmer tout à fait ; le Général commençait à être fort embarrassé de ses trop nombreuses troupes dont la présence lui causait plus d'inquiétude que de réconfort. Il se disait que ses soldats, condamnés à l'oisiveté, « environnés de tous les pièges de la séduction, constituaient bien plutôt une menace de péril qu'un élément de sécurité ». Aussi, lorsqu'il apprit, au mois d'avril, la situation désespérée de $M$. de Blanchelande, Gouverneur intérimaire de SaintDomingue ${ }^{45}$, répondit-il à la demande de secours de son collègue en s'empressant de lui expédier le principal de ses effectifs.

Restait à résoudre la question économique. Pour cela il n'eût fallu rien de moins que Lemercier de la Rivière. Invité à laisser libre cours à ses initiatives,

44 On ne peut s'empêcher d'être surpris de la manière fantaisiste dont le Grand Larousse représente le rôle de Dugommier, Je cite : « Dugommier (à la Martinique) se trouva exposé aux plus grands dangers, ayant à lutter à la fois contre les colons et contre la révolte soutenue par le traître Behague. Pendant 7 mois, il défendit le fort Saint-Elme (?) contre cette double insurrection ; il dut enfin céder à la force ».

45 Les régiments qu'on lui avait envoyés de France s'étaient révoltés. Le colonel de Mauduit avait été décapité et sa tête promenée au bout d'une pique. 
jadis fâcheusement bridées par Berryer et même Choiseul, il eût sans doute donné sa mesure. Celle des délégués sur lesquels le choix du ministre avait dû se rabattre était plus ordinaire. Après six semaines, ils n'avaient encore pris aucune détermination au sujet du commerce. Les planteurs en profitaient pour continuer, sans bruit, à appliquer les dispositions votées par leur assemblée, le 11 septembre 1790, admettant les bâtiments étrangers dans les différents ports de l'île, avec toutes espèces de marchandises et leur permettant d'exporter les denrées coloniales.

Saint-Pierre, dont le négoce était, de ce fait, dans une stagnation absolue, dénonça à grands cris ce qu'il considérait comme une fraude cynique; les capitaines de navires marchands, dont les commissionnaires de la ville n'avaient pu ni payer la cargaison ni fournir le chargement de retour, firent chorus.

Les commissaires, tout en observant que les boutiques de Saint-Pierre étaient garnies presque en totalité de marchandises anglaises, preuve que cette ville ne dédaignait pas non plus la contrebande, se décidèrent à demander des explications aux planteurs. Du Buc leur en donna le plus gracieusement du monde : il était surpris à l'extrême que les envoyés de France ignorassent l'arrêté du 11 septembre 1790, sanctionné par le Gouverneur, et porté à la connaissance du ministre du Roi. Bien entendu, cet arrêté avait été pris à titre exceptionnel ; les planteurs étaient les premiers à désirer réserver leurs produits aux bâtiments français. Si ceux qui avaient touché Saint-Pierre n'avaient pu trouver de chargement dans cette ville, que n'étaient-ils venus dans les autres ports?

Il fallait que le commerce de la métropole se pénétrât de cette vérité : SaintPierre était désormais pour les colons comme s'il n'existait pas. A ce propos, le chevalier Du Buc faisait observer à MM. les Commissaires que le port de la Trinité ne suffisait que pour les quartiers situés au vent de l'île et qu'il y aurait intérêt, pour la Martinique, à ce que Fort-Royal, Le François et Le Marin restassent ouverts sous la condition que le trafic avec les navires étrangers se limiterait aux denrées permises.

Les Commissaires, observant scrupuleusement les instructions de l'Assemblée Nationale, n'autorisèrent que 1'entrepôt à la Trinité et l'ouverture de Fort-Royal, même en dehors de l'hivernage. Peut-être espéraient-ils que le chevalier, satisfait par la création d'un entrepôt sur le lieu de ses propriétés et de celles de sa famille, n'en demanderait pas davantage. Mais Du Buc avait une vue trop haute des évé- 
nements pour borner son ambition à ses intérêts personnels, encore qu'ils ne négligeât pas ceux-ci. En qualité de président du comité des planteurs, il insista si bien sur la nécessité de donner un port aux habitants du Sud-Ouest, que les Commissaires finirent par céder et, le 1er juillet, rouvrirent Le Marin.

Afin de ne pas trop mécontenter les négociants de Saint-Pierre, ils les invitèrent à nommer quatre visiteurs inspecteurs aux frais de l'Etat ; ils représentèrent en même temps aux colons qu'une partie de leurs ventes devait servir à se libérer de leurs dettes. Palliatifs illusoires! Ulcérés, les gens de la place de commerce refusèrent insolemment le contrôle qu'on leur offrait. En revanche, les planteurs répondirent avec beaucoup d'honnêteté que c'était précisément dans le dessein de payer qu'ils s'étaient permis de réclamer l'un des moyens qui leur étaient nécessaires, - mais n'en versèrent pas une piastre de plus à leurs créanciers.

Le rôle de $\mathrm{M}$. de Béhague se réduisait insensiblement à celui de paravent légal du parti planteur; il s'en apercevait bien et en manifestait parfois de l'aigreur ; mais son inspiration personnelle ne le servait pas au-delà des mesures enseignées par la tradition. Les événements de France jetaient dans la perplexité son âme de fervent royaliste.

Quelle autorité représentait-il depuis que Louis XVI faisait figure de prisonnier de la Révolution : celle du souverain légitime ou celle de ce peuple qui se livrait contre ceux de sa caste aux pires menaces, sinon aux pires violences? D'autre part, il n'oubliait pas la mission positive que l'Assemblée Nationale lui avait confiée de veiller sur une colonie dont la possession importait essentiellement à l'économie de la France.

Le parti des planteurs était celui de l'ordre et de la légitimité ; M. de Béhague de par sa formation et ses attaches, devait nécessairement s'y rallier ; il eût désiré le dominer et l'amener à quelques concessions envers le commerce; il ne savait que regimber sous la conduite occulte mais irrésistible du chevalier Du Buc.

Les « patriotes » commencèrent à le considérer comme un traître ${ }^{46}$. Les planteurs, qui le jugeaient tout bas assommant, ne lui marchandaient pas les adresses de félicitations dès qu'ils avaient obtenu ce qu'ils voulaient. Ses fonctions lui va-

46 Ainsi s'explique peut-être l'étrange mention du Grand Larousse que j'ai citée plus haut en note. Voir aux Annexes le Procès-verbal dressé par l'équipage de la frégate l'Embuscade. 
laient encore le respect du plus grand nombre, et l'honnêteté de son caractère l'attachement de ses officiers.

Quant aux forces qu'il avait conservées il ne pouvait guère se fonder sur leur fidélité : les hommes de troupes et ceux des équipages, troublés par les " patriotes » qui leur reprochaient de trahir la Nation, et plus encore par les lettres de France qui leur envoyaient l'écho de ce blâme, se prenaient à douter de leur devoir. Un discours du Commissaire Mondenoix, où celui-ci avait pourtant dosé avec art les louanges et la menace, ne les persuada qu'à moitié. A chaque instant éclataient sur quelque point des révoltes que les officiers parvenaient tant bien que mal à réprimer.

Cependant l'infanterie de marine de $L$ 'Eole se refusa au débarquement de cent fusils que M. de Béhague envoyait à Sainte-Lucie, et l'équipage de L'Embuscade contraignit son commandant, M. d'Orléans, à faire voile pour la France 47.

Les milices étaient plus sûres... à condition que M. de Béhague gouvernât avec les planteurs.

Dès octobre 1791, les quatre commissaires, un peu désabusés, inclinaient à s'accommoder des résultats obtenus et à considérer leur mission comme terminée. La municipalité de Basse-Terre ranima leur zèle en les appelant à la Guadeloupe, où les «patriotes » se disaient victimes de la garnison de Fort Saint-Charles. Ils passèrent donc dans l'île voisine et se mirent en devoir d'y appliquer la recette apprise, dont le premier point consistait à dissoudre l'Assemblée Coloniale et les municipalités. Mais ils avaient compté sans M. de Clugny, lequel, violemment ému par l'évènement de Varennes, tenait pour fort suspects les envoyés d'un gouvernement capable de commettre un tel crime de lèse-majesté. Comme il estimait, en outre, que tout marchait à peu près bien dans son île, il trouvait hors de propos de renoncer à un état de choses relativement satisfaisant pour revenir au chaos. Il le dit tout net ; MM. de La Coste et Magnytôt le prirent très mal. Leurs collègues perdirent leur éloquence à essayer de leur démontrer que la première vertu d'un commissaire conciliateur est l'esprit de conciliation. Ainsi que l'avait observé Mme Roland, M. de La Coste en manquait complètement. Son « emportement dans la contradiction » lui suggéra sa première initiative : il prétendit remplacer M. de Clugny par M. d'Arrost. Magnytôt s'associa à cet acte d'autorité dont le

47 Voir aux Annexes. 
résultat fut que la Guadeloupe faillit rester sans gouverneur : car M. de Clugny résigna ses fonctions et $M$. d'Arrost se récusa.

MM. de La Coste et Magnytôt, grandement échauffés, requirent le Gouverneur général des îles du Vent de renvoyer en France les deux indociles. M. de Béhague répondit en ordonnant à $\mathrm{M}$. de Clugny de reprendre son poste et en lui infligeant vingt-quatre heures d'arrêts « pour s'être permis de suspendre ses fonctions sans l'autorisation de son chef militaire ».

Vexés, les deux conciliateurs s'avérèrent irréconciliables, ils repartirent à grand fracas pour la Martinique, et de là pour la métropole, après avoir disputé âprement les archives de la commission à MM. de Mondenoix et Linger, qui les conservèrent de haute lutte et continuèrent désormais seuls à s'acquitter de leur mission.

Ainsi, demeurait sans suite le succès momentané qu'avaient remporté les Saint-Pierrais en obtenant le rappel de M. de Damas, la dissolution de l'Assemblée Coloniale et l'intervention arbitrale de la métropole, traitant sur le pied d'égalité leurs organisations illégales et les institutions régulières.

Leurs exigences brouillonnes avaient élargi et consolidé leur position. Le chevalier Du Buc avait compris tout le tort que leur causerait une attitude indisciplinée. Il s'était exactement représenté la force qui, même en une période aussi troublée, réside dans l'autorité légale.

La supériorité de son intelligence, sa vue claire de l'essentiel avait fait le reste. Il avait fort bien discerné que les pouvoirs publics, en France, désiraient pardessus tout ne pas compliquer le souci quotidien que leur causaient les événements intérieurs par les préoccupations que pouvait leur donner une possession lointaine. Il avait deviné que, quels qu'ils fussent, les représentants de ces pouvoirs seraient portés à s'appuyer sur ceux qui facilitaient leur tâche. Il avait saisi cette vérité que l'ordre ne s'obtient jamais par le désordre.

Les planteurs, par leur modération, atteignaient leurs buts. La colonie était gouvernée suivant leurs voeux et au mieux de leurs intérêts, l'opposition vaincue, et le calme rétabli. 


\section{CHAPITRE V. RÉFÉRENCES :}

Instructions aux commissaires. 24 janv. 1791. Ministère Colonies Martinique, 275.

Compte-rendu de M. de Behague au ministre.

Lettres des commissaires au ministre.

Proclamations de M. de Behague et des commissaires.

Rapports des assemblées coloniales de la Martinique et de la Guadeloupe.

Rapports du Comité de Saint-Pierre.

Correspondance entre MM. de Behague et de Clugny.

Correspondance entre Lacoste et Mognytot d'une part, Linger et Mondenoix de l'autre.

Discours prononcé par James Eyma à l'Assemblée Nationale, etc...

Archives Nationales Dxxv 116 et Ministère des Colonies. Martinique, 271 et Martinique, 272.

MAY (Louis-Philippe) : «Le Mercier de la Rivière », Intendant des Isles du Vent ». Marcel Rivière, 1932. 


\section{La Révolution française à la Martinique}

Chapitre VI

\section{Remous de France}

$\underline{\text { Retour à la table des matières }}$

La Martinique ne pouvait cependant aspirer à demeurer à l'abri des troubles de plus en plus graves que commençaient à déchainer en France les progrès rapides, les déviations et l'égarement de l'esprit révolutionnaire.

De même que les effervescences de la masse solaire déterminent dans l'atmosphère terrestre les perturbations, les orages et les cyclones, de même les remous qui agitaient la Mère-Patrie ne pouvaient manquer d'avoir leurs répercussions dans sa lointaine colonie.

Du Buc, pilote véritable du frêle esquif dont il veut assurer le salut et la stabilité, s'efforcera cependant, fidèle à sa politique de souplesse et de modération, de tenir aussi longtemps qu'il le pourra sa route au milieu des éléments démontés.

Pour commencer, tout paraît aller assez bien.

Les deux commissaires restants continuent consciencieusement leur tâche, compliquée par les variations survenues dans les idées de l'Assemblée Constituante. Celle-ci vote deux lois nouvelles qu'ils ont charge de promulguer et de faire exécuter. C'est la question capitale de l'accession de la race réputée inférieure aux droits politiques qui va maintenant se poser d'une manière impérieuse et catégorique. 
La première de ces lois, du 15 mai 1791, rétablit les Assemblées Coloniales et en ouvre l'accès aux mulâtres nés de parents libres. La seconde, du 28 septembre, attribue aux Assemblées Coloniales la confection des lois concernant l'état des personnes non libres et l'état politique des hommes de couleur et nègres libres ainsi que les règlements relatifs à l'exécution de ces mêmes lois.

La Constituante, tiraillée en tous sens, inquiète de la surexcitation croissante des esprits à Saint-Domingue, harcelée par les Amis des Noirs, qui n'y voient d'autre remède que d'abolir l'esclavage et d'accorder l'égalité civile et politique intégrale aux opprimés, n'a plus l'air de savoir exactement ce qu'elle veut.

La loi du 15 mai 1791 est mal accueillie par les députés de la Martinique à Paris, Moreau de Saint-Méry et Arthur Dillon, qui se retirent en signe de protestation. Au moins, les commissaires restés dans lîlle auront-ils la sagesse de ne la mettre en vigueur que plusieurs mois plus tard, après avoir préparé les esprits, négocié et attendu le correctif de la loi subséquente du 28 septembre.

Mais à Saint-Domingue, où elle est immédiatement publiée, l'indignation éclate. Les planteurs, qu'une sagesse comparable à celle de Du Buc ne guide pas, s'exaspèrent, s'insurgent, se mettent en rébellion ouverte contre la France, et, par une conséquence naturelle de leurs excès, les mulâtres se dressent contre eux et font alliance avec les noirs. C'est cette circonstance qui fera tourner les événements, dans cette colonie, tout autrement qu'à la Martinique.

La Constituante tergiverse. Sa seconde loi, celle du 28 septembre, revient en arrière sans l'avouer expressément.

Au fond, le pouvoir métropolitain voudrait bien contenter tout le monde et ne plus entendre parler de ces querelles coloniales qu'il se sent mal à l'aise pour arbitrer. Il croit s'en tirer en disant, en substance : « En principe, les hommes de race noire peuvent être électeurs et éligibles ; mais, dans la pratique, que chaque possession s'arrange comme elle veut ».

Planche VIII. Terre des esclaves, terre de la liberté: arrivé là on ne recule pas. Voir Les Classiques des sciences sociales. 
Dans cette incertitude de la pensée directrice, le chevalier Du Buc devait donner une preuve nouvelle de sa pondération et de sa perspicacité.

On a vu déjà qu'il avait, en toutes circonstances, discerné l'importance prépondérante de l'élément de couleur, et qu'il en avait fait le soutien du parti planteur. Il comprenait fort justement que le service rendu valait quelques concessions, judicieusement dispensées. Il avait même pris les devants. D'où l'indignation des Saint-Pierrais, dont nous avons déjà vu tant de manifestations. Un «patriote » n'écrivait-il pas, en octobre 1790, à l'époque de la scission entre la ville et le gouvernement soutenu par la campagne : « Déjà, nous apprenons qu'au Gros Morne on a admis quelques mulâtres au Conseil » 48 .

Lors donc que se réunit à nouveau, le 12 décembre 1791, l'Assemblée Coloniale de la Martinique, où les planteurs étaient tout-puissants, comme dans les précédentes, elle adopta la proposition que lui faisait l'Assemblée Coloniale de la Guadeloupe, acquise aux mêmes tendances, de former un Comité général des Colonies ayant pour objet d'élaborer un statut des gens de couleur commun à toutes les petites Antilles françaises.

Ce Comité général des quatre colonies (Martinique, Guadeloupe, SainteLucie, Tabago), séant à Fort-Royal, accorda l'éligibilité aux quarterons ayant trois grands-parents blancs, et l'électorat aux mulâtres nés libres qui remplissaient les conditions exigées également pour les blancs.

La loi du 28 septembre, par ailleurs, portait amnistie générale pour les faits se rapportant à la Révolution. Les commissaires Mondenoix et Linger suspendirent donc les poursuites et rappelèrent les « patriotes » qui s'étaient exilés dans les îles anglaises.

Tout finissait par rentrer dans l'ordre. La Martinique semblait enfin au seuil d'une ère de tranquillité..

Mais, en France, la fièvre révolutionnaire montait. M. de La Coste, élevé à son tour à la dignité de Ministre de la Marine, n'oubliait pas sa rancune contre MM. de Béhague et de Clugny. Ce sera, cette fois, au tour de la France à gâter les choses.

48 Arch. Nat. Dxxv 118. 
Dès la fin de 1791, Crassous et Dugommier, délégués par Saint-Pierre à Paris, avaient réclamé hautement la destitution de $M$. de Béhague ainsi que l'envoi de nouveaux commissaires dont la fermeté d'opinions donnât apaisement aux «patriotes » derechef sacrifiés 49 .

Mais les préoccupations de l'Assemblée étaient ailleurs.

Ce ne fut que fin mars 1792 que les affaires coloniales purent être de nouveau évoquées. La Législative avait succédé à la Constituante. Les idées libérales avaient fait d'immenses progrès. Les Amis des Noirs trouvaient, pour écouter leurs revendications, des esprits moins hésitants. Les événements dont Saint-Domingue était le siège répandaient l'épouvante et la consternation dans les rangs de l'Assemblée.

Ils étaient en effet terrifiants.

La rébellion des planteurs contre l'autorité légale, dans leur haine démente de l'élément si longtemps tenu en servitude, avait, je l'ai dit, entraîné la révolte des mulâtres et leur alliance avec les noirs. Le 23 août 1791, les hommes de couleur et les esclaves marrons se réunirent aux environs de Cap Français (aujourd'hui Cap Haïtien) et bientôt ce fut l'insurrection généralisée.

La confusion était inimaginable. Une grande partie des noirs s'était soulevée au nom de Louis XVI, et sur l'appel des prêtres. Ils se disaient « Gens du Roi » et se dressaient contre les autorités constitutionnelles. Comme il arrive toujours en un tel tumulte, les sentiments élémentaires et les intérêts irraisonnés avaient vite pris le dessus. La lutte eut le caractère d'une guerre d'extermination entre races. Les noirs, dans les campagnes, égorgeaient les blancs isolés. Ceux-ci se vengeaient en d'impitoyables représailles aux alentours des villes. De part et d'autre, d'effroyables atrocités étaient commises. Ces carnages ne pouvaient que fatalement tourner au désastre pour les blancs, qui étaient à peine 1 contre 10 .

La Législative, éperdue, se figura qu'elle apaiserait les passions en faisant disparaître leur raison apparente. Elle crut donc bien faire en se rangeant à l'avis du ministre de la Marine et en abolissant les distinctions observées par la Constituante. Le 4 avril 1792, elle promulgua une loi qui élevait au rang de citoyen tout homme de couleur libre, quelle que fût son origine.

49 Discours du 7 décembre. Arch. Nat. AD VII 28. 
En vain, les membres du club de Massiac avaient-ils présenté des objections ${ }^{50}$. Le ministre tenait à son texte. Il rappela, fin avril 1792, les commissaires restés à la Martinique. Linger et Mondenoix ${ }^{51}$. Il annonça lui-même à M. de Béhague la nouvelle loi et les nouveaux commissaires chargés de la faire appliquer, dénombrant avec complaisance dans sa dépêche les forces destinées à assurer le succès de leur mission ${ }^{52}$.

Les commissaires (Leroy de Fontigny, la Marre et Girault) sont investis de plus grands pouvoirs encore que leurs prédécesseurs afin d'être en mesure de ramener le calme dans les esprits et d'opérer une pacification complète. « Le but principal de la loi dont l'exécution leur est confiée, écrit le ministre, est d'attaquer un préjugé perpétué dans les colonies et qui pourrait devenir fatal à qui prétendrait le maintenir... » "Sa Majesté se plaît à penser que les habitants des îles du Vent, éclairés sur leurs vrais intérêts, se détermineront sans peine au sacrifice que leur prescrit la Loi afin d'éviter les fléaux qui frappent Saint-Domingue ».

On présume également que «l'égalité des droits politiques qui est accordée aux hommes de couleur libres » n'y sera point une occasion de troubles, «mais qu'ils se livreront tous à la douceur d'une réunion franche et sincère qui doit être pour eux une nouvelle source de richesses et d'abondance. L'intérêt le commande ; la Patrie l'ordonne ; la Loi, la Nation, le Roi le veulent !».

Assurément, l'intention était généreuse. Mais c'est toujours une erreur, pour l'autorité, de paraître avoir la main forcée et d'annuler l'effet de sa bienveillance par les dehors de la faiblesse. Elle doit savoir prévoir les concessions inévitables et les décider en devançant les événements ; elle peut ainsi sérier les réformes, les mesurer suivant l'opportunité, les rendre acceptables pour les opposants et en conserver tout le bénéfice moral vis-à-vis de ceux qui les réclamaient. Les initiatives brusques décidées sous la pression des circonstances sont rarement interprétés autrement que comme une capitulation qui surexcite les appétits qu'on veut calmer. Et il ne suffit point d'invoquer les droits de l'autorité souveraine pour les faire respecter : c'est par la sagesse des actes et non par la grandiloquence des mots que celle-ci sauvegarde son prestige et obtient l'obéissance à ses ordres.

\footnotetext{
50 Voir aux Annexes.

51 Linger venait tout justement de succomber au climat.

52 Lettre en date du 17 avril 1792. Min. Col. Martinique, 227.
} 
A Saint-Domingue, le geste de la Législative fut d'un effet nul pour apaiser les troubles, ramener l'ordre et la paix, sauver la colonie.

Heureusement, à la Martinique, les choses n'en étaient pas à un état aussi critique, et Du Buc veillait.

Le ministre, plein de l'optimisme que lui inspirait la satisfaction de soi-même, avait prophétisé, dans ses instructions aux nouveaux commissaires, la marche des événements.

Dès leur arrivée, ils devront faire procéder à la réélection des assemblées et des municipalités. Ils veilleront à ce que les hommes de couleur et nègres libres puissent voter et soient éligibles. Ils prendront toutes les mesures nécessaires à cet effet. Pour la première fois dans l'histoire du monde, l'égalité des blancs et des noirs deviendra une réalité.

Les nouvelles assemblées feront connaître leurs voeux sur l'administration et l'organisation des colonies. mais tout contact entre elles et les commissaires est rigoureusement interdit; ceux-ci «s'occuperont essentiellement des moyens de maintenir la confiance, la confraternité, la sûreté publique et privée, le travail et la soumission dans les ateliers ».

L'heure de l'émancipation totale, on le voit, n'avait pas encore sonné.

« La volonté nationale une fois connue, blancs, hommes de couleur, tout doit fléchir devant elle! Plus de préjugés ! Plus de passions! Plus de partis ! Des Français ne résisteront pas à la loi, mais pour prévoir l'impossible, « afin d'étouffer jusqu'aux murmures de l'obéissance » une force armée de 13 à 14.000 hommes, commandés par Rochambeau, est dirigée sur les îles du Vent, Toutefois, « la plus puissante de toutes les armes est sans doute la loi même et le développement de ses motifs ». Il faudra donc, avant tout, " persuader »; les événements de Saint-Domingue fourniront des arguments péremptoires.

Les planteurs de la Martinique trouvèrent justement que les événements de Saint-Domingue fournissaient des arguments péremptoires contre les mesures prises par la métropole. 
Ils connurent ces mesures fin mai par une lettre de M. de La Coste. Celui-ci trouvant de bonne guerre de faire porter le premier coup par les Gouverneurs en fonctions, ordonnait que la loi nouvelle fût publiée et exécutée tout de suite.

Les planteurs, outre les raisons personnelles qu'ils avaient de juger impolitique la décision prise par la métropole, commençaient à estimer qu'elle abusait de son droit souverain de changer d'avis et de modifier à tout propos, et même hors de propos, une loi par une nouvelle : tant il est vrai que la stabilité est, en politique, le premier des biens et la règle fondamentale d'un bon gouvernement.

Ils furent toutefois assez avisés pour s'incliner et, selon la méthode chère à Du Buc, pour chercher dans les textes nouveaux les moyens de maintenir leur ligne de conduite. La loi du 28 septembre les leur fournissait.

L'Assemblée Coloniale se forme. Elle s'intitule « Assemblée Constituante déléguée de la Martinique » - caractère que M. de Béhague essaie timidement de lui dénier.

Considérant qu'elle possède le droit de légiférer sur l'état des gens de couleur « droit infiniment précieux à raison de l'affection qu'elle porte à cette classe qui a bien mérité de la colonie », elle déclare le 3 juin : «Que les hommes de couleur et nègres libres de la Martinique jouiront des mêmes droits politiques que les colons blancs de cette île et qu'elle étend à cette classe l'article 4 des Instructions de l'Assemblée Nationale Constituante du 28 mars 1790 ».

Bien mieux, « l'Assemblée s'occupera des moyens d'assurer aux gens de couleur et nègres libres quelques avantages qu'il était dans ses intentions de leur accorder et qui ne se trouvent pas compris dans les dispositions de la loi ».

Mais, pour les troupes, elle n'en veut sous aucun prétexte. Sa méfiance est compréhensible : depuis le 1er septembre 1790, l'Assemblée, le Gouverneur, les officiers de terre et de mer sont continuellement alertés par des révoltes partielles de soldats et de marins gagnés aux idées révolutionnaires.

Le 31 mai 1792, comme pour fortifier le parti planteur dans sa décision, le régiment de Turenne, jusque-là le plus fidèle avec celui des grenadiers, se mutine à son tour, fait entendre « des cris respectifs et réitérés » et régale son colonel, $\mathrm{M}$. de Fressinaux, de cette aimable chansonnette : 
« Ça ira, ça ira, Fressinaux !

Tout soldat bientôt

Te servira de bourreau !»

Le Comité intermédiaire a répondu dès le 26 mai à M. de Béhague qui lui notifiait l'envoi de troupes décidé par la métropole : «Les dispositions favorables des colons de la Martinique pour les gens de couleur libres vous sont trop connues pour que vous ne sentiez pas l'inutilité des forces qu'on nous annonce et qui se trouveraient beaucoup mieux dirigées si elles étaient réunies à celles que la position désastreuse de la colonie de Saint-Domingue exige ». On ne pouvait signifier d'une façon plus nette et plus décente que la métropole devait réserver ses moyens pour les situations rendues désespérées par ses initiatives inconsidérées, et laisser les planteurs de la Martinique, plus avisés, arranger seuls leurs affaires comme ils l'avaient assez sagement fait jusque-là.

L'Assemblée Coloniale, disait cette lettre en terminant, avait arrêté, en conséquence, « que le gouverneur serait prié de mettre cette vérité dans toute son évidence sous les yeux du Roi ».

M. de Béhague ne demandait pas autre chose. Il écrit, à son tour, dans le même sens à $\mathrm{M}$. de La Coste, et la similitude des styles donne à penser que le chevalier Du Buc n'était pas étranger à la rédaction de sa dépêche, habile et fortement motivée.

Le Gouverneur ne manquait pas de rappeler que le Ministre, au temps où il était lui-même commissaire à la Martinique, l'avait, en cette qualité, requis de renvoyer les troupes : était-ce pour lui en réexpédier maintenant?

M. de Clugny, d'autre part, proposait à M. de Béhague de faire immédiatement procéder aux nouvelles élections, dans les deux îles, suivant les instructions données par Paris: de cette façon, disait-il, les nouveaux commissaires, à leur arrivée, trouveraient tout organisé. Il était bien clair que c'était le moyen d'enlever toute utilité à leur mission. M. de Béhague répondit naturellement qu'il partageait l'avis de son subordonné. 
Les patriotes, eux, sont une fois de plus pleins d'espoir dans ces nouveaux commissaires de France qui seront peut-être enfin de vrais républicains. Ils ont bien changé depuis les jours, pourtant récents, où ils criaient haro! sur la couleur. Les gros commerçants de Saint-Pierre, en correspondance régulière avec ceux des ports français, ont évolué dans le même sens que les gens de la métropole ; ils comprennent surtout quelle force utile représentent ces mulâtres. Ne pouvant nier la bonne volonté que témoignent les planteurs à l'égard de ceux-ci, ils font de la surenchère.

Voici ce qu'écrivaient, le 17 avril 1792, MM. Ruste et de Corio, commissaires de Saint-Pierre, aux délégués de la ville à Paris : «Il semble que la faction qui dirige les Assemblées Coloniales du Vent réunies, avait un pressentiment secret des dispositions favorables aux gens de couleur de la part de la Législative... Dans le travail que le Comité général des quatre colonies séant à Fort-Royal vient d'achever, la majeure partie des dispositions du décret du 15 mai y sont consacrées avec cette différence qu'en accordant l'activité à la classe, on tire une ligne de démarcation sur la nuance, de manière que tout nègre et câpre 53 libre ou ayant la nuance du câpre ne peut être admis quoiqu'il réunisse les conditions exigées à la qualité de citoyen actif accordée aux autres nuances qui réunissent les conditions prescrites. Quant à l'éligibilité, elle ne commence qu'aux issus de ceux dont la nuance est connue sous le terme de mamalous ».

Où est le temps où les mêmes dressaient leur fougueux réquisitoire contre $\mathrm{M}$. de Vioménil ?

« Il a publié lui-même, l'épée à la main, à la tête de ses troupes, qu'il fallait regarder les mulâtres comme citoyens, comme confrères et faire société avec eux... Ce n'est pas l'opinion seule qui est blessée par là, c'est aux ordres précis du Roi que M. de Vioménil a contrevenu. Ils établissent la distinction des couleurs et déclarent même déchus de la noblesse ceux qui feraient alliance avec les noirs ».

Il ne faut pas se montrer surpris de ces inconséquences. N'est-il pas constant que les hommes portés au pouvoir par la prédominance de leur parti, après y avoir appliqué des idées fausses, sont souvent chargés d'en redresser les conséquences

53 Les expressions de "câpres » et de «mamalous », employées dans cette lettre, s'appliquent aux quarterons et autres « sang mêlé » selon la prédominance de l'élément noir ou de l'élément blanc dans leur ascendance. 
lorsque les événements ont tourné contre leurs doctrines ? Nul à ce moment ne songe à rendre justice aux clairvoyants. On persiste à les traiter en opposants. Et les aveugles de la veille, loin de déplorer leur cécité, affirment avec l'aisance que donne l'inconscience que jamais leur perspicacité ne s'est trouvée en défaut, l'intransigeance ou les machinations de leurs adversaires ayant été les seules causes de leurs erreurs.

Régulièrement, celui qu'on charge de mettre en œuvre les conceptions que les réalités obligent à reconnaître justes, n'est pas celui qui les a toujours soutenues, mais celui qui les combattait auparavant.

Les « patriotes » de Saint-Pierre n'éprouvent donc aucun embarras de leur palinodie. Ils crient à tue-tête qu'ils nourrissent à l'égard des mulâtres et ont toujours nourri les plus tendres sentiments. Si leurs frères de couleur ont pu en douter, c'est qu'ils étaient abusés par les basses intrigues et les mensonges des planteurs.

Et pour donner une preuve de l'ardeur de leur libéralisme ils s'indignent que la loi du 4 avril 1792 n'ait pas été envoyée, dès sa réception dans la colonie, à la sénéchaussée de Saint-Pierre pour y être enregistrée, promulguée et appliquée le jour même. Ils protestent contre ce retard qu'ils attribuent à une intention ténébreuse de l'autorité : «C'est encore, disent-ils, pour faire croire que nous y sommes opposés ».

M. de Béhague leur répond que leurs doléances sont mal fondées, leur agitation insupportable, qu'il a fait les diligences voulues et que la loi a été affichée en temps normal.

M. de Mondenoix, le seul des quatre commissaires envoyés par la Constituante qui ait pu accomplir sa mission jusqu'au jour de son rappel en France, s'efforce, dès son arrivée à Lorient, d'éclairer le gouvernement sur le véritable esprit qui règne dans la colonie. Il ne laisse aucune illusion sur l'accueil qui attend la nouvelle expédition : les planteurs jugent indésirables autant qu'inutiles les corps de volontaires annoncés, et certes « une des premières propositions qui seront faites sera de faire filer les troupes sur Saint-Domingue... Il y sera insisté très fortement » 54 .

54 Mondenoix au ministre, 3 août 1792. Arch. Nat. Dxxv 116. 
M. de Mondenoix ne se trompe pas.

Les planteurs, renseignés par leurs correspondants de Paris sur les progrès de la poussée révolutionnaire en France, commencent à considérer que le pouvoir central est aux mains d'usurpateurs et d'insurgés. Hommes d'ordre, attachés aux institutions anciennes qui représentent à leurs yeux la forme légale du gouvernement, ils ont témoigné la plus respectueuse déférence aux instructions venues de la capitale, tant qu'ils ont pu croire que rien n'était changé profondément dans l'organisation de l'Etat et que l'autorité royale condescendait à faire, à côté d'elle et sans abandonner ses prérogatives essentielles, une place aux corps élus : ils avaient partagé ainsi les idées des libéraux de l'ancien régime, et trouvé toutes naturelles des concessions depuis longtemps attendues et favorables à leurs intérêts. Mais maintenant, ils se rendent compte que le but est dépassé et que les événements prennent un tour beaucoup plus grave, bouleversant les fondements de l'antique société française. D'instinct, ils se refusent à y voir autre chose que des désordres passagers. Ils ont la plus grande méfiance contre les forces nationales qu'on leur envoie, et que leurs informateurs de la métropole leur ont dépeintes comme un ramassis d'émeutiers, de brigands et de pillards.

Ils prennent leurs dispositions en conséquence. Ils se savent assurés du concours de la marine royale dont tous les officiers sont, par leur origine et leurs convictions, partisans de l'ancien régime. Sous le prétexte que la France est en guerre avec la Hongrie, ils font armer les batteries de Fort-Royal et rassemblent toutes leurs forces.

En France, les événements se précipitent.

La majesté royale avait été déclarée déchue dans cette séance tragique de l'Assemblée Nationale à laquelle Louis XVI assistait, caché dans la loge du logographe où il s'était réfugié après l'invasion des Tuileries par la Commune de Paris.

L'émigration avait commencé.

Dès lors, tout est interprété à la Martinique comme annonçant la montée irrésistible du désordre et la toute-puissance prochaine de « la canaille ». On est à une heure où les convictions vacillent et où l'on ne discerne plus très bien où est le véritable devoir. La patrie se dédouble. A qui est due la fidélité ? 
A la France du passé, identifiée avec ses institutions séculaires et toujours entourée d'un prestige que les vociférations d'émeutiers sortis on ne sait d'où ne sauraient faire oublier ? Ou à la France nouvelle, au visage inquiétant, qui va peutêtre s'effondrer dans la boue et le sang ?

Ne soyons pas surpris que les grands propriétaires coloniaux, aristocrates par la naissance, par l'éducation, par toutes leurs relations, aient incliné vers la première.

Quel beau rôle, en outre, quel titre plus tard à la faveur du maître, pour les colonies des Antilles, d'être demeurées seules fidèles, parmi des provinces si nombreuses, au milieu de la tourmente passagère !

N'apprenait-on pas, d'autre part, qu'à Paris on parlait fort d'un système nouveau qui consisterait à donner l'indépendance à celles des colonies où il faudrait renoncer à faire prévaloir les idées de liberté et d'égalité pour lesquelles s'enthousiasmait la Mère-Patrie ${ }^{55}$. Dès lors, quel reproche pourrait-on faire à celles qui, fidèles au passé, s'organiseraient en vue de cette autonomie ?

Au début de septembre, les planteurs se réunissent et délibèrent en secret sur les moyens de demeurer en liaison avec le pouvoir légitime, ou tout au moins avec ceux qui se donnaient mission, hors de France, de le rétablir dans la plénitude de ses droits et de ses attributions.

Dans l'entourage des Frères du Roi, les esprits n'étaient pas moins préparés à une coopération avec les habitants de la Martinique. Plus d'un grand seigneur de la cour se trouvait lié par ses alliances à cette colonie ou à Saint-Domingue et en tirait personnellement des ressources importantes. Dans le dénuement qu'ils connaissaient en Allemagne et en Grande-Bretagne, ils devaient nécessairement songer aux richesses que pouvaient leur procurer encore les îles à sucre et en particulier la Martinique. " la meilleure et la plus riche colonie qu'eût la France », ainsi que l'avait écrit Voltaire. Leur pensée se rencontrait donc à travers les mers avec celle des planteurs - si les Antilles devaient former un Etat autonome, il était naturel qu'elles le constituassent sous l'égide des Princes. Cette rêverie trouva

55 Lettre du 12 septembre 1792 de Lacaze à l'Assemblée de la Guadeloupe. Ministère Colonies, Guadeloupe, 416. 
pour défenseurs deux émigrés de marque : l'ancien ministre de la Marine et des Colonies, le maréchal de Castries, réfugié à Londres, et, plus près de la personne des comtes de Provence et d'Artois, le célèbre marquis de Bouillé 56 qui avait été pendant six ans, de 1777 à 1783, Gouverneur de la Martinique.

A Londres s'étaient retrouvés aussi bon nombre des habitués de l'Hôtel de Massiac, notamment les trois députés des îles, M. de Curt (Guadeloupe), le chevalier de Perpigna (Martinique) et Malouet (Saint-Domingue).

Le premier surtout, par ses relations personnelles avec l'aristocratie anglaise et son crédit financier, devait servir d'introducteur dans les cercles les plus fermés, aussi bien que de banquier pour tout ce qui avait un nom dans les milieux de l'émigration. La fortune dont il faisait encore étalage, alors que les plus puissantes familles étaient réduites à vivre d'expédients, devait éveiller de profitables réflexions sur l'utilité des colonies des Indes Occidentales.

Désormais, le parti des planteurs est pris. Ils savent ce qu'ils veulent, et surtout ce qu'ils ne veulent pas. Ils iront jusqu'à la sécession s'il le faut, pour épargner à leur petite patrie les convulsions, les misères et bientôt les horreurs qui désolent et déchireront la grande. Mais c'est encore et toujours la France qu'ils veulent faire renaître, fût-ce hors de son antique domaine.

Quant à M. de Béhague, plus hésitant et plus timoré que jamais, il voudrait bien s'en aller.

Dès le mois de juin, il a profité d'une adresse de félicitations qui lui a été faite par l'Assemblée Coloniale pour supplier Sa Majesté «si elle était aussi contente de ses services que la Martinique paraissait l'être, de lui accorder pour récompense la permission de quitter cette colonie ».

Cette unité de vues entre les successifs gouverneurs de la Martinique est vraiment touchante.

Et maintenant que Louis XVI est prisonnier et que Rochambeau arrive avec ses « brigands », le général de Béhague ne sait plus que s'en remettre à Dieu et au hasard.

56 Il s'agit du célèbre marquis de Bouillé qui prépara la fuite du Roi. 


\section{CHAPITRE VI. RÉFÉRENCES :}

Lettres de Linger et Mondenoix au ministre. Ministère Colonies Martinique, 271.

Lettre des commissaires de commerce aux députés de Saint-Pierre auprès de l'Assemblée Nationale. Ministère Colonies Martinique, 274.

Délibération de l'Assemblée Coloniale de la Guadeloupe du 21 déc. 1791. Ministère Colonies. Guadeloupe, 416.

Discours des députés de Saint-Pierre à l'Assemblée Nationale. 7 déc. 1791. Arch. Nat. A. D. vii, 23.

Correspondance entre M. de La Coste, ministre de la Marine, et M. de Behague. Ministère Colonies Martinique, 277.

Instructions aux nouveaux commissaires. 17 juin 1792. Ministère Colonies Martinique, 273.

Délibération de l'Assemblée Coloniale de la Martinique du 3 juin 1792. Ministère Colonies. Martinique, 274.

Correspondance entre M. de Behague et M. de Clugny. Min. Col. Martinique, 274.

Lettres des commissaires de Saint-Pierre, 6 juin 1792. Min. Col. Martinique, 273.

Lettre de M. de Mondenoix au ministre. 3 août 1792. Arch. Nat. Dxxv 116.

Proclamation de M. de Behague du 14 sept. 1792 «pour inviter au calme les colons qui ont mal interprété l'ordre d'armer les batteries du Fort Royal ». Min. Col. Martinique, 273.

Lettre de Lacaze à l'assemblée de la Guadeloupe. Min. Col. Guadeloupe, 416.

Copies de pièces se référant au procès de $M$. de Behague subi par devant « Monsieur » en 1798. Ministère Colonies Martinique, 277. 


\section{La Révolution française à la Martinique}

Chapitre VII

\section{La Rébellion}

Retour à la table des matières

Il y avait bientôt quatre mois que M. de Béhague avait reçu de M. de La Coste le texte de la loi du 4 avril et la lettre lui annonçant de nouveaux commissaires escortés de troupes nombreuses.

Le 16 septembre, vers la fin de l'après-midi, l'Assemblée Coloniale tenait une de ces séances fiévreuses où l'imminence de graves éventualités attirait le Gouverneur et les officiers de la Marine royale, lorsque quelqu'un vint l'avertir qu'on apercevait une escadre au large.

« Messieurs... », commença faiblement M. de Behague désemparé.

Cela fit comme un bourdonnement de mouche dans le silence. Tous les regards étaient fixés sur le vrai chef de la colonie. L.-F. Du Buc.

«Monsieur de Rivière, dit celui-ci, vous plairait-il d'envoyer l'un de vos officiers dénombrer les forces révolutionnaires ? ».

M. Daché, commandant en second, partit, et l'angoisse régna, étouffant les voix, crispant les doigts aux dentelles des jabots.

Au bout d'un moment qui parut long, M. Daché revint avec un visage soucieux que justifièrent ces paroles : «Le convoi est encore trop loin pour qu'on 
puisse aisément reconnaître la nature de ces bâtiments, mais il m'a paru compter au moins trois vaisseaux de guerre ».

L'annonce de ces trois vaisseaux tomba lourdement sur l'Assemblée. La Station navale ne pouvait leur opposer que le vaisseau La Ferme, la frégate $\mathrm{La} C \mathrm{Ca}$ lypso, la corvette Maréchal de Castries et quelques unités de moindre importance. Ne valait-il pas mieux céder ? M. de Béhague le pensait visiblement, presque soulagé de ce que le sort eût décidé à sa place. Il est vrai que M. de Mallevaut, commandant de La Calypso, jurait par tous les saints du paradis et même par tous les diables de l'enfer qu'il se chargeait à lui seul d'envoyer par le fond ces brigands, lesquels avaient vraisemblablement volé leurs bâtiments et en connaissaient mal la manoeuvre. Mais M. de Rivière, qu'on savait tout aussi déterminé et plus rassis, hochait la tête, et Du Buc, sombre, se taisait... La résignation s'insinuait à petit bruit dans tous les coeurs.

Tout à coup, M. Daché, dont personne n'avait remarqué la seconde absence, reparut, et l'on vit à son air qu'il apportait de meilleures nouvelles.

« Excusez-moi, Messieurs, dit-il, j'avais mal vu. Ils ont seulement une frégate et une flûte ; le reste n'est que navires de transport ».

Un envol d'exclamations joyeuses passa dans la salle. A la tribune présidentielle, Du Buc avait dressé son long corps vigoureux. Il calma le tumulte d'un geste. On n'avait pas de temps à perdre. Il fallait envoyer une députation aux commissaires, les amuser jusqu'au matin, et préparer la défense dans la nuit.

« Messieurs, s'écria M. de Béhague, avez-vous bien réfléchi ? Certes, je suis aussi fervent royaliste que vous pouvez l'être, mais nous rebeller contre la France... !

« - Nous ne nous rebellons point contre la France, Monsieur, répartit Du Buc ; nous refusons d'obéir à des scélérats qui ont usurpé le pouvoir et porté une main criminelle sur notre souverain légitime. La présence auprès de nous de Messieurs les officiers de la Marine Royale doit vous être une garantie de la justice de notre cause. Cependant, nous respectons vos scrupules et comme ils pourraient être pour nous une cause d'embarras, nous vous prions respectueusement de bien vouloir attendre la fin de cette affaire dans un appartement que nous vous avons réservé au Fort Saint-Louis. Dès que nous aurons repoussé ces brigands, nous vous 
rendrons les hautes fonctions que Sa Majesté vous a confiées et que vous exercez avec tant de bonheur pour e plus grand bien de la colonie ».

M. de Béhague haïssait fort l'autorité. et l'impertinence polie du chevalier ; mais il ne pouvait méconnaître l'intérêt qu'offrait pour sa sauvegarde personnelle un emprisonnement de quelques jours. Il se laissa faire et le plan de L.-F. Du Buc fut suivi de point en point.

A peine les bâtiments de l'expédition furent-ils entrés dans la rade de FortRoyal que les forts tirèrent le canon d'alarme, tandis que l'aviso Le Ballon se détachait du port. Trois députés y avaient pris place qui venaient assurer aux commissaires que la volonté exprimée par l'Assemblée Législative au sujet des droits politiques des hommes de couleur libres avait été obéie. Ils en montrèrent pour preuve une copie de l'arrêté du 3 juin. Ils remirent en même temps une lettre du Comité intermédiaire invitant les délégués de la métropole à « venir voir par leurs propres yeux », mais à venir seuls, après avoir donné. à leur convoi l'ordre d'aller mouiller à l'Islet aux Ramiers. Les commissaires voulurent en référer à Rochambeau ; les députés feignirent de tomber des nues : ils n'attendaient pas un nouveau Gouverneur! Après toutes les salutations d'usage, ils exprimèrent à nouveau leur désir de voir s'éloigner les forces navales.

« Je jugerai de ce que j'ai à faire lorsque je serai installé dans mon nouveau poste, répondit Rochambeau ; d'ici là, vous devez sentir, Messieurs, qu'il m'est impossible de prendre aucune décision ».

Il était superflu d'insister. D'ailleurs, les pourparlers avaient assez duré pour que la nuit fût close et les députés n'en souhaitaient pas davantage : ils pouvaient regagner la terre, les nouveaux venus ne songeraient pas à débarquer avant le lendemain.

Cependant, une chaloupe de La Sémillante accosta le quai peu de temps après leur aviso. Elle amenait M. de Dancourt, aide de camp de Rochambeau et porteur d'une lettre pour M. de Béhague.

Renseigné par tous avec plus de bonne grâce que d'exactitude, M. de Dancourt se promena une partie de la nuit du Gouvernement au Conseil, du Conseil au Fort 
Bourbon, du Fort Bourbon au Gouvernement. Finalement, on lui conseilla le repos et, pour l'y décider, on le mit en état d'arrestation.

A 8 h. 1/2, il fut relâché et put regagner son bord. Il rapportait au Général sa lettre que personne n'avait voulu recevoir, et l'avis que toute communication était interrompue avec la terre et toute descente interdite. « Au surplus, ajouta-t-il, je dois reconnaître que j'ai été traité avec toute la politesse propre à un peuple civilisé et extrêmement sensible ».

Rochambeau, le sourcil froncé, écoutait encore son aide de camp lorsque $\mathrm{M}$. de Bruix, commandant de La Sémillante, vit venir à lui la frégate La Calypso et s'entendit héler par M. de Mallevault :

— « Oh du bâtiment !

— Oh là ! répondit-il.

— N'est-ce pas vous qui commandez le convoi ?

— Oui Monsieur.

- L'Assemblée Coloniale me charge de vous faire savoir que la colonie vous considère comme un ennemi et vous enjoint de quitter ses parages sur le champ...

- Mais Monsieur...

—...Et je vous fais observer que le vaisseau La Ferme me suit ».

Le commandant de Bruix comprit et mit les voiles. Le Général, dont la souplesse n'était pas la qualité dominante, dut endurer le départ hâtif de son convoi dans une rumeur moqueuse faite du même mot indéfiniment répété par les côtes et la rade : « Adieu !... Adieu !... Adieu !... ».

Non contents de s'être armés pour les empêcher de débarquer, les hommes de couleur libres persiflaient ceux qui leur apportaient l'Egalité ! «Quel vaste champ pour de douloureuses réflexions !» soupirait Rochambeau.

Il en avait cependant de plus pressantes à faire. A quelle île devait-il se rendre ? Il opta pour la Guadeloupe, changea d'avis, perdit son convoi pourchassé par la Marine Royale, le retrouva et aborda enfin à Saint-Domingue, au Cap Français. C'était le lieu que les colons de la Martinique avaient, naguère, signalé à la métropole comme le seul où ses troupes fussent nécessaires. 
Le Général avait été heureusement inspiré en renonçant à tenter un débarquement à la Guadeloupe. L'escadre royale l'avait précédé à Basse-Terre, où ses équipages aidaient à embarquer les "patriotes » de cette ville. Dès lors que Sa Majesté était déchue, enfermée au Temple, les officiers de sa marine n'avaient plus rien à ménager. Ils reprirent le pavillon blanc. M. de Mallevaut s'y montra le plus enragé. Ni le risque de perdre sa grande fortune ni celui de compromettre une famille chère ne purent le retenir : il fit brûler sur sa Calypso pavillons et flammes tricolores et clouer la cocarde au carreau. Il alla ensuite enlever aux Anglais la flûte $L a$ Bienvenue qui, séparée du convoi de Rochambeau, s'était réfugiée à Saint-Christophe, et revint triomphant auprès des Martiniquais. Ceux-ci, voyant l'orage écarté, « rendirent la liberté à $\mathrm{M}$. de Béhague et lui abandonnèrent comme ci-devant les rênes du gouvernement ».

Comme ci-devant, en effet, M. de Béhague tint les rênes et Du Buc conduisit le char. L'interprétation optimiste des nouvelles de France exaltait chez les colons une audace déjà affermie par le succès : la Révolution, se disait-on joyeusement, était aux abois ; ses jours étaient comptés ; les coalisés marchaient sur Paris qui tremblait sous le manifeste que le 25 juillet Brunswick lui avait jeté à la face ; le moment de la restauration du pouvoir légitime était venu.

Le Comité intermédiaire somma M. de Béhague de reprendre la couleur du Roi. Le Gouverneur qui, intérieurement, le souhaitait fort, représenta pourtant non sans bon sens - que «prendre le pavillon blanc avant de s'assurer de l'île de Sainte-Lucie, déjà en insurrection, serait faire de cette colonie la place d'armes du parti républicain, serait indiquer aux bâtiments d'Europe sous pavillon tricolore d'y porter leurs produits et leurs forces, tandis, qu'attirés à la Martinique par l'uniformité des couleurs, ils continueraient à venir dans ses rades d'où, une fois rangés sous le feu de ses batteries, ils ne pourraient s'échapper ».

Mais l'enthousiasme ne s'embarrasse pas de tant d'habileté. Au cours d'un dîner offert par le Comité au Gouverneur, une foule de personnes de toutes classes se précipita en tumulte dans la salle du banquet, couvrant de cocardes blanches la tête des convives, et le pavillon fut aussitôt hissé au mât de la citadelle avec l'accompagnement traditionnel du canon. On en profita, comme il convenait, pour 
festoyer, illuminer et danser. La joie était quasiment unanime car les « patriotes », par crainte de la déportation, s'étaient, pour la plupart, déportés eux-mêmes, et les mulâtres avaient reçu la preuve que l'Assemblée Coloniale ne tiendrait pas pour lettre morte l'arrêté du 3 juin.

Le 5 octobre, en effet, à propos de la réunion imminente des Assemblées primaires en vue de l'élection des députés à la nouvelle Assemblée Coloniale, elle avait décrété que « les gens de couleur et nègres libres qui réuniraient les qualités requises par l'article 4 des Instructions de la Constituante du 28 mars 1790 seraient admis dans ces Assemblées et y exerceraient tous les droits des citoyens actifs ».

Maîtres chez eux, les grands planteurs ne se montrèrent pas aussi fermés qu'on l'a dit aux idées libérales. Ils restaient d'ailleurs reconnaissants aux auxiliaires qui avaient, à plusieurs reprises, fait triompher leur cause. Le chevalier Du Buc était trop intelligent pour verser dans l'esprit de réaction, qui est bien, à l'égal de l'esprit de révolution et même davantage, ce qu'il y a de plus opposé, à l'esprit de conservation.

Lui reprocherons-nous de ne pas avoir été républicain en 1792 ? Ce serait mal se représenter l'angle sous lequel il devait normalement considérer les événements de l'époque et exiger de lui un don de prescience, une vision illuminée de l'avenir que le rationalisme même de son caractère excluait.

Le Comité intermédiaire adressa une circulaire aux armateurs et négociants des ports de France pour les assurer qu'il veillerait toujours aux intérêts du commerce, fort éprouvé sans doute par les désordres de Saint-Domingue et, dans un bel élan sentimental, l'Assemblée Coloniale tout entière signa une adresse an Roi où l'on pouvait lire cette solennelle protestation de dévouement :

« Nous avons su que, mettant le comble à leurs atrocités, les factieux qui perdent le royaume avaient osé Vous suspendre dans l'exercice de l'autorité royale, substituer à cette autorité bienfaisante un horrible fantôme de gouvernement. Nous en avons frémi. Sire, nous qui depuis trois ans luttons constamment contre l'anarchie et qui, conciliant notre conduite avec celle de Votre Majesté, avons maintenu, autant qu'il a dépendu de nous, les principes conservateurs de sociétés... Le moment est venu de manifester nos sentiments d'une manière plus éclatante 
encore ; nous Vous déclarons donc, nous le déclarons à la France, à l'Europe entière : nous ne reconnaîtrons jamais cette indigne, cette vaine autorité. Nous sommes Français, nous sommes Vos sujets et non ceux de quelques factieux, et nous appellerons constamment à la Nation et à Vous de tout ce que ceux-ci ont pu faire. L'Europe indignée s'arme pour délivrer la France du honteux despotisme sous lequel elle gémit... Le succès couronnera sans doute la noble entreprise des libérateurs de la France ; déjà, partout, il les accompagne ; mais, dût le crime triompher, dussions-nous être victimes de notre dévouement, nous nous ensevelirons sous les ruines de notre pays en combattant sous les ordres du chef que vous nous avez donné et qui, dignement, Vous représente ici. Nous mourrons fidèles sujets de Votre Majesté » 57.

Le recul du temps, les transformations profondes que des événements alors imprévisibles ont apportés au cours de plus d'un siècle à la structure de notre société, à nos conceptions politiques, à l'état de l'Europe aussi, nous portent à juger avec quelque sévérité le geste grave de cette rébellion. Aussi bien discerne-t-on, dans cette ardente adresse, le sentiment qu'il y a tout de même dans l'idée de la Patrie quelque chose de plus haut, de plus auguste, de plus sacré que la forme des institutions et le culte de la tradition. Du Buc et ceux qui le suivent en éprouvent le scrupule ; ils s'efforcent de l'apaiser en se persuadant non pas seulement que la France s'identifie avec le Roi, mais que le nouveau gouvernement institué à Paris n'est qu'une autorité insurrectionnelle condamnée à disparaître rapidement. Si elle triomphe, la France, telle qu'ils la conçoivent et l'aiment, aura donc cessé d'être. Leurs protestations de fidélité au pouvoir légitime sonnent comme un apaisement pour leur conscience tout de même troublée.

Avons-nous considéré comme traîtres à leur patrie les Russes qui n'ont pas voulu s'incliner devant le bolchevisme triomphant? Ne soyons pas plus sévères pour Du Buc et ses partisans. Et mettons tout de même à leur actif l'issue en dernière analyse favorable de leur redoutable initiative.

57 Adresse du 8 octobre 1792 signée de 61 noms. Ministère des Colonies, Martinique, 273. 
Ainsi, les dés étaient jetés. La Martinique avait nettement pris position, mais le chevalier ni le Gouverneur ne se dissimulaient que cette position n'était pas de tout repos.

M. de Béhague, qui n'avait rien d'un dictateur, sentait vivement le besoin de se faire avouer par les Princes et d'obtenir d'eux des renforts.

Du Buc voulait que les planteurs recueillissent le profit de leur fidélité au pouvoir légitime, s'il était vrai que celui-ci dût triompher et, dans le cas contraire, fussent à l'abri des représailles républicaines.

Or, la partie où la colonie avait misé son destin se disputait à une distance dont nous n'avons plus d'exemple depuis l'usage de la téléphonie sans fil et de l'avion : une distance de 5 à 6 semaines. Il fallait, de toute évidence, envoyer un habile homme tenir le jeu. Tous les colons nommaient Du Buc mais tous tremblaient de s'en séparer.

Le 8 octobre, l'Assemblée Coloniale agita la question. Le chevalier s'était retiré « pour ne pas gêner les opinions dans une discussion dont il était l'objet ». Plusieurs députés déclarèrent qu'ils regarderaient comme « une calamité publique » « l'absence de celui qui, jusqu'à présent, avait fait tête aux orages, qui avait présidé à toutes les révolutions, dont la sagesse et les talents avaient le plus contribué à sauver les Antilles françaises », mais d'autres ayant fait valoir que « les grands intérêts des colonies liés au sort de la France et à la coalition des puissances allaient se traiter en Europe, et qu'il était convenable d'en charger l'homme qui s'en était le plus occupé », Du Buc fut nommé par acclamations député de la Colonie auprès de Sa Majesté Louis XVI avec des pouvoirs illimités pour toutes les occurrences.

Fort inquiété par le bruit de la retraite précipitée de Brunswick, le chevalier partit pour Londres le 15 novembre, avec le baron de Clairfontaine représentant de la Guadeloupe. Vers la même époque, débarquait, à Douvres, le baron de Constant, neveu de M. de Béhague et aide maréchal des logis à la Martinique. Son oncle l'avait expédié dès octobre, nanti de ces instructions secrètes : tâcher d'atteindre le roi de France ou les Princes, leur détailler la situation de la Martinique, insister auprès d'eux pour faire envoyer de nouveaux pouvoirs au Gouverneur et obtenir d'une puissance alliée deux vaisseaux et 2.000 hommes de troupes. Le baron de Constant, s'il ne pouvait parvenir jusqu'aux Princes, devait négocier avec 
les ministres britanniques en se prévalant du traité de Pilnitz et offrir, pour indemnité des frais qu'entrainerait la protection de l'île, de réserver l'exclusivité des denrées coloniales à l'Angleterre tant que son secours serait nécessaire.

De leur côté, les émigrés et les députés des îles n'étaient pas demeurés inactifs : dans l'entourage aussi des Princes on avait échafaudé des plans.

A Verdun, le jour même où Rochambeau se voyait contraint de quitter la Martinique, Louis-Stanislas-Xavier-Charles-Philippe, plus tard Louis XVIII et s'intitulant alors Régent de France, nommait M. de Cougnacq-Myon «en qualité de commissaire des Princes auprès des colonies de Saint-Domingue, la Martinique, la Guadeloupe, Sainte-Lucie et Tobago, afin d'établir entre elles et les Princes toutes sortes de correspondances convenables ».

Quel était ce personnage ? M. de Montalembert l'avait rencontré au mois d'avril précédent à Londres, chez un de ses amis et avait été frappé par les connaissances très précieuses qu'il possédait sur Saint-Domingue, où il avait vécu plusieurs années. Il y était venu de sa ville natale, La Rochelle, professer la médecine et la chirurgie ; un riche mariage avec une créole l'y avait définitivement fixé, accroissant sa situation matérielle et morale, si bien qu'aux premiers jours de la Révolution ses concitoyens l'avaient choisi pour les représenter. Intrigant, vantard, ambitieux, Cougnacq-Myon s'était bientôt distingué par ses discours révolutionnaires, ce qui lui avait valu d'être des 85 «patriotes » envoyés en France sur Le Léopard, en septembre 1789.

Arrivé à Paris, il avait tâché, de se pousser de mille manières, accablant le Comité Colonial de mémoires et de projets. Mais, en trois ans, ses opinions politiques avaient considérablement changé. Les atteintes qu'avaient dû subir ses biens du fait des excès auxquels s'étaient livrés les "patriotes » de Saint-Domingue l'avaient-elles détourné de la cause révolutionnaire ? Toujours est-il que lorsque M. de Montalembert, revenant d'une mission en Espagne, le rencontra une seconde fois à Londres chez le même ami, M. de Cougnacq-Myon lui manifesta le désir de racheter ses erreurs passées par un entier dévouement au pouvoir légitime. 
Montalembert, qui rejoignait les princes à Verdun, emmena son pénitent et prit sur lui de le présenter. L'entrevue eut lieu au château de Vougier sous le patronage du comte de Vaudreuil. Le « Régent » écouta avec bienveillance les suggestions du transfuge et se laissa aller à lui accorder son pardon et l'investiture qu'il réclamait. Le maréchal de Castries reçut l'ordre de rédiger les instructions et les pouvoirs qui lui furent remis sans perdre un instant.

L'émissaire des Princes devait promettre aux colons - indistinctement - des récompenses et le maintien de leurs privilèges. Les lois prohibitives seraient suspendues, l'introduction serait autorisée de toutes espèces de vivres et de marchandises. Les gouverneurs étaient invités encore à solliciter des Etats-Unis de l'Amérique tous les approvisionnements, tous les secours dont les colonies peuvent avoir besoin en faisant la promesse de "faire déclarer dettes de l'Etat les dettes contractées à cette occasion si la garantie des colonies ne suffisait pas. »

Par la suite, tous les étrangers seraient admis à la fourniture des approvisionnements et des nègres ; la culture serait protégée de toutes manières et l'autorité des planteurs pleinement assurée.

Pour retenir de l'Empire Français ce qu'il pouvait, « Monsieur » ne regardait pas au prix.

Planche IX. Proclamation. Jean-Pierre-Antoine de Behague,

Lieutenant-Général des armées du Roi, Gouverneur-Général

des Îles du Vent, Commandant en chef des Forces de Terre et de Mer.

Voir Les Classiques des sciences sociales.

La Convention, de son côté, n'était nullement disposée à renoncer aux « Iles du Vent ». Elle avait appris - avec l'indignation que l'on conçoit - l'échec de l'expédition Rochambeau et la contre-révolution opérée par le «scélérat Béhague » et le «scélérat Du Buc ». Elle décida aussitôt la mise en accusation de tous les coupables, tant ceux de la Martinique que ceux de la Guadeloupe, où M. d'Arrost avait pris la succession de $M$. de Clugny récemment décédé, et continuait sa politique. 
M. de La Coste, déjà écarté du Ministère de la Marine, et qui avait le malheur d'être à portée des foudres de la Nation, faillit perdre dans l'affaire sa tête quinteuse ; il eut bien du mal à se justifier d'avoir laissé en fonction des hommes aussi peu sûrs.

Pour les autres, avant de les punir, il fallait les vaincre. « Persuadés de l'importance des possessions françaises pour la richesse nationale, convaincue qu'il n'y avait pas de temps à perdre pour soustraire à la tyrannie les patriotes zélés dont surtout les villes de ces isles sont peuplées », la Convention décréta l'envoi de trois bataillons de gardes nationales de 800 hommes chacun, et l'armement en guerre d'un vaisseau de 74 canons qui, avec Le Républicain de 110 canons, déjà armé, et l'escorte de 4 frégates, conduirait aux Iles du Vent, trois nouveaux commissaires investis des plus grands pouvoirs.

Mais voter le décret était plus facile que de le faire exécuter; la métropole n'avait pas trop de tous ses enfants ni de tous ses moyens pour assurer la défense de son propre territoire. D'autre part, Rochambeau, qui devait s'y connaître, écrivait pour conseiller d'agir par la persuasion, rappelant qu'à la fin de la Guerre de Sept ans il n'avait pas fallu aux Anglais «moins de 12 vaisseaux de ligne et 8 à 10.000 hommes de troupes pour s'emparer de la Martinique ».

Dès avant d'avoir reçu la lettre du général, Monge, le nouveau ministre de la Marine, ayant fait les mêmes réflexions, avait chargé le capitaine de vaisseau Lacrosse d'aller faire connaître aux Antilles les actes législatifs de la Convention, « d'empêcher que les citoyens de différentes couleurs ne fussent égarés sur les événements qui ont consolidé la liberté française, et de les attacher à la Métropole par la connaissance de leurs propres intérêts, par l'amour, la reconnaissance et la fraternité ».

Lacrosse partit de Brest le 24 octobre 1792 sur sa frégate La Félicité.

Quinze jours plus tôt, M. de Cougnacq-Myon, après un bref séjour à Londres où il s'était mis en rapports avec les chevaliers de Curt et de Perpigna, s'était embarqué pour les îles. La longueur d'une traversée fort incommode et les escales qu'il voulut faire à la Barbade et à la Grenade furent cause qu'il parvint seulement fin novembre à la Dominique où il avait le projet de se fixer pour observer les événements. L'inutilité de cette expectative lui apparût lorsqu'il eut connaissance de «l'adresse au Roi» de l'Assemblée Coloniale et de l'acte de sécession 
qu'avaient accompli les colons à l'égard de la France révolutionnaire. Il fit donc voile pour la Martinique et y débarqua le jour même où Lacrosse mouillait devant le port.

Ainsi, le ler décembre 1792, la République et la Monarchie, dans les personnes de leurs représentants, arrivaient se disputer les faveurs des Antilles françaises.

Lacrosse, voyant non sans stupeur le pavillon blanc arboré par la flotte et par les citadelles, jugea prudent de s'éloigner. Déjà, d'ailleurs, La Calypso menaçait La Félicité. Par un chassé-croisé assez piquant, l'envoyé de Monge alla prendre à la Dominique le poste d'observation que venait de quitter l'émissaire des Princes. Il n'y resta que peu de temps, s'étant avisé qu'il aurait ses coudées plus franches à Sainte-Lucie, à laquelle la Convention devait plus tard décerner le surnom de « la fidèle ». On le voit, M. de Béhague s'était montré bon prophète lorsqu'il avait déconseillé de reprendre prématurément la couleur du roi.

M. de Cougnacq-Myon, cependant, trouvait tous les fonctionnaires aussi bien que les planteurs empressés à le seconder, mais il aperçut très vite qu'une sourde opposition dressait les colons contre le Gouverneur. Celui-ci, peu brave à fronder ouvertement la Révolution tant qu'il ne se sentirait pas soutenu par des forces envoyées par les Princes, avait cru s'assurer au regard de la Nation des circonstances atténuantes en appliquant avec rigueur le système de l'Exclusif et en réprimant scrupuleusement les abus des planteurs assez enclins à se croire des droits sur les terrains du domaine et les finances de la colonie. Ce faisant, comme il arrive d'ordinaire aux hésitants et aux incertains, il avait surtout réussi à se compromettre autant aux yeux de l'Assemblée Coloniale qu'à ceux de la Convention.

Il n'empêche qu'il avait su jusque-là garder dans son jeu la carte maîtresse : la faveur des gens de couleur libres. Malheureusement pour lui, il n'allait plus la conserver longtemps.

Les instructions des Princes qu'apportait M. de Cougnacq-Myon devaient plaire grandement aux planteurs par la prépondérance politique et la liberté commerciale qu'elles leur promettaient. Mais elles ne pouvaient plaire qu'à eux, et M. de Béhague, lorsqu'elles lui furent communiquées, en resta quelque peu effaré. 
Il faut avouer qu'il y avait de quoi. Avec une complète ignorance des faits acquis, le comte de Provence avait fondé sa doctrine sur l'exclusion absolue des gens de Saint-Pierre et des hommes de couleur, à qui n'était pas accordée la moindre participation dans la gestion des affaires publiques, ainsi que sur le sacrifice entier des intérêts du commerce métropolitain et de ses agents de la colonie.

Il était évident que seule la présence d'une force armée à la dévotion du Roi ou de ses protecteurs étrangers pouvait faire triompher des conceptions si nettement contre-révolutionnaires. Gagné par le délire contagieux des "aristocrates », le Gouverneur se laissa bercer de l'espérance que les nouveaux commissaires envoyés par la Convention pourraient être devancés par une escadre conduite par le marquis de Bouillé ou armée soit par l'Angleterre, soit par l'Espagne. Il voulut, en souscrivant à toutes les propositions de M. de Cougnacq-Myon, faire oublier à celui-ci le peu d'empressement qu'il avait montré à le joindre et la maussaderie de son accueil.

Ainsi, peu à peu, s'accomplissait l'irréparable. La direction des événements, qui était demeurée à peu près possible tant que les questions locales avaient eu le pas sur les grands problèmes qui s'agitaient dans la métropole, passait à des forces de dimensions infiniment plus considérables. Ce ne sont plus les aspirations et les intérêts contraires, mais cependant conciliables, des planteurs et des négociants qui s'affrontent. Les antagonistes sont désormais la République et la Monarchie, la Révolution et la contre-Révolution. La Martinique est définitivement entrée dans la bataille qui va se décider en dehors et au-dessus d'elle, et où son destin propre ne sera plus qu'une bien petite chose.

Le 13 décembre, l'Assemblée Coloniale se réunit. «Il y avait une affluence prodigieuse ». Salué par des acclamations sans fin, le plénipotentiaire des Princes parut entre le Général et l'Ordonnateur. M. de Béhague parla le premier et affirma sa fidélité au Roi. Petit de Viévigne, dans une allocution enflammée, jura de mourir en loyal sujet de son souverain légitime.

«Enfin, j'annonçai, raconte lui-même M. de Cougnacq-Myon, les intentions paternelles de LL. AA. RR., le voeu de toute la noblesse française, les efforts qu'on allait tenter pour appuyer les résolutions généreuses des colonies. Je parlai de la gloire dont la Martinique et la Guadeloupe et leurs intrépides défenseurs 
venaient de se couvrir, je les portai aux mesures d'une résistance honorable et, couvert d'applaudissements, des cris de « Vive le Roi ! Vivent les Princes ! et leur Commissaire ! ", j'eus la satisfaction de voir prendre à l'instant même l'arrêté où vous verrez la détermination très précise en faveur des intentions de leurs Altesses Royales ».

On était, en effet, passé immédiatement des discours aux actes. Et d'abord, pour appliquer à la lettre les instructions de Monsieur, on avait voté l'ouverture du Marin qui servirait de port d'entrepôt aux navires américains. L'Assemblée Nationale ayant déjà ouvert la Trinité, la Martinique se trouvait désormais entièrement livrée au commerce des Etats-Unis.

On s'était avisé ensuite qu'il fallait de l'argent ; c'était ce qui manquait le plus. Depuis 1790, aucune recette n'était rentrée dans les caisses de l'administration et M. de Cougnacq-Myon s'était rendu aux Antilles avec l'espoir d'y puiser des moyens de lutte pour les Princes et non pas avec la volonté d'y porter des secours financiers. « Je l'ai dit et vous le verrez, écrivait-il au maréchal de Castries en le suppliant de hâter l'expédition de Bouillé, les plus grandes ressources des princes sont dans les colonies. Si quelque section de l'armée royale y arrivait, elles seraient aussitôt toutes an Roi et aux Princes et elles leur fourniraient tous les moyens qui leur manquent en Allemagne, mais les malheureux planteurs sont accablés par le nombre des factieux et personne ne fait rien pour les soutenir... Au moins, M. le Maréchal, engagez tous les gentilshommes, tous les colons qui en auront les moyens, de se rendre par la voie de ]'Angleterre à la Martinique. Ils peuvent fréter à bon marché des bâtiments à Londres, ou en Hollande pour la Dominique, qui n'est qu'à quelques lieues ».

L'aide que M. de Cougnacq-Myon apportait était donc purement morale, et les emprunts qu'il était autorisé à souscrire auprès des Américains n'offraient rien d'immédiat. Une fois de plus, il fallait demander aux planteurs des sacrifices pécuniaires. Deux mois plus tôt, ils avaient déjà accepté une imposition extraordinaire de 500.000 livres pour les dépenses de la Station navale. M. de Béhague reprit la parole et, faisant appel à leurs sentiments, les invita à prêter à l'Intendance des vivres, de l'argent et des esclaves. 
Dans un élan de générosité, les colons accordèrent tout ce qu'on leur demanda : ils paieraient de leurs biens comme de leurs personnes ; la Martinique aurait des défenseurs, des munitions, des provisions.

M. de Béhague, pour s'être placé enfin à la tête des planteurs, leur devenait sympathique et prenait figure de héros. Dans les premiers jours qui suivirent cette séance mémorable, il reçut mille témoignages de dévouement et d'admiration. Les dames de la Martinique ne voulurent pas être en reste et lui adressèrent ce délicat billet qu'il put retrouver plus tard, glissé dans ses papiers d'archives comme une petite fleur séchée :

«Monsieur le Gouverneur,

«En confidence, on vous devait un premier remerciement pour nous avoir rendu le repos, pour avoir été le Sauveur de la Martinique. Vos succès ont pu vous dédommager de notre silence.

« En confidence, nous ne pouvons nous taire, mais ne le dites pas aux hommes (car ils ne veulent pas que nous les gagnions de vitesse). Oui, Monsieur le Gouverneur, vous venez d'assurer nos vies, nos fortunes, celle de nos pères, de nos maris, de nos enfants. Hier, oui, la journée d'hier, votre activité et votre prudence (nous savons tout) ont mis le comble à notre reconnaissance; elle est au-dessus de nos expressions. » 58 .

Au moment même où la cause du Roi paraissait ainsi définitivement triompher à la Martinique, elle était déjà irrémédiablement perdue. Moins d'un mois plus tard, avant même que la tête de Louis XVI tombât à Paris, le terrain sur lequel les planteurs avaient bâti leur puissance allait se dérober et l'édifice qu'ils avaient pu croire inébranlable, s'écrouler de fond en comble.

58 Lettre du 15 décembre 1792 signée par les plus notables dames de la Martinique au nombre de 112. Dossier du procès Béhague. Ministère Colonies. Martinique, 277. 


\section{CHAPITRE VII RÉFÉRENCES :}

Avec les rouges aux Isles du Vent. Souvenirs du chevalier de Valous, 1790-93, publiés par le marquis de Valous. Calmann-Lévy, 1930.

Compte-rendu au roi, rédigé par Rochambeau au Cap Français, le 4 oct. 1792. Ministère Colonies Martinique, 273.

Mémoires et lettres de M. de Mallevault, de M. de Bruix, de M. de Rivière, de M. de Dancourt, et nombreuses pièces concernant l'épisode du 16 sept. Ministère Colonies Martinique, 274.

Copies de pièces se référant au procès que $M$. de Behague subit par devant « Monsieur » en 1798 au sujet de la défection de la Martinique en 1793. Ministère Colonies Martinique, 277.

Copie de la Lettre adressée à MM. les commissaires civils délégués aux Iles du Vent par le Comité intermédiaire de l'Assemblée Coloniale de la Martinique. Artch. Ministère Colonies Martinique, 277.

Mémoire de Du Buc. Ministère Colonies Martinique, 277.

Adresse de l'Assemblée Coloniale de la Martinique au roi. 8 oct. 1792. Ministère Colonies. Martinique, 273, et Arch. Nat. Dxxv 118.

Circulaire aux armateurs et négociants des ports de France. Min. Col. Martinique, 273.

Extrait des délibérations de l'Assemblée Coloniale du 8 oct. 1792. Archives Min. Col. Dossier Du Buc.

Lettre de $\mathrm{M}$. de Montalembert à $\mathrm{M}$. de Behague au sujet de $\mathrm{M}$. de Cougnacq Myon. 18 mars 1778. Pièces du procès Béhague. Martinique, 277.

Procès-verbaux de l'Assemblée Nationale, 8 et 9 novembre 1792.

Instructions de Monge à Lacrosse. Arch. Nat. BB 412, p. 161. 
Lettres de M. de Cougnacq-Myon au Maréchal de Castries. Min. Col. Martinique, 277 (décembre 1792 et 23 juillet 1793).

Adresse des dames de la Martinique à M. le Gouverneur. Min. Col. Martinique, 277. 


\section{La Révolution française à la Martinique}

Chapitre VIII

\section{Le Vent tourne}

Retour à la table des matières

Rarement l'Histoire a eu à enregistrer un renversement de situation aussi rapide et aussi complet que celui qui se produisit aux Antilles à la fin de 1793.

Le capitaine de vaisseau Lacrosse, chargé d'agir par la persuasion avant que la République n'eût recours aux armes pour faire respecter son autorité, s'acquitta de sa mission avec un sens politique remarquable et une étonnante habileté de propagandiste.

Dès l'abord, il comprit que toute la force des révoltés résidait dans l'appui. qu'ils avaient trouvé jusque-là auprès des hommes de couleur libres.

C'était cet atout majeur qu'il fallait leur enlever. Il y parvint en quelques semaines.

De Sainte-Lucie, où il s'était rendu dans les premiers jours de décembre, il inonda les îles rebelles de tracts et de proclamations. Il y répandait la nouvelle du miracle de Valmy ; prophétisait le triomphe final de la République, annonçait des représailles ; mais surtout, aux hommes d'une race longtemps méprisée, il offrait des perspectives enchanteresses : «Vos frères, devenus les nôtres, ne faisant plus qu'une famille, s'asseyant à la même table, partageant tous nos plaisirs en société 
comme nos travaux et nos dangers à la guerre... Préféreriez-vous, ajoutait-il, l'ancien régime où une ligne de démarcation humiliante vous séparait des blancs ? »

\section{Planche X. Le Capitaine de Vaisseau Lacrosse. Voir Les Classiques des sciences sociales.}

C'était d'une infaillible logique, et les hommes n'y sont pas insensibles, quand elle leur est exposée avec force et simplicité, dans le cadre de leurs sentiments profonds et de leurs intérêts.

Comment les gens de couleur n'eussent-ils pas été ébranlés ? Ceux-là mêmes qui se souvenaient encore des massacres et des vexations au moyen desquels les « patriotes » avaient naguère tenté de leur démontrer que l'égalité ne les concernait pas, ne pouvaient contester que le temps de ces erreurs était révolu.

Les républicains de l'île, on l'a vu, s'étaient enfin rendu compte de leur hérésie et l'avaient abjurée avec une ferveur d'autant plus vive que de fraîche date. Et ils s'étaient empressés de donner un gage indiscutable de leur sincérité : réfugiés pour la plupart à la Dominique après l'adhésion des planteurs au parti des Princes, ils élurent un mulâtre, Gautier Littée, parmi les suppléants chargés de représenter à l'Assemblée de Paris la colonie dont ils se considéraient malgré l'exil, comme les seuls véritables citoyens 59 .

M. de Béhague ne tardait pas à s'apercevoir que la propagande de Lacrosse gagnait du terrain. Déjà, quelques mulâtres avaient arboré la cocarde tricolore, et il avait dû, sous la pression de l'Assemblée Coloniale, les obliger à faire publiquement soumission et à reprendre la couleur du roi. M. de Cougnacq-Myon note que ce jour-là « $\mathrm{M}$. de Béhague lui parut détester de tout son cœur les colons et leurs partisans ». C'est qu'incapable de réagir mais gardant sa lucidité, le Général maudissait l'aveuglement de ces fous qui organisaient dans une fièvre joyeuse la défense de la Martinique sans prendre garde que le «rempart de la colonie »

59 Gautier Littée fut ainsi le premier représentant de couleur qu'ait eu la Martinique auprès d'une assemblée législative. Les autres députés et suppléants étaient :, Dugommier, Crassous et Armand de Corio. 
s'écroulait autour d'eux à la voix de Lacrosse, comme les murailles de Jéricho au son des trompettes de Josué.

Le mouvement commença par la Guadeloupe, où la propagande révolutionnaire n'avait pas été contrariée par l'élan adverse. En quelques jours, les gens de couleur de Pointe-à-Pitre donnèrent leur adhésion unanime et enthousiaste à la République.

Derrière eux, les colons furent entrainés pour ainsi dire automatiquement. Le Commandant de La Félicité ne les avait d'ailleurs pas oubliés dans ses proclamations. A eux aussi, avec beaucoup d'habileté, il avait trouvé ce qu'il fallait dire :

« Revenez de vos préventions funestes sur les intentions de la France entière ; vos propriétés sont, comme les nôtres, sous la sauvegarde de la Nation. Jamais il n'entrera dans le plan du gouvernement de les détruire en attaquant vos propriétés pensantes ; ceux qui vous l'ont dit vous trompent et vous calomnient. Vous êtes appelés par le vœu national à fixer, pour le bien général, les rapports qui désormais nous seront communs. »

Propriétés pensantes ! Cet euphémisme, pour désigner les esclaves, n'était-il pas à lui seul un chef-d'oeuvre ? De l'abolition de la servitude et de la traite, il n'était donc pas question! Nul ne concevait encore que l'octroi des droits civils et politiques aux hommes de couleur libres devait entraîner fatalement quelque jour l'affranchissement des noirs, et que l'égalité, à ceux-ci non plus, ne pourrait dès lors être refusée.

Mais la logique met plus de temps à cheminer dans les esprits. Pour le moment, les « propriétés pensantes »étaient placées sous la protection de la nation.

La proclamation de Lacrosse continuait ainsi :

«L'égalité, la liberté, telles sont les bases de notre Gouvernement. C'est donc à vous, citoyens de toutes couleurs, que je m'intéresse ! Ne faisons qu'une seule et même famille, notre union sera notre force, votre propriété sera attachée à ses travaux par l'exemple que vous lui donnerez. Au premier coup de canon que la France va tirer contre vous, ne croyez-vous pas que vos ateliers se dispersent ? Attaqués au dehors, menacés au dedans, quels seront vos moyens de résistance ? » 
Planche XI. Le dernier moyen de conciliation, entre la Mère-patrie, et les colonies révoltées.

Voir Les Classiques des sciences sociales.

Quelles bonnes raisons les habitants de l'île auraient-ils eues encore d'affronter les foudres de la métropole ? Une flotte puissante allait bientôt paraître dans la mer des Antilles. L'on était sans nouvelles des démarches des chevaliers de Curt, de Clairfontaine et Du Buc. Les colons pourraient établir leur propre statut, et les biens de tous genres - y compris « les propriétés pensantes » - demeureraient à leurs légitimes possesseurs.

Les habitants de Pointe-à-Pitre changèrent de camp avec une promptitude merveilleuse. Une lettre fort pressante de M. d'Arrost, Gouverneur de la Guadeloupe, en avertit, le 24 décembre, les dirigeants de la Martinique. Les officiers de la Marine royale, Mallevault sur La Calypso, Daché sur la Bienvenue devenue la Royaliste, Valous sur l'Elisabeth partirent à la rescousse. M. de Cougnacq-Myon les accompagnait. Ils arrivèrent trop tard pour faire oeuvre utile. Après avoir passé une heure chez le Gouverneur sous le feu de quatre batteries, l'envoyé des Princes comprit son impuissance à rétablir la situation et fila sur Porto-Rico 60 .

Les derniers royalistes, se voyant débordés, sommèrent $M$. d'Arrost de reprendre la cocarde tricolore. Il n'en voulut rien faire pour la raison « qu'il n'était pas dans son caractère de varier ainsi à chaque instant»; mais " considérant que le gouvernement de la colonie ne pouvait plus être occupé que par un homme qui partageait ses nouveaux principes », il s'embarqua pour Saint-Christophe avec quelques fidèles.

Les unités de la Marine royale avaient déjà regagné la Martinique, abandonnant à leur sort ces colons versatiles qui appelaient maintenant à grands cris le héraut de la Convention, Lacrosse. Celui-ci « vola aussitôt vers eux », ainsi qu'il l'avait promis et prit provisoirement possession du gouvernement.

60 Cougnacq-Myon s'établit en Amérique, y monta une maison de commerce et y gagna beaucoup d'argent, suivant le témoignage d'un certain Prioreau. 
Trois jours plus tard, le 9 janvier 1793, moins d'un mois après cette séance où députés et assistants, ivres d'enthousiasme, avaient juré de mourir fidèles au Roi, l'Assemblée Coloniale de la Martinique, qui s'était transférée au Lamentin pour y délibérer en comité secret, faisait en ces termes amende honorable à la République :

«L'Assemblée Coloniale, plus instruite aujourd'hui de ce qui s'est passé en France, rassurée sur les propriétés des colons, considérant que la Métropole, intéressée à la conservation des colonies, présente aujourd'hui une réunion de volonté et de forces qui la mettent en état de les protéger, que les commissaires qu'elle a délégués ou qu'elle déléguera concourront à ce but et se prêteront à toutes les mesures propres à éloigner des Isles du Vent, seules ressources du commerce, les, malheurs qu'a éprouvés Saint-Domingue.

« Arrête qu'elle révoque son arrêt du 13 décembre dernier et toutes les dispositions qui y sont comprises, déclare, en conséquence, qu'elle rentre sous la domination de la Métropole sous quelque domination politique que ce puisse être. »

Que s'était-il passé ? Simplement ceci : les colons venaient de s'apercevoir que la couleur les avait virtuellement lâchés ${ }^{61}$. Du Buc était loin... Privés de la tête qui pensait pour eux et des bras qui les avaient jusqu'alors défendus, impressionnés par la victoire de Valmy, effrayés par l'idée des forces révolutionnaires qu'ils croyaient toujours voir apparaître, assurés par Lacrosse que la Convention ne songeait point à abolir l'institution servile sur quoi se fondait leur richesse, ils avaient subitement renoncé à la lutte.

Dans la nuit du 9 au 10, M. de Béhague prenait le large comme avait fait $\mathrm{M}$. d'Arrost.

Autant que le désir de se justifier aux yeux de la nation, la vieille inimitié que les planteurs nourrissaient à l'égard du Gouverneur les porta à charger vilainement celui-ci de toutes les responsabilités. Le 13 janvier, les promoteurs de la révolte les plus compromis dans la reprise du pavillon blanc osaient écrire à ceux qu'ils avaient contraints à la fuite :

61 Adresse des citoyens de couleur de la Martinique. Voir aux Annexes le texte complet. 
« Citoyens,

« Béhague est parti ! La colonie respire. Le drapeau national flotte sur nos forteresses et dans nos rades.

«La différence d'opinions qui vous avait fait abandonner vos foyers n'existe plus; bientôt le citoyen Lacrosse sera parmi nous. Il nous fera connaître les formes du gouvernement civil sous lequel nous allons vivre.

« Citoyens, rentrez dans vos foyers! Ce sont vos frères qui vous y invitent. Salut.

CHARLERY, président.

RIGORDY, secrétaire ».

Il est à remarquer que ces mêmes colons qui renièrent sans vergogne leur Gouverneur, en usèrent tout différemment avec le chef de la station navale, M. de Rivière, auquel ils ne cessèrent de marquer un attachement reconnaissant. Ils lui versèrent une contribution de 50.000 livres pour payer ses marins et lui laissèrent toute licence de préparer son appareillage, ce qu'il fit très consciencieusement, enlevant des magasins de la Marine tout ce qui pouvait lui servir, et désarmant la Bienvenue dont il prit l'équipage pour compléter les siens.

Il partit pour Trinidad, emmenant sur ses bâtiments tous les officiers des régiments de la Martinique, à l'exception de deux qui préférèrent rester, et bon nombre de grands planteurs avec leurs familles et leurs esclaves. Indéfectiblement fidèles aux Bourbons, M. de Rivière allait offrir ses services an roi d'Espagne.

Dès que la dernière voile de l'escadre royale eut disparu à l'horizon, l'Assemblée, écrivit à Lacrosse : 
« Citoyen,

« La Martinique peut enfin à son tour se flatter de vous avoir dans son sein : les obstacles qui s'y opposaient finissent. Béhague, la Marine et plusieurs officiers de troupes de ligne ont abandonné cette malheureuse colonie.

«Maintenant réunis sous le drapeau national, tous les colons ont fixé. sur vous leurs regards inquiets. Vous seul pouvez faire passer avec succès dans la métropole les serments qu'ils ont fait de vivre et de mourir sous les loix. Vous seul pouvez cimenter l'union et la paix qu'ils désirent.

«Soyez le conducteur de cette famille égarée, présentez-la à sa mère qu'elle a toujours adorée... L'opinion qui seule mène actuellement les Français est en votre faveur ; vous en avez déjà fait, à Sainte-Lucie et à la Guadeloupe, le plus salutaire usage. Les colons de la Martinique en attendent le même succès.

«Ce ne sont point des lâches qui vous parlent ainsi : ce sont des hommes courageux qui ne voudraient pas que l'erreur d'un moment les mit dans l'affreuse nécessité de prendre un parti désespéré aussi funeste pour la métropole que pour eux.

«Que l'Europe entière apprenne que sans employer d'autre arme que la persuasion et la douceur, vous avez rendu à la France des colonies importantes ! Que votre nom soit à jamais gravé et béni dans le coeur de tous les colons. »

Une députation composée de trois membres de l'Assemblée et de deux « nouveaux citoyens », c'est-à-dire de mulâtres, fut chargée de porter cette adresse brûlante au représentant de la Convention. On le croyait encore à Sainte-Lucie, d'où l'on espérait bien que les messagers le ramèneraient. A la déception générale, ceux-ci revinrent seuls : le héros attendu était occupé au gouvernement de la Guadeloupe.

En son absence, la Martinique dut se contenter du Conseil exécutif provisoire que l'Assemblée Coloniale avait créé au lendemain du départ de M. de Béhague. Il était composé de cinq membres : MM. Levassor, Guignod et Martet, planteurs influents, M. de Molerat major commandant de Saint-Pierre, enfin le capitaine 
Delor, l'un des deux officiers demeurés dans l'île. Tous apportèrent la meilleure volonté a remplir le rôle qu'aucune autorité ne leur avait légalement dévolu, mais que les événements leurs imposaient. Afin d'éviter toute erreur, ils demandèrent à Paris l'envoi immédiat de la collection des lois concernant les colonies.

Quant aux membres de l'Assemblée coloniale, ils préparaient le plaidoyer qu'ils jugeaient nécessaire de présenter à la Convention pour appuyer l'intercession de Lacrosse. Ainsi qu'on va le voir, cet habile « compte-rendu » contenait, à défaut de la vérité, un certain nombre de vérités :

« Citoyens Représentants,

« La colonie de la Martinique, rendue à elle-même, vous doit le tableau fidèle des troubles qui l'ont trop longtemps agitée, des séductions qui l'ont égarée,. de ses intentions, enfin de ses sentiments. Elle parlera de ses erreurs avec franchise, de ses principes avec loyauté, de son union avec la République, avec transport.

«Citoyens, écoutez sans prévention ce que vous diront, dans l'effusion de leurs cœurs, des frères que des circonstances funestes avaient jetés dans l'erreur et qui veulent aujourd'hui vous honorer par leur confiance et s'honorer eux-mêmes par leurs regrets.

« Le despotisme a creusé de ses mains le tombeau dans lequel vous l'avez enseveli, et l'excès de l'oppression a produit la liberté ; mais qui, plus que les colons, avait souffert de cette oppression? Les caprices des tyrans subalternes étaient leurs loix. Un ministre leur dictait impérieusement ses volontés, sans même s'assujettir à ces formalités vaines qui servaient du moins en France, de voile à la tyrannie. Un gouverneur, à la fois esclave et despote, les écrasait souvent du poids de son autorité et leurs plaintes se perdaient dans l'immensité des mers. Ils n'étaient cependant pas nés pour cette servitude ; leur existence plus isolée leur faisait mieux sentir leurs droits ; et la fierté des créoles a plus d'une fois étonné l'orgueil des tyrans.

« Telle était leur position en 1789. Les colons devaient donc voir avec plaisir la Révolution. Aucun intérêt ne les attachait au sort des despotes et ne pouvait leur faire regretter leur empire. Ils ne jouissaient pas des faveurs des rois, on ne les voyait pas à la suite des cours; les biens du clergé n'étaient pas leur partage ; la féodalité n'existait pas chez eux ; ils avaient, au contraire, tout à espérer du nouvel ordre de 
choses ; mais cette révolution devait avoir, aux isles, une autre marche, produire d'autres effets qu'en France.

« Législateurs, nous vous avons promis la vérité, nous allons vous la présenter tout entière.

« Nous sommes vos enfants et vos frères, nous existons pour vous, nos intérêts sont les mêmes et votre bonheur doit faire le nôtre ; mais notre manière d'exister est aussi différente que les productions de notre sol. La Révolution devait être votre ouvrage et ne pouvait être le nôtre ; l'arbre de la tyrannie étendait jusque sur nous ses rameaux funestes, mais ses racines étaient en Europe et à vous seuls était réservée la gloire de les couper. Vous travailliez pour nous, nous n'avions que des voeux à vous offrir.

« Tels étaient même la nature et le malheur de notre situation que les efforts que nous avions faits pour vous seconder auraient été perdus pour vous et devaient entraîner notre ruine. Le passage d'un grand peuple de la servitude à la jouissance de ses droits offre des convulsions terribles ; la chute de l'édifice élevé par le préjugé doit précéder l'établissement du nouvel ordre, et dans la lutte de la tyrannie et de la liberté, la société présente l'image de la désorganisation et du chaos.

« La France devait sortir triomphante de ce combat. une constitution sublime devait en être le terme ; le bonheur public, l'admiration de tous les peuples et de la postérité doivent en être le prix. Mais les colonies françaises devaient mille fois périr dans cette crise si, sans nécessité, elles l'avaient partagée. Les fiers Spartiates auraient succombé sous le nombre des Ilotes, les Romains auraient été va incus par Spartacus, si les uns et les autres s'étaient trouvés dans la position que nous redoutions 62 .

«Les colons planteurs, plus particulièrement intéressés à la conservation des colonies, attendaient donc avec impatience les biens que la Révolution devait leur procurer et s'efforçaient de se maintenir dans l'état de tranquillité qui pouvait seul assurer leur existence. Ils espéraient que les législateurs de France s'occuperaient de leur bonheur comme de celui du reste de l'empire ; leur attente fut longtemps trompée et lorsqu'enfin l'Assemblée constituante s'occupa d'eux, son travail présenta un tel caractère d'insouciance, une telle versatilité de principes, tant de contradictions et d'erreurs qu'il substitua les craintes et les dangers aux espérances.

62 Il ne faut pas oublier que les colons de la Martinique vivaient au milieu d'esclaves 6 à 7 fois supérieurs en nombre (80.000 pour 12.000 blancs). 
« Un danger plus grand nous menaçait encore. Une secte de philanthropes nous épouvantait par l'inflexibilité de ses principes. Trompée par un faux enthousiasme d'humanité, elle aiguisait contre nous ses poignards, sa voix se faisait entendre dans l'Assemblée Constituante, sa voix était écoutée et retentissait jusque dans nos colonies. «Au milieu de ces alarmes, une aveugle docilité nous dirigeait; nous exécutions les décrets qui nous étaient envoyés; des décrets tout contraires leur succédaient et nous les exécutions encore. Sans loix, sans principes déterminés, abandonnés à nous-mêmes, entourés de malveillants et d'ennemis, nous attendions qu'il fût prononcé sur notre sort...

«... Saint-Domingue a succombé à tant de maux; ses campagnes naguère florissantes n'offrent plus que des ruines ; cette colonie importante n'est plus. La Martinique existe encore, mais que son existence a tenu et tient encore à peu de chose ! Des décrets absurdes et contradictoires qui se prêtaient à toutes les interprétations, l'amour de la liberté en opposition avec les établissements du despotisme, des autorités nouvelles dont les principes n'étaient point déterminés et les limites circonscrites, des intérêts divers, des incertitudes funestes, tout devait faire naître partout des mouvements, des agitations et enfin une guerre civile.

" Si cette guerre n'a pas eu les mêmes suites qu'à Saint-Domingue, il faut l'attribuer à ces colons infortunés qui se sont ralliés pour opposer une digue puissante au torrent qui les entraînait et qui, voulant se conserver à la France, ne cessant pas de voir des frères dans les ennemis qui les attaquaient, ont su allier la modération au courage.

"C'est dans ces circonstances qu'un nouveau gouverneur, des commissaires et des troupes nous ont été envoyés. Vous connaissez, législateurs, quels étaient les satellites de l'ancien pouvoir, mais vous ne connaissez point Béhague, actif, infatigable, avide d'intrigues, habile dans l'art de semer des troubles et des divisions. C'est à lui qu'il faut attribuer nos égarements et nos malheurs. Il pouvait nous donner la paix, il pouvait cimenter une réunion que nous désirions tous, il aima mieux agiter le flambeau de la discorde ; il parvint à diviser les commissaires ; il répandit dans la colonie ses projets insensés, ses nouvelles mensongères, des espérances trompeuses ; son caractère fut dévoilé aux yeux du plus grand nombre, mais les choses étaient amenées au point qu'il fallait dissimuler pour ne pas tout perdre et se livrer à ses impulsions pour ne pas éprouver une désorganisation absolue. 
« Rochambeau et des commissaires furent annoncés ; leur arrivée terminait le règne de Béhague; il mit tous ses soins à l'empêcher ; il faut convenir qu'il fut bien secondé par les circonstances. L'objet de cette expédition fut un mystère qui remplit l'esprit des colons d'inquiétude et de terreur. On leur annonça qu'un décret allait leur enlever cette partie précieuse de leurs propriétés dont la perte devait entraîner celle de toutes les autres, et des lettres de toutes les contrées de l'Europe, du commerce même de la métropole, confirmèrent ces bruits. Rochambeau parut ; l'alarme fut générale, des députés envoyés vers les commissaires pour les engager à prendre connaissance de l'état de la colonie avant de faire le débarquement de leurs troupes, ne purent rien obtenir. Leur retour fit naître le désespoir, on s'opposa à la descente. Rochambeau s'éloigna. Béhague, moteur invisible de ces mouvements, conserva son empire.

« Cependant, le bruit de l'invasion en France des ennemis de la liberté. était parvenu à la Martinique ; leur marche nous fut présentée comme une longue suite de triomphes. On nous dit que les Français, partout trahis, avaient été partout subjugués, que le roi de Prusse était à Verdun, que Brunswick était aux portes de Paris, que les jours du despotisme étaient revenus.

« Français! Excusez notre erreur. Nous avons désespéré de votre salut, mais qui n'eût été trompé comme nous ? Si la renommée, partout vendue aux despotes, a séduit en Europe l'opinion de ces nations voisines, si, près de vous, les témoins de votre héroïsme ont pu douter de vos succès, nous, placés à deux mille lieues du théâtre de votre gloire, livrés à tous les genres de séduction, pouvions-nous démêler la vérité à travers tant de nuages dont on la couvrait? Des agents d'un pouvoir qu'on croyait vainqueur prennent la cocarde blanche et la donnent. Béhague la reçoit de leurs mains et la met sur la tête d'un des représentants de la colonie ; bientôt le canon des forts annonce son triomphe et notre asservissement.

" Tout était perdu. Nous cédâmes au torrent qui nous entraînait ; dans le prestige qui nous égarait, au milieu des illusions dont on nous avait enveloppés, nous écrivîmes à un roi qui n'était plus. »

Enfin, Lacrosse, « cet apôtre du républicanisme », était venu dans la mer des Antilles ; il avait calmé leurs inquiétudes et leur avait dévoilé les trames odieuses par lesquelles ils avaient été trompés. Béhague, ce traître, s'était alors enfui. 
« Ici, Législateurs, qu'il nous soit permis d'exprimer un sentiment qui nous est cher. Il paraîtra peut-être hardi, alors que nous avons à nous justifier ou à recourir à votre clémence, de vous parler en faveur d'un autre, mais la reconnaissance est un devoir et la vérité un tribut que nous vous devons. Nous ne craignons donc pas de faire entendre notre voix en faveur du citoyen Rivière, commandant de la station. La colonie lui a dû plusieurs fois son salut ; s'il eût été le maître d'opérer tout le bien qui eût dépendu de lui, vous auriez moins à vous plaindre et nous à gémir. Dût cet hommage nous faire paraître plus coupables, nous ne saurions être injustes ni calomniateurs. »

Cette dernière phrase et le silence religieusement observé par l'Assemblée à l'égard de Du Buc et de Cougnacq-Myon, durent faire faire à M. de Béhague d'assez amères réflexions.

Les colons terminaient en exposant qu'après le départ du Gouverneur ils s'étaient empressés d'appeler Lacrosse, et faisaient, en l'attendant, de leur mieux pour répondre aux vues de la métropole. Ils méritaient donc miséricorde.

« Voilà, Législateurs, le fidèle récit de ce qui s'est passé à la Martinique. Nos erreurs furent l'ouvrage des circonstances. Elles n'ont laissé parmi nous que des regrets et vous seuls pouvez les adoucir. Vos mains ont terrassé les tyrans, elles doivent relever des frères. N'ayez pas des Romains que la valeur ; comme eux, sachez pardonner et que leur devise soit la vôtre :

« Parcere subjectis et debellare superbos. »

« Au Fort de la République, le 21 janvier 1793.

Lucy FOSSARIEU, Président.

LE MERLE, Vice-Président.

RIGORDY et DESLANDES, Secrétaires ».

21 janvier 1793 !... Ce jour-là, de l'autre côté de l'océan, le roi Louis XVI montait sur l'échafaud.

Devant l'illumination soudaine des « aristocrates » qui venaient de se prosterner sur leur chemin de Damas, les «patriotes » se laissèrent aller à la joie. Des 
îles voisines où ils avaient été se poser ils revinrent en foule sur l'invitation pressante et chaleureuse de l'Assemblée, qui leur promettait toutes sortes de bénédictions et leur ouvrait les bras. Il en arriva trois mille à Saint-Pierre en moins d'une semaine. Le passé était oublié, le présent était à l'union. Que serait l'avenir ?

\section{CHAPITRE VIII. RÉFÉRENCES :}

Adresse de Lacrosse à tous les habitants. ses frères et amis. Arch. Nat. Dxxv 118.

Avec les Rouges aux Isles du Vent. Souvenirs du chevalier de Valous (déjà cité).

Proclamation du citoyen Lacrosse, capitaine de vaisseau, commandant de $\mathrm{La}$ Félicité à tous les habitants. Déc. 1792. Min. Col. Martinique, 274.

Lettre de M. d'Arrost à M. de Behague. Min. col. Martinique, 277.

Délibération de l'Assemblée Coloniale du 9 janvier 1793. Min. Col. Martinique, 276.

Proclamation du 13 janvier an II. Papiers Behague. Min. Col. Martinique, 277.

Adresse de l'Assemblée Coloniale à Lacrosse. 13 janv. 1793. Min. Col. Martinique, 276 et 277 .

Compte rendu à la Convention Nationale par l'Assemblée Coloniale de la Martinique. Arch. Nat. Dxxv 118, dossier 124. 


\section{La Révolution française à la Martinique}

Chapitre IX

\section{La Dictature républicaine}

$\underline{\text { Retour à la table des matières }}$

L'expédition dont la Convention avait décidé l'envoi, et dont l'annonce avait exercé une si grande influence sur l'état des esprits dans l'île, n'était pas près d'aborder aux rives de la Martinique.

A peine partie, elle dut rebrousser chemin devant une tempête et rentrer au port. Là elle se disloqua et s'émietta peu à peu. La métropole avait besoin de ses soldats et de ses navires ; elle les reprit les uns après les autres. Le grand projet s'évanouit. Ainsi que le constataient mélancoliquement les Commissaires désignés pour porter au delà des mers l'expression de la volonté souveraine : «Il n'en restait plus qu'un chimérique et douloureux souvenir pour ceux qui s'y étaient attachés. »

D'ailleurs la Convention, aussitôt voté le décret du 8 novembre 1792, avait réfléchi et apprécié combien l'exécution allait en être malaisée. La faiblesse de la marine détournait d'envoyer plusieurs unités dans la mer des Antilles, où leur situation eût pu devenir critique en cas de guerre avec l'Angleterre. Or cette guerre paraissait imminente.

De Lacrosse et de ses tracts on n'avait osé raisonnablement espérer autre chose qu'une « préparation des esprits », propre à faciliter le succès de l'action militai- 
re. De celle-ci Rochambeau restait chargé. On ne lui tenait pas rigueur de son échec, le sachant brave, bon général et sincère républicain. Et l'on en revenait à se demander s'il était bien nécessaire de lui envoyer les renforts prévus pour qu'il pût tenter un retour offensif et s'acquitter de sa mission.

Lui-même était de cet avis. Depuis son débarquement à Saint-Domingue, il s'était morfondu dans une situation mal définie. Le commandement en chef y revenait à M. d'Esparbès. Etait-il à la disposition de celui-ci ou devait-il toujours se considérer comme le chef d'une expédition indépendante, que la première occasion favorable devait ramener vers son objectif initial ?

Dans sa correspondance il s'offrait de lui-même à réduire les îles insurgées, et il exposait à cette fin divers projets.

Ignorant la mission confiée à Lacrosse, il préconisait surtout une propagande intensive. C'était là, comme on a pu le voir, une conception très juste de la situation. Mais ses suggestions ne se bornaient pas à ce seul moyen, si puissant qu'il lui parût, et il écrivait : «Quelque parti que l'on prenne, je tâcherai de le mettre à exécution. Lié par devoir et par goût au sort de la Révolution française, je prouverai à l'Assemblée Nationale mon respect pour les lois nouvelles ${ }^{63}$.»

La Convention se laissa 'convaincre et lui envoya l'ordre de reprendre, les armes à la main, les Petites Antilles qui méconnaissaient la souveraineté républicaine.

\section{Planche XII.}

Voir Les Classiques des sciences sociales.

Il partit le 13 janvier 1793, sur l'aviso le Lutin, louvoyant avec circonspection pour échapper à la flotte royaliste, dont il était bien éloigné de penser qu'elle fît route pour Trinidad. Ce ne fut qu'à Sainte-Lucie qu'il apprit la réussite quasi miraculeuse de Lacrosse. Il alla aussitôt rejoindre celui-ci, qui présenta aux Guadeloupéens transportés « le général en chef des troupes des îles du Vent ».

Rochambeau, grandement émerveillé des résultats obtenus par le capitaine de vaisseau, l'assura dans la fonction de gouverneur provisoire de la colonie et s'em-

63 Lettre du 24 octobre 1792. Ministère des Colonies, Martinique, 273. 
barqua avec lui sur la Félicité pour aller prendre possession de la Martinique. Ils furent reçus à Saint-Pierre avec des clameurs de joie, à Fort-Royal avec crainte et respect.

Le moment ne manquait pas de grandeur : la campagne faisait sa soumission, les anciennes citadelles de la monarchie passaient à la République. Lacrosse exultait et il en avait le droit : « Je venais de conquérir, par la seule opinion, deux colonies, je les remettais aux mains d'un général que la République envoyait pour les réduire par les armes. »

Pour Rochambeau, son contentement de voir la cause qu'il servait triompher sans effusion de sang n'était pas exempt de mauvaise humeur. Assez enclin à exercer sa verve aux dépens d'autrui, il n'aimait guère prêter lui-même le flanc à la raillerie. Or, après avoir eu le ridicule de virer de bord sous la menace des canons quand il apportait la Paix et la Fraternité, il avait à présent celui d'être accueilli à bras ouverts alors qu'il était venu pour combattre. L'impatience qu'il en ressentait et l'obligation où il se croyait de décourager toute velléité d'ironie excitèrent le penchant naturel à l'autocratie qui distinguait ce républicain convaincu.

Les instructions qu'il avait reçues de la Convention étaient pourtant sans doute conçues dans le même esprit que le mémoire rédigé par elle à l'intention des commissaires échoués au port de départ. L'Assemblée Nationale, si sévère pour les métropolitains, faisait preuve envers les coloniaux d'une douceur quasi évangélique. «Les commissaires recommandait-elle, montreront la République comme une mère outragée par des enfants ingrats, mais dont la tendresse l'emporte sur le courroux et qui est toujours prête à pardonner... Ils prépareront les esprits au nouveau gouvernement que l'heureuse révolution du 10 août nous a donné ; ils dissiperont les erreurs dans lesquelles on a plongé les planteurs ; ils calmeront les craintes qu'on leur a inspirées sur leurs propriétés ; ils leur montreront que désormais, liées plus étroitement avec la métropole, les colonies partageront avec elle le bonheur qu'elle achète par tous les sacrifices. »

« Ils feront taire l'affection irréfléchie des colons pour les rois et la royauté en leur présentant les bienfaits que le régime républicain va répandre sur un peuple éclairé ; ils opposeront ce tableau à la peinture des maux inséparables de l'Ancien 
Régime sous lequel un gouverneur disposait au gré de ses caprices de l'honneur et de la fortune d'un citoyen. »

On retrouve là le verbiage grandiloquent de l'époque et les truismes affectionnés de tous les novateurs révolutionnaires. Mais tout cela n'était que rhétorique, car à la vérité, ni le sensible Vioménil, ni le bon Damas, ni l'hésitant Béhague, ni aucun des «suppôts de la Tyrannie » n'eût osé se conduire aussi despotiquement que fit Rochambeau.

Certes, il voulait faire régner la Liberté, l'Égalité et la Fraternité, mais son sentiment était qu'on n'y pouvait réussir sans le secours d'une ferme autorité, la faiblesse humaine incitant chaque individu à compromettre l'équilibre général en faveur de ses intérêts personnels.

On s'étonne parfois de voir les hommes qu'un principe ou une idée ont portés au pouvoir, être précisément ceux qui font prévaloir, dans l'action, le principe ou l'idée contraires. Il n'y a pourtant là rien que de très naturel.

La politique, c'est-à-dire l'art de conduire les sociétés, repose sur des vérités éternelles, parfaitement indépendantes des doctrines qui se disputent la faveur des partis et du consentement populaire. Les premières retrouvent toujours leur importance dès que les événements reprennent leur cours normal et que les situations se stabilisent ; les secondes ne sont que des drapeaux pour mener les troupes à la bataille. Les premières sont d'ordre logique et appartiennent au domaine du réel ; les secondes sont d'ordre sentimental et appartiennent au domaine de la passion. On conquiert dans la fièvre, on stabilise dans l'ordre.

Lorsqu'une formule en remplace une autre, c'est que l'ancienne précisément s'est écartée, en fait, de la règle morale qu'elle prétendait encore représenter. Lorsqu'un régime tombe, c'est qu'il a cessé, par la faute de ceux qui l'incarnaient, d'être une expression valable et respectée des lois profondes et permanentes avec lesquelles, du fait même qu'il s'était établi et avait duré, il avait fini par s'identifier.

Pour les Français de la Révolution, la monarchie avait été longtemps le symbole de l'ordre et de l'autorité. Ceux qui la défendaient comme ceux qui l'attaquaient ne se rendaient pas compte que la raison primordiale de son déclin, c'était précisément qu'elle avait laissé s'affaiblir et se dégrader ce qui avait fait sa force 
et son prestige. Et si la poussée révolutionnaire combattait, en apparence, les principes qui avaient consolidé la Monarchie, elle ne pouvait rien faire de durable qu'en revenant à ceux-ci. Les novateurs qui réussissent sont toujours invariablement des hommes d'autorité qui s'ignoraient. Rochambeau nous en est un exemple. L'histoire nous en a montré beaucoup d'autres.

Planche XIII. Au nom de la République française. Proclamation.

Nous Donatien-Marie-Joseph Vimeur ROCHAMBEAU,

Lieutenant-Général des armées de la République,

Gouverneur Général de la Martinique et Commandant-Général des Isles du Vent.

À tous les hommes libres de la Colonie.

Voir Les Classiques des sciences sociales.

Le 4 février 1793, Rochambeau lance sa première proclamation et passe aussitôt aux actes.

Pour bien montrer que tout lien avec le passé est rompu et qu'une ère nouvelle commence, il substitue sur-le-champ l'appellation de Républiqueville, ou FortRépublique, à celle de Fort-Royal, et celle de "Convention Nationale " à l' « odieux nom de Fort-Bourbon ».

«Il fallait tout changer dans ce pays et les dieux et l'idole, pour y faire vénérer ceux que les Français reconnaissent aujourd'hui et pour toujours. »

Mais ce n'était là que préliminaires symboliques à un nouvel ordre de choses. Dès le lendemain, Rochambeau suspend l'Assemblée Coloniale et casse «le prétendu Conseil exécutif ».

Levassor et ses collègues eurent beau exciper de leur bonne foi et protester contre les accusations d'usurpation qui étaient portées contre eux dans la proclamation du Général, ils ne purent obtenir gain de cause.

Quant à l'Assemblée, un peu gênée malgré tout par ses récentes palinodies, elle n'opposa aucune résistance. 
Rochambeau se souvint ensuite que le principal de la mission dont il avait été chargé à son départ de France était l'application intégrale de la loi du 28 mars-4 avril, loi à laquelle l'Assemblée Coloniale avait donné son adhésion le 3 juin et le 5 octobre 1792, mais dont les effets étaient loin d'avoir été pleinement réalisés. La Convention tenait expressément à ce qu'ils le fussent. Si des raisons d'économie politique et de prudence élémentaires la retenaient encore de libérer la multitude des esclaves, ses opinions sentimentales, d'accord avec ses intérêts, la poussaient à exiger l'assimilation aux blancs de tous les hommes libres, quelle que fût la nuance de leur peau, et à condamner une fois pour toutes un préjugé qui n'était d'ailleurs enraciné que chez les Français des colonies.

Mais chez ceux-ci il l'était encore profondément malgré les apparences. Rochambeau, qui arrivait du Cap-Français, avait pu s'en rendre compte à SaintDomingue, et le citoyen Leborgne, commissaire aux armées, qu'il avait amené à sa suite de cette colonie, avait pu le constater également, car il écrivait au ministre, en parlant de l'état des esprits dans la grande île : « Le croirait-on, le 27 novembre, dans le sein d'une société qui avait pris pour titre le symbole de l'Egalité et du Patriotisme, puisqu'elle portait celui des Amis de la Convention Nationale, j'ai été menacé d'être immolé à la tribune de cette société parce qu'on m'accusait de protéger les hommes de couleur ? »

Le Général jugea donc que les élections en vue des Assemblées primaires risquaient non seulement d'attiser les passions mal éteintes mais encore de ne pas donner les résultats qu'il désirait. Il trouva plus expéditif et plus sûr d'instituer une espèce d'administration provisoire sous forme de «Comités de Surveillance et de Police », jouissant de tous les pouvoirs attribués aux municipalités ordinaires. Les membres en furent nommés par des commissaires conciliateurs qu'il choisit luimême avec soin, prétextant, pour ne pas faire appel au corps électoral, «que les hommes gangrenés et pourris y domineraient, parce que tous les citoyens sur lesquels on pouvait compter n'étaient pas encore rentrés ». Il put ainsi, selon un savant dosage, introduire, dans chacun de ces comités, quelques hommes de couleur. « Pour la première fois, par la volonté de Rochambeau en conformité avec les intentions de la République, les mulâtres entraient comme égaux dans la grande communauté française. » 
En vérité, pour faire participer aux affaires du pays des hommes depuis six mois seulement réputés éligibles, il ne fallait rien de moins que le procédé dictatorial employé par le Général. Si l'on avait eu recours aux élections, les gens de couleur, par un reste de soumission et de timidité, eussent sans doute, une fois de plus, donné leurs voix aux blancs.

On le vit lorsqu'il s'agit de pourvoir au remplacement de certains officiers de la milice. Les mulâtres, dont ce corps était en grande majorité composé, nommèrent naïvement les planteurs auxquels ils avaient accoutumé d'obéir. Rochambeau dut confier aux commissaires conciliateurs le soin de rectifier leur choix et de leur attribuer à eux-mêmes une partie des postes vacants, tant il est vrai que la liberté elle-même ne peut être que le fruit de l'autorité !

Le Général fut ardemment secondé dans sa tâche égalitaire par Leborgne, dont il avait fait un commissaire conciliateur.

Ce citoyen, qui s'intitulait pompeusement le « Marat des colonies, le Missionnaire des principes de la Convention », avait un mérite qui supplée souvent aux dons les plus rares. Il était l'homme d'une idée et d'une idée juste, encore que son application demandât quelque prudence parce qu'elle comportait de grands risques : l'intérêt qu'avait la République à se concilier la couleur. " Pour peu, disaitil, que l'on donne à Rochambeau le temps de mettre complètement à exécution la loi du 28 mars-4 avril, les Anglais ne nous feront pas tant de mal qu'on le pense en Amérique. Les hommes de couleur des îles voisines, et dans lesquelles le plus grand nombre est français, ne tarderont pas à demander la même justice ; nous y aurons un parti considérable. »

Leborgne, on le voit, poussait d'emblée son idée jusqu'aux conséquences extrêmes. Il prévoyait, comme tout le monde alors, l'intervention imminente de l'Angleterre contre la République, et il trouvait dans sa conception non pas seulement le moyen de résister à une attaque armée, mais celui de répliquer par une offensive vigoureuse qui aurait ébranlé les bases mêmes de l'action adverse.

Ce n'était pas si mal pensé.

La lutte de la Monarchie contre la République prenant la figure d'un conflit entre l'Angleterre et la France, il y avait tout avantage à la transposer sur un terrain encore plus large, celui de la rivalité des blancs et des hommes de couleur. La cause de la Révolution devenait celle des opprimés de toute race et en tous lieux ; 
elle trouvait des alliés chez ses adversaires mêmes, et comme ces alliés étaient le nombre et la force, la partie changeait aussitôt de caractère.

Nous avons vu, en Europe même, une aussi profonde transformation de l'idée, quand elle a cheminé à travers les nationalités.

Ce que Leborgne n'apercevait pas encore, c'est que, par une extension bien naturelle, le principe qui valait pour les hommes de couleur libres s'appliquerait inévitablement aux esclaves, et que c'était une transfiguration complète des conditions d'existence des sociétés coloniales qu'il fallait envisager à plus ou moins court terme. Mais les conceptions ne se haussaient pas encore à cette vision de l'avenir. L'institution servile était le fondement de la vie économique des possessions européennes en Amérique. Elle demeurait un dogme que personne ne songeait à mettre en question. La Liberté était une chose, l'Egalité une autre. La seconde n'était due qu'à ceux qui jouissaient de la première.

\section{Planche XIV. Extrait des registres des délibérations de l'Assemblée représentative de la Martinique. Séance du 26 octobre 1793, l'an 2 de la République. Voir Les Classiques des sciences sociales.}

Rochambeau et Lacrosse s'étaient attachés, pour donner une plus grande efficacité à la propagande républicaine, à favoriser la formation de sociétés populaires. C'était d'ailleurs aussi, aux yeux du premier, un moyen le canaliser l'ardeur des « patriotes » dans une direction où elle ne pouvait gêner son magnifique autoritarisme administratif et politique.

Ainsi se constituèrent un peu partout des clubs des Amis de la Convention, comme cela s'était déjà produit à Saint-Domingue 64 .

Celui de Républiqueville fut fondé le 21 février 1793, par vingt-deux notables. Leborgne en fut un membre éminent et son apostolat put s'y exercer à l'aise.

64 Tout ce qui concerne le club des Amis de la Convention est tiré de l'article que M. de Cardinal lui a consacré dans les Annales historiques de la Révolution Française (juin 1931, pages 289 à 260). 
Il n'apparaît pas, à vrai dire, que cette société. ait donné à son activité une orientation d'un caractère positif et pratique capable d'influer sur le cours des événements et l'évolution des idées. Elle était essentiellement préoccupée de manifester son zèle républicain par des initiatives sentimentales et symboliques conformes au goût du jour, et dont on n'oserait dire même qu'elles eussent une portée morale.

Quand on y avait terminé la lecture en commun du « Patriote des Antilles » ou de la Gazette de l'imprimeur Willox, on discutait sur les moyens de frapper les esprits par quelque geste sensationnel dont l'idée enthousiaste germait dans quelque cerveau hanté du besoin d'affirmer, de façon rare et prestigieuse, sa ferveur doctrinaire.,

Les décisions étaient prises presque toujours « avec transport » et à l'unanimité. C'est ainsi qu'on résolut notamment de faire bénir les drapeaux après un service funèbre célébré à la mémoire des victimes de la guerre ; d'organiser un feu de joie avec les débris combustibles recueillis dans l'île rappelant l'Ancien Régime, et avec « les effigies de Louis Capet et de nos autres rois »; de planter un arbre de la République, ce qui donna lieu à une bien intéressante discussion sur la nature de l'arbre à choisir pour ce rôle symbolique ; finalement on écarta le palmiste pour lui préférer le tamarin, « cet arbre étant de plus longue durée et étendant davantage ses rameaux ». On se préoccupa également de remplacer une figure de la Renommée, surmontant le globe de Saturne, symbole du Monde, par un Diogène tenant une lanterne à la main : le sens de la nouvelle composition allégorique était éclairci par le secours de cette légende . «Ici, naguère je ne trouvais pas un homme, aujourd'hui j'en rencontre plusieurs. » Enfin, d'un commun accord, on fit inscrire, en grosses lettres, au-dessus du siège présidentiel, l'hymne des Marseillais, auquel on substitua, plus tard, l'hymne de la Martinique, dont il ne nous est malheureusement pas parvenu d'échos.

Pendant ce temps Rochambeau prenait, moins bruyamment, des mesures plus lourdes de conséquences.

Pour faire éclater la nullité des actes de l'Assemblée Coloniale, il mit à néant tous les décrets concernant le régime des ports, qu'ils fussent d'ouverture ou de fermeture, et, - plus intraitable que la Convention qui avait autorisé. l'entrepôt de 
la Trinité et l'accès de Fort-Royal aux étrangers pendant l'hivernage -, il revint purement et simplement à l'édit du 30 août 1784. Le Pacte colonial était rétabli dans toute sa rigueur ; les Saint-Pierrais jubilaient. Le refus du Général de reconnaître comme dette publique les 50.000 livres versées par les planteurs à la Station Navale, leur parut également fort louable.

D'ailleurs Rochambeau ne cachait pas sa prédilection pour Saint-Pierre. Il l'avait déjà manifestée en choisissant cette ville pour y débarquer, puis en lui demandant un détachement de 200 hommes destiné à assurer son autorité sur FortRépublique. Les «patriotes » s'étaient disputé avec un tel enthousiasme l'honneur et le plaisir de monter la garde au siège de l'ancien gouvernement, foyer de toutes les réactions, qu'ils avaient dû tirer au sort ce privilège.

Quant aux planteurs, ils étaient aussi penauds et terrifiés que peuvent l'être des gens qui s'aperçoivent qu'ils ont donné dans un piège. Ils maudissaient et leur crédulité et l'intransigeance du Gouverneur. "Puisque la colonie s'est remise à lui, gémissaient-ils, il devrait passer l'éponge sur nos erreurs. » Rochambeau oubliaitil que Lacrosse leur avait dit en propres termes. "Vous êtes appelés, par le vœu national, à fixer, pour le bien général, les rapports qui désormais nous seront communs »?

Le Général l'oubliait si peu qu'il en maugréait à longueur de journée contre le commandant de La Félicité dont la victoire lui semblait à présent moins surprenante et plus douteuse. Il en venait à penser qu'en réalité ce triomphateur, dont Monge vantait si haut les mérites à l'Assemblée nationale 65, avait fait beaucoup plutôt capituler la Révolution devant les colons, qu'il n'avait rallié ceux-ci à la Révolution.

Lacrosse devait éprouver lui-même à quel point il est plus agréable de faire des promesses mirifiques et contradictoires que de ne pas les tenir, car il insistait pour céder son poste de gouverneur de la Guadeloupe au général Collot, qui

65 « Ce succès inopiné est dû en entier au courage, au zèle éclairé et aux paternelles remontrances du républicain Lacrosse, commandant de la frégate La Félicité que j'y avais envoyé dans l'intention de préparer les esprits ». Le ministre de la Marine à la Convention, il mars 1793. 
l'avait occupé pendant quelques jours après le départ de M. d'Arrost, et « dont les intentions disait-il, étaient aussi pures que les siennes » 66 .

Mais bien qu'il vit assez clairement les difficultés pour souhaiter de les éluder, le capitaine de vaisseau n'en blâmait pas moins, tout bas, les mesures dictatoriales prises par Rochambeau. Il n'était pas le seul. Parmi les « patriotes » même, quelques-uns reprochaient au Général d'éloigner du bon chemin ceux qui se seraient volontiers réunis à eux. Ils devaient lui reprocher le contraire plus tard. Il n'est pas douteux que Rochambeau avait eu le tort de laisser percer sa rancoeur dans ses « proclamations fulminantes » du début. Il ne l'est pas davantage que le séduisant programme de Lacrosse comprenait des articles incompatibles.

Comment une Assemblée coloniale, en supposant même qu'elle fût sincèrement convertie aux idées républicaines, eut-elle accueilli la proposition d'assimiler entièrement et sur-le-champ les hommes de couleur libres aux blancs ?

On en pouvait juger par la manière dont les colons se terraient dans leurs lointaines habitations, et s'arrangeaient pour se soustraire à l'autorité civile et militaire lorsque celle-ci était exercée par l'un des «nouveaux citoyens ». Sans doute, les planteurs avaient toujours témoigné aux mulâtres une réelle "bienveillance » mais ce terme même indiquait assez la nature des relations qu'ils entendaient avoir avec eux.

Ulcérés, convaincus que les commissaires civils que la France devait envoyer dans l'île, et dont on agitait toujours le spectre, allaient mettre bientôt le comble à leur malheur, beaucoup de notables habitants se détachaient l'un après l'autre et partaient pour Trinidad, où le nombre des émigrés s'accroissait sans cesse. Ceux qui ne pouvaient se décider à quitter leurs propriétés essayaient de s'y faire oublier. Le parti des « aristocrates » ne sentait que trop qu'il avait perdu le principe de sa force en perdant le dévouement de la Couleur.

Mais l'Océan touche à bien des rives et porte plus d'un pavillon...

Qu'ils fussent exilés ou maîtrisés, les colons sentaient se ranimer au fond de leur coeur la flamme vacillante de l'Espoir au seul chuchotement de ce nom : Du Buc.

66 Lacrosse à Rochambeau, 24 février 1793. Arch. Nat. Dxxv 116. 
Qu'était devenu leur envoyé, l'homme dont la pensée les avait éclairés, dont l'énergie les avait soutenus, et dont l'initiative réfléchie ne pouvait tout de même avoir eu pour résultat de les abandonner sans espoir à leur malheureux sort ?

\section{CHAPITRE IX. RÉFÉRENCES :}

Lettre des citoyens Antonelli et Corroler, commissaires de la Convention Nationale aux Iles du Vent. Brest, 10 février 1793. Archives Nationales Dxxv 118.

Lettre de Rochambeau aux citoyens ministres. Octobre-novembre 1792. Ministère des Colonies Martinique, 273.

Lettre de Lacrosse au ministre. 13 février 1793. - Du viel Acquart à son fils, 9 février 1793. Ministère des Colonies Martinique, 276. - De Rochambeau au ministre du 10 février 1793, Martinique, 94.

Protestation des membres du Conseil Exécutif. 5 février 1793. Ministère Colonies Martinique, 94.

Mémoire pour les commissaires de la Convention (sans date). Ministère des Colonies, Martinique, 94.

Proclamation de Rochambeau. Ministère Colonies Martinique, 94.

Adresse à la Convention Nationale présentée par le citoyen commissaire Leborgne. Arch. Nationales Dxxv 118.

Lettre du citoyen Leborgne au ministre Fort République. 7 mars 1793. Archives Ministère Colonies Martinique, 276.

Annales historiques de la Révolution Française. Article de M. de Cardinal, sur le club des Amis de la Convention. Juin 1931, pages 239 à 260.

Mémoire de Berclery. Ministère Colonies Martinique, 278. 


\section{La Révolution française à la Martinique}

\section{Chapitre X \\ L’Intervention Anglaise échoue}

Retour à la table des matières

Du Buc et M. de Clairfontaine, voyageant de compagnie, étaient arrivés à Londres vers la fin de 92. Ils y avaient retrouvé les chevaliers de Perpigna et de Curt, ex-députés de la Martinique et de la Guadeloupe auprès de l'Assemblée de Paris.

Mieux qu'aucun autre, Louis de Curt était en mesure de les éclairer et de les seconder dans leur mission. Grâce à sa grande fortune et aux relations qu'il avait à la cour d'Angleterre, il faisait, depuis l'émigration, figure de personnage. Bien des « ci-devant » lui devaient d'avoir échappé à la misère, et des seigneurs qui avaient compté parmi les plus prestigieux de la cour de Versailles, recherchaient son appui. Les frères du Roi eux-mêmes avaient recours à ses bons offices pour obtenir un crédit dont le besoin les talonnait.

Les mandataires des Princes s'étaient également adressés à lui pour emporter l'adhésion du gouvernement britannique à leurs desseins sur les Antilles françaises. Les rapports courtois que Louis de Curt entretenait avec lord Hawkesbury, président du Conseil du Commerce et des Colonies, ne pouvaient que faciliter les pourparlers. 
Cependant ces pourparlers n'avançaient guère. Comme l'ancien député de la Guadeloupe l'exposa à Du Buc, le maréchal de Castries, qui traitait au nom de Monsieur, désirait obtenir le prêt de quelques vaisseaux. Le marquis de Bouillé, était disposé, à prendre le commandement de l'expédition ; de nombreux créoles, inquiets sur leurs biens, et un petit corps de monarchistes avides de servir la bonne cause, trépignaient d'impatience à Douvres et à Portsmouth. Mais le cabinet britannique ne semblait pas très enclin à engager des dépenses pour des Princes qui, en dépit des protestations d'amour fraternel qu'ils recevaient des souverains européens, n'étaient même pas parvenus à se faire « reconnaître ». L'offre qu'avait apportée le baron de Constant de réserver toutes les denrées des îles à l'Angleterre pour aussi longtemps qu'on aurait besoin de son secours, avait paru retenir l'attention des ministres, mais ceux-ci n'en continuaient pas moins à réserver leur réponse.

A la lumière de ces renseignements, Du Buc aperçut toute la naïveté du chevaleresque projet cher à son ami le commandant Rivière . "Conserver encore une petite possession de l'empire de son maître Louis XVII, sous l'étendard des lys et y offrir un asile aux différents membres de son Auguste Famille dispersés en Europe 67 . »

Il lui parut douteux que les monarchistes, avec leurs moyens limités à quelques navires empruntés et à un matériel de fortune, fussent à même de protéger les Iles du Vent contre toute entreprise. L'obtention même de la petite escadre sollicitée semblait fort problématique. Le temps pressait. L'ouverture des hostilités entre la France et l'Angleterre, s'avérait inéluctable. Derrière les atermoiements du cabinet de Saint-James, n'y avait-il pas cette pensée que la déclaration de guerre autoriserait la Grande-Bretagne à conquérir les Antilles françaises pour son propre compte?

Le chevalier Du Buc avait hérité de son père cet esprit logique et réaliste qui faisait l'admiration de l'abbé Raynal. D'accord avec MM. de Curt, de Clairfontaine, de Perpigna, de Charmilly et Malouet, il reprit les négociations sur des données nouvelles et conclut bientôt, avec les ministres de Georges III, un arrangement dont l'exécution devait, à son sens, « contenter tous les intéressés ».

67 Souvenirs du chevalier de Valous. 
Les députés des îles, ignorant l'apostasie des Assemblées coloniales, posaient en principe que leurs commettants ne voulaient à aucun prix reconnaître la République Française « qui, d'ailleurs, les exterminerait ».

Ils se faisaient fort de « mettre en la possession et sous l'autorité de S. M. Britannique la Martinique et la Guadeloupe, leurs ports, forteresses, arsenaux, vaisseaux de guerre, frégates et autres bâtiments, en un mot tout ce qui appartenait à l'autorité royale », à la condition que l'Angleterre s'engageât à restituer les colonies à la France «dans le cas ou, à la fin de la guerre actuelle, aucun des Princes de la branche française de la maison de Bourbon (à l'exclusion de Philippe Egalité et de sa race) remonterait sur le trône ». Naturellement le Prince devait, de son côté, rendre toutes possessions britanniques dont les armes françaises pourraient s'être emparées, et rembourser les dépenses.

Le traité fut signé, à Whitehall, le 19 février. L'Angleterre était entrée en guerre contre la France le 31 janvier.

Dans le préambule, Georges III assurait aux colons le maintien de leurs privilèges et de leurs franchises, la conservation de l'état social sur lequel se fondait leur richesse, le respect de leur religion, un régime de liberté analogue à celui dont jouissaient toutes les colonies de la Couronne.

L'histoire a jugé avec sévérité cette initiative du chef des planteurs. Pour beaucoup de ceux qui se sont penchés sur les événements complexes de cette époque si trouble, Du Buc porte l'opprobre d'avoir été l'homme qui a vendu la Martinique à l'Angleterre.

Vendu ? Manifestement non. La tractation, pour condamnable qu'elle soit, était exempte de tout esprit de vénalité chez Du Buc comme chez ses commettants. « Livré » serait plus juste, et encore faut-il ajouter : « provisoirement ».

Il n'empêche que le geste était grave, et qu'il choque douloureusement notre sentiment de Français portés à tout comprendre, sinon à tout excuser, sauf le reniement de la patrie.

Certes Du Buc avait stipulé le retour des colonies à la France, dès le rétablissement de l'autorité qu'il considérait comme la seule légitime et régulière, et ses conceptions de grand aristocrate devaient le conduire à penser que, tôt ou tard, 
l'événement était certain : aussi bien la République ne pouvait-elle être, à ses yeux, qu'un accident, un gouvernement insurrectionnel, fruit du désordre et de l'émeute, dont les jours étaient nécessairement comptés, ne fût-ce que du fait de toutes les causes de ruine et de décomposition qu'il portait en lui-même.

Mais comment n'éprouvait-il pas quelque hésitation intérieure à l'idée que les jugements humains sont toujours faillibles ? Comment n'admettait-il pas que, si sûr qu'il se crût de voir juste, sa perspicacité pouvait tout de même être en défaut ? Comment ne songeait-il pas aux conséquences redoutables de la situation qu'il créait, si, par aventure, jamais la dynastie qu'il entendait servir indéfectiblement, ne remontait sur le trône?

Alors son traité prendrait une signification terrible : la fidélité jurée aux Bourbons ne serait plus que le culte d'un souvenir aboli, et le fait réel serait que sa terre natale aurait pour toujours cessé d'être française.

Nous ne pouvons, malgré l'évidente pureté de ses intentions, malgré l'estime que méritent la lucidité de son intelligence et la fermeté de son caractère, ni l'absoudre ni même lui trouver une excuse valable. Au moins a-t-il droit aux circonstances atténuantes. Par-dessus la France du moment, dont le visage convulsé ne lui présentait plus l'image de la patrie qu'il aimait, il croyait servir la France éternelle. Les faits, d'autre part, tournèrent sinon exactement comme il le supposait, du moins dans un sens voisin de celui dont il se croyait certain. Napoléon, puis Louis XVIII portèrent sur lui et sur son rôle un jugement favorable.

Le 24 août 1824, le Conseil d'Etat, appelé à fixer le montant de la pension due au chevalier, décida de lui tenir compte des années pendant lesquelles il avait rempli, comme président de l'Assemblée Coloniale, du Directoire administratif et du Comité intermédiaire, des fonctions non rétribuées, considérant : "Que c'est seulement en raison de celle position et par la conduite qu'il y a tenue, qu'il a réussi à négocier avec le gouvernement anglais le traité au moyen duquel, tandis que la Révolution ravageait les autres colonies, la Martinique prospérait et était conservée à la France pour être rendue au roi, au retour de la paix. »

Sans qu'il faille entièrement ratifier ce jugement, dont la bienveillance comporte quelque partialité, nous devons reconnaître que Du Buc, sans desservir effectivement la France, servit, de toute sa sincérité, la Martinique. 
Le chevalier et ses collègues, nous l'avons dit, avaient assuré que l'accord négocié par eux était de nature à satisfaire tout le monde, et devait plaire à tous les intéressés. Ils n'avaient cependant pas la naïveté de croire qu'il leur plairait en effet. Il s'en rendaient si bien compte qu'ils n'en révélèrent les clauses qu'avec une extrême circonspection.

Les monarchistes ne pouvaient si facilement renoncer à leur chimère. M. de Cougnacq-Myon s'y obstina particulièrement. Il était persuadé, sur la foi de conversations avec des généraux espagnols, que $\mathrm{S}$. M. très catholique était prête à accorder son aide à ses cousins en toute générosité. Lorsqu'il eut connaissance de la convention de Whitehall, il manifesta une violente indignation. « Nous ne donnerons pas la colonie, nous, écrivait-il au maréchal de Castries ; une telle pensée n'est jamais entrée dans notre esprit, mais nous la reconquerrons pour nous pour notre Roi. » Il dut toutefois reconnaître la fragilité de son espoir lorsqu'ayant essayé d'obtenir un concours financier des Etats-Unis les Princes lui refusèrent la permission de contracter l'emprunt au nom du Régent, pour ce qu'aucune garantie sérieuse ne pouvait honnêtement être offerte.

Quant à M. de Béhague, l'exil lui avait fait une âme héroïque et aventureuse au point qu'il formait le dessein de reprendre la Martinique par ses propres moyens. N'avait-il pas suffi qu'il se montrât en 91 pour que tous les rebelles s'inclinassent devant lui ? Ses officiers lui étaient demeurés fidèles, il avait encore quelques troupes ; il en aurait davantage, et tout un matériel de guerre. Il n'y fallait que de l'argent. Mais comment s'en procurerait-il ? C'était précisément là qu'éclatait le génie de Jean-Pierre-Antoine de Béhague. Méprisant les emprunts onéreux, humiliants et d'ailleurs irréalisables, il résolut de s'emparer de haute lutte des gourdes, piastres et livres nécessaires à son entreprise. En raison de quoi il pria M. de Rivière de bien vouloir se livrer à la guerre de course et s'emparer des bateaux chargés de sucre qui sortaient de Saint-Pierre "pour acquérir par la richesse de ces prises une prompte supériorité de forces en tout genre ».

Le commandant de la station navale résidait à Trinidad, dont le gouverneur, M. de Chacon, l'avait accueilli, lui et ses officiers, de la manière la plus touchante. Il y attendait la réponse de Charles IV d'Espagne à ses offres de services. Sans doute méconnut-il l'excellence du plan de M. de Béhague, car il se déroba en prétextant que la Ferme n'était pas en état. Ce qui ne l'empêcha pas de reprendre la 
mer moins d'un mois plus tard, sur les nouvelles que lui apporta une petite délégation de planteurs de la Martinique !

Le parti «aristocrate » s'était relevé. Cela avait commencé par des doutes échangés de bouche à oreille sur la venue de la flotte fantôme. Bientôt s'y ajouta le bruit que l'Angleterre était entrée en guerre contre la France. Une lettre de Du Buc circula sous le manteau; les planteurs se prirent à interroger l'horizon marin avec plus d'espoir que de crainte. Le 4 avril ils y aperçurent la frégate anglaise $l a$ Blanche, qui croisait au large de Fort-République. Le fait qu'elle s'enfuit devant la Félicité, sans accepter le combat, leur fit conjecturer qu'elle n'avait tenté que de communiquer avec eux. Enhardis par ces présages, plusieurs habitants ayant à leur tête un grand sucrier du nom de Percin, se retirèrent sur le morne Le Maître qui domine Case-Navire, et y formèrent un camp qu'ils nommèrent « Le Camp Décidé ».

Rochambeau ne prit pas tout d'abord la chose au sérieux. Mais lorsque le 15 avril les séditieux eurent, en effet, prouvé leur décision en razziant les armes et les munitions de Case-Navire, il résolut de faire cesser sur-le-champ cette mauvaise plaisanterie et se porta à l'attaque du retranchement. Il l'eût vraisemblablement enlevé si les deux colonnes qui composaient son expédition eussent pu se joindre au lieu et à l'heure prévus. Celle qu'il commandait y parvint seule ; la seconde en fut empêchée par un incident regrettable : en cours de route, le soldat Barberoux, poussé par son zèle révolutionnaire, avait imaginé de fusiller son chef, le colonel de Saint-Cyran, dont la modération lui semblait suspecte.

De ce fait, Rochambeau n'avait remporté qu'un demi-succès. Il le crut suffisant pour dégoûter les factieux, et, le lendemain, 17 avril, ordonna par voie d'affiches, à tous les citoyens, de dissoudre leurs rassemblements dans les 48 heures, sous peine d'avoir affaire à la force publique. A quoi le Comité intermédiaire qui, bien qu'officiellement suspendu, se réunissait a nouveau en quelque point de la campagne, répondit que le Général commençât par dissoudre les clubs et toutes ces sociétés populaires «formées d'hommes tombés du ciel ou plutôt sortant de l'enfer ». Il ajoutait que si les planteurs se voyaient encore obligés de prendre les armes pour se défendre « ce serait un combat à mort ». 
Les choses en étaient là quand, le 27 avril, la Blanche réussit à débarquer à La Caravelle, fief des Du Buc 68, l'ancien gouverneur de Sainte-Lucie, M. de Gimat, qui apportait le texte de l'accord de Whitehall. L'effet en fut immédiat. Les « aristocrates », revenus à la monarchie, piquèrent à leurs chapeaux des cocardes de deuil, arborèrent le pavillon blanc sur tous les forts et les batteries situés sur leur territoire et coupèrent les communications avec l'ouest de l'île. Les Anglais devaient pouvoir, ainsi, disposer de plusieurs ports pour effectuer leur descente. Le Comité intermédiaire tenait parole : le combat à mort était engagé.

A l'annonce de ces événements, M. de Rivière dépêcha le chevalier de Valous à l'amiral Gardner et le comte de Mallevault à M. de Béhague.

Celui-ci, prié par le commandant de la Calypso de venir à la tête de ses troupes fidèles coopérer à la reprise de la colonie que le Roi lui avait confiée, sentit sa belle ardeur se glacer. Il se confondit en phrases dilatoires : « Je ne suis plus ce que j'ai été... Je remercie de l'intérêt que l'on me porte... Plus tard, peut-être... » M. de Mallevault, qui estimait sa démarche de pure forme, salua et remit à la voile.

À la Martinique, le Club des Amis de la Convention se montrait à la hauteur des circonstances. Le 2 mai y vit de ces heures où l'enthousiasme jaillit en une flamme si noble qu'elle justifie tout ce qui l'alimente. On décréta avec transport et à l'unanimité « que les patriotes ne marcheraient en campagne que la torche d'une main et la Déclaration des Droits de l'Homme de l'autre » (ce qui était sans doute une image littéraire) ; que le Gouvernement serait prié d'accorder provisoirement la liberté aux esclaves qui se réuniraient sous la bannière nationale (ce qui risquait de créer des difficultés ultérieures) ; que la colonie devait être déclarée en danger ; qu'un aviso porterait à la Convention le procès-verbal de la séance et qu'en tête de ce procès-verbal figureraient ces mots : EVEIL AUX BONS PATRIOTES. Enfin on invita les citoyens des galeries à descendre dans le sein de l'Assemblée pour se confondre avec leurs frères ; on chanta la Marseillaise et tout le monde s'embrassa, ce qui était excellent pour porter le moral des futurs combattants au point où l'héroïsme paraît facile.

68 Dépendant du bourg de Trinité. 
Le même jour, Du Buc, enfin libéré des obligations qui l'avaient retenu plus longtemps qu'il n'eût voulu en Angleterre, s'embarquait sur la Vengeance.

\section{Planche XV. Lord Gardner.}

\section{Voir Les Classiques des sciences sociales.}

Le 7 mai, à la grande joie des planteurs et de M. de Gimat qui s'était mis à leur tête, la Ferme mouilla devant Case-Navire.

Rochambeau, fort démuni de troupes, avait dû, comme naguère les colons, puiser dans la masse des esclaves. Il en avait retiré un corps de chasseurs ; mais, en dépit de cet accroissement d'effectifs, il jugea préférable d'évacuer Case-Navire et fit ranger, dans le Cul-de-Sac, les deux seuls bâtiments de guerre dont il disposât : la Félicité et la Bienvenue. Il ne pouvait envisager une bataille navale : Mallevault et Valous rejoignaient avec la Calypso et le Coureur. Et, derrière eux, apparaissaient les huit puissants vaisseaux de l'escadre anglaise.

Celle-ci était commandée par le vice-amiral Gardner. Ce noble lord s'efforçait présentement à déguiser l'irritation que lui avait causée le message de M. de Rivière, et dont le messager, $M$. de Valous, avait essuyé, sans patience, le premier feu. Comment l'officier de S. M. Britannique eût-il pu se contenir quand le chef de l'escadre royale de France l'avisait tout tranquillement qu'il s'était offert à Charles IV et n'attendait que l'agrément de ce prince pour rallier la flotte espagnole ? Etait-ce là remplir les promesses de Du Buc ? Dans sa colère, l'amiral avait balancé à s'emparer de vive force des bâtiments convoités. La réflexion l'avait incité à plus de diplomatie. « Rien n'est perdu tant que l'affaire n'est pas conclue, pensaitil. Les conditions que je puis offrir à M. de Rivière sont assez avantageuses pour l'amener à se dégager vis-à-vis de l'Espagne. »

C'était bien mal connaître le commandant de la Ferme. Quand celui-ci avait une fois pris une résolution, rien ne l'en eût pu faire dévier d'une ligne. Il s'était lié, par serment, aux Bourbons ; n'en fût-il resté qu'un et sur un îlot perdu, qu'il eût estimé lui devoir ses services.

Aussi les ouvertures que lui fit lord Gardner n'eurent-elles aucun succès. Les deux hommes en seraient promptement venus aux propos les plus vifs si chacun 
n'avait eu intérêt à ménager l'autre. Huit jours se perdirent en conversations, cependant que la flotte anglaise croisait nonchalamment au large de la baie. Le commandant et l'amiral ne s'entendaient non plus que deux sourds ; l'un parlait Martinique et secours aux colons, l'autre navires à annexer.

Rochambeau, que n'avaient pu intimider les forces considérables dressées en face de sa petite armée, sentit l'indécision du camp adverse et résolut d'en profiter. Son plan fut bientôt fait : il laisserait la Garde Nationale dans les forteresses, afin de se réserver de solides points d'appui, et tiendrait lui-même la campagne avec des troupes légères.

Bien secondé par ses lieutenants, notamment par l'homme de couleur Bellegarde qui, à la tête d'une compagnie de ses semblables, se distingua à l'attaque de l'habitation Levassor, il reprit plusieurs postes aux planteurs. Ceux-ci se défendaient de leur mieux, cédant le terrain pied à pied. Le sucre ne les protégeait plus. Rochambeau n'était pas en situation de l'épargner et faisait mettre le feu aux cannes chaque fois qu'il le jugeait nécessaire. Les chasseurs apportaient en cette besogne un zèle particulier, joyeux de piller et de brûler ces ateliers et ces moulins où ceux de leur race avaient été assujettis, sous la menace des rigueurs de l'institution servile, à un dur travail.

En peu de temps, le Général se rendit maître de toute la partie comprise entre Fort-République, le Lamentin et la Rivière-Salée. Il continua vers le sud-est de l'île sa marche victorieuse. Des bateaux anglais et français on la pouvait suivre des yeux aux incendies qu'elle allumait.

Gardner n'en bougeait pas davantage. Pressé par Rivière, il finit pourtant par émettre l'avis qu'il serait peut-être opportun de débarquer quelques troupes, mais que l'affaire regardait les généraux Bruce et Garth, restés à la Barbade. Il se décida même à les aller chercher et partit le 17 mai en laissant deux vaisseaux pour aider à assurer le blocus.

Si le général Bruce ne s'était pas encore mis en route, il avait du moins déterminé $\mathrm{M}$. de Béhague à le faire, en s'adressant à lui comme au chef des armées de terre et de mer des Antilles françaises. L'ancien Gouverneur en avait sur le coup recouvré le sentiment de son importance et des responsabilités qu'elle entraînait, et s'était empressé de rejoindre, à la Barbade, le général anglais. Lord Gardner les y trouva tous les deux qui buvaient des boissons glacées sous les cocotiers en ar- 
rêtant les détails de l'occupation de la Martinique. De la conquête, il n'était pas question. Dès qu'il disposait, grâce à ses alliés, « de l'apparat de la force qui en prévient l'usage », $M$. de Béhague considérait le problème résolu. " Je ne doute nullement, exposait-il, que les rebelles au Roi ne se rendent à discrétion à la première sommation comme les dissidents l'ont fait à mon arrivée, en 1791. » Il connaissait par coeur l'art et la manière d'opérer : négociations avec les habitants « de confiance »; débarquement sur l'un des points qu'ils occupent ; publication de la loi martiale; proclamations péremptoires, désarmement général, exil des " méchants » et des « dangereux ». « Il n'y a aucune raison, pensait-il, pour que ce programme qui m'a si bien réussi une première fois, ne réussisse pas une seconde. » « Il y en a encore moins, pouvait soupirer Du Buc, pour que M. de Béhague comprenne jamais quoi que ce soit aux événements où il a été appelé à jouer un rôle supérieur à ses moyens ».

Le général Bruce avalait gravement les sornettes de son collègue français et les trouvait fort de son goût. Il étudiait la carte de la Martinique avec lui et lui soumettait les proclamations qu'il avait fait imprimer. M. de Béhague n'aimait pas beaucoup que celles-ci fussent au nom du « Georges III, roi de Grande-Bretagne, d'Irlande et autres terres », et non pas à celui de « Monsieur, Régent du Royaume », mais l'Anglais assurait que cela revenait au même.

L'amiral Gardner, quelque peu interloqué, dut constater qu'il y avait aussi loin de la Martinique à la Barbade que de la coupe aux lèvres. Il lui fallut trois semaines pour venir à bout des illusions du général Bruce. Celles de $M$. de Béhague s'effondrèrent brutalement le 10 juin lorsqu'il apprit, à son réveil, que les Anglais venaient de lever l'ancre, emmenant tous les émigrés royalistes. Il courut à la grève ; l'escadre était déjà loin. Elle filait en bon ordre, toutes voiles déployées sur l'azur. M. de Béhague chancela sous l'affront : lui, Gouverneur et Général des Iles du Vent de par la volonté du Roi, avait l'humiliation d'être délaissé aux yeux de toute l'armée !

Sur le pont de la Ferme, $M$. de Rivière, dévoré d'impatience, jetait tantôt des regards désespérés sur la vigie et tantôt scrutait lui-même, de sa longue-vue, la mer vide. Quand donc Gardner se déciderait-il à reparaître ? Depuis huit jours, le commandant avait en poche les dépêches officielles de Madrid l'admettant lui, ses 
bâtiments et ses troupes de terre et de mer, dans l'armée espagnole. M. de Chacon, qui les lui avait transmises, y avait ajouté. l'ordre de rallier Trinidad au plus tôt ${ }^{69}$. " Mais Rivière ne pouvait se résoudre à abandonner les infortunés colons de la Martinique à la seule protection du commodore Murray qui ne montrait de l'énergie qu'à répudier toute initiative

Car on pense bien que Rochambeau n'avait pas perdu le temps que ses adversaires lui accordaient si bénévolement.

Après un répit de quelques jours, il avait, dès le 28 mai, repris l'offensive avec des troupes tout animées par leurs récents succès. Cette fois, il était remonté vers le Nord, dégageant d'abord ses voies de communications avec Saint-Pierre ; puis, il s'était attaqué au Gros-Morne dont la possession avait pour lui un intérêt majeur, parce qu'elle lui ouvrait le chemin de la Trinité, seul grand port fortifié que ne bloquassent pas les navires anglais. Le 8 juin, grâce à une habile manoeuvre d'encerclement, il était parvenu à se rendre maître du Morne ; le lendemain, les insurgés évacuaient la Trinité. Le Général avait atteint tous ses objectifs, récupéré 33 canons et quantité d'armes, de munitions et de vivres.

Il ne manqua pas, dans le compte-rendu qu'il fit à la Convention, de signaler tous ceux dont « l'aide zélée » avait permis la victoire : Bellegarde, promu dès les premiers engagements commandant des chasseurs, - La Rochette, un autre mulâtre, capitaine au même corps, - les officiers La Corbière et Pierre Bose, - Toraille, commandant aux gardes nationaux de Saint-Pierre, -- René Mestre, - enfin le courageux Lenclume et le capitaine Souques, tombés au champ d'honneur.

Les planteurs, à bout de souffle, et M. de Rivière, pris entre son respect pour la discipline et ses sentiments d'humanité, poussèrent des cris de délivrance à la vue de l'escadre anglaise.

Il leur fallut presqu'aussitôt déchanter. Lord Gardner, furieux d'apprendre que la flotte française échappait à sa convoitise, fit au commandant une scène épouvantable. « Non seulement je vous empêcherai de partir, vociférait-il, mais je vous défends d'arborer le pavillon espagnol. » -« J'arborerai pourtant ce pavillon, répar-

69 «Les conditions n'étaient pas aussi agréables (que celles des Anglais), dit le chevalier de Valous, mais nous avions rempli notre devoir à l'égard de la Maison de Bourbon et cette idée consolante adoucit notre ennui ». Avec les rouges aux isles du Vent. 
tit froidement M. de Rivière, et si vous le trouvez mauvais vous ferez votre devoir et moi le mien. Vos neuf vaisseaux peuvent me combattre ; ils ne me prendront jamais. » Ces paroles et l'air duquel elles furent prononcées modérèrent les éclats de l'amiral sans améliorer son humeur.

Cependant M. de Rivière différa son départ. Il était inquiet de la mauvaise volonté des Anglais. Le général Bruce, lui aussi, trouvait qu'il y avait maldonne : on lui avait dit qu'on lui livrerait la Martinique et non qu'il faudrait la conquérir ; si les Martiniquais n'étaient pas en état de tenir les engagements pris par leurs députés, le général estimait que l'expédition de S. M. Britannique n'avait plus qu'à virer de bord.

En vain les membres du Comité intermédiaire lui représentaient l'extrême facilité de la conquête : les Anglais pouvaient débarquer 1.700 hommes d'excellentes troupes et 5 à 600 matelots ; que pèseraient, devant ces forces fraîches et bien entraînées, les soldats improvisés de Rochambeau, déjà éprouvés par un mois de campagne ? En vain Rivière, Gimat et tous les officiers français, faisant appel à la générosité des Britanniques, cherchaient-ils à les émouvoir en leur peignant les colons immolés à la fureur des révolutionnaires dès que la flotte aurait disparu. Gardner restait irréconciliable, Bruce plus impassible qu'un soliveau, et Garth épouvanté à la seule idée qu'on pût le soupçonner d'avoir une opinion personnelle.

Dans ces conjonctures, l'arrivée de M. de Béhague sur un petit bateau prêté n'obtint qu'un succès d'estime. Accueilli sur la Ferme, avec une courtoisie distraite, le général, ulcéré, résolut de forcer l'attention admirative de tous ces ingrats en allant s'engager, comme simple volontaire, au poste Lacoste. Mais la situation des planteurs était trop tragique pour qu'aucun d'eux eût le coeur à sourire. Les Anglais les abandonnaient décidément. Le 13 juin, au matin, ils commençaient à appareiller, quand parut la Vengeance, portant le chevalier Du Buc.

Les officiers britanniques purent constater qu'un honnête homme sait bannir toute inconvenance de son langage sans en atténuer la vigueur. "Il faut avoir l'apathie et l'ineptie de M. Bruce, écrivait Du Buc dans son journal, pour entendre sans en être seulement ému tout ce qu'il entendit dans cette matinée. » Cependant les Anglais ne laissaient pas d'être impressionnés par les reproches de celui qui avait traité avec lord Hawkesbury et sir Henri Dundas : «Les planteurs avaient 
pris la Trinité, le Marin, toutes les batteries de la côte, leur disait-il ; vous pouviez débarquer sans tirer un coup de fusil. Si vous vous étiez distingués autrement que par votre inertie vous seriez, à présent, les maîtres de la Martinique à laquelle les ravages des incendies eussent été épargnés. Jusqu'au 8 juin, les colons ont gardé le Gros Morne et vous ont tenu la Trinité ouverte, et vous n'en avez pas profité. »

Lord Gardner semblait ébranlé ; Du Buc redoubla d'efforts. Il ne se faisait aucune illusion sur les talents militaires comparés de Rochambeau et du général Bruce ; mais il était sûr néanmoins que celui-ci réussirait, s'il en avait la volonté, à cause de la grande supériorité de ses forces et parce que «quelqu'incapable qu'il soit on pourrait suppléer à son incapacité ». Aussi s'obstinait-il à entreprendre cette tête de bois, assisté en cela par le Comité, M. de Rivière et M. de Gimat qui « mettaient alternativement en usage tout ce qui leur paraissait propre à produire quelque effet».

Le chevalier était allé, entre deux assauts, prendre un peu de repos sur son navire, lorsqu'on lui annonça M. de Béhague qui avait, en trente-six heures, épuisé toutes les joies du métier de simple soldat. Louis-François Du Buc comptait, à cette époque, 34 ans et son hôte 66 . Il le reçut avec la plus déférente amabilité : par malencontre, il avait quelques affaires pressantes à régler ; il priait M. le Général de bien vouloir l'attendre un moment et d'en user comme chez lui.

M. de Béhague attendit trois jours. Le 17 juin, il vit apporter sur un brancard M. de Gimat qui devait, peu après, mourir de ses blessures. Le parti des « aristocrates » était en déroute ; Rochambeau et la Révolution triomphaient.

L'avant-veille, à la suite d'une discussion sans issue, Du Buc avait déclaré : «Fort bien! messieurs; mais comme nous sommes responsables au Roi et en quelque manière à la Grande-Bretagne de cette expédition, nous tenons à établir qu'elle ne manque que par votre faute. M. Bruce fera ce qu'il voudra, mais il doit au moins nous donner acte de notre demande et de son refus. » Cette fois le général Bruce, coincé entre deux responsabilités, s'était troublé. Encouragé par lord Gardner il avait fini par accepter l'idée d'un débarquement. 
Le jour même il mit à terre un millier d'hommes à Fond-Capot. Son dessein était d'attaquer Saint-Pierre du côté du Carbet, de manière à couper les relations avec Fort-République et à garder le contact avec les insurgés de Case-Navire. Escomptant un effet de surprise, il fit commencer le mouvement à 11 heures du soir.

La surprise eut lieu mais elle fut pour son armée : Rochambeau avait eu la même idée que lui. Avec trois ou quatre cents hommes il était parti de SaintPierre à la nuit close. Si ses troupes étaient inférieures en nombre, elles avaient l'avantage d'être familiarisées avec le pays. Les Anglais, assaillis en pleine marche nocturne sur des chemins inconnus, s'affolèrent ; ils tiraillèrent au hasard sans plus distinguer leurs ennemis de leurs alliés. En un instant le désordre fut à son comble chez les coalisés; la terreur panique précipita la déroute. A 6 heures du matin les derniers fuyards étaient rentrés au camp.

Du Buc parcourait à cheval les différents postes des planteurs lorsqu'on vint l'avertir que les officiers britanniques le demandaient d'urgence. Il les trouva vexés et dépités, irrévocablement décidés à la retraite. Ils envisageaient de lever l'ancre dans la matinée, sans s'inquiéter du massacre éventuel des colons.

Du Buc s'insurgea contre ce projet ; il voulait, au moins, sauver ses compatriotes. La défection des Anglais avait naturellement amené dans leurs troupes un désarroi lamentable. Chacun voulait quitter ces rives où il n'avait plus à espérer que la mort. Tous refluaient sur la plage, suppliant qu'on emmenât au moins leurs femmes et leurs enfants.

Le chevalier organisa le sauvetage : il réussit à retenir l'escadre le minimum de temps nécessaire, obtint, non sans peine, que l'on gardât encore les postes vingt-quatre heures pour ne pas donner l'éveil aux «patriotes », fit venir en hâte des bateaux de la Dominique.

Il ne s'agissait de rien de moins que d'embarquer 6 à 7.000 personnes. On en plaça partout, sur les vaisseaux anglais comme sur ceux de $\mathrm{M}$. de Rivière ; les chaloupes même furent chargées à couler. " Après trois journées affreuses, écrivait Du Buc, nous eûmes au moins la consolation de voir que tout le monde, à peu près, s'était sauvé »; mais il ajoutait amèrement : «Rien ne pressait l'escadre de se retirer... on aurait pu préserver de la misère, pour un temps, les malheureux 
colons, parce qu'il eût été très facile d'enlever au moins la moitié de cette immense quantité de sucres qui étaient fabriqués. »

Le 21 juin, Rochambeau connut qu'il avait définitivement gagné la partie. aussi loin que pouvait porter son regard, la mer était libre. Grands et petits, tous les navires s'en étaient allés, les uns vers La Barbade ou La Dominique, les autres vers Trinidad.

Parmi les passagers de ceux-ci se trouvait M. de Béhague. Si préoccupé que fût Du Buc, il n'avait pas oublié de le réexpédier à M. de Rivière.

\section{CHAPITRE X . RÉFÉRENCES :}

Journal de M. de Curt en émigration à Londres, 1794. Publié par Paul Roussier dans la « Revue Historique des Antilles ». Nov-déc. 1929.

Pièces du procès Béhague (déjà cité). Ministère Colonies. Martinique, 272.

Avec les Rouges aux Isles du Vent. Souvenirs du chevalier de Valous (déjà cité).

Duplicata des propositions faites à l'Angleterre par Du Buc, de Curt et de Clairfontaine. 19 fév. 1793. Ministère Colonies. Dossier de F. Du Buc.

Conseil d'Etat. Séance du 24 août 1824. Min. Col. Dossier L. F. Du Buc.

Lettre de M. de Cougnacq-Myon au Maréchal de Castries. 23 juillet 1793. Ministère Colonies Martinique, 277 (déjà citée).

«Eveil des bons patriotes». Compte rendu de la séance des Amis de la Convention, 2 mai 1793. Arch. Nationales Dxxv 118. Dossier 128.

Nombreuses lettres de particuliers au sujet du camp Percin et des événements qui se sont déroulés à la Martinique en avril-juin 1793. Arch. Nat. Dxxv 118.

Proclamation de Rochambeau, 27 avril 1793. Min. Col. Martinique, 276. 
Compte rendu de Rochambeau au ministre. 27 juin 1793. Min. Col. Martinique, 94.

Journal de Du Buc. Min. Col. Martinique, 276 et 277.

Journal de M. de Rivière. Min. Col. Martinique, 276 et 277.

Pièces du procès Béhague. Min. Col. Martinique, 276 et 277.

Mémoire de Berclery. Min. Col. Martinique, 278. Certificat de M. Deslandes, procureur du roi près le tribunal de première instance de Fort-Royal de la Martinique, au sujet de la conduite de L.-F. Du Buc avant et après l'échauffourée du Carbet. Pièce versée au procès de 1824. Min. Col. Dossier Du Buc. 


\section{La Révolution française à la Martinique}

Chapitre XI

La Révolution progresse

Retour à la table des matières

Une fois de plus, donc, les événements venaient de faire apparaître quelle était, aux Antilles, la véritable force de révolution capable de faire pencher la balance en faveur du régime nouveau et qui, par une conséquence forcée, en devait orienter l'évolution suivant ses aspirations propres.

De même que, au début, les planteurs n'avaient dû leur prépondérance qu'à l'appui des hommes de couleur, et que ceux-ci avaient, par la force des choses, obtenu, pour prix de leurs services, une appréciable amélioration de leur condition et des droits qu'ils n'avaient même pas songé tout d'abord à revendiquer, de même Rochambeau n'avait pu triompher de la révolte des « aristocrates », appuyée par l'intervention étrangère, qu'en se conciliant ce même élément, détaché des colons par la propagande de Lacrosse, et encore renforcé par l'enrôlement des esclaves.

La Révolution, née du long travail des idées, dans un vieux pays réfléchi et profondément homogène, suivait, dans un monde complètement différent, l'inéluctable logique des situations. Ardente revendication de liberté et d'égalité au profit d'une classe longtemps brimée, bien qu'elle fût la majorité et la source de toute puissance, elle ne pouvait manquer de poser la même question au profit d'une race dédaignée, écrasée, bien qu'elle fût le nombre et le véritable instrument 
de prospérité, et dont l'oppression légale était, dans les colonies, le fondement même de l'ordre social.

Nul à ce moment, ne paraissait apercevoir cette conséquence qui nous semble aujourd'hui évidente. Les hommes se décidaient, sans se poser un aussi grand problème, selon l'opportunité, selon la pression de leurs intérêts bornés, selon les suggestions des circonstances immédiates. A travers leurs actes fragmentaires, le destin s'accomplissait.

\section{Planche XVI.}

Voir Les Classiques des sciences sociales.

Rochambeau allait bientôt s'apercevoir de cette vérité, rendue familière par le conte de l'Apprenti Sorcier, qu'il est plus facile de déchaîner les forces inconnues que de les diriger, de les contenir et, le moment venu, de les faire rentrer dans l'inaction.

Et, comme il arrive toujours, il devait se trouver des hommes pour chercher à profiter d'un état de choses propice au développement d'instincts qui s'ignoraient.

Le général républicain, victorieux, pouvait croire sa situation affermie.

Le contraire se produisit. Il avait mené au combat, non point une armée organisée, mais des soldats d'occasion et ceux-ci, émerveillés d'un succès qui leur paraissait prodigieux, en enflaient démesurément les proportions et s'en attribuaient presque tout le mérite.

Rochambeau cependant, on l'a vu, avait été le premier à reconnaître la part qui revenait à ses collaborateurs. De même, il s'était fait un devoir de vanter à la Convention le dévouement des habitants de Saint-Pierre « qui l'avaient secondé de tout leur cœur, tenant campagne sans la moindre solde, et souvent sans vêtements ni subsistances ». Il n'imaginait pas pour cela qu'il dût désormais obéir à ceux qu'il avait mission de gouverner. Il lui fallut néanmoins faire de nombreuses concessions. Comment des gens, qui disaient - et croyaient sans doute - avoir repoussé avec des moyens de fortune toute une escadre anglaise, eussent-ils modéré leurs prétentions? 
L'ambition, l'envie, la haine s'épanouirent en une floraison spontanée. Le Club des Amis de la Convention rendait des oracles; les mulâtres, enivrés de leur prompte élévation, devenaient turbulents ; les esclaves qui avaient combattu refusaient de reprendre le travail. Sans être soumis à aucune discipline militaire, ils restaient dans leurs camps, narguant et menaçant leurs anciens maîtres. Le gouvernement, à qui ils venaient de rendre un signalé service, était bien forcé de les fournir de vivres, et les derniers noirs demeurés dans les ateliers se sentaient bien naturellement tentés d'aller partager l'agréable sort de ces privilégiés.

Il fallait pourtant penser aux nécessités matérielles. L'héroïsme ne nourrit pas. La détente qui lui succède est goûtée si délicieusement qu'on la voudrait éternelle. Mais les besoins reviennent. Il faut reprendre le collier de misère. On ne s'y résigne pas aisément. Rochambeau se trouvait en face du problème qui se pose après toutes les guerres, et surtout les guerres civiles. La solution en apparaissait singulièrement malaisée.

Si rudimentaire que fût leur intelligence (et elle l'était d'autant plus qu'on avait évité avec soin de la développer), ces esclaves, qui s'étaient battus au nom de la Liberté, retenaient de ces événements extraordinaires une impression profonde et durable. Ils tiraient des faits d'excellentes raisons pour ne pas retourner sous le joug.

Qu'il fallût des bras pour la culture, que les exploitations des colons fussent menacées de ruine, que l'émancipation brusquée dût entraîner une crise économique et sociale effroyable, c'étaient là des arguments qui passaient au-dessus de leurs têtes.

Malheureusement pour eux, le Gouverneur trouvait, lui, ces arguments péremptoires. « J'imagine, écrivait-il, qu'on ne pense pas à la Convention Nationale à traiter l'affranchissement des noirs avant d'avoir abordé l'abolition de la traite. Si l'on songeait à donner la liberté aux nègres, il ne serait pas, je crois, nécessaire de nous laisser ici, car alors la métropole renoncerait à ses colonies et l'on pourrait nous employer plus utilement ailleurs ».

Rochambeau, je l'ai dit, bien que révolutionnaire convaincu, avait le sens de l'ordre. Il jugea politique de fractionner la difficulté pour la résoudre. Il enrégimenta régulièrement une partie de ses chasseurs ; il en forma deux bataillons qu'il 
entraîna à quelque discipline et réussit à faire rentrer le reste aux ateliers. L'habitude de la soumission rendait les noirs assez maniables.

Les blancs et les mulâtres devaient se montrer plus difficiles à conduire.

Pourtant, Rochambeau put croire un moment avoir recouvré toute son autorité grâce au prestige que lui valut l'application de la loi sur les biens des émigrés.

Jamais mesure ne fut plus populaire que celle-ci. Elle résolvait le plus simplement du monde l'insoluble question des dettes.

Elle donnait l'impression d'une richesse considérable tombée légitimement et par la faute même de ses possesseurs aux mains de la collectivité. Elle satisfaisait enfin aux exigences financières de l'administration dont le dénuement en vivres et en numéraire était fort grand.

La vente des denrées coloniales échappées aux incendies permit au Gouverneur de regarnir sa caisse et ses magasins. La mise sous séquestre d'habitations dont la valeur globale, à l'estimation de Lacrosse, dépassait cent millions de livres, fut, pour les commissionnaires, une garantie qu'ils obtiendraient le paiement de leurs créances. Ceux à qui l'on ne devait rien, y trouvèrent au moins une satisfaction à leurs animosités et le gage de l'éviction définitive des grands sucriers. Enfin, les planteurs les moins compromis furent retenus ou rappelés dans l'île par la crainte de se voir dépouillés de leurs biens.

L'ascendant de Rochambeau sur ses administrés semblait donc plus grand que jamais.

Ceux de ses collaborateurs qui avaient espéré prendre de l'importance s'en émurent. L'un d'entre eux était l'ancien constituant Pélauque, dont l'intelligence et l'instruction servaient d'autant mieux l'esprit d'intrigue que le personnage ne s'embarrassait d'aucun principe de moralité.

Rochambeau l'avait amené de Saint-Domingue en qualité de secrétaire. Tout comme son ami Leborgne, Pélauque était une des lumières du Club des Amis de la Convention. L'un et l'autre y avaient d'abord vanté jusqu'au délire celui qui les patronnait. Ils assuraient leur situation sur la sienne en attendant leur heure. 
Ils sentirent que cette heure allait passer si l'île retombait sous la domination absolue du Général. Cependant ils hésitaient, rongeant leur frein, quand un incident fort mince décida Pélauque contre son protecteur. Un soir qu'il était traité avec d'autres personnes à la table de Rochambeau, le secrétaire se permit une tenue et des propos inconvenants qui lui valurent d'être vertement rappelé à l'ordre par le Général, à qui l'ardeur républicaine n'avait pu faire oublier les manières de la cour de Versailles.

Cette leçon donnée en publie piqua au vif Pélauque et en fit un adversaire mortel. D'apologiste, il devint détracteur outrancier. Leborgne lui emboîta le pas et tous deux s'instaurèrent les juges impitoyables de celui qu'ils avaient fait profession d'encenser. Aucun des actes du Gouverneur ne trouva désormais grâce à leurs yeux ; chacun de ses discours fut dénoncé comme attentatoire à la Liberté. Son air même, sa manière de vivre trahissaient, d'après eux, une hauteur et un mépris insupportables. C'est une mésaventure assez commune aux révolutionnaires qui prétendent assigner une limite aux entrainements de l'esprit nouveau.

Leborgne, qui savait du reste de quel poids était l'opinion des mulâtres, la travaillait en artiste. Après les avoir flagornés de mille façons - n'alla-t-il pas jusqu'à exiger que « dans les écrits et les conversations on ne les qualifiât plus d'hommes de couleur mais de ci-devant hommes de couleur » ? - il les plongeait dans l'épouvante et la consternation en leur persuadant que le Gouverneur songeait à les priver à nouveau de leurs droits.

Pélauque convainquit facilement les jacobins du Club de la nécessité qu'il y avait à imposer des barrières au despotisme d'un général trop populaire et cidevant noble. Il suggéra la création de municipalités, avec l'espoir d'augmenter ainsi le zèle des éléments politiciens, plus utiles à la réalisation de ses projets subversifs que la population laborieuse, paisible par tempérament et plus soucieuse de s'adonner à ses occupations normales que de fomenter des intrigues 70 .

Enfin, les deux démagogues incitèrent les clubs à réclamer une Assemblée Coloniale ainsi qu'un Comité Central, dont ils eurent la modestie de ne pas dési-

70 Observation de Lemaret, 1793 : « Ce régime ne convient pas du tout... Dans les campagnes jamais un habitant ne voudra être maire ou officier municipal, ce qui lui prendrait une trop grande partie de son temps. Il en résultera que les municipalités ne seront, en totalité, composées que d'intrus ». Archives Ministère Colonies. Martinique, 276. 
gner les membres. Les « patriotes » et surtout les hommes de couleur, qui tremblaient pour leurs libertés, se rallièrent d'enthousiasme à cette idée. Rochambeau s'inclina d'assez bonne grâce devant le vœu du peuple qu'il ne voyait plus grand inconvénient à exaucer.

Au surplus, il se souciait beaucoup moins de jouer un rôle de petit potentat à la Martinique que de combattre l'Anglais en attaquant à son tour ses possessions antillaises.

Dans toutes ses lettres au « citoyen ministre », le Général suppliait : « Faitesmoi passer des soldats, des armes, de l'argent, 8 ou 10.000 hommes de troupes de débarquement... Je suis bien convaincu que le théâtre est si beau qu'il ne me sera pas difficile d'entrer en scène à mon avantage... Ne me laissez pas ici comme un plastron qui reçoit toutes les bottes sans en porter aucune ». Le citoyen ministre, fort empêché de satisfaire à ces demandes dont il ne méconnaissait pas la légitimité, ne répondait même plus. Il avait des soucis autrement impérieux que le sort des Antilles.

Loin de recevoir de nouvelles forces, Rochambeau vit les siennes encore diminuées par la disparition inattendue de son unique vaisseau.

« Je suis privé par un hasard extraordinaire de l'équipage de la Félicité et de cette frégate commandée par le capitaine Lacrosse " ${ }^{71}$, écrivait-il. En effet, Lacrosse ayant obtenu du Général la permission d'aller en croisière au vent de la Barbade, avait tout tranquillement fait voile pour la France. Peut-être voulait-il savoir enfin ce qu'il en était du convoi et des commissaires civils annoncés depuis un an ? En fait, il déserta avec la plus étrange désinvolture.

Rochambeau fut le seul à s'en inquiéter. Les " patriotes », tout à leur joie de réaliser l'organisation politique pour laquelle ils avaient lutté quatre années, s'empressèrent à substituer aux Comités de Surveillance les corps municipaux prévus par la loi. Les Assemblées primaires, convoquées le 12 septembre, élirent leurs « commissaires représentants » à la nouvelle Assemblée. Celle-ci se réunit le 22 à Saint-Pierre et prit le nom « d'Assemblée Républicaine de la Martinique ».

La Martinique révolutionnaire allait pouvoir enfin s'exprimer librement. Aux chambres des « sucriers », dont tous les décrets décelaient « le délire et l'impu-

$71 \quad 16$ octobre 1793. 
dence ", succédait une chambre démocratique, propre à étonner la colonie par la sagesse et la nouveauté de ses conceptions.

Aussi bien faut-il reconnaître que la nouvelle institution, loin de justifier les appréhensions que ses origines et les conditions de sa formation pouvaient faire concevoir, fit, au contraire, preuve d'un réel esprit politique et d'une louable modération.

Il n'y a pas lieu de s'en étonner. La vie coloniale habitue les hommes au sens des réalités, au goût de l'initiative guidée par l'interprétation de l'expérience, au sentiment des responsabilités. A gouverner quotidiennement ses propres affaires au lieu de devenir un rouage inerte dans la machine sociale, on acquiert les qualités de pondération, de juste discernement et de prudence nécessaires à la conduite des affaires publiques.

Aussi bien, tous les éléments capables de réflexion, quelle que fût la couleur de leur peau, se sentaient directement tributaires des nécessités économiques, intéressés au maintien de la prospérité générale, portés en conséquence à ne pas risquer, pour la satisfaction de passions passagères ou d'idées abstraites, les bases mêmes d'un édifice où chacun, après tout, se savait abrité et sûr du lendemain.

Les griefs formulés contre les anciennes assemblées étaient, au surplus, surtout théoriques. Leur administration n'avait pas été de nature à provoquer de violentes réactions.

On reprochait à l'Assemblée Coloniale du 16 novembre 1789 d'avoir été inconstitutionnelle, pour la raison qu'elle ne représentait pas toute la colonie, les députés de Saint-Pierre s'étant, on se le rappelle, abstenus, et plusieurs paroisses n'ayant pu venir à bout de leurs consultations électorales.

On arguait que l'Assemblée du 7 juillet 1790 avait été nommée dans une atmosphère de crainte qui avait intimidé l'opposition et faussé les résultats.

Cette même Assemblée du 7 juillet avait pris des décisions qui dépassaient ses attributions. Ainsi, elle avait dépouillé l'Intendant de ses fonctions pour en charger un Directoire revêtu de tous les pouvoirs des corps similaires créés dans les départements de France. Elle avait réduit le rôle du Gouverneur jusqu'à ne plus laisser à celui-ci qu'une autorité nominale. Elle avait constamment anticipé sur les déci- 
sions de l'Assemblée Nationale et tendu à établir une administration autonome sous le protectorat de la métropole.

Enfin, toutes les Assemblées «d'aristocrates » avaient trouvé des prétextes pour ouvrir les quatre ports pendant des laps de temps plus ou moins longs et cette mesure d'ordre économique était peut-être celle qui avait laissé le plus d'amertume dans le souvenir des Saint-Pierrais.

L'Assemblée républicaine, dès sa première séance, put constater qu'elle était, elle aussi, fort incomplète. Dix-sept paroisses seulement sur vingt-sept avaient envoyé leurs délégués ; Républiqueville, (aujourd'hui Fort-de-France), entre autres s'était abstenu. L'Assemblée jugea néanmoins, tout comme celles qui l'avaient précédée, qu'elle représentait valablement toute la colonie et Rochambeau, qui ne voyait aucune utilité à recommencer les élections, déclara la session ouverte.

Planche XVII. Extrait des registres des délibérations de l'Assemblée représentative de la Martinique.

Séance du 26 et 28 octobre 1793, l'an 1er de la République.

Voir Les Classiques des sciences sociales.

Mesure plus contestable : l'Assemblée interdit formellement le scrutin secret dans les Assemblées primaires. Les citoyens devaient voter à haute voix, ce qui, a une époque d'émulation révolutionnaire et de suspicion générale, supposait un grand courage de la part des opposants.

Tant de gouvernements, prétendus démocratiques, ont fait de même qu'on ne saurait se montrer exagérément sévère pour cette atteinte à la liberté d'opinion.

La nouvelle Assemblée décréta ensuite «que la colonie de la Martinique serait considérée comme département quant à son administration civile, indépendante des îles françaises du vent de l'Amérique » ${ }^{72}$.

L'évolution ultérieure de nos institutions a confirmé cette conception. C'est elle qui régit en fait, sinon en droit, la Martinique. Elle est appliquée depuis tant

72 Arrêté du 30 octobre 1793. 
d'années qu'elle n'a plus à être discutée. On ne saurait prétendre que les résultats en soient mauvais.

Les fonctions administratives déléguées par la Constitution aux Directoires de départements furent dévolues à une Administration centrale composée de quatre Directeurs, d'un Procureur syndic et d'un secrétaire greffier. Ces fonctionnaires devaient choisir les receveurs de districts et le trésorier général de la colonie. Ils devaient être eux-mêmes élus au suffrage universel, ce qui leur eût conféré une autorité assez dangereuse. Le procureur syndic fût devenu, en définitive, le souverain maître de la colonie qui l'eût plébiscité, et le Gouverneur eût été sinon écarté du moins neutralisé.

On comprend néanmoins que, dans le zèle qu'inspirait alors à tous le principe électif, ces inconvénients n'aient pas été aperçus. Si le système avait fonctionné il se serait de lui-même amendé dans la pratique.

Toutes ces dispositions devaient entrer en vigueur le ler janvier 1794.

Les circonstances en décidèrent autrement. Cependant, quelques-uns des décrets votés par l'Assemblée Républicaine purent être appliqués et, en premier lieu, celui concernant le commerce. Il ouvrait à nouveau les ports secondaires aux navires étrangers pour une période de six mois ${ }^{73}$.

Lorsque l'on songe à l'opposition violente qu'avait soulevée semblable mesure, quand elle avait été prise par les Assemblées des planteurs, on est étonné de tant de libéralisme et de sagesse maintenant que la prépondérance était échue au camp adverse.

Comment ce qui avait été réputé naguère innovation diabolique s'était-il mué en tolérance légitime et sage ? Une circonstance l'explique : les créances des négociants de Saint-Pierre, qui s'élevaient à environ 20 millions de livres, se trouvaient garanties plus de cinq fois par les biens confisqués aux émigrés. Les farouches défenseurs de l'Exclusif s'apercevaient, dès lors, que la carence du commerce de la métropole menaçait de priver du nécessaire des colons qui ne produisaient guère que du sucre ; ils s'avisaient aussi que l'enrichissement de tous les quartiers ne pouvait que servir la fortune de Saint-Pierre. Le port tirait de sa situation géo-

73 Arrêté du 25 septembre 1793. 
graphique et de son site particulier des avantages qu'aucune loi humaine ne lui ferait perdre et, tous comptes apurés, il était assez sûr de lui pour accepter une réforme profonde dans les rapports commerciaux de la Martinique avec le monde extérieur.

Tout cela, somme toute, était parfaitement raisonnable.'

L'Assemblée Républicaine, toutefois, prit deux autres mesures d'un caractère moins apaisant. Elle proclama que les biens du clergé étaient à la disposition de la Nation et institua un tribunal révolutionnaire ${ }^{74}$.

Mais il faut dire tout de suite, à la louange des Martiniquais, que les effets en furent anodins.

Les hôpitaux des Frères de la Charité et la maison d'éducation des Ursulines, où les jeunes filles recevaient un enseignement élémentaire avant d'aller achever leurs études en France, excitaient d'autant moins la convoitise que, pour le premier surtout, le passif dépassait largement l'actif. D'ailleurs, ce pays, qui pendant plus d'un siècle et demi n'avait possédé d'autres organes que les paroisses, était trop profondément catholique (il l'est demeuré) pour que ses habitants fussent tentés de se livrer à des violences contre les religieux ou à des actes de vandalisme. Le Club des Amis de la Convention se borna à offrir de belles noces et la cure de Républiqueville au premier prêtre qui se hasarda a prendre femme ${ }^{75}$. On conviendra que c'était avoir l'anticléricalisme aimable.

Quant au tribunal révolutionnaire, il ne se montra pas bien féroce. L'accusé, pour en sortir indemne, devait convaincre ses juges qu'il avait pris part forcément et non volontairement à la rébellion, ce qui ouvrait une échappatoire assez large. Au surplus, les citoyens reconnus criminels ne risquaient que la déportation et la confiscation de leurs biens, avec cette assurance assez réconfortante qu'une pension serait servie à leurs femmes et à leurs enfants 76 .

74 Arrêtés du 24 septembre et du 18 octobre 1793. Archives Nationales A. F. 11302, dossier 2511.

75 Louis de Cardenal (déjà cité). Ce fut Bouchard, prêtre de la Rivière Pilote, qui fut l'heureux bénéficiaire de ces générosités.

76 Arrêté du 11 décembre 1798. 
Rochambeau laissait faire avec une indifférence désabusée et railleuse qui vexait beaucoup les apprentis politiciens. « On remarque en lui un grand changement, notait le maire de Républiqueville. Il devient moins communicatif avec les patriotes et commence à tourner leurs demandes en ridicule, talent qu'il possède assez bien ».

En réalité, le Général n'attachait pas plus d'importance aux travaux de l'Assemblée Républicaine que le commandant d'un vaisseau poussé par le vent et la mer entre deux écueils n'en peut attacher aux divertissements des passagers inconscients du péril.

Rochambeau voyait clairement que si les forces de la métropole, auxquelles personne ne croyait plus, n'arrivaient pas à bref délai, la Martinique allait succomber ou à une nouvelle attaque mieux concertée des Anglais, ou à la révolte générale des noirs encadrés par des mulâtres, comme il était arrivé à SaintDomingue.

De nombreux prodromes le lui faisaient pressentir. Les hommes de couleur, non pas parce qu'ils étaient « de couleur », mais parce qu'ils étaient des hommes, avaient pris beaucoup plus fortement conscience de leurs droits que de leurs devoirs. L'erreur généreuse mais redoutable du libéralisme que ne tempère pas le sens de l'autorité nécessaire, est de tenir pour axiome la perfection de l'être humain. Les mulâtres avaient cela de commun avec les blancs qu'ils n'étaient pas parfaits. Devant la débilité des forces du gouvernement, ils se prenaient à songer que la suprématie devait l'emporter en agréments sur l'égalité surtout sur une égalité de commande qui, malgré la bonne volonté des républicains, ne masquait qu'à demi un préjugé fortement enraciné.

Bellegarde, qui jouissait à présent d'une grande notoriété parmi ses semblables, tenait en main les deux bataillons de chasseurs auxquels tous les noirs de la colonie n'eussent pas demandé mieux que de se joindre. Il bénéficiait en outre des conseils de Pélauque, lequel, non plus aveugle que le Général mais moins bien intentionné, avait abandonné à son sort le club des Amis de la Convention pour s'attacher au chef mulâtre avec qui il avait ouvert une maison de commerce à la Trinité.

Pour défendre la Martinique contre l'un ou l'autre des dangers qu'il jugeait imminents, Rochambeau ne pouvait compter que sur les 270 soldats et matelots 
qui lui restaient encore et sur un parti de fidèles, habitants ralliés ou négociants de Saint-Pierre, chez qui, au dire des purs, « le patriotisme s'était changé en adoration pour le général ». Que pouvait-il faire d'autre que de chercher à «tenir » le plus longtemps possible et d'en imposer à tous par les apparences d'une autorité sûre d'elle-même ? Il ne cessait, par ailleurs, de bombarder les « citoyens ministres » de lettres où le dédain superbe de l'orthographe ajoutait à la véhémence hautaine.

Une aimable aventure vint tempérer pour lui l'anxiété de ces mois d'attente. Au cours de ses tournées dans l'île, il lia connaissance avec une jeune et belle créole. Sans être aussi célèbre que Joséphine de Beauharnais, Mme d'Hullie atteste, elle aussi, par l'impression qu'elle fit sur Rochambeau, le pouvoir des Martiniquaises sur les généraux de la République. Elle était fort loin de penser que la vertu pût consister à décevoir et à chagriner vilainement ceux qu'il était charmant de rendre heureux. Bien qu'elle passât pour une " aristocrate achevée », Rochambeau lui parut être de ceux-là. Au cours de promenades à cheval, qu'ils firent ensemble dans la campagne, elle découvrit maints attraits au nouveau Régime et bientôt personne n'ignora plus la nouvelle conquête du Général.

Les austères Amis de la Convention s'en montrèrent affreusement scandalisés. «Les sociétés populaires qui sont les sentinelles du Peuple lui firent, à ce sujet, des observations » ${ }^{77}$, qu'il reçut comme on peut imaginer. Cela acheva de l'exaspérer contre les « patriotes » de Républiqueville. Il quitta la capitale et vint s'installer à Saint-Pierre, « où les riches habitants le reçurent avec avidité ».

Cependant, même au milieu de ses plaisirs, Rochambeau ne parvenait pas à oublier ses soucis. Bellegarde se révélait de plus en plus suspect. L'un de ses chasseurs, un noir nommé Dautremard, menait campagne pour lui auprès de ses congénères ; il dénigrait le Général au profit du Commandant, établissant entre eux un parallèle tout à l'avantage du second, et prêchait la destruction de tous les

77 Hector Montrom ou Moutrom. Archives Nationales Dxxv 118. C'est le même qui écrit après avoir exposé tous les devoirs qu'avait à remplir le Général : « Au lieu de cela, que fait-il ? L'amour à une femme archi-aristocrate, et des promenades à cheval ». 
blancs qui ne seraient pas du parti de son chef. Malgré les ordres donnés à cet effet, il n'était pas encore arrêté.

Et Rochambeau, tout en caressant sa belle maîtresse, songeait : Qui gagnera la course ? Les Français, les Anglais ou « la Couleur »? Au cas où les citoyens ministres, « plongés dans un sommeil de léthargie, continueraient à donner la mesure de leurs talents et de leur capacité, en abandonnant les braves défenseurs de la République Française dans ces parages », le Général n'était plus très loin de penser, comme Du Buc, que la victoire des Anglais serait encore le moindre mal. Il comparait la Martinique « déchirée par les désordres et les divisions intestines à un agonisant qui attend le remède sans s'embarrasser du nom ni du pays du médecin $\gg 78$.

Parole saisissante, qui demeure la plus forte justification de l'adversaire dont le séparaient ses idées et dont le rapprochait son caractère et qui, en triomphant de lui, se félicitait de sauver précisément l'oeuvre sacrée de la France à la Martinique : la civilisation.

\section{CHAPITRE XI. RÉFÉRENCES :}

Lettres de Rochambeau au ministre, 21 juin, 20 juillet et 5 août 1793. Min. Col. Martinique, 94.

Lettre de Lacrosse au ministre. 6 juillet 1793. Min. Col. Martinique, 276.

Mémoire de Berclery. Min. Col. Martinique, 278.

Lettre de Rochambeau au ministre. 16 oct. 1793. Min. Col. Martinique, 275.

Observations de Lemaret, 1793. Minist. Colonies Martinique, 276.

Procès-verbal de la séance de l'Assemblée Républicaine de la Martinique, 22 sept. 1793. Min. Col. Martinique, 276.

78 Lettre de Rochambeau. Archives Nationales Dxxv 117. 
Arrêtés de l'Assemblée Républicaine de la Martinique, 1793. Arch. Nat. A. F. 11, 302. Dos. 2511.

Article de Louis de Cardinal sur le Club des Amis de la Convention (déjà cité).

Journal tenu par le citoyen Lecourt, maire de Républiqueville. Arch. Nat. Dxxv 118.

«Mon idée sur les causes de la perte des colonies ». Hector Moulsom ou Montrom. Arch. Nat. Dxxv 118.

Lettres de Rochambeau au ministre. Arch. Dxxv 117 et Min. Col. Martinique 94 et Martinique 275. 


\section{La Révolution française à la Martinique}

Chapitre XII

\section{La Révolution succombe}

Retour à la table des matières

Le 4 février 1794, des hauteurs du François, on vit, au soleil couchant, trente à quarante bâtiments qui dirigeaient leur marche sur la Martinique. D'un bout à l'autre de l'île, ce ne fut qu'un cri : « Les secours de France. »

La nouvelle souleva Rochambeau d'une orgueilleuse joie. Enfin ! la patrie s'était souvenue qu'elle avait des colonies !

Cette illusion dura le temps que mit l'escadre à s'approcher assez pour que l'on pût distinguer son pavillon. C'était le pavillon anglais.

Il n'est pas dans les habitudes de l'Angleterre d'abandonner une affaire qu'elle juge profitable. L'occupation de la Martinique présentait pour elle deux avantages importants : celui de préserver de la contagion révolutionnaire les hommes de couleur de ses propres possessions, et celui de lui fournir un gage «pour avoir quelque proposition à faire en cas d'arrangement » ${ }^{79}$. L'opération comportait le minimum de risques à condition qu'on ne regardât pas à la dépense, et le gouvernement britannique avait d'autant moins pensé à y regarder qu'elle devait être acquittée soit par la colonie elle-même, soit par la France au moment de la restitution.

79 Rochambeau au ministre. Archives Nationales Dxxv 117. 
Les bâtiments aperçus furent rejoints par d'autres. Au total, l'Angleterre avait envoyé, pour conquérir une île de 90.000 hectares dont elle savait la population désagrégée par des inimitiés irréductibles et les défenseurs dénués de toute espèce de moyens ${ }^{80}, 77$ bateaux de guerre, 16.000 hommes de troupes et un matériel considérable. Elle estimait à sa valeur le général Rochambeau.

Celui-ci, loin d'être troublé par ce déploiement de forces, ne s'en trouva que plus résolu à la résistance.

Comme tous les énergiques, Rochambeau se sentait plus calme, plus sûr de lui, plus éclairé sur son devoir, du moment que l'action commençait.

L'attaque anglaise mettait fin à ses incertitudes. Il savait désormais à quel danger il avait à faire face. Il se rendait d'ailleurs parfaitement compte de la disproportion de ses moyens avec ceux de l'adversaire, et ne pouvait douter un seul instant que celui-ci finit par l'emporter, à moins que la France ne se décidât à envoyer enfin les renforts indéfiniment attendus et tant de fois réclamés. D'une façon comme de l'autre, le péril majeur - la révolte généralisée des hommes de couleur et des esclaves - n'était plus à craindre.

Dès lors, le devoir devenait simple et d'une lumineuse certitude : à tout prix, et le plus longtemps possible, tenir. Tenir, pour donner aux secours de la métropole, si improbables fussent-ils devenus, le temps d'arriver.

En 1762, ne s'en était-il pas fallu de deux jours pour que les renforts survinssent à point ? Quarante-huit heures de résistance de plus, et les ministres de Louis XV n'eussent pas eu, lors du traité de Paris, à débattre s'il valait mieux sacrifier le Canada ou les îles à sucre ${ }^{81}$. Rochambeau se jurait de tenter l'impossible pour épargner pareil mécompte à la République. Il harcèlerait l'ennemi aussi longtemps qu'il le pourrait en menant une sorte de guérilla ; le climat serait son allié, «car les nouveaux venus d'Europe soutiennent difficilement leur premier séjour dans la

80 Il est à remarquer que nous avons soutenu le siège sans avoir un seul ingénieur pour conduire les défenses, sans artilleurs pour servir les batteries, sans troupes pour défendre la place, sans mineurs, sans palissades, sans officiers d'état-major, sans officiers d'administration, enfin dénués de tout... (Rochambeau).

81 MAY L. Ph. : Histoire économique de la Martinique. 
colonie » 82 . A la dernière extrémité seulement, il se retrancherait dans les forts ; vaincu, il ferait encore traîner les négociations.

Malheureusement, il dut renoncer presque tout de suite à la guerre de campagne. « Il est impossible de bien faire, constatait-il avec dépit, lorsqu'on a affaire à des sots ou à des traîtres. » La première de ces épithètes concernait les Amis de la Convention ; la seconde, les officiers de couleur qui entouraient Bellegarde.

L'amiral Jervis, qui commandait la flotte anglaise, l'avait partagée en deux groupes dont l'un devait s'emparer du Marin pendant que l'autre opérerait un débarquement à la Trinité. Ce dernier port était occupé par Bellegarde. Rochambeau envoya au commandant un bataillon de chasseurs de renfort, un plan de défense fort précis et l'ordre de se replier sur le Gros Morne en cas de malheur. Lui-même se rendit au Marin par le Lamentin, la Rivière-Salée et la Rivière-Pilote, comptant organiser des postes le long de son parcours. Hélas ! moins heureux que le Diogène qui trônait au club sur son globe de Saturne, il ne rencontra pas un homme : les gardes nationales des diverses paroisses, après une molle ébauche de rassemblement, s'étaient dispersées, partie se réfugiant dans les bois et partie se rendant aux Anglais.

Quant à Bellegarde, il évacua la Trinité sans coup férir et se sauva d'une seule traite jusqu'à Saint-Pierre, semant ainsi d'autant mieux la terreur et le découragement qu'il s'était acquis, au premier siège, une réputation de bravoure.

Cette dérobade générale força Rochambeau à regagner les citadelles de Républiqueville. Il y reçut la déclaration de l'amiral et du général anglais au nom de Georges III. Elle garantissait à tous ceux qui se soumettraient la sécurité personnelle et la jouissance de leurs biens « conformément à leurs anciennes lois et usages ». L'Angleterre omettait d'y mentionner la restitution éventuelle de la colonie à un prince de Bourbon ; elle misait uniquement - et d'ailleurs habilement - sur la peur qui avait gagné les «patriotes » comme les « aristocrates » de se voir submergés par la marée irrésistible des noirs et de sombrer dans une catastrophe analogue à celle de Saint-Domingue.

Les Anglais n'attendirent pas l'effet de cette proclamation pour développer leur attaque. Le 7 février, une vingtaine de leurs bâtiments contournèrent lîle par 
le sud pour aller tenter une troisième descente à Case-Navire. Après quelques difficultés, leurs troupes y purent prendre pied et, le 11, elles parvinrent à réaliser leur jonction avec celles précédemment débarqués sur la côte Est. Le 12, les assaillants s'emparaient de 1'llet aux Ramiers et la totalité de leur flotte y venait mouiller.

Rochambeau s'efforça de rassembler les courages. Dans l'espoir de rallumer la flamme révolutionnaire qui semblait vaciller dangereusement, et pour établir tout au moins un noyau de résistance morale et d'organisation, il créa un Comité de Salut Public composé de six membres. Ces gens sauraient mieux que lui, que sa dure franchise et son sens de l'ironie y faisaient répugner, user du sublime pathos propre à hausser jusqu'à la vaillance le cœur des citoyens : «0 toi, Amour de la Patrie, embrase nos cœurs! Et toi, cher Brutus, ne nous abandonne pas! Crois que tu trouveras dans les Français un peuple qui, à ton imitation, ne balancera pas entre le salut des siens et celui de la Patrie ! Ce « Cri » 83 nous fera oublier toute alliance et toute parenté lorsqu'il la croira offensée. Il suivra tes principes et saura à ton exemple périr ou terrasser les ennemis de sa Liberté ! ${ }^{84}$. »

De fortes paroles du genre de celles-ci (qui avaient été prononcées quelque temps auparavant au Club des Amis de la Convention) relevèrent les énergies, et les volontaires vinrent se grouper à Républiqueville. Le Comité du Salut Public prouva également son utilité en se rendant maître de la caisse publique et des vivres. En outre, par son entremise, le général obtint des capitaines de commerce le prêt d'une somme de 170.000 livres.

Le 16 février, Saint-Pierre, attaqué, par terre et par mer, s'était rendu aux Anglais. La Martinique française se trouvait donc réduite aux seuls forts de la Convention et de la République et à la cité de Républiqueville. Rochambeau s'enferma dans les citadelles avec ses quelques 300 soldats et marins, débris des régiments de Turenne, de la Sarre, de Bassigny ou de l'équipage de La Bienvenue, et trois à quatre cents gardes nationales.

83 «Le cri des Patriotes », chanson révolutionnaire.

84 L. de Cardinal (déjà cité). 
Bellegarde, qui l'avait rejoint, demanda au Général la permission de s'y enfermer avec lui ; il essuya un refus catégorique. Rochambeau n'avait que de trop bonnes raisons de se méfier ; il venait d'être l'objet d'une tentative d'assassinat de la part d'Elie et de Pierre Millet, hommes de couleur du corps de chasseurs, et le bruit courait que Pélauque, âme damnée du commandant mulâtre, avait eu de longues conversations avec les commissaires anglais.

Bellegarde reçut l'ordre de garder le morne Laborde qui défendait le chemin de la ville. Là, ses ingénus chasseurs, « abandonnés à leurs réflexions, car les bombes, les obus et les boulets ne les inquiétaient guère », eurent tout le loisir de s'interroger sur les causes de leur défaillance.

Ils ne pensèrent à les rechercher ni dans le fait qu'ils avaient eu cette fois à combattre des troupes réglées et aguerries dotées d'un puissant matériel de guerre, ni dans la trahison de leur commandant, mais s'imaginèrent les trouver dans la puissance du Diable et s'accordèrent à reconnaître en Dautremard l'agent de l'Esprit Malin. Ils se saisirent de ce noir, le rasèrent d'un côté, l'épilèrent de l'autre, ce qui est, comme chacun sait, le moyen infaillible de neutraliser le pouvoir d'un sorcier. Ils lavèrent ensuite à l'eau bénite les canons qu'il avait touchés ; puis, s'étant eux-mêmes baignés et habillés de neuf, ils entendirent sous les armes, officiers en tête et drapeaux déployés, une messe du Saint-Esprit que Bouchard, le curé nouvellement marié aux frais de la République, leur chanta pour leur argent.

Quoi qu'on puisse penser de l'efficacité de ces exorcismes, on doit reconnaître qu'ils témoignaient de la part des pauvres gens qui s'y livraient l'intention de rester fidèles à la France. Bellegarde s'inquiéta fort peu des sentiments de ses hommes. Sous prétexte de les mener à l'attaque de l'habitation Mathilde, il leur fit abandonner leur poste, dégarnissant ainsi le dernier point extérieur de défense, ce qui permit aux Anglais de compléter l'investissement de la ville en s'en emparant aussitôt.

Rochambeau pesta contre ce qu'il croyait « la manoeuvre ridicule d'un imbécile » jusqu'au jour où il apprit que Bellegarde et Pélauque venaient de recevoir des Anglais « 200.000 livres et un bateau pour aller aux Etats-Unis y promener leur 
honte et leur friponnerie » ${ }^{85}$. Du corps de chasseurs, on n'entendit plus parler ; il avait été désarmé et livré à l'acquéreur.

« Cette troupe, conclut philosophiquement le Général, cette troupe s'est donc évaporée avec la même facilité qu'elle s'était recrutée ; elle était la première intéressée à défendre cette cause et la première elle la déserta ».

Le marché avait été négocié à l'habitation Dillon. Ce domaine où nombre de dames créoles s'étaient réfugiées dès le début des hostilités et que, pour cette raison, les assiégés épargnaient, semble avoir été le G. Q. G. des parlottes, des accommodements et des trahisons.

Des patriotes, venant visiter leurs épouses entre deux combats, y rencontraient des Britanniques ; l'on devisait ensemble, l'on échangeait des aperçus sur la situation actuelle de la Martinique et sur son avenir probable. Après quoi, les interlocuteurs s'étant salués fort courtoisement, chacun rentrait chez soi.

Mme d'Hullie, qui n'était pas la moins séduisante des gracieuses apeurées, acceptait de paraître aux dîners offerts par les officiers anglais. Aristocrate, elle désirait le succès de ces derniers ; amoureuse, le salut et la gloire de son amant. Pour contradictoires que pussent sembler ces voeux, ils avaient toutes les chances d'être exaucés. Sir John Jervis était trop sûr du résultat final pour le vouloir payer d'un sang inutilement versé, et Rochambeau n'était pas homme à quitter la partie avant la fin, malgré que les autres en eussent.

Planche XVIII. Le Général Grey.

Voir Les Classiques des sciences sociales.

Le 19 février, le général Grey lui fit remettre une lettre dans laquelle il lui exposait que toute résistance de sa part était inutile : «... La faiblesse de vos garnisons et la certitude où vous êtes de ne recevoir aucun secours me sont aussi bien connues que de vous-même. La France est hors d'état de vous envoyer aucun renfort ; ses ports sont bloqués et ses armées navales détruites... D'après cet exposé, vous pouvez, Monsieur le Général, me faire des propositions pour la capitulation

85 Rochambeau au ministre. 
des forts et vous devez compter que tout ce qui peut intéresser votre honneur et la sûreté et la propriété de vous et de tous les habitants vous sera accordé sans difficulté ».

Rochambeau se refusait à admettre que la France fût hors d'état de lui envoyer du secours et cependant, ce secours, il ne l'espérait plus guère. "Livrez-vous à vos remords, écrivait-il aux ministres, et réfléchissez au crime énorme que vous avez commis en abandonnant lâchement des citoyens fidèles à vos loix. » Mais il ne se croyait pas dispensé pour cela de faire son devoir de Français et son métier de soldat. Il répondit à Grey le même jour : «Monsieur le Général, j'ai reçu la lettre que vous m'avez fait l'honneur de m'écrire le 19 février, ancien style, ainsi que les deux pièces qui y étaient jointes. Je les ai communiquées aux troupes de la République ; elles sont résolues à se défendre ».

Il n'ajoutait pas que « les troupes de la République » se réduisaient à la poignée d'hommes enfermée avec lui dans les forts. La municipalité, fâcheusement impressionnée par le bombardement auquel la ville était soumise depuis quatre jours, avait préféré taire son avis. Quant au Comité de Salut Publie, vexé de la manière dont le Général avait apprécié quelques-unes de ses initiatives en tactique, à la vérité plus curieuses que recommandables, il boudait et refusa d'encourager la résistance.

L'opiniâtreté des assiégés parut si déraisonnable à Sir Charles Grey qu'il crut devoir insister. Il accorda un nouveau délai de vingt-quatre heures à son adversaire « en l'engageant à faire sentir à ses garnisons combien leurs moyens étaient faibles ». - « Mes troupes sont déterminées à combattre », répliqua Rochambeau.

Ses deux messages avaient été remis à l'Etat-Major anglais par l'aide-de-camp Naverre, «passablement bête et garçon parfait » ${ }^{86}$, dit un " patriote ». Il justifia la première partie de cette opinion en faisant, dès son retour, une description lyrique de l'immense déploiement des forces ennemies. Cela n'était évidemment pas de nature à exalter les courages. Les boulets qui ne cessaient de tomber sur la ville ne l'étaient pas davantage, ni la nouvelle que le général Grey venait de recevoir l'appoint de mille grenadiers. Epouvantés, les habitants de Républiqueville présentèrent à Rochambeau une pétition pour capituler. « On ne doit plus demander des conseils quand il faut se battre », leur répondit-il rudement et, le lendemain, il

86 Lecourt, maire de Républiqueville. 
déclina une troisième proposition que lui fit, au nom de Sir Charles, le capitaine ingénieur de l'armée anglaise.

Planche XIX. View of the storming and taking the Fort and

Town of Fort Royal in the island of Martinico

by General Sir Charles Grey, March 1794.

Voir Les Classiques des sciences sociales.

Ce fut alors à qui déserterait parmi les gardes nationales restées dans la ville. Le mauvais exemple donné par Bellegarde produisait son effet de démoralisation. Des officiers de couleur, que ne défendaient pas contre les faiblesses humaines le long entraînement militaire et les traditions d'honneur de l'armée régulière, vacillèrent dans leur résolution. Comment ne pas se laisser aller à réfléchir sur tout ce que la combinaison de Bellegarde lui avait offert de profit et de sécurité ?

Rochambeau ne cherchait point à s'abuser. "L'abattement des esprits est à peine concevable, note-t-il ; les garnisons ne tiennent plus que par un fil imperceptible. Ce fil est la confiance qu'ils ont en moi. Quant aux intrigants, ils me ménagent parce qu'ils sentent bien que je suis le seul qui peut conclure la paix avec l'ennemi et obtenir quelques conditions avantageuses pour eux » 87 .

Le Comité de Salut Publie lui ayant demandé de permettre qu'on évacuât les femmes et les vieillards infirmes, il répartit qu'on le fit « et qu'on leur joignît les jean-f... » 88 .

Pour lui, rien ne put le détourner de sa résolution. Le 7 mars, il vit que les travaux de terrassements, menés par les Anglais avec célérité et prudence, se trouvaient terminés et que les assiégeants étaient au point d'en venir à l'attaque générale. Considérant alors la cité démoralisée et ses garnisons réduites aux deux tiers par les bombardements et la dysenterie, il en dégagea cette moralité : «De tout cela, il résulte que nous aurons plus de mérite à prolonger notre défense en cherchant à la rendre célèbre.

87 Rochambeau. Journal du siège.

88 Mémoire de Berclery. 
« Je vais donc travailler pour l'histoire ».

Cette admirable énergie, cet héroïsme poussé jusqu'à l'absurde transportèrent d'enthousiasme les quelques braves qui l'entouraient; à l'approche du dernier combat, ils sentirent se ranimer une vaillance qui se dissolvait dans l'inaction. On ne fait jamais vainement appel aux Français pour une cause qui leur parait d'autant plus belle que plus désespérée. On peut dire que Rochambeau exprima la pensée de chacun de ses soldats lorsque le 12 mars, après avoir essuyé une démonstration meurtrière, il répondit à Jervis et à Grey, toujours soucieux de sauvegarder leurs effectifs : « Résigné sur l'avenir, je suis résolu à me défendre de manière à mériter votre estime et celle des troupes qui sont à vos ordres ».

Ces intrépides tinrent huit jours sous une grêle de projectiles à laquelle ils ripostaient comme ils pouvaient, manquant de tout, dévastés par la dysenterie. Leur Général, par son exemple, les avait exaltés jusqu'au point où l'esprit de sacrifice se nourrit de sa seule noblesse.

«Lucas, canonnier de la Bienvenue, consigne Rochambeau dans son journal du siège, eut l'épaule emportée d'un coup de canon. Ce brave m'envoya chercher pour me dire qu'il désirait que tous ses camarades fissent leur devoir aussi bien que lui... Le jeune Roch, homme de couleur, enfant de 16 à 17 ans, eut le bras droit emporté d'un éclat de bombe ${ }^{89}$. Il recommanda qu'on me remit son sabre pour l'employer contre les ennemis de l'Etat dès qu'il pourrait de nouveau s'en servir ». La Martinique se doit de retenir le nom de cet enfant et de ceux de ses congénères qui rachetèrent par leur héroïsme la trahison de Bellegarde.

« Le colonel Mestre de l'artillerie a eu la tête emportée d'un boulet de canon. J'ai été couvert de son sang et j'ai eu une légère contusion au talon, continue le Général. Cet officier était d'un grand mérite et sa perte est irréparable. Il était jour et nuit sur les remparts, jouant le rôle de directeur de l'artillerie, de capitaine d'ouvriers, de pointeur et bombardier. Il laisse une femme et deux enfants ; la République doit avoir soin d'eux et leur faire une pension, car ce brave n'avait pour toute fortune que ses talents, son courage et ses vertus ». Marlet, l'aide de camp de Rochambeau, était blessé aux reins par les os du crâne du malheureux colonel...

89 Le jeune Roch avait été emmené par Bellegarde lorsque celui-ci vendit son bataillon aux Anglais. Il réussit à s'échapper et revint près de Rochambeau. Journal du siège. Archives, Nationales Dxxv 118. 
Cependant, les batteries ennemies augmentaient la puissance de leur feu. Leur plus gros effort était porté sur le fort de la Convention, mais celui de la République était bombardé par terre et par mer et la cité recevait également sa part. Le quatrième jour, ses habitants, affolés de voir leurs maisons s'écrouler parmi le fracas de la canonnade, demandèrent grâce au Gouverneur : « Un tiers de nos frères d'armes mis hors de combat vous a assez prouvé l'envie que nous avions de nous montrer dignes de votre estime et de celle de notre Mère-Patrie. La République, toujours juste, ne pourra que plaindre ses enfants de la Martinique et ne les blâmera jamais après une si ferme résistance' ».

Rochambeau fit la sourde oreille.

Mais le 20 mars, le Comité du Salut Public et la municipalité le requirent de capituler, lui représentant que le fort de la République était, à présent, hors d'état de continuer la lutte. Cette fois, Rochambeau consentit, avec l'assentiment de ses hommes, à envoyer un parlementaire à Sir Charles Grey.

«Monsieur le général, les troupes de la République Française qui sont à mes ordres vous demandent une capitulation honorable que vous ne pouvez leur refuser après la conduite qu'elles ont tenue depuis le moment où vous avez ouvert la tranchée devant elles. »

Les clauses de la reddition furent rapidement débattues. Les Anglais, fort heureux d'en avoir terminé, et rendant hommage à la magnifique bravoure des défenseurs, se montrèrent magnanimes. Ils souscrirent à presque toutes les conditions demandées par leur héroïque et malheureux adversaire.

Le 25 mars, Rochambeau sortit de la forteresse à la tête de ses troupes tambour battant et drapeau déployé. Le siège avait duré quarante-trois jours. L'armée anglaise, rapporte un témoin, fut stupéfaite de voir le petit nombre d'hommes qui lui avait opposé une si grande résistance. Le total n'excédait pas trois cents 90 .

Donatien-Marie-Joseph de Vimeur, ci-devant vicomte de Rochambeau, avait, à l'exemple de son père, illustré sa maison et sa patrie. Devant l'apparente abdica-

90 Naverre. Archives Nationales Dxxv 118. 
tion de celle-ci il n'espérait et, nous l'avons dit, ne souhaitait sans doute faire mieux. Au début du siège, n'avertissait-il pas le gouvernement français ? «Les plus grands dangers environnent cette colonie quand bien même on parviendrait à en expulser les Anglais. Les hommes de couleur ont mésusé de leurs droits, ils ont affiché des prétentions exagérées, ils ont mésusé partout où il fallait user sobre ment. Les blancs les haïssent mortellement. Ces deux classes, victorieuses des Anglais, se déchireront entre elles si les forces promises par la métropole n'arrivent incessamment pour rétablir un contrepoids suffisant et maintenir l'ordre publie ».

Le Général n'était d'ailleurs pas le seul à constater la faillite de la politique révolutionnaire. Un « patriote »indulgent et désabusé disait au même moment des mulâtres que « ramenés tout à coup dans la région que la nature avait assignée à l'homme, placés sous l'arbre de ses droits, comme des enfants ils l'ont ébranché pour en avoir les fruits sans réfléchir qu'ils en privaient les autres » ${ }^{91}$. Tandis qu'un troisième reconnaissait sans ambages que « si les Anglais avaient tardé tous les blancs étaient perdus ».

Or, le 4 février, le jour où l'escadre de Sir John Jervis s'était montrée devant la Martinique, la Convention, avant d'être en mesure d'armer une expédition assez importante pour assurer l'ordre aux colonies, avant même d'avoir envisagé l'abolition de la traite, avait, d'un trait de plume, décidé la libération des centaines de milliers d'esclaves des Antilles Françaises.

Faut-il penser de tout ceci que son généreux idéal était une erreur ? Non, puisqu'il a pu être réalisé plus tard sans trouble et sans succomber.

Faut-il dire que les hommes de couleur et les noirs étaient encore à ce moment indignes d'avoir accès dans la collectivité française sur le pied de la plus complète égalité ? Non, puisqu'aux premiers jours leur concours s'était montré loyal, compréhensif et sage.

Les reproches qu'on pourrait adresser à leurs entraînements, à leurs fautes, à leur rapide démoralisation ne sont pas différents de ceux qu'encouraient, au même moment, les masses populaires françaises. Le glissement vers la surenchère, le déséquilibre croissant des esprits au milieu d'un ordre social qui s'effondre, sont

91 Berelery. Ministère Colonies, Martinique, 278. 
certainement plus excusables chez des hommes brusquement jetés d'une condition misérable et servile dans la liberté, que chez des esprits qu'une longue accoutumance aux idées nouvelles devrait avoir préparés à des devoirs élargis.

Ce qu'il faut retenir, c'est que l'état révolutionnaire est toujours un mal ; que rien d'utile ne se construit au milieu de l'instabilité, et que les transformations les plus nécessaires et les plus fécondes ne sont viables que lorsque les forces contraires qui s'y combattaient ont fait la paix et mis en commun la part de vérité de chacune. Il fallait 1793 pour préparer 1848. Mais il fallait que 1793 échouât pour que 1848 pût réussir.

La liberté et l'égalité sociale ne s'improvisent pas. Ceux-là mêmes qui, à première vue, semblent en retarder l'avènement, travaillent, sans le savoir, à les préparer plus sûrement en les obligeant à une éducation préliminaire.

La Martinique évitait une crise plus redoutable que toutes celles qui l'avaient jusque-là secouée. Elle gardait ses chances pour accomplir dans l'ordre et le progrès des idées l'évolution qui la mènerait plus tard à la pleine réalisation de ses aspirations et au haut degré de civilisation où nous la voyons aujourd'hui. Et si Rochambeau avait travaillé pour l'histoire, Du Buc avait, lui, travaillé pour l'avenir et aussi, comme il apparut plus tard, pour sa petite et pour sa grande patrie.

Planche XX. La Convention Nationale déclare abolie l'esclavage des nègres dans toutes les colonies; en conséquence, elle décrète que tous les hommes, sans distinction de couleur, domiciliés dans les Colonies, sont citoyens français et jouiront de tous les droits assurés par la Constitution.

Voir Les Classiques des sciences sociales. 


\section{CHAPITRE XII. RÉFÉRENCES :}

Journal du Siège. Rochambeau. Archives Nationales Dxxv 118 et Ministère Colonies Martinique, 278.

Lettres de Rochambeau au ministre. Avril 1793. Archives Nationales Dxxv 117.

Mémoire de Berclery (membre du Comité de Salut public, créé par Rochambeau). Ministère des Colonies Martinique, 278.

Louis de Cardinal (déjà cité).

Dépositions des prisonniers anglais débarqués à Saint-Malo. Archives Nationales Dxxv 118.

Déposition de Grandmaison fils aîné. 26 Prairial, an Il. Archives Nationales Dxxv 118.

Journal du siège de Républiqueville, tenu par le citoyen Lecourt, maire de cette ville. Archives Nationales Dxxv 118.

Déposition de Naverre, aide de camp de Rochambeau. Archives Dxxv 118.

Mémoire de La Corbière. Archives Nationales Dxxv 118.

Adresse des citoyens de Fort République, 18 mars 1794. Ministère Colonies Martinique, 278.

Copie de la capitulation. Archives Nationales Dxxv 118.

Procès-verbaux de la Convention Nationale, 16 Pluviôse, an II. 


\title{
La Révolution française à la Martinique
}

\author{
Chapitre XIII
}

\section{Fin et Conclusion}

Retour à la table des matières

La Révolution était terminée à la Martinique. Quatre ans et demi d'événements tumultueux passaient à l'état de simple souvenir. Tout rentra dans l'ordre ancien.

Les émigrés reprirent possession de leurs domaines dont la plupart avait été préservés de la vente publique par la rapidité des événements. L'Assemblée Coloniale et le Conseil intermédiaire furent rétablis selon la loi de 1787 ; ils décidèrent de conserver deux innovations républicaines : les municipalités et l'égalité devant l'impôt. Du Buc qui, après la retraite de Case-Navire, était resté à La Barbade auprès de sir Charles Grey, en qualité de député, chargé des pleins pouvoirs de la Martinique, fut nommé Administrateur général. L'île était, en définitive, rendue à ses anciens propriétaires par la Grande-Bretagne qui assumait désormais la charge de la protéger.

Ces services là se paient. L'Angleterre présenta une note de 15 millions sous forme d'imposition extraordinaire ; mais elle donna aux planteurs les moyens de l'acquitter en les faisant bénéficier de la plus large liberté commerciale. Les droits d'entrée et de sortie furent supprimés, les ports ouverts, le ravitaillement de la colonie en comestibles assuré dans les meilleures conditions en vertu d'un traité 
avec les Etats-Unis. Si bien que, malgré le poids de cette contribution, la Martinique se releva rapidement de ses ruines.

Je pourrais finir ici mon récit. Il me paraît cependant nécessaire de narrer brièvement les tentatives faites par la France pour récupérer sa colonie, et le retour de celle-ci à la collectivité nationale.

La Convention avait tout de même fini par sortir de son inaction et par organiser, au moins de façon embryonnaire, l'expédition de secours tant réclamé. Le 23 avril 1794 partit de Rochefort une escadre composée de deux frégates et de quatre bâtiments de transport que montaient un millier d'hommes de troupes. C'était loin du compte qu'avait fait Rochambeau, et plus loin encore des 77 vaisseaux que l'Angleterre avait estimés nécessaires à la conquête des Iles du Vent. Mais la France a accoutumé de laisser à ses enfants une large part d'ingéniosité et d'héroïsme.

Ceux qu'elle chargeait de rétablir ses affaires dans la mer des Antilles étaient tout exaltés à la pensée d'aller jouer le rôle de hérauts de la Liberté. Les deux commissaires civils du convoi, Pierre Chrétien et Victor Hugues, un jeune homme de 24 ans, déchaîné, écrivaient, au moment de leur départ, à la Convention :

« Vous nous avez confié le sort de trois importantes colonies, Citoyens Représentants, vous nous avez mis en mains, pour des frères qui n'ont jamais connu de patrie, le premier article de l'Acte constitutionnel. Vous nous avez ordonné de préserver nos îles du vil système anglican. Hé bien! nous partons au pas de charge (sic) et nous ne vous disons pas comme certains hommes que la pusillanimité ou la malveillance dirigent : « Nous ferons ce que nous pourrons ». Nous, républicains intrépides, nous vous disons, au contraire : «Nous ferons « ce que vous désirez et vous garantissons d'avance que la France aura des îles françaises et des îles anglaises républicanisées! Salut et Fraternité ${ }^{92}$.»

Malheureusement quand ils arrivèrent aux Antilles il n'y avait plus d'îles françaises. Après la conquête de la Martinique cela n'avait été qu'un jeu pour les Anglais de prendre Sainte-Lucie au gouverneur Ricard, qui ne disposait que de cent

92 Lettre du 3 floréal, an Il (23 avril 1794). Ministère Colonies. Martinique, 278. 
hommes pour la défendre. La Guadeloupe s'était ensuite rendue après une résistance d'une dizaine de jours.

La résolution des républicains ne fut pas entamée pour si peu. Ils se croyaient invincibles, ce qui les rendait bien près de l'être. Ils avaient capturé, au cours de leur traversée, deux navires anglais. Ils ne doutaient pas que la Fortune ne les favorisât.

Elle le fit : ils eurent la chance de parvenir en vue de la Guadeloupe, après que l'amiral Jervis eut ramené sa flotte à La Barbade. Ils s'entendirent avec les patriotes de la Grande-Terre, débarquèrent dans la nuit du 2 au 3 juin, emportèrent de vive force Pointe-à-Pitre. Trois jours plus tard la Grande-Terre était entièrement au pouvoir des commissaires français, tous les noirs s'étant naturellement déclarés pour ceux qui leur apportaient la liberté.

La Guadeloupe proprement dite n'était pas intervenue. Le hasard qui aidait les Français voulut que mourût, précisément à ce moment, sir Henry Dundas, gouverneur anglais de la colonie.

«Il a été remplacé, rapporte un planteur, par la plus insigne bête qu'il soit permis d'imaginer et qui, après mûre délibération, s'est décidé d'aller compter les vaisseaux ennemis dans sa longue vue et en est revenu deux heures après dans l'opinion qu'il fallait mettre Basse-Terre en état de défense ${ }^{93}$. »

L'amiral Jervis, accouru à la rescousse, ne put déloger les Français de la Grande-Terre. Il se résigna à les y laisser, comptant sur le climat pour amollir leur courage. Mais, avant la fin de l'année, Victor Hugues, secondé, par le capitaine d'artillerie Pélardy, qu'il venait d'élever au grade de Général de division, forçait les Anglais à évacuer la Basse-Terre et reprenait également Marie-Galante.

Ces succès le confirmèrent dans le sentiment qu'il remplirait de bout en bout le programme qu'il s'était tracé, pourvu qu'il reçût quelques renforts. Il en demanda instamment à la Convention. De son côté, Rochambeau, réfugié à Newport où il se faisait gloire de ses haillons, continuait d'invectiver audacieusement contre le Comité de Salut Public : « Reprenez pour vous-mêmes la cause du rappel du général Jourdan : il croyait, dites-vous, avoir tout fait quand il restait quelque chose

93 Lettre d'un nommé Grandpré. Ministère des Colonies Martinique, 278. 
à faire. Vous avez abandonné les colonies du Vent. Jugez-vous donc vous-mêmes avec sévérité. » " Plaignez ceux que votre inertie a réduits à la triste situation de prisonniers puisque vous n'avez pu leur offrir que des regrets impuissants. Allez, vous vous êtres couverts d'ignominie ${ }^{94}$. »

La Convention s'émut-elle de cette véhémence ou fut-elle persuadée par les arguments de Victor Hugues? Le certain est qu'elle fit les frais d'une nouvelle expédition qui arriva à la Guadeloupe le 6 janvier 1795.

Deux nouveaux commissaires, Goyrand et Lebas, amenaient à Victor Hugues 15.000 hommes et un matériel assez nombreux mais d'une qualité fort médiocre. Ils apportaient, en outre, un million et demi de francs.

L'hivernage passé, les commissaires tentèrent, selon un plan maintes fois exposé par Rochambeau, d'attaquer en même temps toutes les îles soumises à la Grande-Bretagne, avec l'espoir d'y provoquer un soulèvement général des esclaves. Mais ceux-ci n'avaient plus les illusions des premiers jours. Ils avaient appris, par l'expérience de leurs frères de la Guadeloupe, que la liberté ne consistait pas, comme ils l'avaient pu tout d'abord imaginer, à vivre une longue suite de fêtes civiques et pastorales, mais à travailler pour gagner les quelques sous nécessaires à une maigre subsistance ${ }^{95}$, sort assez peu différent de celui qu'ils avaient connu sous la domination de leurs maîtres ; ce qui, en outre, les incitait fortement à rester tranquilles, c'était l'annonce d'une nouvelle escadre anglaise portant une armée de 25.000 hommes.

94 Rochambeau aux ministres, 21 floréal. Newport. Ministère Colonies, Martinique, 278. écrivait exactement : Alles vous vous êtes couvert d'ignomie.

Entre temps, il admonestait le ministre plénipotentiaire de la République Française aux Etats-Unis qui voulait le convaincre de rentrer en France. « Vous m'avez donné des conseils d'abord ; vous me faites des sommations ensuite, vous m'intimez des ordres pour conclure. Votre marche n'est pas égale, citoyen ministre. Et bien, je vous reppette que je ne suivrai pas plus vos conseils que je n'écoute vos sommations et que je ne me crois engagé par vos prétendus ordres. Il n'y a pas je crois de double entente à des réponses aussi précises ». En effet...

95 «Il faut que ces derniers (les citoyens de couleur) apprennent et n'oublient jamais que ceux qui $n$ ont pas de propriété sont obligés de pourvoir par leur travail à leur subsistance, à celle de leur famille, et concourir en outre par ce moyen au soutien de la Patrie ». Proclamation de Victor Hugues, 19 prairial, an II. En réalité, il instaura un régime draconien de travail forcé. 
Les républicains ne purent reprendre que Sainte-Lucie « la Fidèle ». La Martinique restait inaccessible à leurs efforts.

En décembre 1795, les capitaines Beuze et Borelli y risquèrent une descente avec 62 volontaires. Ils mirent pied à terre au Vauclin, dont ils se rendirent maîtres sans coup férir. Mais l'alarme ayant été rapidement donnée, de nombreux éléments britanniques se portèrent à leur rencontre. Après un combat acharné, au cours duquel ils tuèrent beaucoup plus d'hommes qu'ils n'en perdirent, les Français se réfugièrent dans les bois.

Le lendemain parut devant Le Vauclin un navire qui portait Goyran avec un détachement de 120 soldats. Ils venaient aider au succès présumé de l'avant-garde. Le commandant fit les signaux convenus avant d'entrer dans la passe ; ne recevant pas de réponse, il interpréta ce silence de la manière la plus pessimiste et vira de bord.

Beuze et la plus grande partie de ses volontaires réussirent néanmoins à se tirer de ce mauvais pas et à regagner Sainte-Lucie sur des pirogues qu'ils enlevèrent en quelque point désert de la côte. Borelli fut arrêté et passé par les armes avec un jeune mulâtre nommé Chapelle qui l'avait secouru.

Une expédition à la Grenade n'ayant pas donné de meilleurs résultats, Victor Hugues se contenta dorénavant de régner sur la Guadeloupe. Ce ne fut pas pour le bonheur des habitants de cette colonie, si l'on en juge par les plaintes qu'ils en firent au Comité de Salut Publie.

En 1799, le Directoire se décida à rappeler le jeune terroriste dont on lui brossait des portraits de ce genre : «De tous les hommes le plus grossier, le plus rustre, le plus mal embouché, c'est Victor Hugues; le plus parfait élève de Robespierre, c'est Victor Hugues ; de tous les dilapidateurs, de tous les fripons le plus adroit, c'est encore Victor Hugues. Enfin de tous les intrigants, de tous les égoïstes, le plus grand ennemi de la Révolution, c'est Victor Hugues ${ }^{96}$. »

96 Notes particulières sur les agents du Directoire. Ministère Colonies. Guadeloupe, 419. 
Les Martiniquais ne purent que s'applaudir d'avoir échappé à la tutelle de ce personnage et à celle de son collègue Le Bas dont « les moyens étaient si analogues à son nom » 97 .

Cependant lorsque la République revint avec Bonaparte à l'ordre et à la modération, les Martiniquais commencèrent à soupirer pour leur vraie patrie. « Il faut que ce mal français soit bien violent 98 », confessait ingénument un particulier de Saint-Pierre.

Ce « mal français » » avait en effet des racines trop profondes pour être jamais extirpé. il se réveilla dès qu'il ne fut plus combattu par le souci, après tout légitime, que les colons prenaient de leurs intérêts. Les Martiniquais n'avaient désormais que faire de la protection des Anglais.

La Révolution revenait sur elle-même. Un régime nouveau de glorieuse régénération avait succédé aux troubles. L'institution servile n'était plus en question ; la France avait si bien étendu ses conquêtes que ses frontières dilatées faisaient entrer dans la communauté nationale des populations considérables, jadis étrangères, et que l'Exclusif français devenait presque synonyme de libre échange.

Si l'on songe, en outre, que, seule île à sucre préservée des désastres révolutionnaires, la Martinique pouvait prendre dans l'économie française la place que la Jamaïque occupait sans rivalité possible dans celle de la Grande-Bretagne, on imaginera la joie que souleva, en 1802, le traité d'Amiens par lequel l'Angleterre restituait toutes les colonies qu'elle avait enlevées à la France aussi bien qu'à la Hollande et à l'Espagne, ses alliées ${ }^{99}$. Dès le 20 janvier, sans même attendre que le traité fut signé les colons nommaient Du Buc député auprès du gouvernement français.

97 Ibid. Lettre d'un particulier de Saint-Pierre, 23 mars 1795. Min. Col. Martinique, 278.

98 Notes particulières sur les agents du Directoire. Ministère Colonies. Guadeloupe, 419.

99 « On a eu plus d'une fois occasion de s'apercevoir précédemment du tort que faisait ici la concurrence des nombreuses colonies d'Angleterre, et on sent généralement avec vérité ce que deviendrait à la paix la Martinique, conservée intacte à une métropole aussi vaste que la France et élevée par la force des choses et sans rivalité au premier rang de ses colonies ». VillaretJoyeuse au ministre. Ministère des Colonies. Martinique, 281. 
La personnalité du Premier Consul qui avait épousé la créole Maris-Josèphe Tascher de la Pagérie contribuait à rallier toutes les sympathies et l'on pense bien qu'il n'était pas une famille de planteurs qui ne se découvrît des liens de parenté avec la citoyenne Bonaparte.

Lorsque l'amiral Villaret de Joyeuse et ses troupes vinrent, le 14 septembre 1802, reprendre possession de la Martinique, ils furent unanimement fêtés. En dépit de la loi du 10 prairial an $\mathrm{X}$, qui annulait le précédent décret d'abolition, les noirs prirent leur part de l'enthousiasme général avec un entrain qui ne laissa pas de déconcerter l'amiral. « Une foule de nègres, écrit-il, accompagnait l'officier de police chargé de cette publication. Ils faisaient retentir l'air du cri de : "Vive la République! » Voilà comment ils ont accueilli la loi qui maintient l'esclavage. Si l'on veut comparer cet accueil à celui que j'ai reçu à Saint-Domingue, quand j'allais annoncer la liberté à leurs semblables, il est facile d'apprécier les théories et les éloquentes déclamations de leurs « Amis » 100.

Cette réflexion de l'amiral est bien injuste. Elle attribue aux noirs une inconscience et une incompréhension de leurs véritables intérêts qui, même pour des hommes dégradés par le régime servile et dont nul n'avait pris encore soin de développer l'intelligence, sont tout à fait invraisemblables.

Je pense, - et je crois être plus près de la vérité humaine --que l'enthousiasme de ces pauvres gens avait des raisons plus sûres et plus hautes.

Tous les événements qui s'étaient déroulés autour d'eux, et surtout la domination étrangère, si libérale qu'elle ait pu être, leur avaient donné le sentiment obscur mais puissant qu'ils étaient partie intégrante de la collectivité française. Celle-ci n'avait jamais été pour eux ni dure ni hautainement méprisante, car c'est à l'honneur du caractère français d'avoir la compréhension innée des races attardées, de savoir leur plaire et les attirer, tandis que l'Anglo-Saxon, sans avoir le goût de la brutalité, leur fait sentir qu'il les tient pour essentiellement négligeables, sinon même moralement inexistantes.

100 Villaret-Joyeuse au ministre. ler Vendémiaire, an II, Ministère Colonies. Martinique, 279. 
Le retour aux vieilles habitudes, le rétablissement de coutumes que la brume du passé enveloppait de son charme, et aussi, sans doute, la restauration des vieux rites d'une religion où communiaient tout de même les âmes, pour lesquelles il n'est point de couleur, apparaissaient comme choses très douces et apaisantes à cette humble multitude. Elle comprenait qu'elle avait sa place dans la fête de gloire et de grandeur qui magnifiait la France. Elle y éprouvait ces sentiments profonds et simples, instinctifs et sublimes, dont se forme et se nourrit le culte de la patrie. Elle justifiait, à sa façon, la grande parole du penseur grec : "Mieux vaut être obscur et pauvre dans une patrie heureuse, que riche et considéré dans une patrie malheureuse. »Et, ce faisant, elle se rendait d'avance digne d'y occuper la place honorable et juste que l'avenir lui réservait et pour laquelle elle se qualifiait. La France a rendu aux noirs l'amour qu'ils lui témoignaient.

Tout le passé revivait donc. Les innovations elles-mêmes se naturalisaient françaises, en quelque sorte, dans son ambiance rassérénante. L'organisation de la colonie resta à peu près ce qu'elle était devenue. Chacun fut confirmé et maintenu dans ses fonctions. Le renouveau exigeait seulement que fussent changées les dénominations, satisfaction inoffensive que l'esprit de conservation donne habituellement au désir de transformation. Ainsi, le Gouverneur général devint Capitaine général, le Conseil souverain, Cour d'appel ; un Préfet colonial et un Grand Juge se partagèrent les charges de l'ancien Intendant. Enfin, le fort Convention fut baptisé fort Desaix, et Républiqueville s'appela désormais Fort-de-France.

Au lendemain de la paix d'Amiens, le commerce français retrouva, dans la Martinique, un débouché et une source de matières premières d'une importance capitale pour son développement. Quelques jours à peine après le débarquement des troupes, on comptait en rade de Saint-Pierre, redevenu l'entrepôt général des Antilles, une trentaine de bâtiments de la métropole. Les relations économiques subirent un renouveau qui fit augurer un épanouissement merveilleux. Les produits de France étaient versés en abondance tandis que les denrées de l'île atteignaient de très hauts prix. La fortune souriait aux colons.

Malheureusement, la Martinique retomba, une troisième fois, entre les mains de l'Angleterre, de 1809 à 1814. Lorsqu'elle fut rendue à la France, elle reprit son 
rang privilégié en tête des autres possessions de la monarchie restaurée mais ne put retrouver toute sa splendeur passée.

Par une conséquence imprévisible du blocus continental, les pays d'Europe, appliquant la découverte du chimiste allemand Margraff, étaient parvenus à tirer de leurs betteraves le sucre qu'ils ne pouvaient plus recevoir des îles. Le marché du sucre de canne s'en trouva à jamais rétréci.

L'Angleterre, d'autre part, à partir de 1810, inséra dans tous ses traités l'interdiction de la traite ; l'institution servile avait moralement vécu ; une transformation profonde s'opérait, - en dépit d'une fraude largement tolérée, - qui devait modifier du tout au tout les conditions d'exploitation du sol et l'équilibre tout entier de la société coloniale.

On s'étonnera peut-être que les Anglais, dont le premier soin en 1794 avait été d'interdire les affranchissements à la Martinique, sous quelque prétexte que ce fût, se soient donné quinze ans plus tard figure d'apôtres de l'abolition.

Ne diminuons pas l'honneur qui leur revient de cette belle attitude. Constatons cependant que les circonstances la rendaient plus aisée.

L'effort et l'attention de la Grande-Bretagne se portaient de plus en plus vers l'Inde qui lui offrait 300 millions d'hommes à organiser, et un formidable marché de production et de consommation à exploiter. Les raisons d'intérêt ne venaient plus aussi vivement contrarier l'évolution des idées et des moeurs.

Ainsi put se préparer sans heurt, avec le plein assentiment de la conscience française, le grand acte d'affranchissement qui demeurera l'honneur du XIXe siècle, et dont la mémoire, aux Antilles françaises, reste indissolublement liée à la noble figure de Victor Schoelcher et à la Révolution de 1848.

La France a ainsi pleinement accompli sa mission. La Martinique est, pour elle, un titre éclatant de gloire coloniale. Le résultat obtenu, après trois siècles d'efforts, est de ceux qui s'imposent à l'admiration du monde.

Rien n'atteste mieux la valeur d'une civilisation que la densité de substance humaine et de bonheur humain qu'elle est capable de réaliser.

La Martinique, surpeuplée, mène une existence sans troubles dans une prospérité que les crises les plus violentes n'ont pu sérieusement compromettre. La paix publique y règne dans l'union des races. Quelle nation, en quel point de l'univers, 
a pu réaliser ce que le génie français, par ses dons de compréhension, d'éducation et d'assimilation a créé là ? Quelle oeuvre a jamais été illustrée d'un tel succès et payée d'un tel tribut de reconnaissance et de fidélité ?

De cette épopée j'ai essayé d'évoquer, dans les pages qui précèdent, le moment le plus critique, celui où le destin semble avoir le plus gravement hésité avant de se fixer.

La Révolution, à la Martinique, ne fut cependant ni tragique ni même marquée par une bien violente agitation. Si on compare les événements qui se déroulèrent dans lîle de 1789 à 1794, à ceux qui, pendant la même période, convulsaient la métropole, on ne peut s'empêcher de les trouver bien peu tumultueux et, somme toute, empreints d'une réelle modération. Il y eut fort peu de sang versé ; ni l'un ni l'autre des partis qui eurent successivement la prépondérance, n'abusa de son pouvoir ; il est particulièrement suggestif de constater que l'assemblée républicaine, qui succéda en 1793 à l'assemblée monarchiste, ne fit guère que confirmer tout ce qu'avait décidé sa devancière. Un seul épisode fait, en quelque sorte, saillie au milieu de cette relative sérénité : l'intervention militaire de l'Angleterre. Encore eut-elle un caractère plutôt sportif que guerrier : n'eût été l'énergique résistance de Rochambeau, qui combattit pour l'honneur et pour la gloire plutôt que pour des nécessités vitales, elle ne troubla point profondément les consciences. De tous temps, - et encore aujourd'hui -, la solidarité européenne, rarement comprise en Europe, est fortement ressentie dans les pays exotiques, où les nations colonisatrices servent une cause qui, par dessus leurs rivalités, leur est commune. Et d'ailleurs, dans la circonstance, les esprits s'accordaient de part et d'autre à ne voir dans l'occupation britannique qu'un incident transitoire.

La crise que traversa la Martinique ne fut donc qu'une réplique très atténuée de celle qui bouleversait au même moment la France. Il y avait à cela beaucoup de raisons.

L'une des principales fut certainement la douceur même de la vie coloniale et son influence apaisante sur les moeurs et sur les caractères. Aucun instinct sanguinaire ne vivait au fond de l'âme de ces colons, négociants aussi bien que planteurs, dont l'existence était large et facile. Il y avait bien entre eux des rivalités et parfois des aigreurs. Il n'y avait pas de haines. Le bonheur ne prédispose pas à la 
violence. Les sociétés prospères, - et la Martinique l'était au plus haut degré -, ne sont jamais déchirées par des conflits dramatiques ; seuls, le désespoir et la misère peuvent pousser les passions au paroxysme. Lorsque les hommes trouvent dans le milieu où s'exerce leur activité le calme, la sécurité, du lendemain, une relative aisance, ils ne songent point à demander davantage à des aventures dont ils sentent obscurément l'incertitude et les risques. Aucun mouvement révolutionnaire, même quand il est provoqué du dehors, n'a chance de réussir dans un pays qui jouit d'un satisfaisant équilibre économique. C'est là une vérité que tous les dirigeants, et spécialement les nôtres en ce moment devraient avoir constamment présente à l'esprit ; le rôle de l'Etat n'est jamais de compliquer les problèmes par des initiatives qui ne sont pas dans ses attributions, mais de faciliter l'effort des particuliers qui, de toutes parts, cherchent d'eux-mêmes à rétablir la prospérité.

Ce que j'en dis pour la Martinique de l'époque révolutionnaire, et spécialement pour son élite dirigeante de colons blancs, s'applique également à sa population de couleur, dont l'existence était alors à peine aperçue.

Le régime fait aux affranchis, et même aux esclaves, participait lui-même à cette ambiance de facilité, née du bien-être général. Il y avait certainement, dans la condition de ce considérable élément, quelque chose de choquant, d'inadmissible, d'inhumain et d'irrationnel, qui ne pouvait durer indéfiniment. Mais cette anomalie ne dégénérant pas en excès, n'était pas perçue clairement, ni surtout jugée intolérable. Du reste, elle avait tendance à s'atténuer.

Le Français est naturellement accueillant et compréhensif, porté à respecter tout ce qui, dans les autres peuples et dans les autres races, éveille en lui le sentiment très profond et très large de la dignité et des droits naturels de tout être humain. L'institution servile s'était déjà détendue sous l'ancien régime. Tous sentaient qu'elle s'assouplirait encore et ferait place quelque jour à des conceptions plus libérales. On en voit la preuve dans le peu de résistance que provoquèrent chez les blancs de la Martinique, malgré des protestations momentanées et qui venaient surtout du côté où elles semblaient le moins probables, les mesures égalitaires décidées un peu brusquement par la métropole. Aussi serait-il faux de dire qu'il y eût, dans les masses écartées de la vie politique, des ferments bien actifs de mécontentement et de révolte. 
Au fond, ce qui frappe surtout, c'est que la Révolution ne trouvait pas à la Martinique un terrain préparé. Livrée à elle-même, la colonie n'y serait pas arrivée. La perturbation n'avait pas de germes locaux. Ce fut un phénomène d'importation, une sorte de contagion. Rien ne se serait passé dans l'île si la métropole n'était pas elle-même entrée en effervescence. Et cette effervescence, étant donné l'éloignement, ne se communiqua qu'assez faiblement et surtout avec beaucoup de retard.

On commençait seulement à comprendre le sens véritable des événements de France quand, dans la mère patrie, ils atteignaient leur période la plus aigue, préface d'un déclin rapide. Même sans l'intervention de l'Angleterre, qui à ce moment coupa brusquement les communications et arrêta les apports nouveaux de la fièvre qui allait s'exaspérant à Paris, il est peu probable que la Révolution eût fini par dégénérer, dans lîle, en excès caractérisés. L'effet calmant de son déclin subit, après le 9 thermidor, se serait certainement produit avant que les choses se fussent sérieusement envenimées. La seule incertitude, sur ce point, provenait de l'extrême faiblesse des moyens dont disposait Rochambeau, et il est à supposer tout de même que son énergie, son autorité auraient su, pendant le court temps nécessaire, faire face à la situation.

Ce qu'il y a de déplorable dans les révolutions, c'est qu'elles ne parviennent jamais à se dominer et sont entraînées malgré elles par les éléments de plus en plus troubles qu'elles ont mis en mouvement. Le plus grand bien politique, c'est la stabilité. Pour se développer librement et produire tous leurs effets bienfaisants, les activités humaines ont besoin de conditions permanentes qui permettent d'établir des prévisions et de mener à bien des efforts longuement continués dans le même sens et avec les mêmes données. La « règle du jeu » ne peut être à chaque instant modifiée sans désorienter les initiatives et finalement les réduire à l'impuissance et à l'inertie.

L'incertitude du lendemain est ce qu'il y a de plus démoralisant pour le développement normal d'énergies qui ont besoin du facteur temps pour réaliser leurs desseins.

Sans doute stabilité ne signifie pas immobilité. Les sociétés sont en perpétuelle évolution, ne fût-ce que du fait du progrès des idées et des techniques. 
Mais cette évolution doit être régulière et en quelque sorte naturelle. Elle doit procéder non par bonds et soubresauts mais par adaptations et ajustements. Toute la grandeur du peuple britannique provient de ce qu'il porte en lui, enraciné au plus profond de l'inconscient national, cet instinct de la conservation sociale : ce qui a longtemps duré a, par là même, prouvé sa valeur et acquis une sorte de justification expérimentale, supérieure à tous les raisonnements abstraits; il n'y faut donc toucher qu'avec prudence, et occasionnellement, en s'abstenant de tout ce qui dépasse le cercle de la nécessité évidente, immédiate, strictement limitée au cas concret qui commande l'innovation. Cette conception tutélaire a empêché les Anglais, jusqu'à présent, de se lancer dans l'aventure des réformes systématiques de grande envergure ; elle ne les a rendus ni plus rétrogrades ni moins libéraux que d'autres, - au contraire.

Ce qui apparaît clairement, pour quiconque se penche sur l'histoire de notre grande Révolution, c'est que le goût du peuple français pour les généralités et les abstractions, l'a rapidement entraîné loin des réalités, lui masquant cette règle supérieure de sagesse politique. Cette époque si fertile en idées généreuses et en caractères fortement trempés a été marquée par une ruée progressivement aggravée vers l'instabilité. Après avoir réformé d'évidentes défectuosités, les premiers acteurs ont fait place à des surenchérisseurs de plus en plus ardents, emportés toujours plus loin dans leur zèle novateur. Tout ce qui était le passé apparaissait par cela même détestable. On ne croyait plus qu'à la vertu des improvisations, et comme l'une détruisait l'autre, toute œuvre accomplie était aussitôt remise en question. La frénésie du changement empêchait toute reconstruction.

Si la France d'alors a pu retrouver son équilibre, c'est qu'elle portait en ellemême, à son insu, des forces immenses d'ordre et de cohésion. L'ancien régime lui avait donné une armature d'une rare solidité : non seulement dans son administration et dans son armée, que la tourmente laissa en grande partie intactes, mais dans le sentiment de l'unité et de la grandeur nationales.

Pour beaucoup, - et les planteurs de la Martinique, Du Buc en tête, étaient de ce nombre -, la monarchie s'identifiait avec la patrie : non qu'ils bornassent le culte de celle-ci à celui d'un homme ou d'une famille, mais parce qu'au contraire leur loyalisme envers le pouvoir royal n'était que la forme concrète d'une foi plus large et plus haute, celle qu'ils avaient dans les destinées éternelles de la France. 
Et les autres, qui abandonnaient l'idée monarchique pour suivre une idée émouvante et belle, celle de la Nation souveraine, n'en conservaient pas moins, au fond d'eux-mêmes, la forte empreinte des disciplines en apparence abolies. Rochambeau est un exemple de ces caractères, qu'une irrésistible gravitation ramenait vers l'autorité, fondement nécessaire de tout ordre et de toute organisation.

À la Martinique, petite société isolée, nous voyons mieux encore que dans la mère-patrie quelle résistance cette structure solide de la vieille France devait opposer aux entraînements de l'esprit de démagogie déchaîné au centre même de la collectivité nationale.

Il serait injuste de ne pas voir d'ailleurs l'esprit remarquable de sagesse et de modération qui, en ce qui concerne notre colonie, subsistait même aux pires jours dans les esprits les plus exaltés de la métropole. Si la tempête révolutionnaire n'a pas plus durement secoué les Antilles, c'est beaucoup aussi à cause de la conception très juste qu'eurent la Constituante, la Législative et même la Convention de la différence profonde des milieux et de la nécessité de laisser aux Français d'outre-mer le soin de déterminer eux-mêmes, dans une large mesure, les institutions locales qui pouvaient le mieux leur convenir. J'ai noté, au cours de mon récit, les preuves répétées de cette bienveillance et de ce libéralisme.

De la sorte, il était naturel que la Révolution, au moins dans ses effets les plus directs, ne fît pas grand ravage à la Martinique.

Les orages de doctrine qui tonnaient dans la métropole passèrent au-dessus de la tête des habitants de l'île. Ce qu'ils virent dans la perturbation, ce fut surtout l'occasion de réaliser des aspirations très anciennes et, somme toute, raisonnables: l'obtention d'une relative autonomie, la participation à l'administration, l'abrogation ou tout au moins l'assouplissement du régime de l'Exclusif.

Ces revendications n'étaient nullement incompatibles avec l'esprit nouveau; elles se plaçaient, au contraire, tout naturellement dans son cadre. Elles devaient aboutir sans grandes difficultés, ne se heurtant qu'à des rivalités locales, ne soulevant que des questions de modalités et permettant de concilier tous les intérêts sur le plan d'une liberté plus large et d'une prospérité accrue. 
Planche XXI. Fraternité.

Voir Les Classiques des sciences sociales.

Mais - ce que nul n'avait vu tout d'abord - l'idée révolutionnaire, transportée sur la terre antillaise, devait mettre le feu à un explosif infiniment plus puissant, qui n'existait pas en France : la condition respective des races. A Saint-Domingue, il anéantit complètement l'édifice social. A la Martinique et dans les îles voisines, il ne détona pas avec la même violence : les passions étaient moins surchauffées et les hommes furent plus raisonnables. Ce fut cependant le seul danger réel, et à partir du moment où il se précisa, ce grave problème passa au premier plan, rejetant dans la pénombre ceux qu'on avait d'abord agités.

On ne saurait se dissimuler que l'influence, très agissante et finalement prépondérante, de la Société des Amis des Noirs faillit déchaîner, par une précipitation inconsidérée, un cataclysme irrémédiable. Et cependant, les Amis des Noirs avaient raison : leurs vues étaient justes ; elles n'avaient le tort que de devancer de trop loin la marche des événements et de vouloir précipiter en un instant ce qui devait exiger encore plusieurs décades, une accoutumance progressive des esprits et surtout une transformation des conditions économiques qui ne pouvait être l'œuvre d'un jour.

L'esprit politique de Du Buc, la perspicacité et le sens des réalités dont il sut faire preuve, et aussi la fermeté de Rochambeau, disons même l'intervention anglaise, concoururent à éviter une catastrophe et, en ménageant le temps nécessaire à l'évolution des esprits, à préparer un grand bonheur.

En 1794, l'affranchissement général des noirs, en effet, aurait presque immanquablement abouti à la guerre civile, comme il advint à Saint-Domingue, et à d'affreux massacres.

Quelque cinquante ans plus tard, il pouvait être réalisé dans la paix publique ; la France pouvait accorder aux opprimés non seulement la liberté, mais, l'égalité civile et politique, et cette grande réforme pouvait se développer dans l'union et 
l'estime mutuelle des races, sans que rien vint jamais donner matière à aucun regret.

Quelques-uns s'étonneront peut-être qu'au cours de mon récit, j'aie pu présenter sous des couleurs peu défavorables la cause des grands aristocrates pour qui la France s'identifiait avec la monarchie et qui, malgré leurs concessions opportunistes, tenaient pour infranchissable la ligne de démarcation entre les races. Ils me blâmeront peut-être aussi d'avoir laissé paraître les faiblesses, les inconséquences, parfois les ridicules et les pauvretés intellectuelles ou morales de beaucoup de ceux qui purent se croire les plus dévoués artisans des temps nouveaux.

Je leur répondrai simplement que j'ai entendu dans cet ouvrage faire œuvre d'historien et non de partisan. J'ai respecté strictement la vérité telle que l'ai vue à travers les archives où elle restait enveloppée. Sang-mêlé moi-même, je sais ce que les hommes de mon origine doivent aux principes de la Révolution, à sa foi dans la Justice, à son élan d'amour pour les hommes tous égaux devant le droit, et tous frères. Mais mes convictions pour s'exprimer n'ont pas besoin de travestir les faits ni de dénigrer ceux qui - avec un idéal différent - désiraient être, eux aussi, des ouvriers de la grandeur nationale.

L'histoire n'est pas un plaidoyer. C'est un témoignage. J'apporte le mien en toute conscience, tel que j'en ai recueilli les éléments dans les documents de l'époque. Les petitesses des hommes n'altèrent point la noblesse des idées qui les dominent. Et la grandeur des caractères, par contre, ne se communique pas aux erreurs qu'ils peuvent commettre.

Dans le recul du temps, d'ailleurs, les passions des acteurs s'effacent et s'harmonisent. Il est réconfortant de constater que les adversaires qui s'affrontaient en croyant servir des causes inconciliables étaient en réalité les serviteurs d'un même idéal, et qu'à travers leurs gestes discordants s'accomplissait le travail lent et sûr de forces supérieures. Car par-dessus les péripéties mouvantes de ces quelques années, court chapitre dans l'existence de ma petite patrie antillaise, ce que j'ai aperçu et dont je voudrais laisser la vision à mes lecteurs, c'est l'auguste visage de la France, accomplissant à travers les vicissitudes des événements son destin de générosité, de lumière et de beauté. 


\section{CHAPITRE XIII. RÉFÉRENCES :}

Proclamation du 30 mars 1794 de Charles Grey. Arrêt du Conseil souverain du 23 avril. Durand Molard, tome IV.

Proclamation du 12 avril de Robert Prescot, lieutenant général et gouverneur de la Martinique. Arch. Min. Col. Martinique, 279.

Lettre des commissaires à la Convention, 3 floréal, an II. Min. Col. Martinique, 278.

Lettre d'un particulier de la Guadeloupe (M. Granpré) reçue le 23 sept. à FortRoyal. Min. Col. Martinique, 278.

Lettres de Rochambeau aux ministres. Newport. Floréal, an II. Min. Col. Martinique, 278.

Proclamation de Victor Hugues, 19 prairial, an II. Min. Col. Guadeloupe, 418.

Lettres de Victor Hugues aux ministres. 21 prairial et 20 fructidor, an III. Min. Col. Guadeloupe, 419.

Rapport de Lemaître. Frimaire, an IV. Min. Col. Guadeloupe, 420.

Notes particulières sur les agents du Directoire. Min. Col. Guadeloupe, 419.

Lettre d'un particulier de Saint-Pierre. 23 mars 1795. Min. Col. Martinique, 278.

Lettres de Villaret-Joyeuse au ministre. Vendémiaire et brumaire, an XI et décembre 1803. Min. Col. 279 et 281. 
La Révolution française à la Martinique

\section{Références générales}

$\underline{\text { Retour à la table des matières }}$

Ayant conçu, à la suite de diverses confrontations, une méfiance invincible pour les sources imprimées autres que le « Code de la Martinique », de Durand Molard, ou les Procès-verbaux des Assemblées publiés dans Le Moniteur, j'ai établi presque toute ma documentation sur les manuscrits conservés aux Archives Nationales et au Ministère des Colonies.

Archives Nationales :

Fonds Colonies C8 A 89 et C8 A 90 concernant l'année 1789 ;

Fonds Marine B BI 5 et B BI 12 ;

Série Dxxv 15-116-117 et 118 pour les années 1790-1791-1792-1793-1794.

\section{Archives Colonies :}

Registres Martinique, 268 à 281

Registres Guadeloupe, 416 à 420. 
Les deux seuls livres imprimés où j'ai puisé assez largement sont :

$1^{\circ}$ « L'Histoire économique de la Martinique », de Louis-Philippe May (pour l'introduction);

$2^{\circ}$ " Avec les rouges aux Isles du Vent ». Souvenirs du chevalier de Valous, commandant de l'Elisabeth, sous les ordres de M. de Rivière. Publiés chez Calmann Lévy par le marquis de Valous, en 1931.

On peut citer encore : Louis de Cardinal, Paul Roussier, Albert Duchêne, J. Saintoyant et Hurard. 


\title{
Documents annexes
}

\author{
Arch. Dxxv 116, p. 103. Procès-verbal dressé \\ par l'équipage de la frégate l'Embuscade commandée \\ par M. d'Orléans.
}

\section{$\underline{\text { Retour à la table des matières }}$}

Par le travers de l'Isle Dominique, le 30 septembre 1791, ce jourd'hui, 29 sept. 1791, à 8 h. du soir, nous étant réunis sur le gaillard d'arrière et fait demander le capitaine, et lui avons communiqué d'une voix unanime notre intention d'aller en France, plutôt qu'à la Basse Terre Guadeloupe, vu que nous étions incertains sur notre mission relativement aux troubles qui règnent actuellement tant à la Pointe à Pitre que dans 1'lle Sainte-Lucie, et que nous ne voulons point commettre les mêmes hostilités contre nos frères que celles qu'on nous reproche d'avoir commis envers eux, et d'après des lettres datées du 15 juillet où on nous reproche notre conduite passée et qui font mention que nous sommes dénoncés dans tous les clubes (sic) du royaume comme criminels de Lèse-Nations, ce qui nous a déterminés à faire route pour la France.

En foi de quoi nous avons dressé le procès-verbal pour nous servir et valoir ce que de raison.

Fait et arrêté à bord de la frégate L'Embuscade, étant par le travers de l'Isle Dominique à une heure après-midi le 30 septembre 1791 .

Suivent les signatures de tout l'équipage. 


\section{ADRESSE \\ des Citoyens de couleur de la Martinique \\ à l'Assemblée Coloniale séante au Lamentin le 9 janvier 1793}

$\underline{\text { Retour à la table des matières }}$

Messieurs,

Un grand événement vient de fixer l'attention de l'Europe ; la France a changé son gouvernement. Une seconde révolution, moins étonnante, mais plus heureuse que la première, a fait succéder à une monarchie qui n'en avait que le nom, et qui n'était qu'une source éternelle de regrets de la part du roi, de défiance de la part de la nation, une République fondée sur la liberté et l'égalité. Reconnaîtrons-nous cette nouvelle forme de gouvernement ou demeurerons-nous sous un pavillon également ennemi de la constitution détruite, et de celle qui l'a remplacée ? Voilà la question soumise à votre décision, et telle est son importance, que notre sort, celui de nos enfants, celui des générations futures, peut-être même leur existence, peut dépendre de la détermination que vous allez prendre.

Loin de nous, messieurs, la pensée d'influencer vos opinions ; notre confiance en vous est entière ; et nous sommes persuadés que si l'artifice, l'imprudence et l'erreur ont ouvert un abîme sous nos pas, votre sagesse saura le fermer. Aussi aurions-nous attendu, dans un respectueux silence, que vos intentions bienfaisantes nous fussent manifestées, si des malintentionnés n'avaient répandu le bruit que nous ne voulions pas reconnaître la République et que nous nous réunirions aux contre-révolutionnaires, pour vous empêcher de revenir au seul parti que vous conseillent la raison, la justice et le salut de la colonie.

Il est de notre devoir de démentir hautement cette calomnie et de vous protester que, loin de vouloir méconnaître la République, nous sommes prêts à lui jurer une obéissance et une fidélité inviolable. 
Nous serons toujours prêts à combattre et, s'il le faut, à mourir avec vous, pour la défense des lois, pour la sûreté des personnes et des propriétés ; mais nous ne voulons pas nous sacrifier pour une cause qui nous est également étrangère ; qui est même contraire à nos communs intérêts ; car qu'aurions-nous à gagner à une contre-révolution, si elle pouvait avoir lieu ; et devons-nous la désirer ? vous verriez renaître les ordres privilégiés, et nous, la démarcation humiliante qui nous séparait des citoyens blancs.

Nous ne doutons pas, messieurs, de votre loyauté. Nous sommes bien convaincus que tout ce que vous nous avez promis vous voudriez le tenir ; mais cela dépendrait-il de vous ? Le roi, devenu absolu, ne voudrait ni municipalités, ni assemblées coloniales ; dès lors, nous perdrions le droit d'élection. Le roi nommerait à toutes les places et serions-nous les objets de son choix ? Nous ne sommes pas assez aveugles pour le croire.

Et vous-mêmes, messieurs, n'avez-vous encore remarqué aucune variation dans la conduite des ci-devant nobles à votre égard ? Cette égalité, cette fraternité qu'ils affectaient avec vous, ne commençait-elle pas à disparaître, à mesure que les troupes autrichiennes approchaient de Paris ? Pour nous, la différence nous a paru très sensible.

Nous connaissons les grands. Dans le malheur amis ; Ingrats dans la fortune et bientôt ennemis. Nous sommes de leur gloire un instrument servile ; Rejeté par dédain, dès qu'il est inutile ; Et brisé sans pitié s'il devient dangereux.

On veut en vain nous enrayer par l'idée des vengeances et des proscriptions de la Mère-Patrie. Nous sommes persuadés qu'elle ne veut que faire reconnaître son nouveau gouvernement par ses colonies et non pas les détruire. Et quel crime a donc commis la Martinique ? la prise du pavillon blanc ne fut pas son ouvrage et si votre dernière assemblée n'a pas hautement désavoué cette démarche funeste, à quoi faut-il l'attribuer qu'au défaut de liberté des suffrages ? le parti que vous avez pris cette fois de délibérer à huis-clos, de changer même le lieu ordinaire de vos 
séances, en est une assez bonne preuve. Tel brave la mort sans crainte, qui n'ose braver les huées et les menaces des galeries 101 .

Et quand vous auriez librement conçu le dessein de vous séparer de la métropole, vous n'auriez projeté que ce qu'allaient effectuer ses provinces méridionales ; elles étaient au moment de se déclarer indépendantes et de répudier pour jamais un gouvernement anarchique, éternel aliment de haines intestines, de conspirations et de crimes, lorsque sa destruction a réuni tous les coeurs, tous les esprits, toutes les volontés à la République. Leur intention bien connue fut louée par les patriotes les plus purs et approuvée par l'Assemblée Nationale elle-même ${ }^{102}$. Comment le même projet qui fut considéré comme une preuve de civisme de la part de ces provinces, pourrait-il être regardé comme un crime, de la part des colonies qui, par leur existence politique et leur distance de la métropole, sont bien moins susceptibles d'être régies par une même forme de gouvernement ?

La République, d'ailleurs, n'existait pas lorsqu'on a arboré le pavillon blanc et, pour pouvoir se rendre coupable de rébellion envers un gouvernement quelconque, il faut d'abord qu'il existe, il faut qu'il soit légalement connu ; il faut qu'il soit notifié à ceux qu'on y veut soumettre : il ne l'a point été ; il ne l'est pas encore.

On voudra, messieurs, intéresser votre honneur au sort des officiers de terre et de mer, qui ont servi la colonie : eh bien, ces officiers ont arboré le pavillon blanc avec nous ; ils arboreront le pavillon de la République avec nous ; et ceux contre lesquels il n'existe pas de décret d'accusation n'ont pas plus à craindre que nous : ceux qui s'y refuseraient seront libres de quitter la colonie et vous ferez pour eux ce que vous prescrit la reconnaissance.

Quant à ceux qui ont répondu naguère à vos offres de service, à l'expression de votre reconnaissance qu'ils avaient tout fait pour le roi et rien pour la colonie ;

101 Il y a peu de jours qu'un officier de ci-devant Turenne, menaçait encore publiquement, au nom de ses camarades, de tirer sur l'Assemblée coloniale, si elle reconnaissait la République. On peut juger par ce seul trait, entre mille autres, si l'assemblée pouvait délibérer librement sous le canon du Fort Bourbon et si elle n'a pas pris un parti sage de se transférer au Lamentin ; on peut juger aussi de l'étrange liberté qui a présidé à sa dernière session.

102 Voyez la lettre du 3 septembre de M. Roland, ministre de l'Intérieur, à l'Assemblée Nationale, dont l'envoi fut ordonné aux 88 départements. 
qu'ils n'avaient pas besoin d'intermédiaire entre le roi et eux 103 : c'est du roi et non de la colonie qu'ils doivent attendre leur récompense.

Nous sommes, messieurs, avec une respectueuse confiance,

Vos concitoyens, vos amis et vos frères.

Signé : Ducassou, représentant des citoyens de couleur des Trois Ilets ; $\mathrm{M}$. Minel, du Saint-Esprit ; Edouard Munier, Ch, Lavalette, Olivier et Christophe Duguin, du Saint-Pierre ; T. Lacoste, du Robert ; A. Rémy, du Marin ; Blaise, Modeste et Hipolite, du Vauclin ; L. Ducasse, de Sainte-Luce ; L. Bayet, de la Rivière Salée ; Hilaire, du Prêcheur ; C. Bouquet, du Marigot ; Jh. Muraire et Romain, de la Trinité.

Signatures du Fort Royal :

S. Ginen, Hector, Macel, S. L. Raynaud, Héris, Lembon, Lafonde, Frédéric, Laure, Louis Flamand, S. Dubois, D. Bech fils, S. L. Moreau, Dumas Sablon, Saint Jacques, L. Sophy, P. Millet, Soubeiran, C. Mantet, Lajoys, C. Diogène, S. Mamon, Armand, S. Demil, Baltazard, Montreuil, Pélage, Jacque, Saint Rose de Lisle, Aug. Houpart, P. Alarie, F. Latour, Ballaire, Belle Isle, Duranto, Eugène fils, P. Louis, L. Larvire, L. Laparant, Duvedat, Julien Cavet, Léger, Gouget, J. Lot, A. Dubois, Frédéric Zeine, Aurélien Cocq, P. Madas, Lubin, Franchin, Gépéon Hauzier, N. Laurent, N.-M. Rose, Latendresse fils, N. Bouché, Alexis René, S. Montreuil, S. Borely, Fabien Père, Edouard, Sainte Rose Berne, Prévost, C. Bouquet, Dumasse Mondésir, Noël Labottière, Cloux, L. Alexandre, Laurent Larcher, L. Judie, J. Marie, P. Dorin, Hilaire, L. Vincent, Yoyotte Durand, J. M. Cadet, Comperre Ergan, P. L. Raymond, E. Double, J.-Q. Lyon, Mondésir, Voly, M. Joseph, E. Vincent, Jean-Marie.

Conforme à ce que j'ai reçu :

LABROSSE.

103 Cette réponse fut faite à l'Assemblée Coloniale, par le sieur Fressineau, colonel du régiment ci-devant Turenne, au nom des officiers de son corps. 


\section{LETTRE DE SIR EDWARD MATHEW A MONSIEUR DE DAMAS (Archives D xxv 116, Dossier 909, No 65)}

Retour à la table des matières

Sir,

I have the honor to inclose your excellency a copy of my answer to a letter from the concil of the city of St Pierre in the island of Martinique.

I am with great consideration, etc...

Signé : Edward MATHEW.

Copie de la réponse de Sir Edward Mathew au Conseil de Saint-Pierre :

Gentlemen,

It is with much concern I learn the violent troubles which at present agitate the island of Martinique and should esteem my fift very formate could I apply any thing to your relief. It is beyond of my commission to take any part on this occasion. But as an individuel, I cannot help feeling for you, and my ideas of the circonstances in which you now stand, lead me to think that, if M. de Damas could be reconsited to a proposal which I am informed he once approved, of chosing once respectable character out of each Parish to form a concil to aid the governer it would thereby reasonnable and necessary that the military should retourn to their states and the Kings fort be again put into the hands of it governor. The neat mesure would undoubtedly procure from $\mathrm{M}$. de Damas in the demission of all 
people under arms of Wath color soever, and in this state I should conceive the colong migtot proced to put in execution for their re establistement the orders they have received from Europe.

I am, gentlemen, etc...

Edward MATHEW.

\section{Fin du texte}

